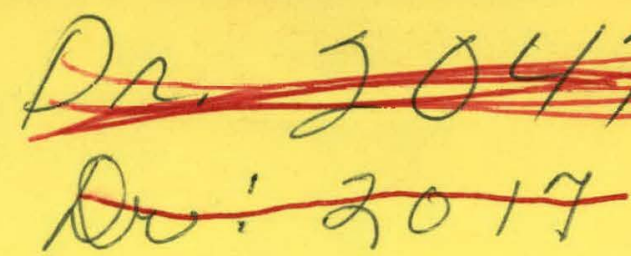

\title{
APPLIED RESEARCH
}

$\mathrm{ON}$

ENERGY STORAGGE AND CONVERSION

FOR

PHOTOVOLTAIC AND WIND ENERGY SYSTEMS

\author{
FINAL REPORT
}

VOLUME III

WIND ENERGY SYSTEMS WITH ENERGY STORAGE

\section{JANUARY 1978}

\author{
PREPARED FOR \\ NATIONAL SCIENCE FOUNDATION \\ AND THE \\ U.S. DEPARTMENT OF ENERGY \\ ASSISTANT SECRETARY FOR ENERGY \\ TECHNOLOGY \\ DIVISION OF ENERGY STORAGE \\ SYSTEMS \\ UNDER CONTRACT NO. NSF C-75-22221-01
}




\section{DISCLAIMER}

This report was prepared as an account of work sponsored by an agency of the United States Government. Neither the United States Government nor any agency Thereof, nor any of their employees, makes any warranty, express or implied, or assumes any legal liability or responsibility for the accuracy, completeness, or usefulness of any information, apparatus, product, or process disclosed, or represents that its use would not infringe privately owned rights. Reference herein to any specific commercial product, process, or service by trade name, trademark, manufacturer, or otherwise does not necessarily constitute or imply its endorsement, recommendation, or favoring by the United States Government or any agency thereof. The views and opinions of authors expressed herein do not necessarily state or reflect those of the United States Government or any agency thereof. 


\section{DISCLAIMER}

Portions of this document may be illegible in electronic image products. Images are produced from the best available original document. 
Available from:

National Technical Information Service (NTIS)

U.S. Department of Commerce

5285 Port Royal Road

Springfield, Virginia 22161

Price: Printed copy: $\$ 12.00$

Microfiche: $\$ 3.00$ 


\title{
APPLIED RESEARCH \\ $\mathrm{ON}$ \\ ENERGY STORAGE AND CONVERSION FOR \\ PHOTOVOLTAIC AND WIND ENERGY SYSTEMS
}

\author{
FINAL REPORT \\ VOLUME III \\ WIND CONVERSION SYSTEMS \\ WITH \\ ENERGY STORĀGE
}

JANUARY 1978

Prepared By

General Electric

Space Division

Valley Forge Space Center

P.O. Box 8555

Philadelphia, Pennsylvania 19101

For The

National Science Foundation and

U.S. DEPARTMENT OF ENERGY

This report was prepared as an account of work sponsored by the United States Govemment. Neither the Uidied States nor the Unitéd States Department of

Energy, nor any of their employees, nor any of their

contractors, subcontractors, or their employees, makes

any warranty, express or implied, of assumes any legal liability or' responsibility for the accuracy, completeness of uscfuluess of any information, apparatus, product or process disclosed, or represents that its use would not infringe privately owned rights.

Assistant Secretary for Energy Technology

Division of Energy Storage Systems

Washington, D.C. 20545

Under Contract No. NSF C-75-222.21 
Notice

This report was prepared as an account of work sponsored by the United States Government. Neither the United States nor the National Science Foundation, The Department of Energy, nor any of their employees, contractors, subcontractors or employees of their contractors or subcontractors makes any warranty, express or implied, or assumes any legal liability or responsibility for the accuracy. completeness or usefulness of any information, apparatus, product $\mathrm{cr}$ process disclosed or discussed, or represents that use of such products or processes or other information presented would not infringe privately owned rights. 
FंOREWORD

This report presents the results of a study of the use of energy storage in conjunction with photovoltaic and wind energy conversion systems. The program was conducted under National Science Foundation contract number NSF-C-75-22221 with direction from the Energy Research and Development Administration, through Dr. George C. Chang, ERDA Program Monitor. Dr. Richard Schoen of NSF provided initial program direction prior to September, 1976.

The report consists of three volumes. Volume I contains a Study Summary of the major results and conclusions. Volume II contains a description of the study methodology, procedures, analyses, and results associated with use of energy storage in conjunction with Photovoltaic Systems. Volume III contains information similar to that of Volume II, but directed toward use of energy storage with Wind Energy Conversion Systems.

The study was conducted by Advanced Energy Programs - General Electric Company, Space Division. Principal contributors included A.W. Johnson, Program Manager, E.J. Buerger, Dr. R. Fogaroli, A. Kirpich, R. Landes, R. McCarthy, N.F. Shepard, H. Thierfelder and S.M. We inberger. In addition, the following organizations provided information, consultation and/or analyses pertinent to the study:

C\&D Batteries Div., of Eltra Corp., Plymouth Meeting, Pa.

GE Corporate R\&D Center, Schenectady, N.Y.

GE Direct Energy Conversion Programs, Boston, Mass.

GE Electric Utility Systems Engineering Dept., Schenectady, N.Y.

Public Service Electric and Gas Co. of Newark, N.J. GE TEMPO, Santa Barbara, Calif. 
Mr. W.R. Terrill, Manager, Solar Electric Power Programs, and Mr. R.J. Barchet, Manager, Photovoltaic Programs, provided overall guidance for the study within General Electric.

Additional contributions to the study report were received from the review team which included the following members:

Dr. Len Magid

Dr. Doug Warschauer

Dr. Mort Prince

Dr. Hal Macomber

Division of Solar Energy, ERDA

Mr. Don Teague

Dr. Bob Thresher

Dr. George Chang

Dr. Al Landgrebe

Mr. Rufus Shivers

Dr. Wayne Coffman

Division of Energy Storage Systems, ERDA

Mr. Larry Gordon

NASA-Lewis Rescarch Center

Dr. Henry Dodd

Sandia Laboratories, Albuquerque, NM 
VOLUME III

TABLE OF CONTENTS

PAGE

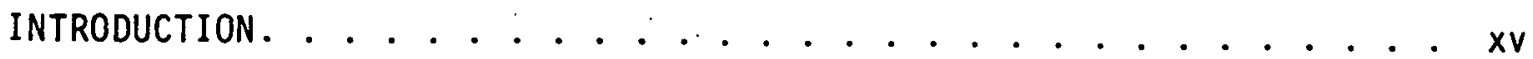

SECTION

1 SUMMARY AND CONCLUSIONS ................ 1-1

1.1 Study Objectives and Scope ............. 1-1

1.2 Study Approach ................. 1-2

1.3 Overall Findings - Energy Storage with

Wind Energy Conversion Systems . . . . . . . . . 1-2

1.4 Storage with Wind Systems - Utility Application . . . . . . 1-10

1.4.1 Candidate Storage Concepts . . . . . . . . . 1-10

1.4.2 Methodology for Utility Application Analys is ...... 1-10

1.4.3 General Results and Findings - Utility Application... 1-11

1.4.4 Parametric Effect on Worth of Storage - Utility

Applications .............. 1-16

1.5. Storage with Residential Wind Systems .......... 1-21

1.5.1 Candidate Storage Concepts ... . . . . . . . 1-21

1.5.2 Methodology for Residential Application Analysis ... 1-21

1.5.3 General Results and Findings - Residential Application . 1-22

1.5.4 Parametric Effects on Worth of Storage - Residential

Application ............ . 1-24

1.6 Storage with Intermediate Wind Systems .......... 1-27

1.6.1 Candidate Storage Concepts . . . . . . . . . 1-27

1.6.2 Methodology for Intermediate Applicátion Analys is $\because 1-28$

1.6.3 General Results and Findings - Intermediate

Application .............. 1-28

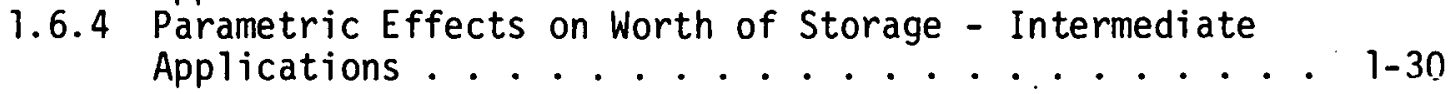

1.7 Special Utility System Planning Analysis . . . . . . . 1-34

2 BASELINE WIND CONVERSION AND STORAGE SYSTEM CONCEPTS . . . 2-1

2.1 Utility Systems ............... 2-1

2.1.1 Basic Energy Conversion Svstem ........... 2-1

2.1.2 Overall Wind Conversion System Operation...... 2-4

2.1.3 Storage System Integration and Interconnection to

Wind Energy Conversion System ........ 2-5 
VOLUME III

TABLE OF CONTENTS (CONT.)

SECTION

PAGE

2.2 Residential Systems . . . . . . . . . . . . 2-40

2.2.1 Basic Energy Conversion System . . . . . . . . 2-40

2.2.2 Wind Conversion System Operation......... 2-40

2.2.3 Storage System Integration and Interconnection to the Wind Energy Conversion System ......... 2-41

2.3 Intermediate Systems . . . . . . . . . . 2-55

2.3.1 Basic Energy Conversion System . . . . . . . . 2-55

2.3.2 Overall Wind Conversion System Operation...... 2-56

2.3.3 Storage System Integration and Interconnection to

the Wind Energy Conversion System ........ 2-56

3 WIND ENERGY STORAGE ASSESSMENT . . . . . . . . . . . . 3-1.

3.1 General .......................... 3-1

3.2 Method of Analysis . . . . . . . . . 3-2

3.2.1 Utility Applications ............... . . 3-2

3.2.2 Residential Applications . . . . . . . . . . 3-3

3.2.3 Intermediate Applications ........... 3-4

3.3 Analys is and Projection of Cost Goals in Utility Applications . 3-5

3.3.1 Energy Management . . . . . . . . . . . . 3-5

3.3.2 Wind Energy Availability and Conversion. . . . . . . 3-14

3.3.3 Utility Load Demands . . . . . . . . . . . . . . 3-21

3.3.4 Generation and Load Matching . . . . . . . . . . . 3-26

3.3.5 Break-Even Cost Methodology. . . . . . . . . . . 3-34

3.3.6 Cost Goals and Parametric Analysis .......... 3-51

3.3.7 Utility System Planning Analysis .......... 3-74

3.4 Analysis and Projection of Residential Storage . . . . . . . . 3- . . . . . . . . . . . .
System Cost Goals

3.4.1 Energy Management . . . . . . . . . . . . 3-100

3.4.2 Wind Energy Availability and Conversion. ....... 3-101

3.4.3 Load Demands . . . . ........... 3- . . . 104

3.4.4 Generation and Load Matching without Storage . . . . . . 3-107

3.4.5 Generation and Load Matching Incorporating Storage . . 3-107

3.4.6 Cost Goals and Parametric Analys is ........ 3-112 
3.5 Analysis and Projection of Intermediate Wind System Cost Goals . 3-132

3.5.1 Energy Management ............ 3-132

3.5.2 Wind Energy Availability and Conversion . . . . . 3-133

3.5.3 Load Demands . . . . . . . . . . . . . . 3-134

3.5.4 Generation and Load Matching without Storage .... . 3-136

3.5.5 Generation and Load Matching Incorporating Storage . 3 3-137

3.5.6 Cost Goals and Parametric Analysis ......... 3-140

3.6 Effects of Multiple-Source Charging and Wind Forecasting . . 3-159

3.6.1 Utility System Energy Allocation ......... 3-159

3.6.2 Model for Multiple Source Charyiny ......... . 3-16]

3.6.3 Cost Goals and Parametric Trade-0ffs ........ 3-161

3.6.4 Effects of Wind Forecasting .......... 3-169

3.7 Value of Transient Smoothing. . . . . . . . . 3-176

3.7.1 Objective of Investigation . . . . . . . 3-176

3.7.2 Description of the Smoothing Problem . . . . . . 3-176

3.7.3 Effect of Generation and Load Relationships..... 3-177

3.7.4 Special Case - Potential Value of Smoothing for Intermediate Applications ......... 3-186

REFERENCES AND BIBLIOGRAPHY . . . . . . . . . . . . R R-1

\section{APPENDICES}

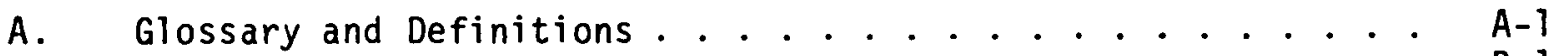

B. Data Tables ..................... B-1 
1.5 MW Wind Generator System Characteristics... .

Energy Al iocation for Assumed Generation Mix System

Typical Computer Run Format, Wind System

Annual Energy Credit Multiplier :

Utility Application. . . . . . . . . . . . 3-57

3. $3-10$

Cunslrucliun Cust Factors and Fixed Charge Rates

$10 \mathrm{~kW}$ Wind Generator System Characteristics . . . 


\section{LIST OF TABLES (CONT.)}

PAGE

Reduction in Residential Annual Energy

Representative Range of Residential

Energy Credit Multiplier, Residential Application.

$500 \mathrm{~kW}$ Wind Generator System Characteristics . . . 3-133 Annual Loads - Intermediate Application . . . . . 3-135 Intermediate Load Matching with a

Sample Computer Output for Utility/Multiple

B-1 Wind Energy Conversion System Storage Charging Utility Application(Lubbock, TX, Wind Data)... . . B-1 


\section{LIST OF ILLUSTRATIONS}

NUMBER

PAGE

Annual Savings Due to Storage at Representative Storage Capacities .. . . . . . . 1-3 Increased Utility Fuel Savings Due to

Multi-Source Charging of Storage

Conditions Leading to Economic Viability

of Utility and Residential Battery Storage

Systems - Wind Energy Conversion . . . . . . . 1-7

1.4-1 Economic Viability of Utility Energy

$1.4-2$

Storage Concepts - Wind Dedicated Charging . . . . . 1-12 Economic Viability of Utility Energy

1.4-3

Storage Concepts, Multi-Source Charging . . . . . 1-13

$1.4-4$

Range of Parameters - Utility Application . . . . . 1-17

Break-even Costs Compared with System Cost

Estimates, Wind Energy Conversion,

$1.4-5$

Utility Application ............... . . 1-18

Break-even Costs Compared to System Cost

Estimates - Utility Application . . . . . . . . 1-20

1.5-1 Economic Viability of Residential

$1.5-2$

Energy Storage Concepts

Location Effect on Residential Energy

$1.5-3$

Displacement using Storage.

Storage Break-even Cost vs. Start

$1.5-4$

Year for Residential Battery Storage Systems . . . . . 1-25

Effect of Energy. Storage on Total System

Energy Capture, Wind Energy Conversion,

$1.5-5$

Residential Application .............. 1-26

Break-even Costs Compared to System Cost

Estimates, Wind Energy Conversion,

Residential Application ............ . 1-27

1.6-1 Economic Viability of Intermediate

$1.6-2$

Energy Storage Concepts ............. . 1-29

Storage Energy Displacement -

$1.6-3$

Intermediate Application .............. 1-3l

Break-even Costs Compared with System

Cost Estimates - Intermediate Application . . . . . 1-32

1.7-1 Special Case Study Findings and

Related Study Results for WECS with Storage . . . . 1-35

2.1-1 Typical 1.5 MW Wind Turbine Generator (WTG) . . . . 2-1

2.1-2 Baseline 1.5 MW Wind Energy Conversion

2.1-3 Concentrated Wind Turbine Generator Plant at
$375 \mathrm{MW}$ Total Output Rating in a Moderate Wind Regime . 2-3 
VOLUME III

LIST OF ILLUSTRATIONS (CONT.)

NUMBER

PAGE

2. 1-4 Wind Energy Conversion with Pumped

2.1-5 Wind Energy Conversion with Compressed

Air Storage - Utility Application . . . . . . . . 2-15

2. $1-6$

Wind Energy Conversion with Lead-Acid Battery

$2.1-7$

Storage - Utility Application

Wind Energy Conversion with Flywhee?

2. $1-8$

Energy Storage - Utility Application . . . . . . . . . 2-26

$2.1-9$

2. $1-10$

$2.1-11$

Slip Power Dissipation in Variable Speed Coupling . . . 2-29

Wind Energy Conversion with Hydrogen Generation

and Storage System - Utility Application . . . . . . 2-33

Compressed Gas Storage Subsystem . . . . . . . . . 2-36

$2.2-1$

Electrolyzer Configuration with Compressor Eliminated . 2-37

$2.2-2$

Residential Battery Energy Storage

System - Wind Energy Conversion . . . . . . . . . . 2-43

Representative Lead-Acid Battery Module

$2.2-3$

$2.2-4$

for a Residential Storage System . . . . . . . . . 2-44

Residential Flywheel Energy Storage

System - Wind Energy Conversion . . . . . . . . . 2-47

Residential Pneumatic Energy Storage

2. 2-5

System - Wind Energy Conversion

$2-50$

Residential Thermal Energy Storage

System - Wind Energy Conversion

2.3-1

Baseline $500 \mathrm{MN}$ Wind Energy Conversion

System Block Diagram .. . . . . . . . . . . 2-55

3.3-1 Wind Energy with Dedicated Energy

3.3-2 Wind Energy Re-Distribution Utilizing

Storage for Utility Applications . . . . . . . . 3-5

Energy Storage - Utility Application . . . . . . 3-6

3.3-3 Theoretical Maximum Energy Credit for

Storage - Utility Application ... . . . . . . . 3-9

$3.3-4$

Effects of Start Year and Energy Price

Escalation Rate on Levelized Energy Savings -

$3.3=5$

Utility Application

Diurnal Variation Model of Wind Energy in

3. 3-6

the. Three Favorable Wind Regimes'

Seasonal Variations Model of Wind Energy

in the Favorable Wind Regimes . . . . . . . . . . 3-15

3.3-7

3. $3-8$

3. 3-9

$3.3-10$

3. 3-11

3. 3-12

Wind Data Sites vs. Regional Wind Regimes... . . . 3-16

Wind Turbine Power Output for Various Wind Velocities . 3-19

Annual Cumulative Hourly WTG Output (Lubbock, TX) . . 3-20

Annual Cumulative Hourly WTG Output (Gt. Falls, MT) . . 3-20

Annual Cumulative Hourly WTG Output (Blue Hill, MA) . . 3-2l

Representative Week- System "B" Load Demand . . . . . . 3-22 
VOLUME III

LIST OF ILLUSTRATIONS (CONT.)

NUMBER

PAGE

3. 3-13

3. 3-14

3. 3-15

3. 3-16

$3.3-17$

3. 3-18

3. 3-19

3. 3-20

3. 3-21

$3.3-22$

$3.3-23$

3. 3-24

3. $3-25$

3. 3-26

$3.3-27$

3. $3-28$

3. 3-29

3. $3-30$

3. 3-31

$3.3-32$

Summer Seas on Load Duration Curve for System "B" . . . 3-24

Winter Season Load Duration Curve for System "B'". . . 3-24

Computer Model Logic Diagram - Wind Energy

Conversion - Utility Application . . . . . . . 3-26

Typical Daily Profile of Load and

Generation Matching Results .. . . . . . . . 3-31

Typical Weekly Profile of Load and

Generation Matching Results .. . . . . . . . . 3-32

Delivered Energy Performance With and Wi thout

Energy Storage (Lubbock, TX,Wind Data) . . . . . . . 3-34

Cost-of-Generation Strata vs. Annual

Utility System Load . . . . . . . . . . . . . . . . 3-37

Monthly Value of Storage with WTG Charging . . . . 3-39

Annual Fuel Cost Savings with Storage for

Lubbock, TX, at 10 Percent Penetration . . . . . . . 3-40

Annual Fuel Cost Savings with Storage for

Blue Hill, MA, at 10 Percent Penetration.
Location, Penetration and Storage Discharge

Rate Effects, Wind Energy Conversion,

Utility Application ... . . . . . . . . . 3-53

Annual Energy Credit Comparison for

Various Efficiencies............... 3-54

Storage Efficiency Correction Factor,

Wind Energy Conversion. - Utility Application . . . . . 3-55

Composite Energy Credit, Wind Energy

Conversion, Utility Application . . . . . . . . 3-56

Mean Value of Storage Discharge Energy -

Utility Application . . . . . . . . . . . . . . 3-59

Estimated Effective Load Carrying Capacity

for Dedicated Wind Charging of Energy

Storage - Utility Application . . . . . . . . . 3-61

Range of Break-even Costs and Projected Storage

System Costs for Selected Economic Conditions,

Wind Energy Conversion - Utility Applications . . . . 3-65

Range of Break-Even Costs and Projected Storage

System Costs for Selected Economic Conditions,

Wind Energy Conversion - Utility Applications . . . . 3-66

Viability Comparisons for Selected Energy Storage

Technologies, Wind Energy Conversion - Utility

Applications . . . . . . . . . . . . . . 3-67

Impact of Start Year and Fuel Price Escalation

(Cost of Generation) on Storage Break-even Cost

Goals, Wind Energy Conversion, Utility Application . . 3-69

3.3-33 Impact of Start Year and Fuel Price Escalation

(Cost of Generation) on Storage Break-even Cost

Goals, Wind Energy Conversion, Utility Application . . 3-70 
VOLUME III

\section{LIST OF ILLUSTRATIONS (CONT.)}

NUMBER

PAGE

3. $3-34$

Optimum (Economic) System Sizes for Selected

Energy Storage Methods, Wind Energy

$3.3-35$

Conversion, Utility Application

Impact of Start Year and Fuel Price Escalation

on Optimum Energy Storage System Capacity,

Wind Energy Conversion, Utility Application . . . . 3-73

3.3.7-1

3. $3.7-2$

3. $3.7-3$

3. $3.7-4$

$3.3 .7-5$

Study Analysis Tools.............. . 3-75

Capacity Displacement Result . . . . . . . . 3-79

WECS Breakeven Cost with Storage . . . . . . . . . 3-80

Storage Breakeven Value Calculation . . . . . . . 3-80

Illustration of WECS and WECS with Dedicated

3. 3. 7-6

3. 3.7-7

Storage for the Month of December . . . . . . . . . 3-91

Contrast of Dedicated and System Storage for WECS . . 3-94

3. 3. $7-8$

Contrast of WECS Breakeven Cost and Fuels

Displacement for Gas Turbine vs. Nuclear Displacement. 3-96

Contrast of Breakeven Cost and Fuels Displacement

of WECS with Storage. . . . . . . . . . . . 3-97

3. 4- 1

$3.4-2$

Wind Energy Conversion with Dedicated Storage . . . 3-100

Wind Turb ine Power Output vs. Wind Velocity,

3.4-3

$3.4-4$

$10 \mathrm{~kW}$ Residential Unit

Diversified Residential Load Demand Profile . . . . 3-106

Residential Hot Water Heater Electrical

3. 4-5

3.4-6

Load Demand Profile . . . . . . . . . . . . 3-106

Typical Residential Winter Heating Demand Profile . . 3-106

Location Effect on Residential Energy

3.4-7

Displacement Using Storage

Representative Mean Residential Energy Displacement

3.4-8

Due to Storage

Annual Residential Mean Energy Credit Versus

3.4-9

Storage Capacity

Effect of Storage Efficiency on Residential

Energy Displacement . . . . . . . . . . . . . 3-118

3. $4-10$

$3.4-11$

Residential Storage Efficiency Correction Factor . . 3-119

Energy Storage Breakeven Cost Goals for

Residential Battery Systems . . . . . . . . . 3-125

3. $4-12$

$3.4-13$

Energy Storage Breakeven Cost Goals for

Res idential Flywheel and Pneumatic Storage
Storage Break-even Cost vs. Start Year for

Residential Battery Storage Systems . . . . . . . 3-128

$3.4-14$

Storage Breakeven Cost vs. Start Year for

Residential Flywheel. and Pneumatic Storage Systems . . 3-129

3. $4-15$

Increase in Wind System Break-even Costs due to 
VOLUME III

LIST OF ILLUSTRATIONS (CONT.)

NUMBER

PAGE

$3.5-1$

$3.5-2$

$3.5-3$

$3.5-4$

$3.5-5$

$3.5-6$

$3.5-7$

$3.5-8$

3. $5-9$

3. $5-10$

$500 \mathrm{~kW}$ WTG Power Output Versus Wind Velocity. . . . . 3-134

Assumed Load Profile for Intermediate Application . . . 3-135

Annual Energy Displacement, Intermediate Application. . 3-139

Mean Energy Displacement due to Addition of

Storage - Intermediate Application . . . . . . . . 3-140

Mean Energy Credit versus Storage Capacity -

Intermediate Application . . . . . . . . . . . 3-143

Effect of Storage Efficiency on Energy Displacement

due to Storage - Intermediate Application . . . . . . 3-145

Storage Efficiency Correction Factor -

Intermediate Application . . . . . . . . . . . 3-146

Energy Storage Breakeven Cost Goals -

Intermediate Application . . . . . . . . . . . 3-154

Storage Breakeven Cost vs. Start Year for

Pumped Hydro and Underground Compressed Air

Intermediate Application . . . . . . . . . . . 3-156

Storage Break-even Cost Vs. Start Year for

Battery Storage Systems - Intermediate Applications . . 3-157

3.6-1

$3.6-2$

3.6-3

$3.6-4$

The Role of Utility Make-up In Multiple Source Charging 3-160

Annual Energy Savings - Utility only Charging . . . . 3-163

Comparison of Storage Energy Credit with WTG

Charging vs. Baseload Charging (2000 MWh

Storage Capacity) . . . . . . . . . . . . 3-163

Range of Breakeven Costs and Projected Storage

System Costs for'Selected Economic Conditions,

3.6-5 Range of Breakeven Costs and Projected Storage

System Costs for Selected Economic Conditions,

Utility Only Charging (Multiple Source) . . . . . . 3-166

3.6-6 Impact of Start Year and Fuel Price Escalation

(Cost of Generation) on Storage Breakeven Cost Goals -

3.6-7 Impact of Start Year and Fuel Price Escalation

(Cost of Generation) on Storage Breakeven Cost

Goals, Utility only Charging (Multiple Source) . . . 3-168

$3.7-1$

Load Dedicated Systems .. . . . . . . . . . 3-179

$3.7-2$

Representative Wind Velocity Trace . . .. . . . . 3-181

$3.7-3$

$3.7-4$

Multiple Unit Systems with Distributed Loads . . . . . 3-182

$3.7-5$

Wind Conversion System Us ing DC Generation . . . . 3-184

Typical Industrial Electric Rate Schedules . . . . 3-187 
INTRODUCT ION

The variability of energy output inherent in wind energy conversion systems (WECS) has led to the investigation of energy storage as a means of managing the available energy when immediate, direct use is not possible or desirable. Several energy storage concepts have been successfully. employed for many years in the United States and elsewhere. The most notable examples are hydro systems, representing an upper level of storage size or "capacity" and batteries and flywheels for important but smaller scale applications. In Germany, thermal storage has been used successfully as a means of utility load leveling. This portion of the General Electric study was directed at an evaluation of those energy storage technologies deened best suited for use in conjunction with a wind energy conversion system in utility, residential and intermediate applications. Break-even cost goals are developed for several storage technologies in each application. These break-even costs are then compared with cost projections presented in Volume I of this report to show technologies and time frames of potential economic viability. The form of the presentation allows the reader to use more accurate storage system cost data as they become available. The report summarizes the investigations performed and presents the results, conclusions and recommendations pertaining to use of energy storage with wind energy conversion systems. 


\section{SECTION 1}

SUMMARY AND CONCLUSIONS

\subsection{STUDY OBJECTIVES AND SCOPE}

The principal objectives of the study with respect to wind energy conversion systems (WECS) and their use of energy storage were:

1. The assessment of selected candidate storage concepts.

2. Evaluation of the effects of selected parameters on the attractiveness and worth of energy storage utilization.

The scope of the investigations included both utility and non-utility applications. In addition to establishing cost goals for storage, the impact of charging storage from multiple sources, as well as from wind systems alone, was included, along with the effects of wind forecasting and transient smoothing of the wind system output.

Representative loads and average fuel costs were utilized. Generation mix per se was not included as a variable. Three basic wind turbine system sizes were included: $1.5 \mathrm{MW}$ single W1nd Turbine Generator (WTG) units clustered to provide selected amounts of "penetration" of wind systems in terms of total system capacity, a $500 \mathrm{~kW}$ WTG unit for intermediate applications, singly or in multiples, and a $10 \mathrm{~kW}$ WTG unit for residential application. Results were based on wind data from three widely separated locations which could be considered representative of conditions in coastal, mountain and plains areas of the contiguous United States. 


\subsection{STUDY APPROACH}

The study was conducted using the following general procedural steps:

1. Review of current concepts for the use of eleven storage methods including mechanical, thermal, electrical and electrochemical types of storage devices.

2. Assessment of suitability of concepts for use with wind energy conversion.

3. Determination of present through the year 2000 cost goals for energy storage vs. storage capacity under different conditions relative to:
a) Application
b) Avai lable wind energy/location
c) Wind system penetration (utility case)
d) Storage efficiency
e) Fuel price escalation rate
f) Other cost/viability factors

\subsection{OVERALL FINDINGS - ENERGY STORAGE WITH WIND ENERGY CONVERS ION SYSTEMS}

This section of the study report presents the overall findings and general conclusions reached as a result of the study. These findings and conclusions are described below. More detailed findings related to the specific study baseline conditions and assumptions are presented in the sections immediately following and elsewhere throughout the body of the report. It is significant to note that because of the interaction of basic parameters involved in actually applying wind and energy storage, the overall study results provide general guidance which must be supplemented by detailed investigations for any specific system design proposed. 
1. Energy storage improves both the energy utilization and the worth of wind generated energy over that of systems not using storage. This is illustrated in Figure 1.3-1 for the utility and residential cases, with the cross-hatched area indicating the increased savings due to storage over and above the basic wind sys tem savings. Intermediate storage system savings followed a pattern similar to the residential savings. The range and implications of the storage improvements are discussed in more detail for each application level.

- wind system storage charging $\square$ added by storage $\begin{gathered}\text { wing SYSTem Storage charging } \\ 10 \mathrm{~kW} \text { WTG }\end{gathered}$

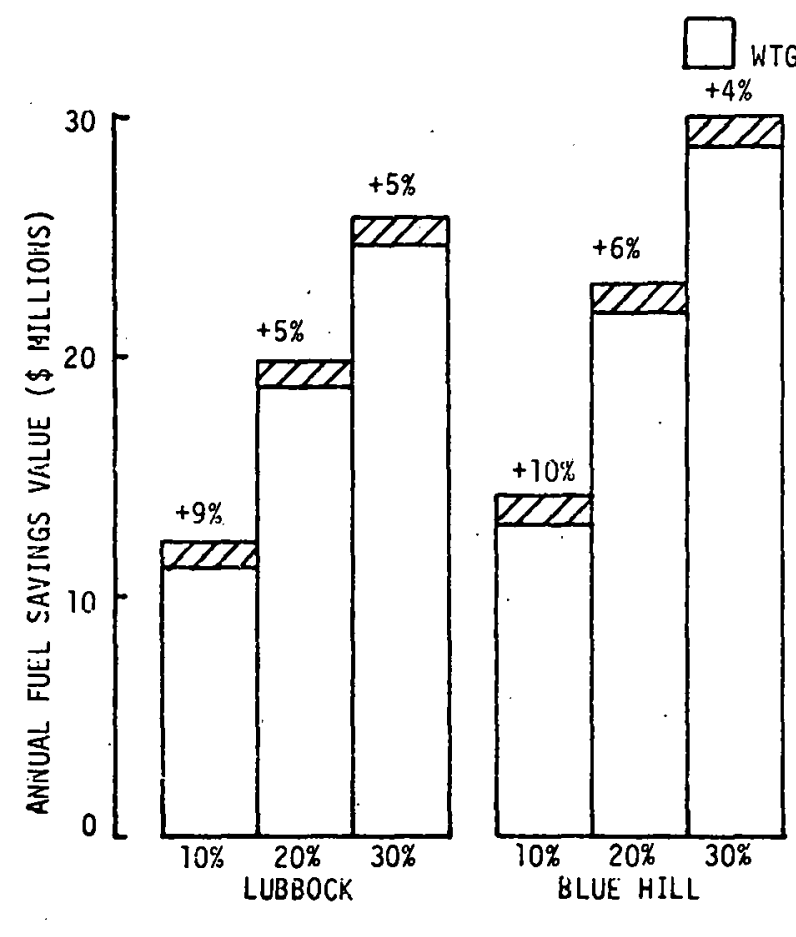

LOCATIOH AHD PERCENT PENETRATION
A. UTILITY (1000 MWh)
B. RESIDENTIAL (24 kWh)

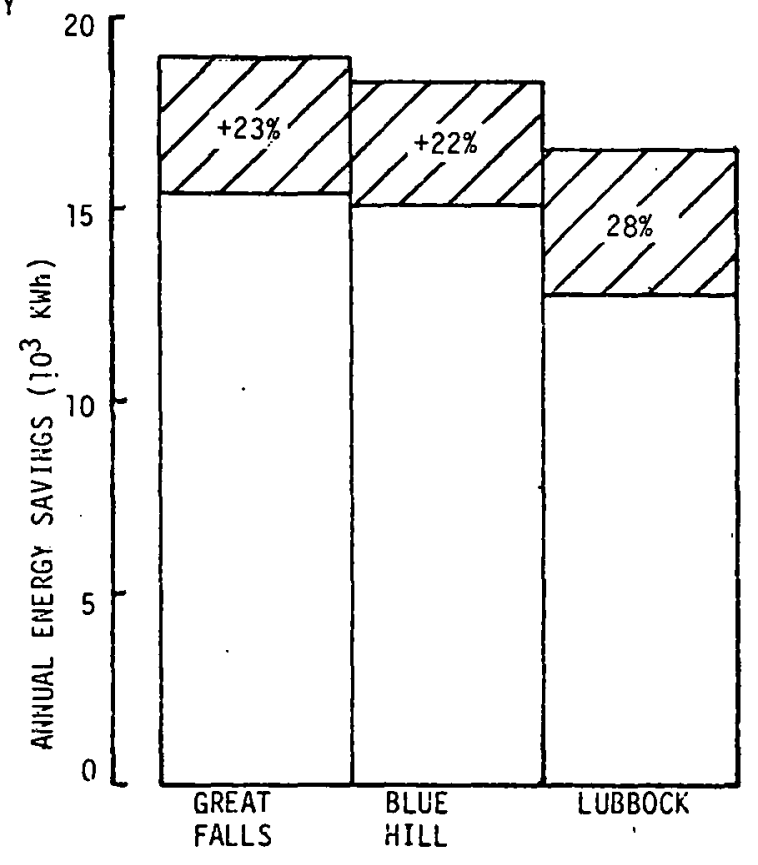

FIGURE $1.3-1$. ANNUAL SAVINGS DUE TO STORAGE AT REP.RESENTATIVE STORAGE CAPACIT IES 
2. On the utility level, energy storage provides a substantial additional benefit due to displacement of other generation equipment and, in some cases, transmission and distribution equipment.

3. Of the eleven energy storage concepts considered in the study, none show economic viability at current storage costs and energy prices when dedicated to use with wind energy conversion systems (wind system-only charging).

4. Energy storage on the utility level is always significantly more useful and economically attractive if it is charged on a system-wide or multiple source basis rather than dedicated to wind system charging alone. This is shown in Figure 1.3-2 which shows the added multi-source charging value as a dashed area above the previously presented dedicated charging savings.

5. A further advantage of multi-source charging is increased displacement of other generation equipment due to more reliable storage operation.

6. Pumped hydro storage systems offer the best storage economics for those applications (primarily utility) with proper scale and site characteristics. In addition, current pumped hydro storage costs represent cost goals for large scale storage systems, since they are presently economic on a system wide charging basis in many utility systems. 


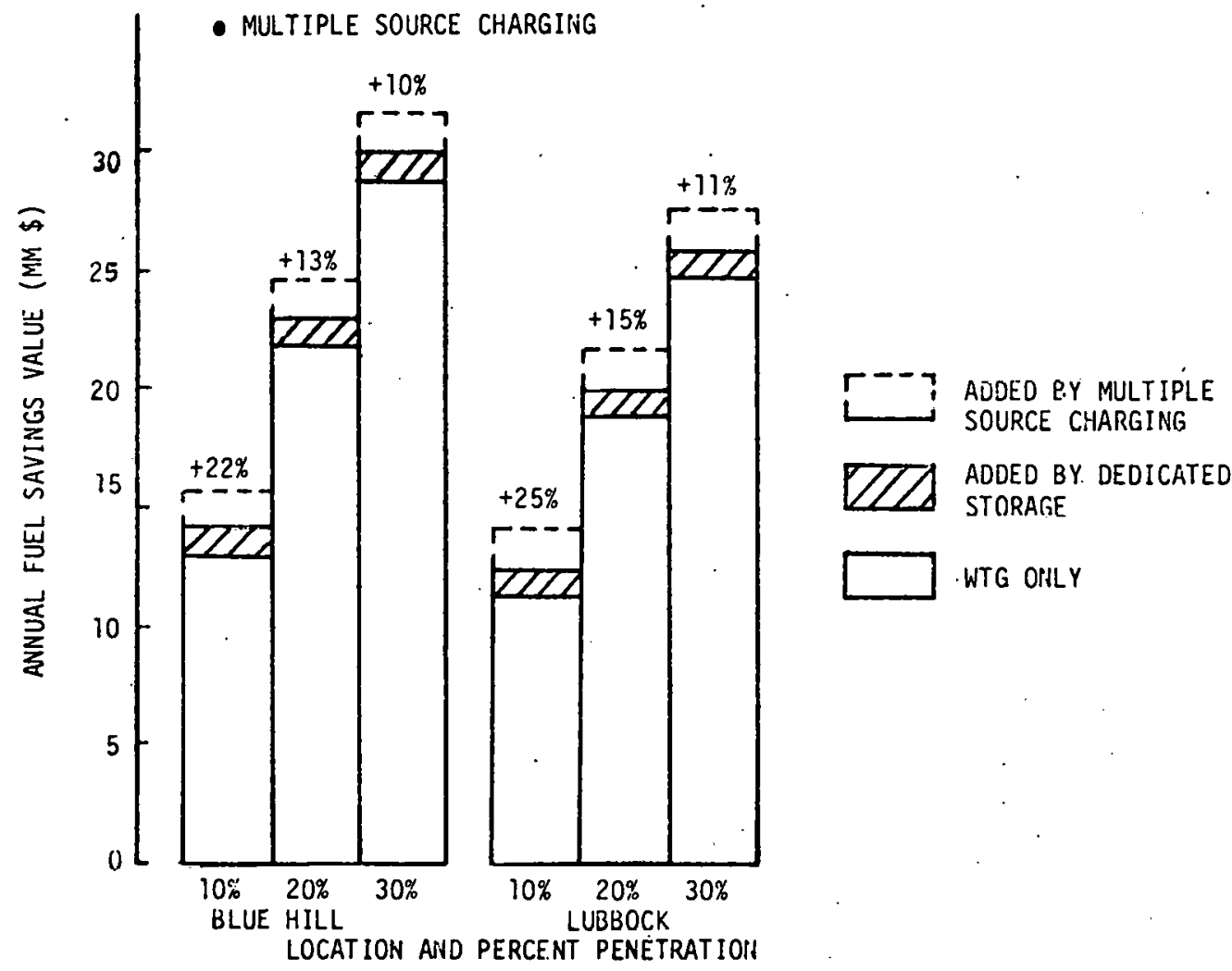

FIGURE 1.3-2. INCREASED UT IL ITY FUEL SAVINGS DUE TO MULT I-SOURCE CHARGING OF STORAGE

7. Of the several relatively near term storage technologies, battery energy storage is the most universally attractive across the range of applications studies. An advanced battery at projected 1985 conditions was the only storage concept with wide applicability to show potential economic viability in the near term.

8. Energy storage systems other than pumped hydro will offer economic viability if increasingly severe economic conditions are postulated 
between now and year 2000. Figure 1.3-3 presents break-even cost goals for utility and residential batteries at several electricity price escalation rates and start years of 1985 and 2000 . Current costs of lead-acid batteries and the 1985 cost projection for advanced batteries are also shown. Battery life was assumed at 10 years. If a 20 year life battery becomes available, the break-even cost goals would increase by over $30 \%$ in the residential application and by 7 to $14 \%$ in the utility application. The clear superiority of system wide or multi-source charging of storage is again shown.

9. Although the type of energy storage system should be selected on an individual application basis, the differences in storage system characteristics suggest that a mix of storage concepts may be desirable. For example, a utility network could employ pumped hydro storage for 10 hour discharge duty and advanced batteries for peaks of shorter duration where battery economics closely approach pumped hydro. The transmission and distribution facilities of a utility system may also make a mix of storage technologies desirable.

10. Wind forecasting appears to offer only a modest improvement in storage value over what can be obtained using reasonably straight-forward judgmental storage operational strategies.

11. Energy storage in residential and intermediate applications can achieve as high as a 30 to 40 percent increase in total system energy capture. When realistically achievable storage costs are considered, storage can, at best, increase the worth of the basic wind system by 10 to 15 percent. 

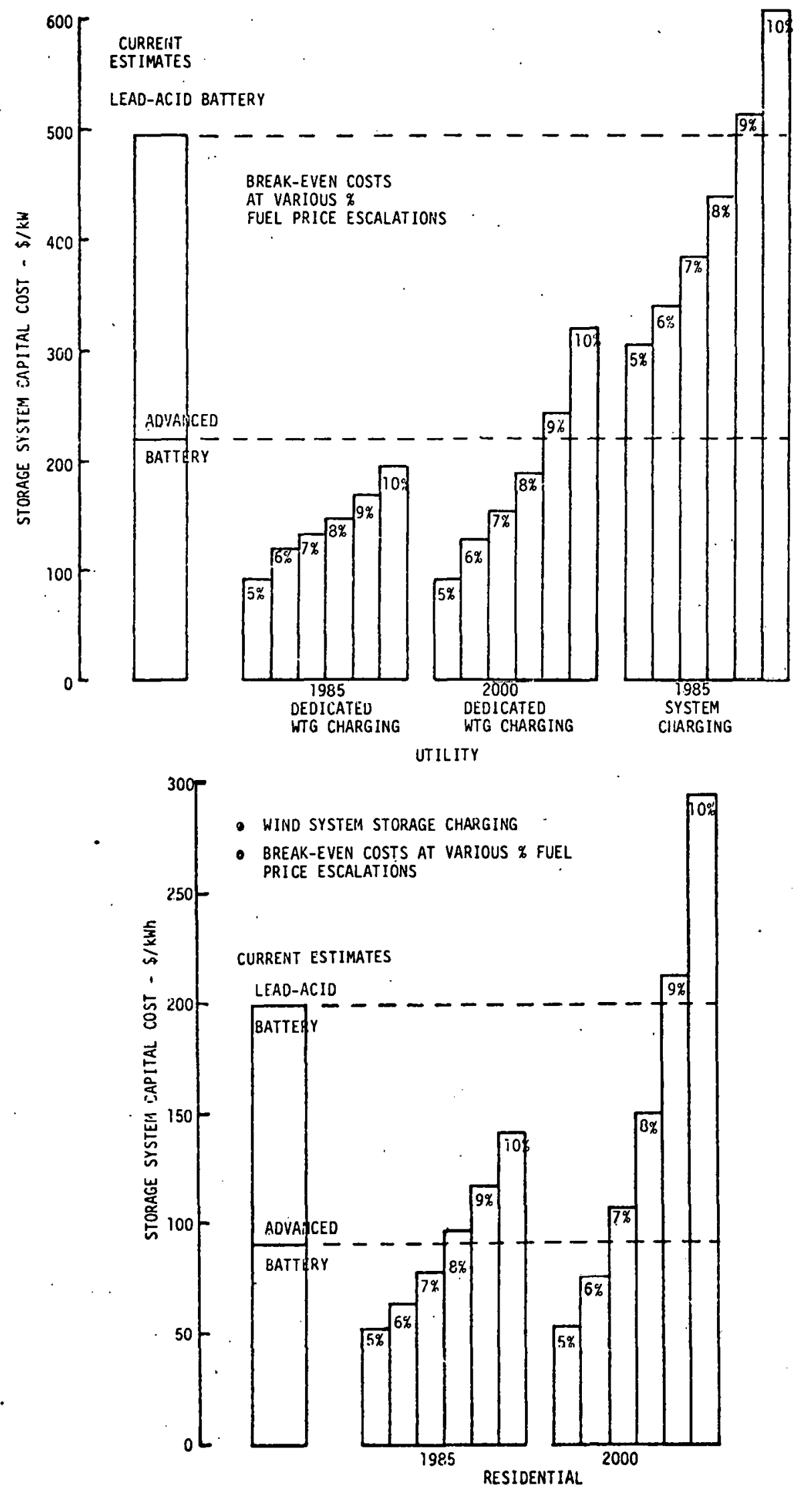

FIGURE 1.3-3. CONDITIONS LEADING TO ECONOMIC VIABILITY OF UTILITY AND RESIDENTIAL BATTERY STORAGE SYSTEMS WIND ENERGY CONVERSION 
12. High electric rates combined with the non-tax-deductibility of energy costs make the residential energy storage system generally much more economic than the intermediate, under present pricing and tax policy.

13. The special utility case studies performed by GE-EUSED, using a Monthly Production Simulation Program analysis, produced worth of storage results similar to other study findings. The case study results indicated that:

(a) Operating storage in a dedicated manner with WECS can lead to a significant economic penalty.

(b) There is a significant $(\sim 25 \%)$ potential to improve the value of system storage in WECS applications by accurate weekly forecasting of WECS output.

14. The smoothing of WECS output with energy storage devices is a technical requirement for certain types of single generator-single load situations. For large scale or utility type operations, the requirements for stability of output are better met by other means. No economic value results from using storage for output smoothing except in the intermediate applications. Rate structures in these applications can make smoothing attractive in cases where lower level power demands can be achieved with a corresponding reduction in cus tomer charges. 
15. Over the range of parameters studied and at the baseline economic conditions of 1985 start and $6 \%$ fuel price escalation, cost goals (break-even costs) for energy storage fell in the following approximate ranges in $1976 \$$ :

$$
\begin{aligned}
& \text { Utility } \quad-\quad 300-400 \$ / \mathrm{kW} \\
& \text { Residential - 60-100 \$/kWh } \\
& \text { Intermediate } \quad-\quad 15-25 \$ / \mathrm{kWh}
\end{aligned}
$$

Specific cosl godls are both techmolugy and application dependent. The methodology and results for each application will be discussed. in the sections that follow, along with individual concept applicability for use with WECS. 


\subsection{STORAGE WITH WIND SYSTEMS - UTILITY APPLICATION}

\subsubsection{CANDIDATE STORAGE CONCEPTS}

Candidate energy storage concepts selected, in conjunction with the concept reviews discussed in Volume I of this report, for further investigation for use with wind energy systems in utility applications included:

1. Pumped Hydro

a. above ground

b. underground

2. Underground Compressed Air

3. Batteries
a. lead acid
b. advanced

4. Inertial (Flywheel)

5. Hydrogen

Note that thermal storage systems were not considered further in this portion of the study due to their inapplicability to electrical output energy systems such as wind turbine-generator systems. This is discussed in Part B of Volume I. Similarly, superconducting magnetic energy storage was not considered further because of the present immaturity of the technology.

\subsubsection{METHODOLOGY FOR UTILITY APPLICATION ANALYSIS}

The available information and data on the candidate storage concepts, experience to date, and development status were reviewed in detail. Suggestions, advice and other inputs were obtained from several other organizations including other General Electric departments, a utility 
company (PSE\&G) and a battery manufacturer (C\&D Batteries). In addition, contacts were made with various other Government agencies and investigators. A summary description of the various general storage technologies was prepared for reference and is presented in Volume I of this report, along with projected costs for each concept.

A set of candidate storage evaluation criteria was prepared, selectively reduced to key criteria and subsequently used for preliminary ranking of the various storage concepts. Part B of Volume I of this report presents the results of this ranking for each appijication and for both wind and photovoltaic energy conversion systems.

In order to establish values for the "worth" of storage under various conditions, selected locations, loads and generating capacities were analyzed using computer routines. Present estimates of system life, 0\&M requirements and interest during construction (CCF) were used in the analysis (see Table 5.3-1 of Volume I). The analytical procedures are described in detail in Section 3 of this volume.

\subsubsection{GENERAL RESULTS AND FINDINGS - UTILITY APPLICATION}

Dedicated wind energy storage in utility systems was found to be noneconomic at current system cost estimates and nominal energy price escalation projections. Figure 1.4-1 displays economic viability tested against increasingly severe economic conditions for each of the seven utility storage concepts which survived the initial concept screening. 


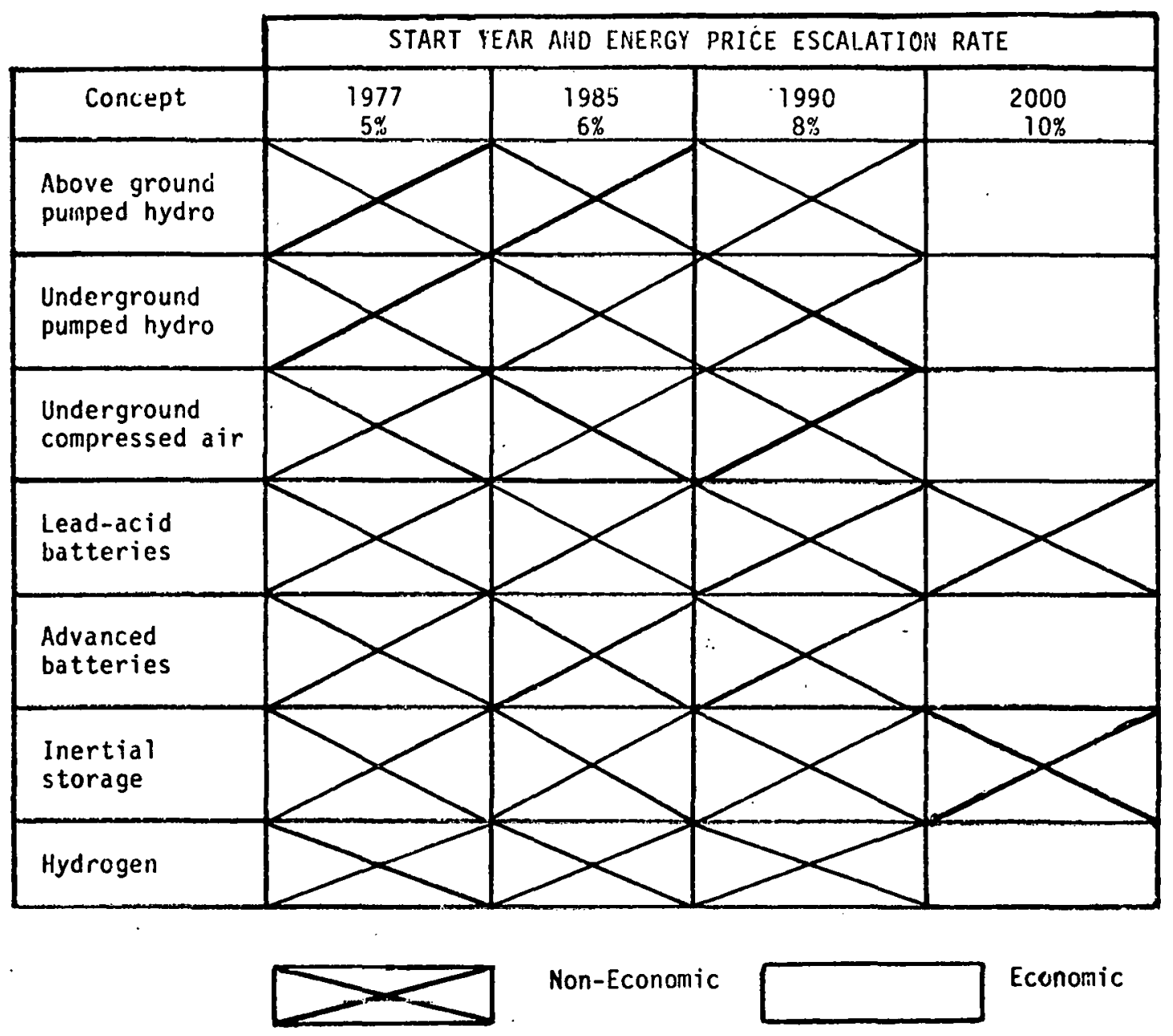

Figure 1.4-1 ECONOMIC VIABILITY OF UTILITY ENERGY STORAGE CONCEPTSWIND DEDICATED CHARGING

The escalation rates shown range from 0 to $5 \%$ over the assumed general inflation level of $5 \%$. Note that only the extreme year $2000,10 \%$ escalation conditions result in viability for five storage concepts operating in a wind dedicated charging mode. 
System wide, or multi-source, charging substantially improves storage economics as shown in Figure 1.4-2.

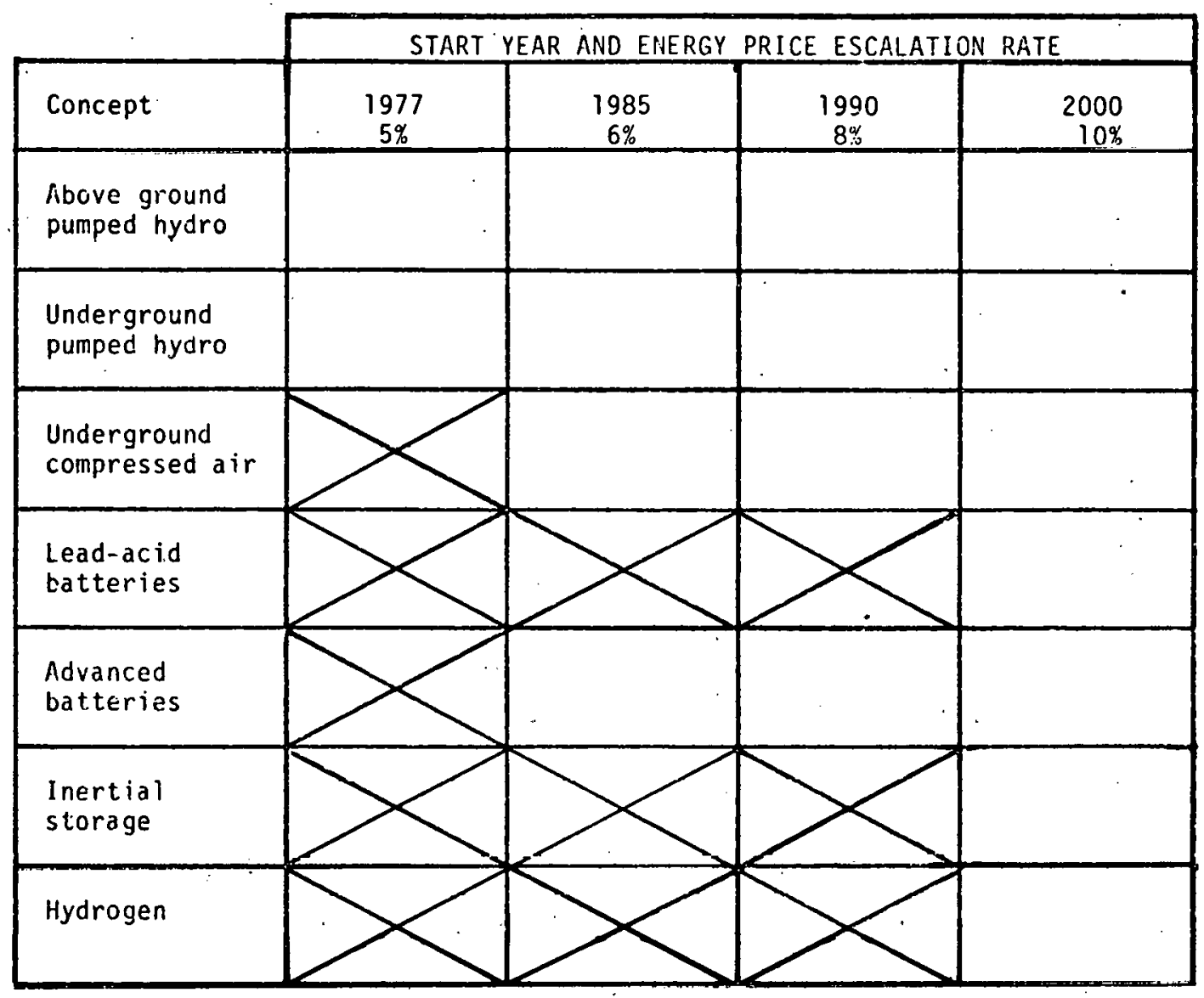

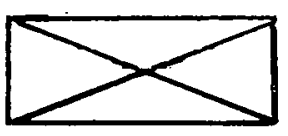

Non-Economic

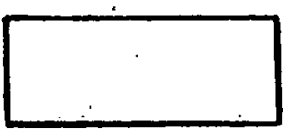

Econoulic

Figure 1.4-2 ECONOMIC VIABILITY OF UTILITY ENERGY STORAGE CONCEPTS MULTI-SOURCE CHARGING. 
Multi-source charging results in four storage concepts becoming viable at the baseline 1985 start, 6\% price escalation condition. Both types of pumped hydro show present viability with $5 \%$ price escalation (zero differential escalation).

With regard to overall (non-economic) attractiveness of the various concepts for wind system use, the following was concluded for the utility case:

1. Although all seven concepts can be interfaced with a wind energy source, the hydro and compressed air systems present modularity problems due to the variability of the wind source. When specific system designs are attempted, the system costs for windonly charging would, therefore, tend to be increased over nominal projections for these technologies.

2. Inertial storage does not look particularly attractive in terms of drive systems and input-output conversion equipment requirements. In addition, the developing flywheel technology requires additional work to meet the energy density and operational requirements at the utility level.

3. Hydrogen systems appear to offer possibilities for reasonable modularization, but the variability of the wind source input could result in both an increase in modularity requirements and possible further reductions in system efficiency (already low) and reliability. 
4. Battery systems, taken as a general class, possess the best overall characteristics for use directly with wind systems. There are significant differences between the so-called advanced battery systems now under development, and it is not clear which of these advanced systems might eventually emerge as the most technically successful. Although there are design and/or developmental problems to be resolved, these are being pursued in a manner that will lead to a conclusive type of testing via the Battery Energy Storage Testing (BEST) program. The successful development of an "advanced" battery must be matched by achievement of low cost. Present lead-acid battery costs, for' example, preclude showing viability with dedicated windutility equipment unless very extreme future economics are encountered even beyond those used as study parameters. For wind-only storage charging, even the present advanced battery cost predictions do not make an "advanced" battery attractive until economic pressures increase substantially.

A further overall conclusion is that: When both technical and economic characteristics are considered, the use of utility-level energy storage is more attractive and provides more options if it is approached on a multisource charging basis. Under the latter condition, hydro, compressed air and possibly hydrogen systems could be used where siting conditions permit. Batteries and possibly flywheels, at some future point in time, could provide system peaking power at dispersed locations. Thus, a range of options is left open which may be tailored to specific utility company needs. 


\subsubsection{PARAMETRIC EFFECT ON WORTH OF STORAGE - UTILITY APPLICATION}

The parameters examined for utility applications using wind turbine systems are presented in Figure 1.4-3 and include the following:

1. Location/wind characteristics

2. Wind system penetration (as a percent of utility generation capacity)

3. Storage charge/discharge rate

4. Storage efficiency

5. Storage size

6. Fuel price escalation rate

7. Start year

Storage break-even cost computations resulting from computer data analyses were adjusted to account for the major differences in storage conceptpeculiar parameters, such as efficiency, operation and maintenance and component replacement requirements. The adjusted break-even costs were then used as a basis for establishing the relative viability of the various concepts. Concepts of greatest promise/interest were then evaluated in further detail over a range of economic conditions through the year 2000 .

The general effects of the above pardilelers on 3 toragc cconomics are as follows:

1. For moderate wind regimes, location showed an effect of about $\pm 29 \%$ on the mean energy savings and thus on the capitalized energy credit.

2. The maximum effect of wind system penetration on energy credit was approximately $\pm 21 \%$, occurring at the higher storage capacities.

3. Use of a 5 hour versus a 10 hour discharge rate indicated a maximum energy credit improvement of about 15\% at the same penetration level.

4. Storage system efficiency increasing over a range from $60 \%$ to $90 \%$ showed an overall $34 \%$ energy credit improvement.

5. Energy credit per unit of storage was seen to consistently decrease as system size was increased, although total energy credit increased. 


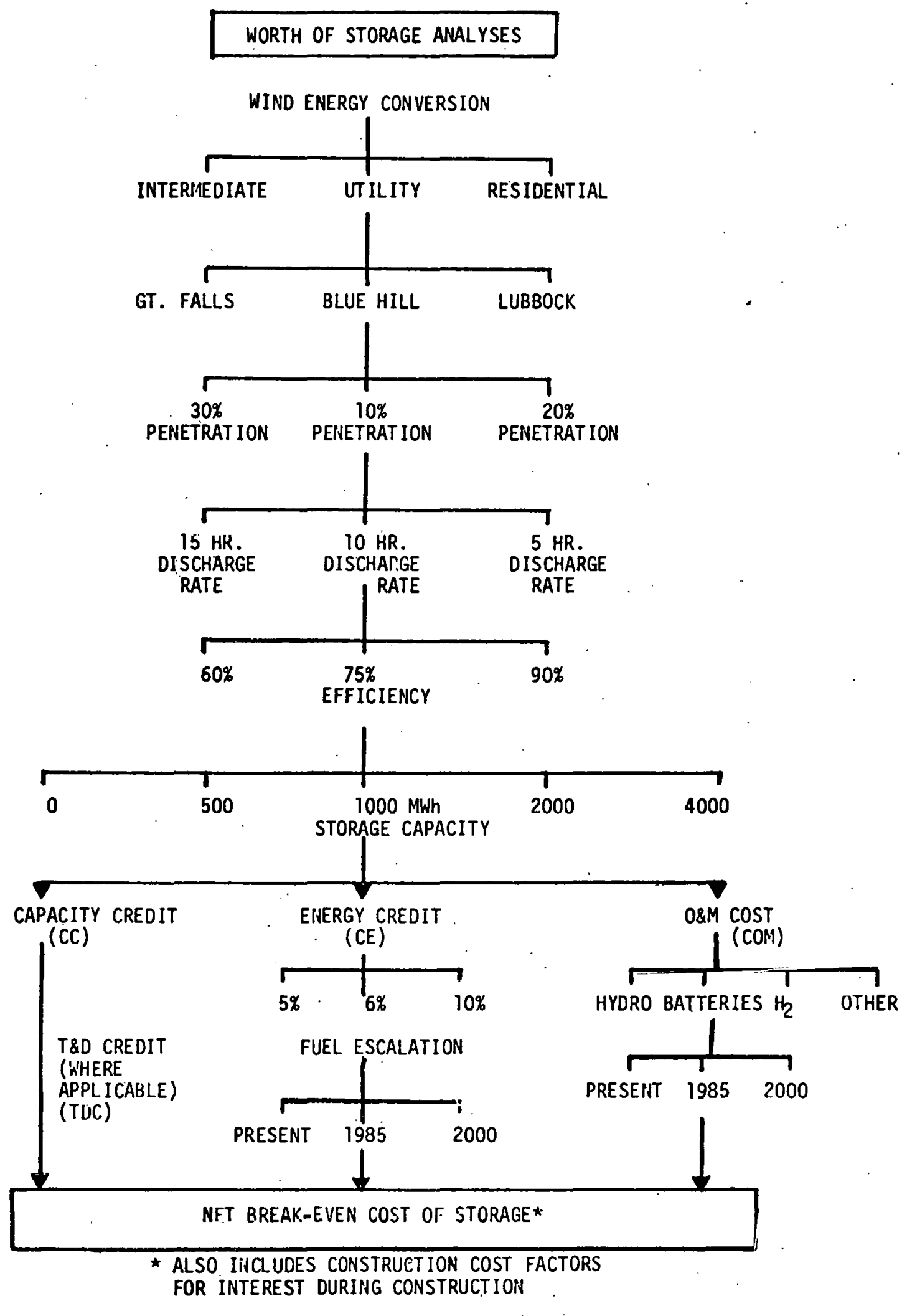

FIGURE 1.4-3. RANGE OF PARAMETERS - UTILITY APPLICATION 
6. Energy credit obviously increases as fuel price escalation rate increases.

7. For fuel price escalation rates greater than general inflation, assumed at $5 \%$ in the analysis, energy credit increases as start year is moved out in time.

Figure 1.4-4 presents the results of break-even cost computations for 1000 MWh of dedicated storage capacity, 5 and 10 hour discharge rates, and the extreme economic conditions of $10 \%$ fuel price escalation rate and a year 2000 start. Representative system cost estimates are also shown for comparison. Break-even costs higher than cost estimates indicate potential for economic viability.

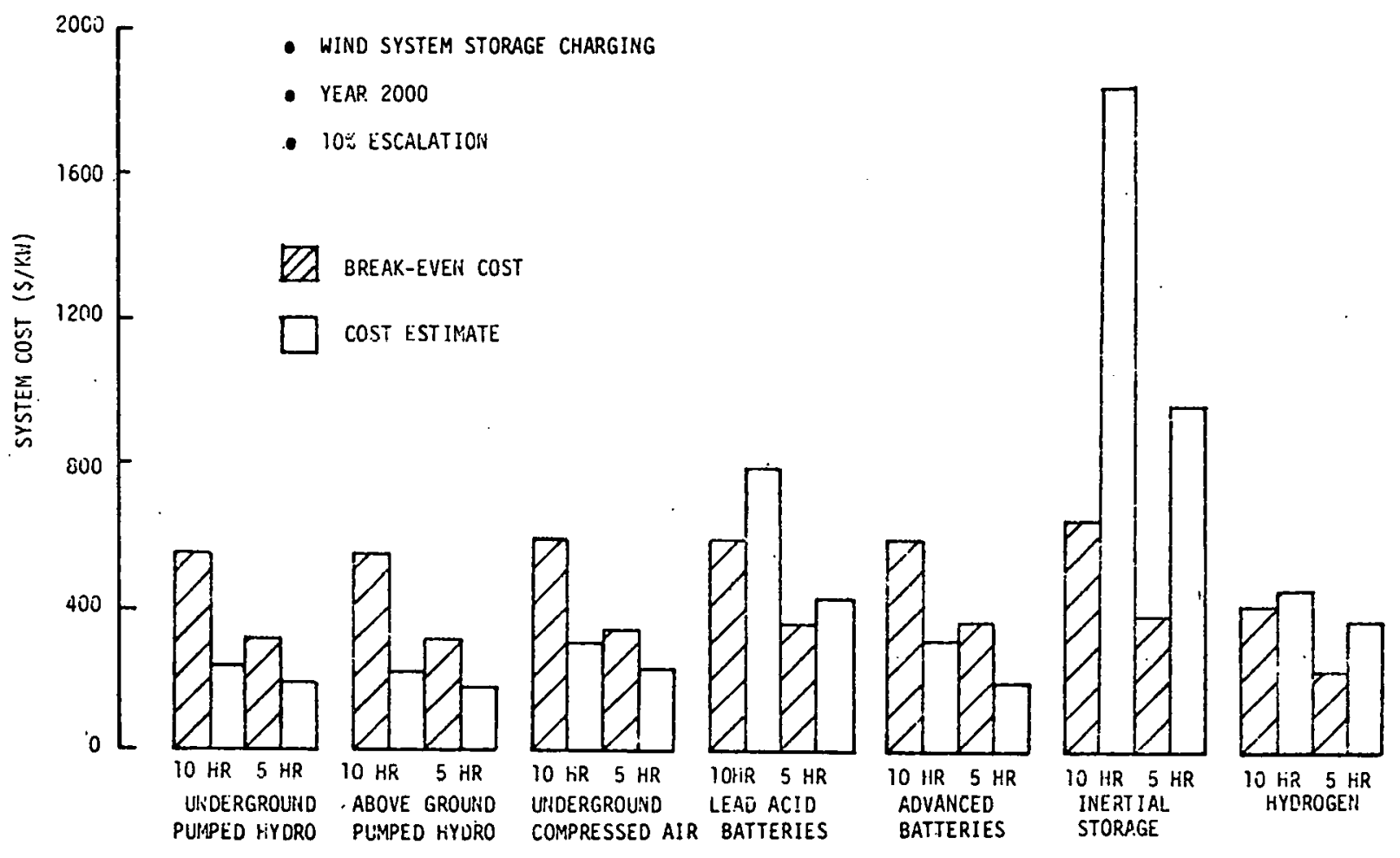

FIGURE 1.4-4. BREAK-EVEN COSTS COMPARED WITH SYSTEM COST ESTIMATES, WIND ENERGY CONVERSION - UTILITY APPLICATION 
Capacity credit and transmission and distribution credits (where applicable) are included in the above data, which indicate four systems of potential viability - both types of hydro, compressed air and advanced batteries. These four plus lead-acid batteries (due to wide-spread interest in this concept) were selected for more detailed economic analysis as presented in Section 3.3.6.

The above analysis at extreme economic conditions affords maximum opportunity for a storage concept to demonstrate economic potential. System cost estimates shown are taken from the year 2000 projected values as given in Volume I of this report. It should be noted that the concepts showing potential viability at the ten hour discharge rate are also viable when a 5 hour discharge rate is assumed. Discharge rate affected viability potential only for multi-source charging. (Figure 1.4-5).

An important finding of the utility break-even analysis is that energy credit alone is not sufficient to achieve viability. There must be some form of benefit due to displacement of other equipment. Estimates of these benefits - capacity credits and transmission and distribution (T\&D) credits, have been drawn from several sources and nominal values incorporated in the break-even results.

A major conclusion of the utility allalysis as prevfously stated is that system wide storage, or multi-source charging, is much more attractive than dedicated wind system storage, with break-even costs increased by more than two to one. This is further evident in Figure 1.4-5 below, which indicates 211 of the seven storage concepts having some degree of economic 
potential at the $10 \%$ escalation year 2000 condition. Ten and five hour discharge rates are shown to point out clear differences in application potential. As can be seen, hydro and compressed air storage are much more at.tractive on a ten hour basis while battery systems and inertial storage are more cost effective at five hours.
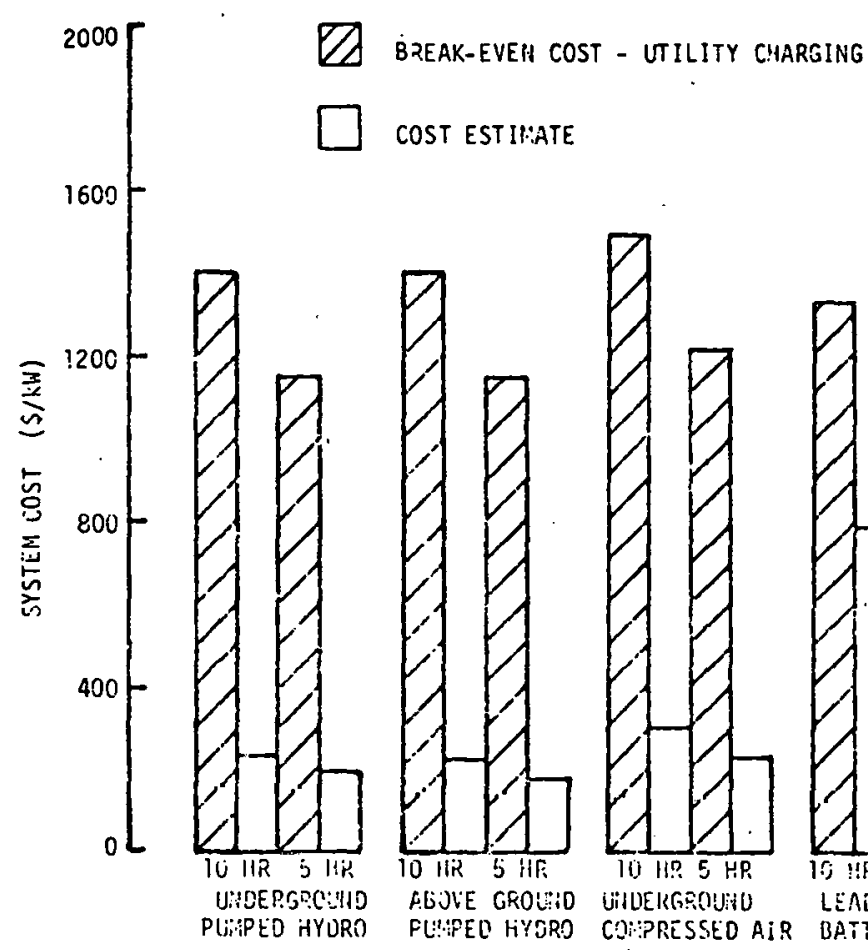

- 10:. escalation
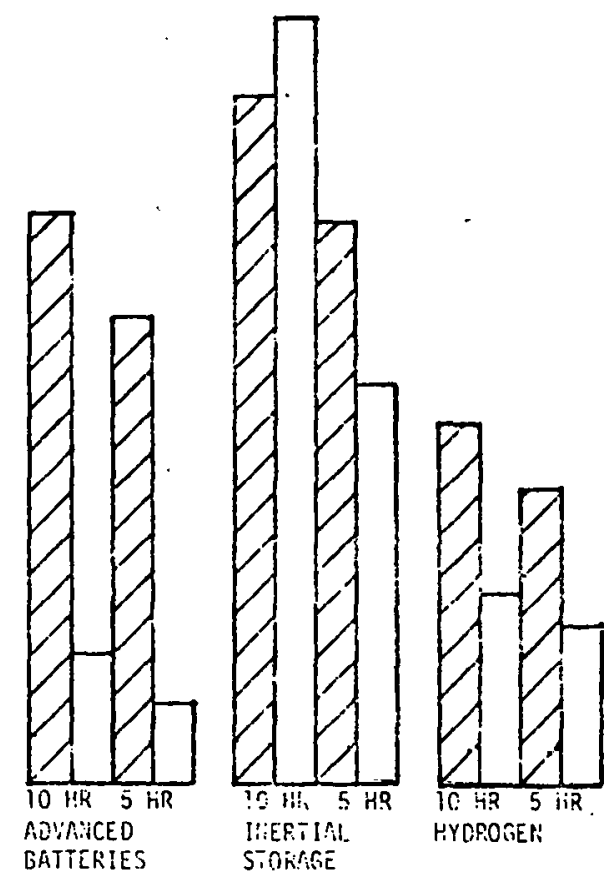

Figure 1.4-5 BREAK-EVEN COSTS COMPARED TO SYSTEM COST ESTIMATES UTILITY APPLICATION

Note that the four storage concepts selected for detailed investigation due to their economic potential on a wind system dedicated basis retain their lead in economic attractiveness when utility or multi-source charging is considered. 
Wind forecasting in conjunction with multi-source charging indicated only a slight improvement in energy credit for perfect forecasting over what could be achieved with simple storage operational strategies. Forecasting must necessarily involve not just wind conditions but load demands, to determine the net requirements on dispatchable generation equipment. Several judgmental storage operational strategies that could be easily implemented with only knowledge of load trends, gave energy credit within $10 \%$ of that achieved with perfect prior knowledge of daily net load.

\subsection{STORAGE WITH RESIDENTIAL WIND SYSTEMS}

\subsubsection{CANDIDATE STORAGE CONCEPTS}

Candidate storage concepts for use with residential wind energy systems, selected in conjunction with the concept reviews presented in Volume I of this report include:

1. Compressed air/pneumatic storage

2. Batteries

a. Lead-acid

b. Advanced

3. Inertial (flywheel)

All of the above systems were deemed to be of sufficient interest to carry forward for more detailed economic comparison against break-even cost goals.

\subsubsection{METHODOLOGY FOR RESIDENTIAL APPLICATION ANALYSIS}

Evaiuation of candidate storage technologies for the residential application followed the procedure described for the utility application (Section 1.4.2). 
Available information and data were reviewed, evaluation criteria examined and subsequently reduced to key criteria, and the four technologies cited in Section 1.5.1 were selected for more detailed investigation. Values for the worth of storage analyses were obtained by matching typical residential loads and wind turbine generator output for several locations and then employing energy storage to improve the match. Current estimates of system 1 ife and operation and maintenance requirements were used in the analysis (see Table 5.3-2 of Volume I). The analytical procedures are described in detail in Section 3 of this volume.

\subsubsection{GENERAL RESULTS AND FINOINGS - RESIDENTIAL APPLICATION}

Energy storage in conjunction with residential wind energy systems proved to be non-economic at current system cost estimates and nominal energy price escalation projections. Figure 1.5-1 presents economic viability tested against increasingly severe economic conditions for each of the four residential storage concepts which survived the initial concept screening.

Inflation was assumed at $5 \%$, thus the escalation rates shown range from zero differential to $5 \%$ over inflation. The advanced battery is the only storage concept which reaches economic viability at the $1990,8 \%$ case. 


\begin{tabular}{|c|c|c|c|c|}
\hline & \multicolumn{4}{|c|}{ START YEAR AIID ENERGY PRICE ESCALATIOH RATE } \\
\hline Concept & $\begin{array}{c}1977 \\
5 \%\end{array}$ & $\begin{array}{l}1985 \\
6 \%\end{array}$ & $\begin{array}{c}1990 \\
8_{x}^{*}\end{array}$ & $\begin{array}{r}2000 \\
10 \%\end{array}$ \\
\hline $\begin{array}{l}\text { Advanced } \\
\text { Battery }\end{array}$ & & & & \\
\hline $\begin{array}{l}\text { Lead-acid } \\
\text { Battery }\end{array}$ & & & & \\
\hline $\begin{array}{l}\text { Inertial } \\
\text { Storage }\end{array}$ & & & & \\
\hline $\begin{array}{l}\text { Pneumatic } \\
\text { Storage }\end{array}$ & & & & \\
\hline
\end{tabular}

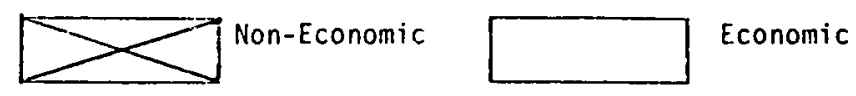

FIGURE 1.5-1. ECONOMIC VIABILITY OF RESIDENTIAL ENERGY STORAGE CONCEPTS

With regard to overall (non-economic) attractiveness of the storage concepts considered for wind system use, the following was concluded for the residential case:

1. The inertial and pneumatic storage systems both require equipment which would pose owner-operator difficulties. Excessive noise is probable in both cases, and both have potential personnel hazards that would require special attention in storage system designs.

2. Battery systems offer the same advantageous load and input responsiveness as in the utility case. System design problems are present in that specifically designed control and switching systems are required, but these do not appear to be insurmountable problems. A diversity of opinion seems to exist on the questions of hazards in the residence due to use of $d c$ voltages, acid or other chemical release, and (in the case of lead acid batteries) hydrogen release. In the final analys is, the subjective issues concerning the potential chemical and hydrogen hazards appear the most difficult to resolve.

3. Additional work on the details of control and interface of the residential wind conversion and storage system will be required for achievement of a significant future market. 


\subsubsection{PARAMETRIC EFFECTS ON WORTH OF STORAGE-RESIDENTIAL APPLICATION}

The parameters investigated in the residential application of energy storage to wind energy systems include:

1. Location/wind characteristics

2. Storage efficiency

3. Storage size

4. Fuel price escalation rate and start year

5. Effect on wind system worth

Storage break-even cost computations were adjusted to account for concept peculiar differences in such factors as efficiency and operation, maintenance and replacement requirements. The general effects of the above parameters on storage economics are as follows:

1. Over a range of loads and WTG output, the energy savings from storage as a function of storage size remained quite constant. This is shown in Figure 1.5-1.

2. An increase in storage system efficiency from $60 \%$ to $90 \%$ increased energy savings only $8 \%$. This suggests that within this range storage efficiency is relatively unimportant in residential storage economics.

3. Energy displacement per unit storage steadily decreased with storage size, as can be seen in Figure 1.5-2. The effect is to make storage sizes above $24 \mathrm{kWh}$ economic only under the more severe conditions of price escalation. From 12 to $24 \mathrm{kWh}$ appears to be the best storage capacity range for residential energy storage with wind energy conversion systems, at least under near-term conditions.

4. Storage break-even cost increased with energy price escalation rate and start year delay. The effect is shown in Figure 1.5-3 for both lead-acid and "advanced" batteries. An "advanced" battery was the only approach which offered possible viability at a nominal 6\% electricity price escalation and 1985 start conditions. 


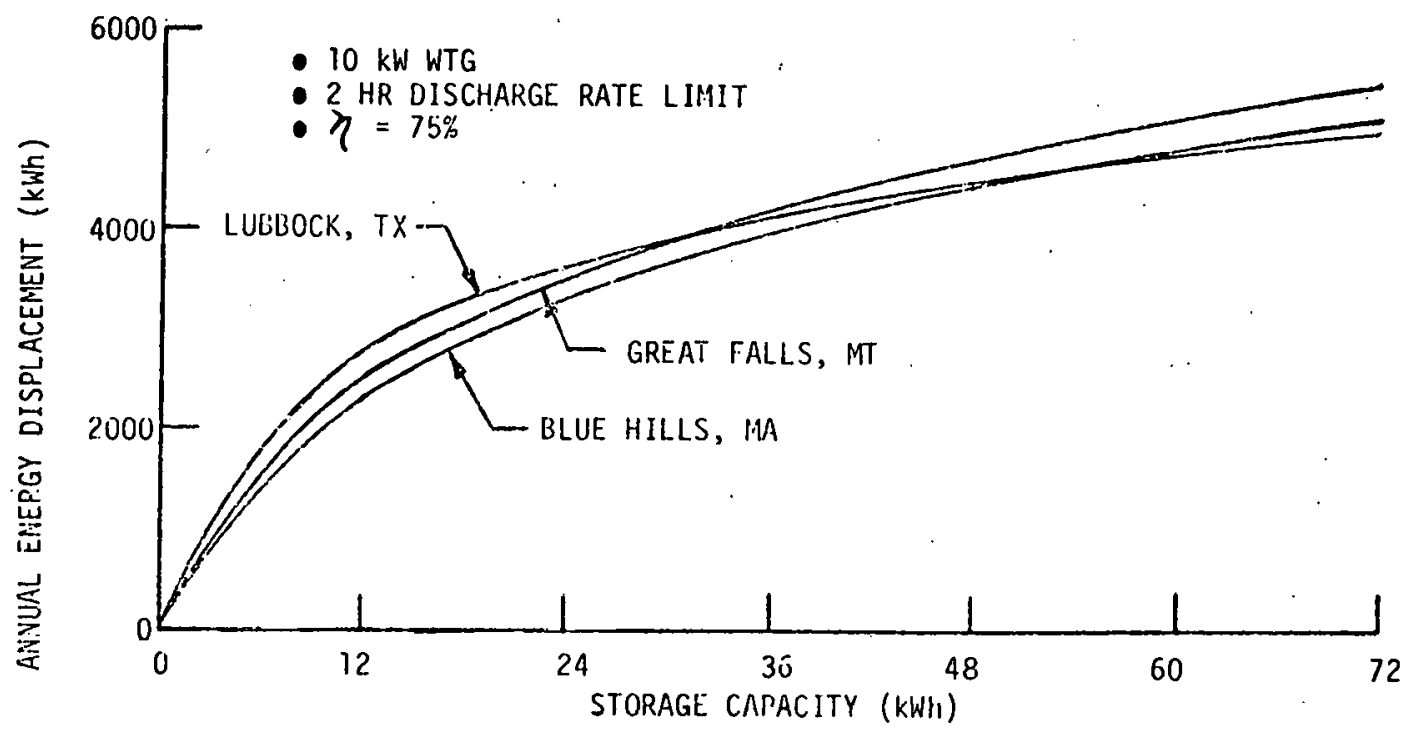

FIGURE 1-5-2. LOCATION EFFECT ON RESIDENTIAL ENERGY DISPLACEMENT USING STORAGE

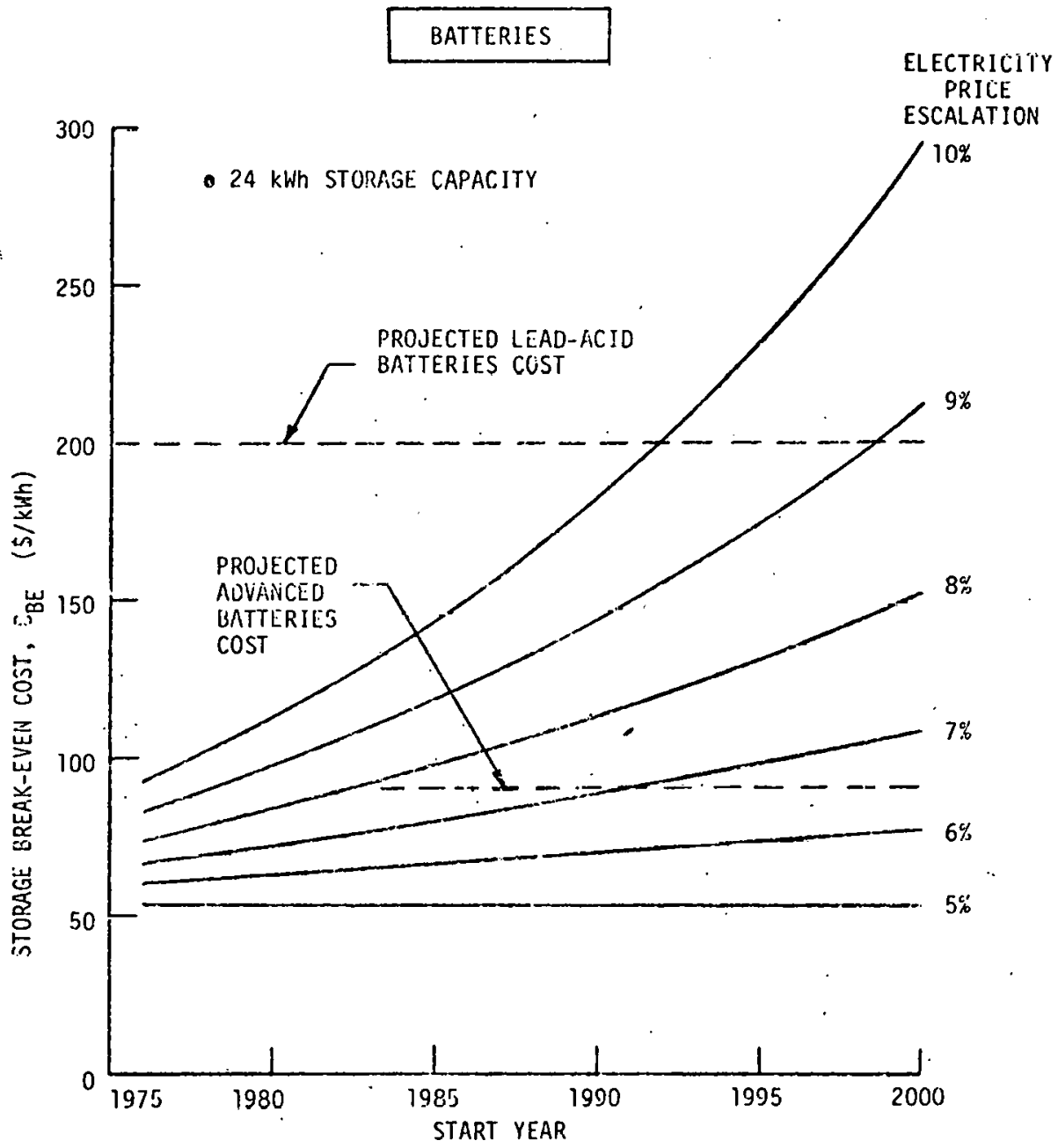

FIGURE 1-5-3. STORAGE BREAK-EVEN COST VS. START YEAR FOR RESIDENTIAL BATTERY STORAGE SYSTEMS 
5. Energy storage is unable to significantly improve the value of the wind system at realistically achievable storage prices. The basic effect is shown in Figure 1.5-4. Even the largest storage capacity ( $72 \mathrm{kWh})$, increased energy capture by only $37 \%$. At a more reasonable size of $24 \mathrm{kWh}$, the improvement was 25\%. Energy storage must be priced below its break-even cost for any of the 25\% improvement to be reflected in a higher allowable WTG cost. At a very low storage price of $\$ 40 / \mathrm{kWh}$ the allowable WTG cost was seen to increase by only about 10 to $15 \%$ at nominal conditions and $20 \%$ at the extreme $10 \%$ escalation year 2000 start conditions.

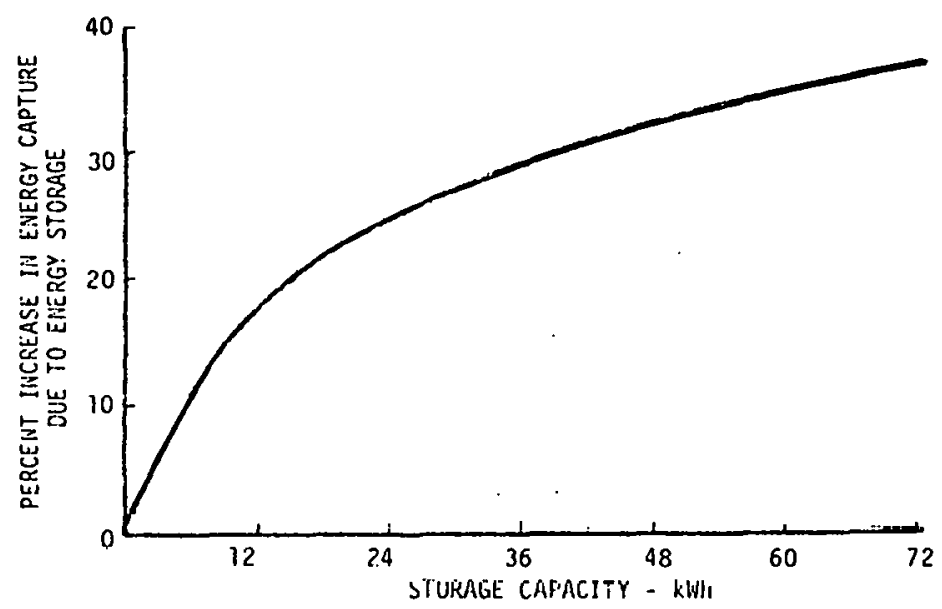

Figure 1.5-4. EFFECT OF ENERGY STORAGE ON TOTAL SYSTEM ENERGY CAPTURE, WIND ENERGY CONVERSION-RESIDENTIAL APPLICATION.

Figure 1.5-5 gives the results of break-even cost computations for $24 \mathrm{kWh}$ capacity residential systems at the $1.0 \%$ energy price escalation rate and year 2000. The projected system costs shown, permit comparison between concepts under these favorable conditions. Break-even costs higher than system costs indicate viability potential for all four concepts, with an "advanced" battery by far the most attractive. 
- WIHD SYSTEM STORAGE CHIARGING

- yeAR 2000

- lón ESCALATIOIN

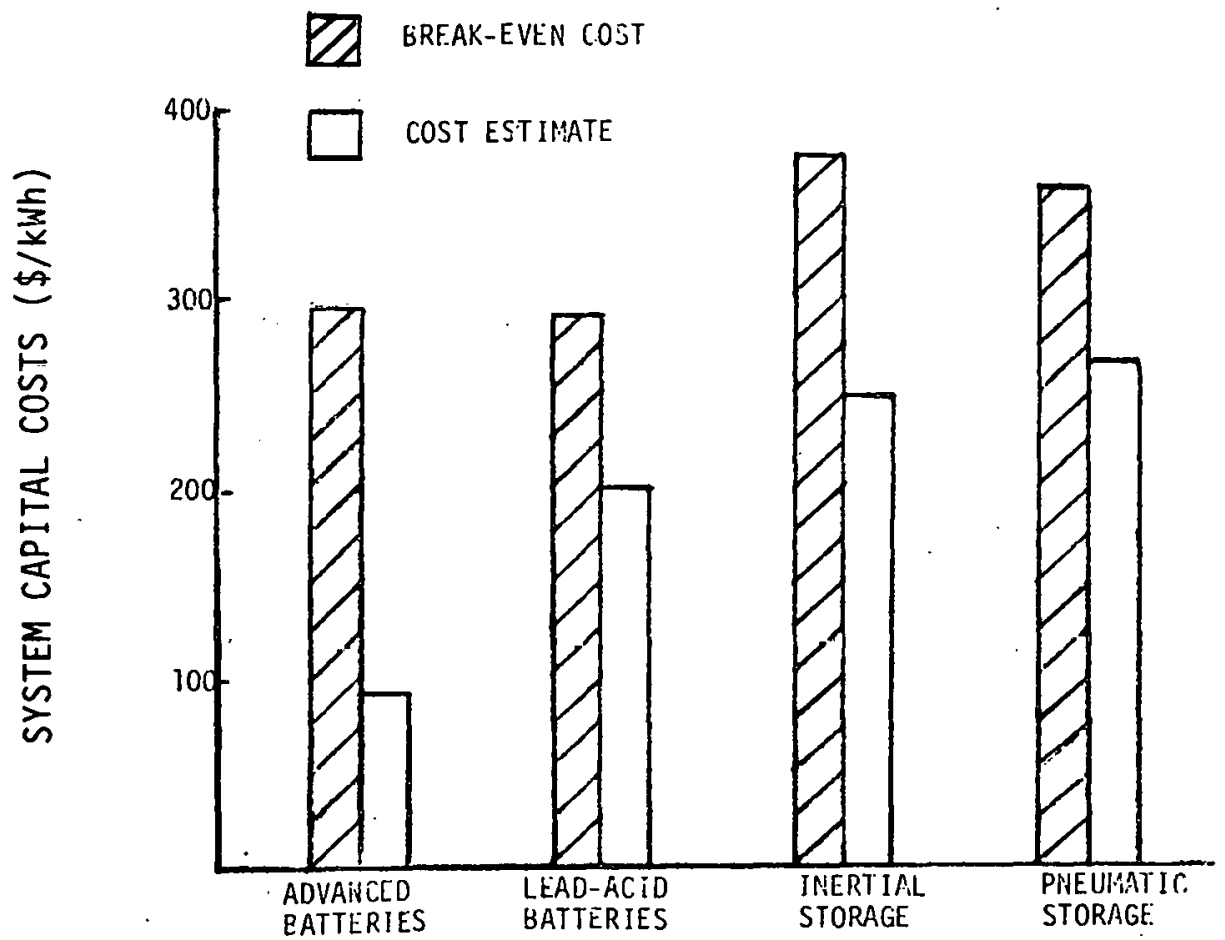

FIGURE 1.5-5. BREAK-EVEN COSTS COMPARED TO SYSTEM COST ESTIMATES WIND ENERGY CONVERSION - RESIDENTIAL APPLICATION

\subsection{STORAGE WITH INTERMEDIATE WIND SYSTEMS}

\subsubsection{CANDIDATE STORAGE CONCEPTS}

Candidate energy storage concepts selected for further investigation for use with wind energy systems in intermediate applications included:

1. Pumped hydro

a. above ground

b. underground

2. Underground compressed air 
3. Batteries

a. lead-acid

b. advanced

4. Inertial (flywheel)

5. Hydrogen

Thermal systems were eliminated from further analysis in this portion of the study due to their general inapplicability to electrical output energy systems such as wind turbine-generators. (See Part B of Volume I). Of the remaining concepts, several (particularly hydro and underground compressed air) would be applicable only to very large scale intermediate applications.

\subsubsection{METHODOLOGY FOR INTERMEDIATE APPLICATION ANALYSIS}

Candidate storage technologies were selected for the intermediate application using the same techniques described previously for the utility and residential applications. Values for the worth of energy storage were obtained by matching wind turbine generator outputs for several locations to a load selected as typifying a shopping center operating routine. Current estimates of system 1 ife and operation and maintenance requirements are used in the analysis (see Table 5.3-1 of Volume I). The analytical procedures are detailed in Section 3 of this volume.

\subsubsection{GENERAL RESULTS AND FINDINGS - INTERMEDIATE APPLICATION} Energy storage with intermediate wind energy systems proved to be economic only in extremely large scale applications with site characteristics adaptable to hydro or underground compressed air systems. Figure 1.6-1 presents economic viability tested against increasingly severe economic conditions for each of the seven storage concepts considered. 


\begin{tabular}{|c|c|c|c|c|}
\hline & \multicolumn{4}{|c|}{ START YEAR AND ENERGY PRICE ESCALATION RATE } \\
\hline Concept & $\begin{array}{c}1977 \\
5 \% \\
\end{array}$ & $\begin{array}{c}1985 \\
6 \% \\
\end{array}$ & $\begin{array}{c}1990 \\
8 \% \\
\end{array}$ & $\begin{array}{r}2000 \\
10 \% \\
\end{array}$ \\
\hline $\begin{array}{l}\text { Undergrou } \\
\text { pumped hy }\end{array}$ & & & & \\
\hline $\begin{array}{l}\text { Above gro } \\
\text { pumped hy }\end{array}$ & & & & \\
\hline $\begin{array}{l}\text { Undergrou } \\
\text { compresse }\end{array}$ & & & & \\
\hline $\begin{array}{l}\text { Lead-acid } \\
\text { batteries }\end{array}$ & & & & \\
\hline $\begin{array}{l}\text { Advanced } \\
\text { batteries }\end{array}$ & & & & \\
\hline $\begin{array}{l}\text { Inertial } \\
\text { Storage }\end{array}$ & & & & \\
\hline Hydrogen & & & & \\
\hline
\end{tabular}

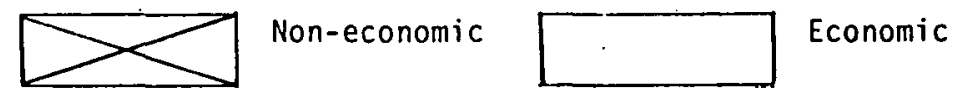

Figure 1,6-1 ECONOMIC VIABILITY OF INTERMEDIATE ENERGY STORAGE CONCEPTS

Inflation was assumed at $5 \%$, thus the escalation rates shown range from zcro differential to $5 \%$ over inflation. Note that not until the extreme $10 \%$ escalation, year 2000 condition does a storage concept with a wide 
application range (advanced batteries) achieve economic viability.

With regard to technical and operational attractiveness of these seven concepts, the following was concluded for the intermediate application:

1. Hydro and compressed air concepts below the utility scale could be utilized only for very special cases such as large relatively isolated industrial or commercial operations where both the siting and scale of operations were compatible.

2. The possible future use of flywheel or hydrogen systems, is dependent upon further development and the evaluation of specific system designs.

3. Batteries offer a degree of attractiveness if available along. with suitable interface hardware. The range of possible system sizes, specific designs and requirements is so broad as to preclude meaningful generalizations. The level of owneroperator responsibility achievable, could range all the way from the residential situation to something approaching utility-level skills.

4. The most meaningful way to attack the problem of energy storage implementation for intermediate applications would appear to be to select one or two high potential applications, assuming availability of the stonrage t.erchnology desired, and proceed from that point to develop a specific design. Other nontechnical issues such as user acceptance and compliance with local regulations should also be considered at that time on a case basis. The drive to develop utility-level storage devices is a more likely forcing function in the development of advanced storage technology than fixed-plant intermediate applications.

\subsubsection{PARAMETRIC EFFECTS ON WORTH OF STORAGE-INTERMEDIATE APPLICATIONS}

The parameters investigated for energy storage in conjunction with wind energy systems in intermediate applications include:

1. Location/wind characteristics

2. Energy and power demand levels

3. Storage efficiency 
4. Storage size

5. Fuel price escalation rate and start year.

Storage break-even costs were adjusted to include the effects of concept-particular factors such as efficiency, interest during construction (where applicable), and operation, maintenance and replacement requirements. The principle results and findings include:

1. For the two wind sites investigated and over a range of load requirements, the energy savings from storage versus storage capacity remained relatively constant as shown in Figure 1.6-2.

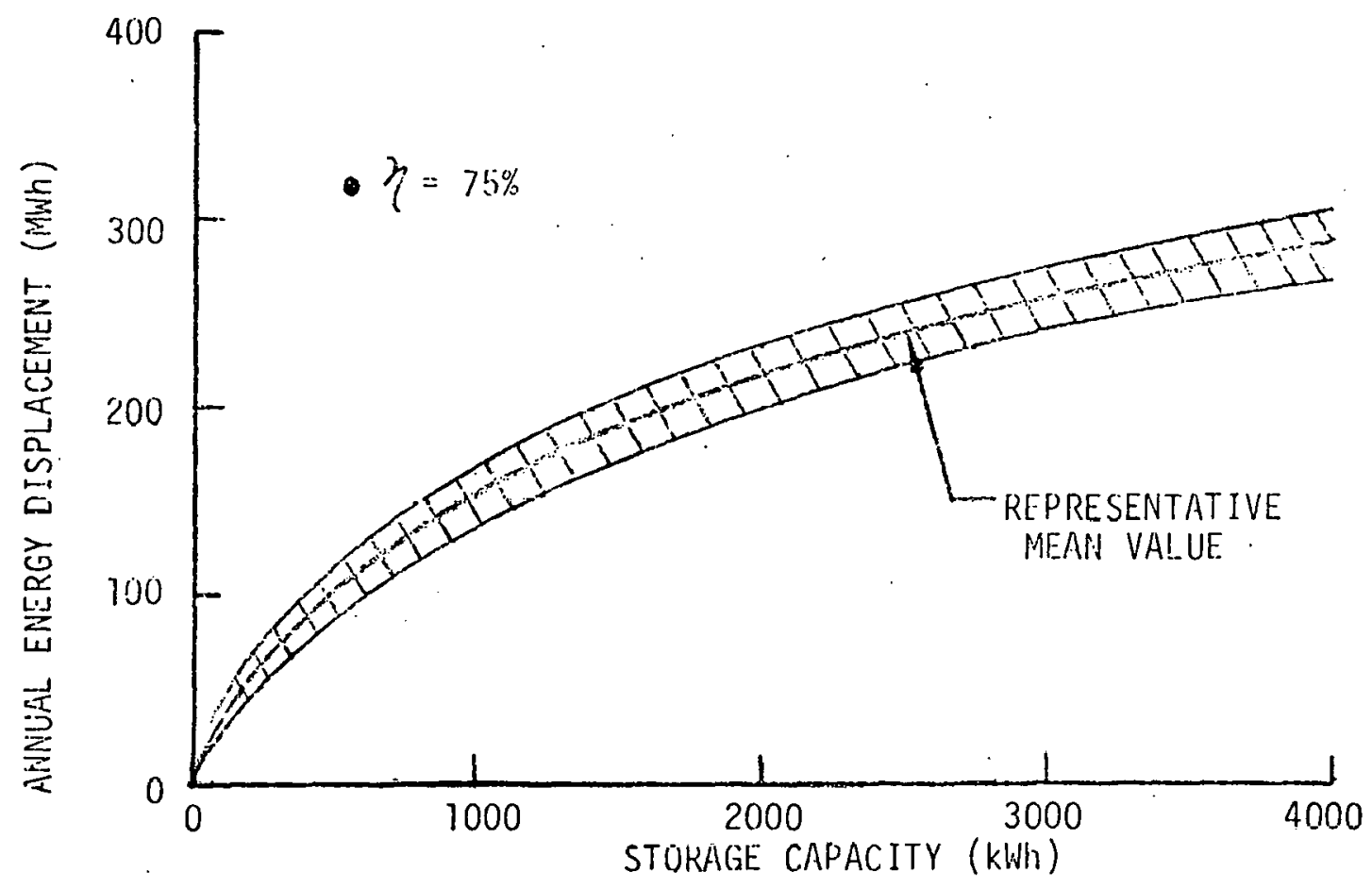

Figure 1.6-2 STORAGE ENERGY DISPLACEMENT-INTERMEDIATE APPLICATION 
2. An increase in storage efficiency from 60 to $90 \%$ increased energy savings by $20 \%$. This effect was comparable to the utility results and a much more significant factor than in the residential case.

3. Energy savings per unit storage size decreased with size as can be seen in Figure 1.6-2.

4. Storage break-even cost increased with energy price escalation rate and start year delay as expected.

Figure 1.6-3 presents adjusted break-even costs for $1000 \mathrm{kWh}$ capacity intermediate storage systems at the $10 \%$ energy price escalation rate, year 2000 condition. Potential viability is tested by comparison with current system cost estimates as shown.

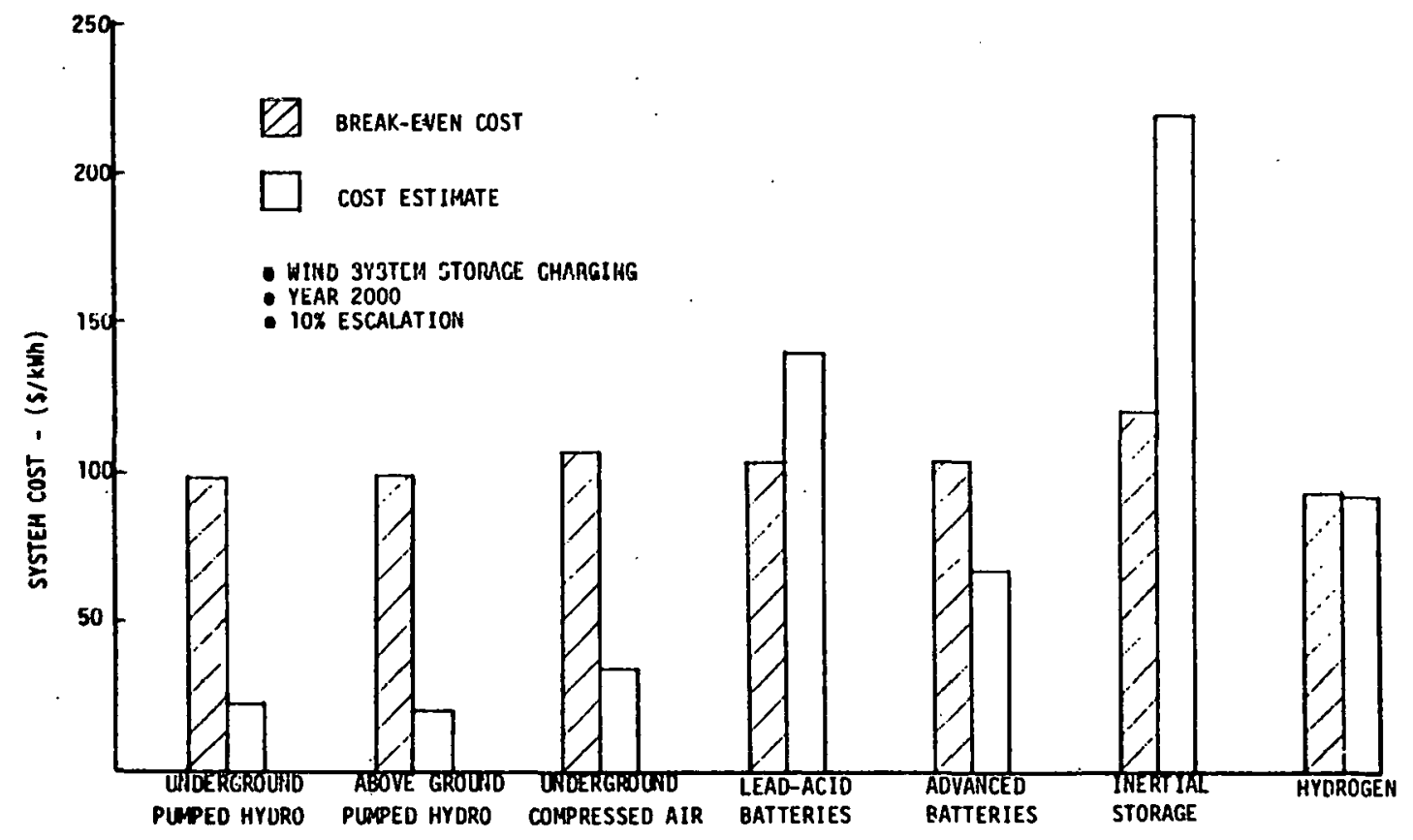

Figure 1.6-3 BREAK-EVEN COSTS COMPARED WITH SYSTEM COST ESTIMATESINTERMEDIATE APPLICATION 
The four concepts with viability potential at the utility level again showed potential for an intermediate application. These, plus lead-acid batteries, were carried forward for more detailed break-even cost analysis. A comparison of break-even costs of the above figure with corresponding values for the residential application (Figure 1.5-4) clearly show the large reduction in break-even cost resulting from low electricity price and energy tax deductibility in the intermediate application. 


\subsection{SPECIAL UTILITY SYSTEM PLANNING ANALYSIS}

The special case studies performed by GE-EUSED are described in detail in. Section 3.3-7. The work performed consisted of establishing a baseline for realistic 1995 operating conditions in the Boston area/New England Power Pool and determining the results of adding both WECS and energy storage to the system. These results were compared with the more generalized study analyses and found to agree closely. Figure 1.7-1 presents the findings of the special case studies along with related study data for comparison purposes.

The results indicate:

1. Identical breakeven results for use of dedicated storage both in the special case study and in the general study analysis.

2. Nearly identical results with the assumption of perfect WECS output forecasting and system-wide stonrage.

3. A small reduction in break-even cost when WECS is added to the system under no-forecast conditions with system-wide storage.

4. An improvement in break-even cost of about $25 \%$ when perfect forecasting of WECS output is projected with system-wide storage.

5. Superiority of system-wide storage by about 2.3:1 over dedicated storage. 


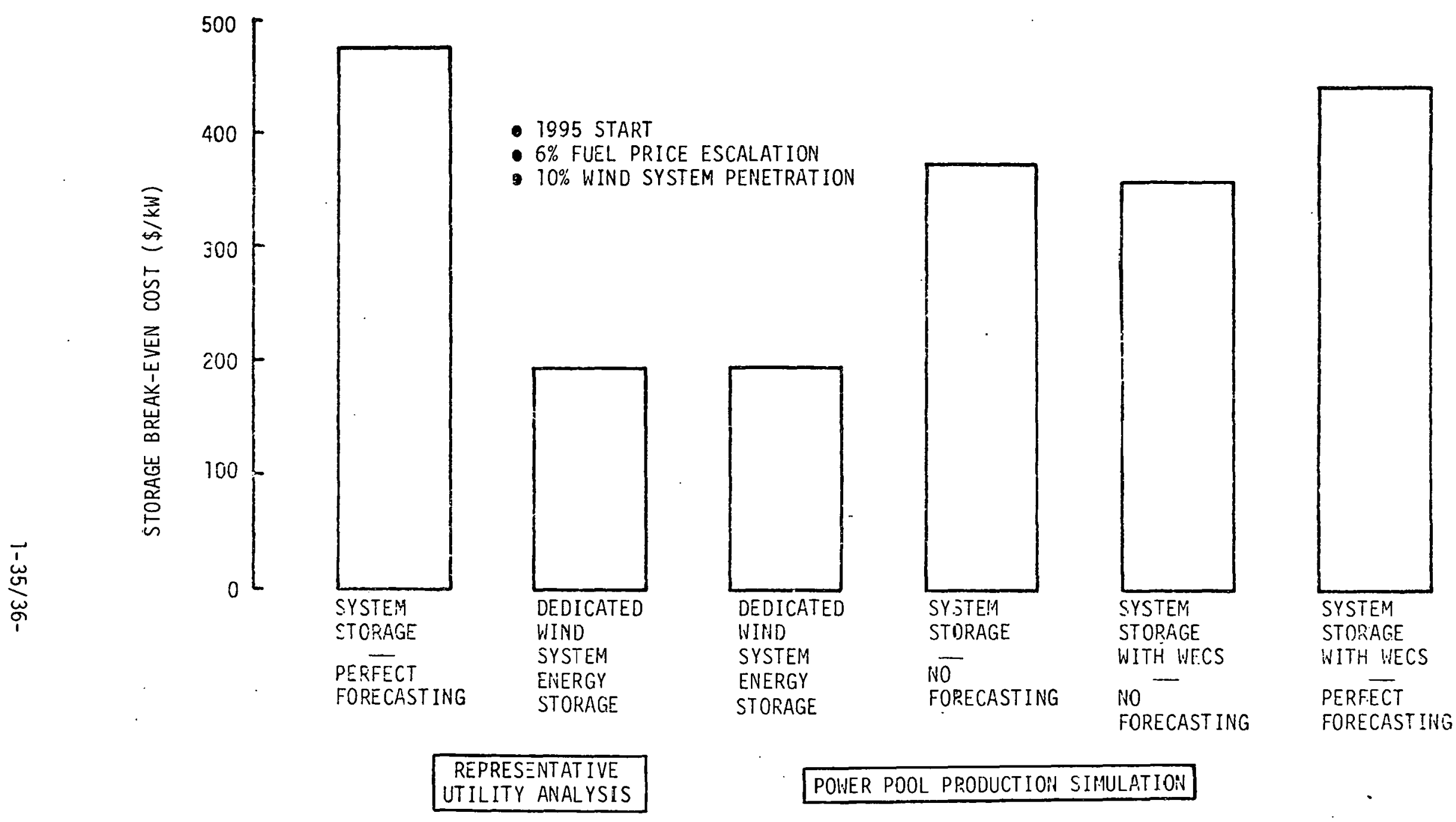

FIGURE 1.7-1. SPECIAL CASE STUDY FINDINGS AND RELATED STUDY RESULTS FOR WECS WITH STORAGE 
SECTION 2

BASELINE WIND CONVERSION AND STORAGE SYSTEM CONCEPTS

\subsection{UTILITY SYSTEMS}

\subsubsection{BASIC ENERGY CONVERSION SYSTEM}

The basic unit for a utility wind energy conversion system was assumed to be a wind turbine generator rated at $1.5 \mathrm{MW}$ output. Figure 2.1-1 illustrates the unit configuration for this size wind turbine. The configuration and design parameters are based on a prior study ${ }^{\top}$ and continuing development work by the General Electric Company, the Boeing Company, and others.
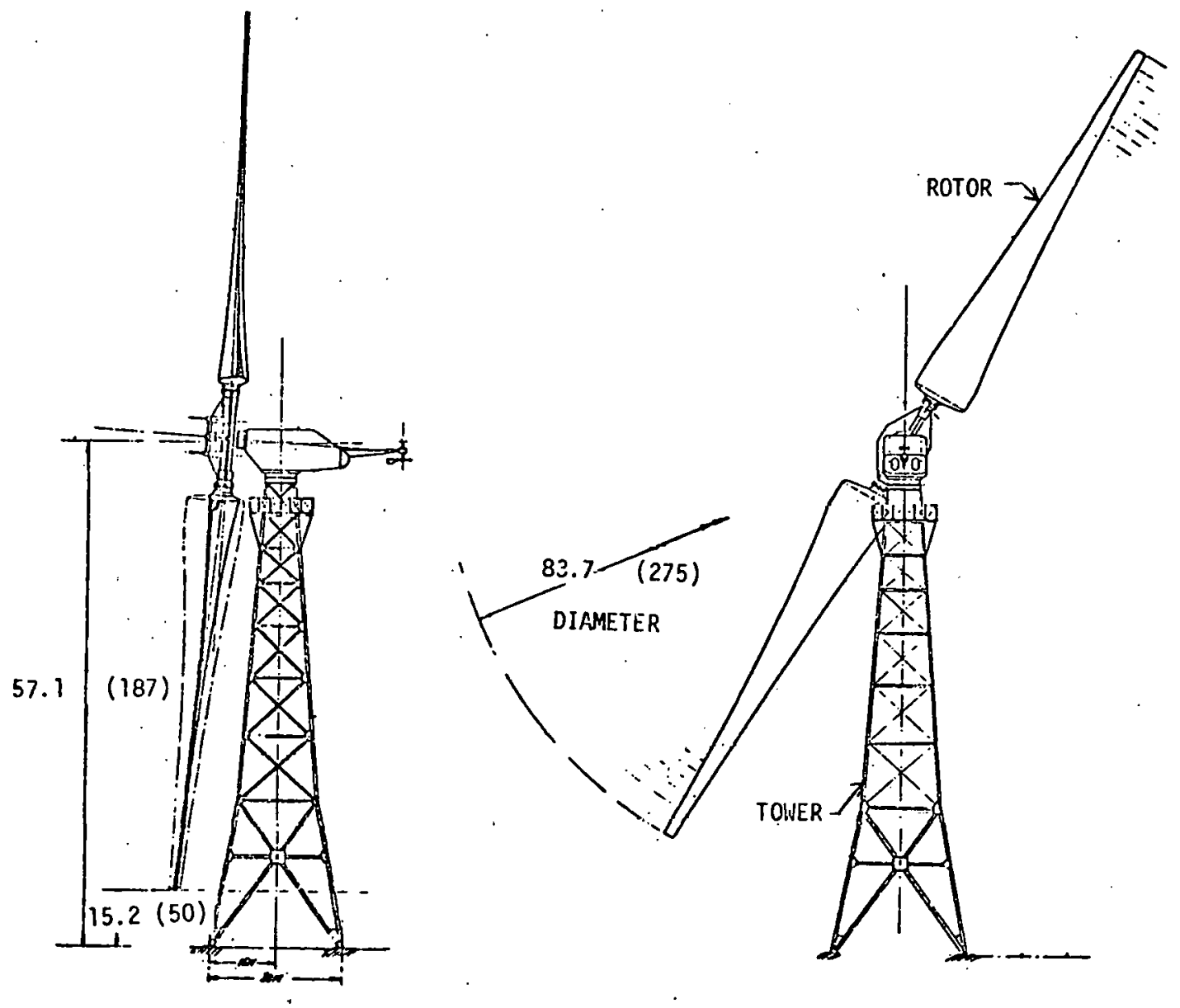

(DIM. IN METERS/FT.)

FIGURE 2.1-1. TYPICAL 1.5 MW WIND TURB INE GENERATOR (WTG) 
For utility use, "clusters" of such units would be arranged in one of a number of alternative configurations. Consideration of smaller distributed "clusters" may be more appropriate depending upon the specific installation; however, for study purposes, the wind turbine units were treated as an entity having a combined output to be contributed to the utility grid in proportion to the penetration of wind units as a percentage of total utility system generating capacity. Wind system total output ratings from approximately 375-1100 MW were considered. This range incorporates penetrations of about $10 \%, 20 \%$, and $30 \%$, in a nominal 4000 MW capacity "representative" utility system. Figure 2.1-2 shows the basic block diagram of the 1.5 MW wind conversion system.

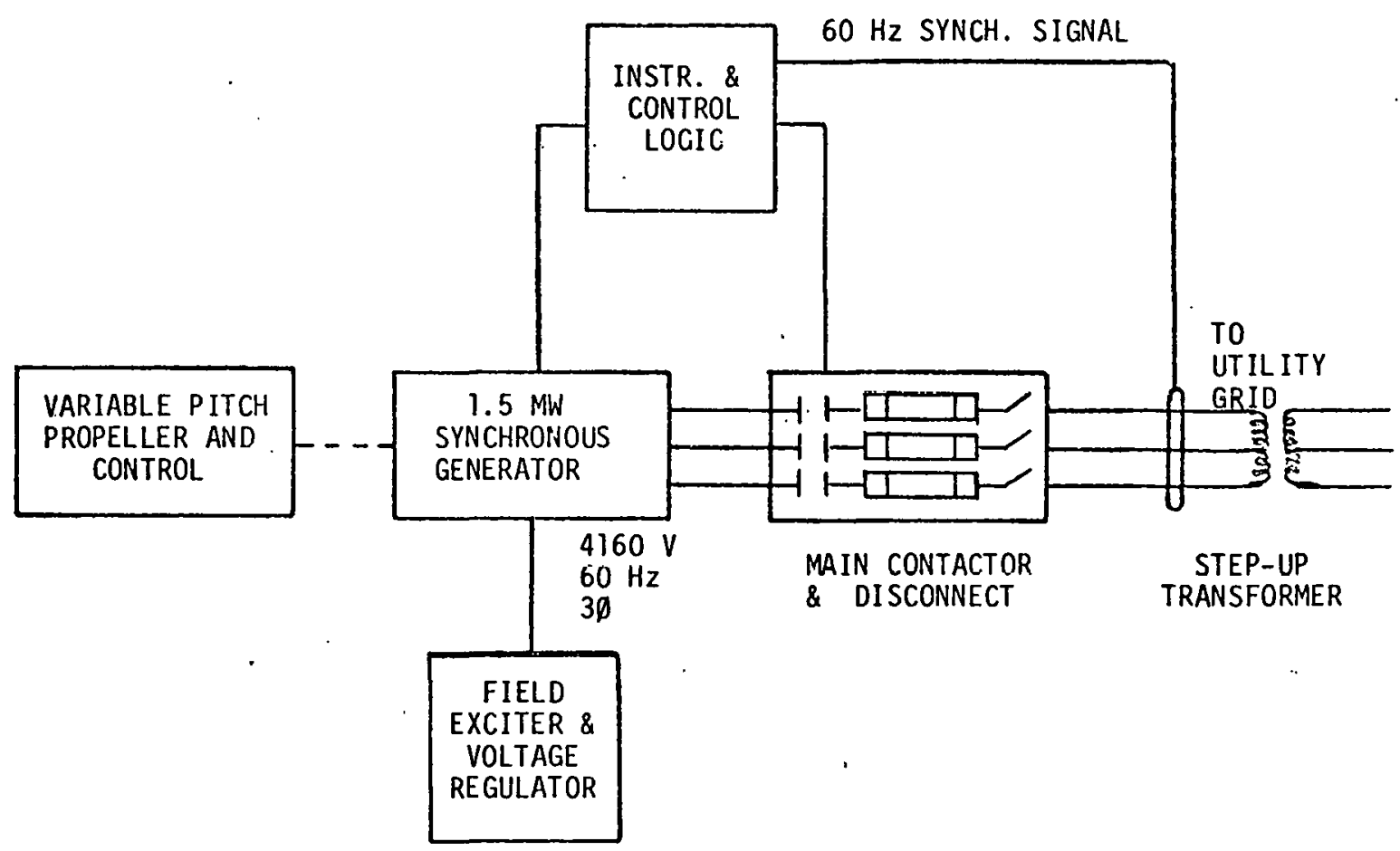

FIGURE 2.1-2. BASELINE 1.5 MW WIND ENERGY CONVERSION SYSTEM BLOCK DIAGRAM 
The tctal land area required for the basic plant could be considerable, depending upon the total penetration assumed. With a large land area requirement, the physical proximity of any energy storage facility utilized becomes a matter of major interest. Figure 2.1-3 shows the approximate total occupied land area for the case of a concentrated 375 MW installation with unit separation at 15 times the rotor diameter of the WTG's. Although

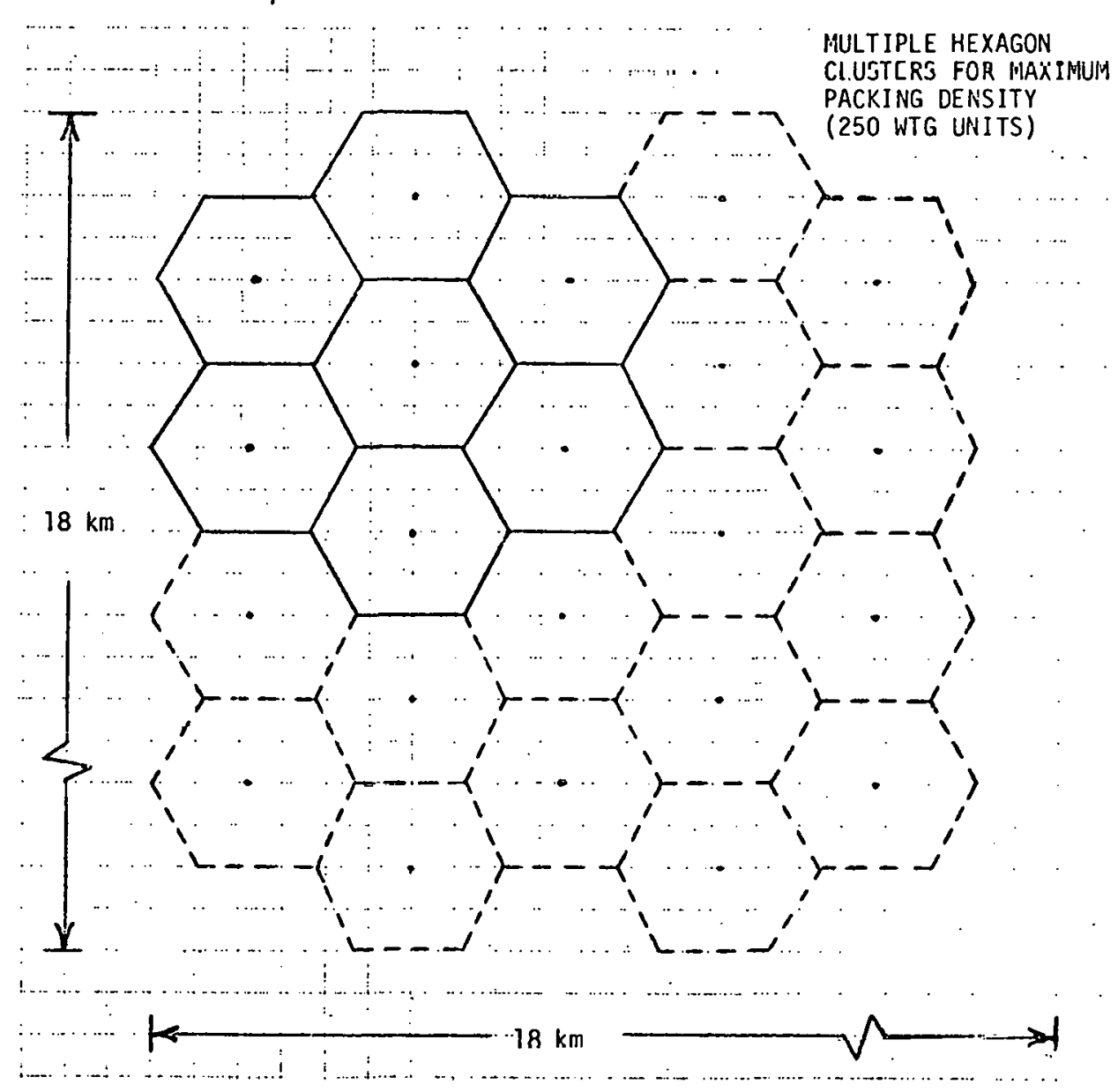

FIGURE 2.1-3. CONCENTRATED WIND TURBINE GENERATOR PLANT AT 375 MW TOTAL OUTPUT RATING IN A MODERATE WIND REGIME 
significant separation distances are required, it should be noted that a high percentage of this occupied area would be available for other (dual) usage since the actual "footprint" to accommodate tower siting would be less than $1 \%$ of the total.

It could be expected that tie-lines and any distributed storage units would be located within right-of-way areas for the WTG units. However, in practice, this would be a major consideration because of the extensive rature of the power "gathering" system. Trade-offs are involved which could be resolved only when the specific location and type of storage were known, and a specific design configuration established.

\subsubsection{OVERALL WIND CONVERSION SYSTEM OPE.RATION}

The electrical output of each WTG unit is assumed to be AC, with the output of each unit stepped up to a suitable line voltage dependent upon the specific plant configuration. The point of tie-in with the utllily grid would generally determine the ultimate voltage step-up required, but could extend to the 230-375 kv range for long distance power transmission. For distributed wind systems, interconnection would normally occur at distribution voltage levels up to $34.5 \mathrm{kV}$.

As may be noted in the block diagram, the wind turbine requires controls and instrumentation to insure that rotor pitch is adjusted to maintain operation within the specified range of wind velocity. In addition, the electrical output must be synchronized to the tie line which it feeds. In event of wind cessation or a fault, the output must be temporarily interrupted to avoid improper current draw and/or power flow. 
Table 2.1-1 presents the major design parameters of the basel ine WTG units which are of interest for purposes of this study.

TABLE 2.1-1. 1.5 MW WIND GENERATOR SYSTEM CHARACTERISTICS ${ }^{1}$

\begin{tabular}{|c|c|}
\hline Rated Power & $1.5 \mathrm{MW}$ \\
\hline Desigr Wind Velocity & $5.36 \mathrm{~m} / \mathrm{s}(12 \mathrm{MPH})$ \\
\hline Generator Parameters & $\begin{array}{l}\text { Synchronous, } 1.5 \mathrm{MW}, 4160 \mathrm{VAC} \text {, } \\
60 \mathrm{~Hz}, 3-\text {-Phase, } 1800 \mathrm{RPM}\end{array}$ \\
\hline Rntor & $2-B l$ dde, $21.6 \mathrm{RPH}$ \\
\hline Rotor Diameter & $83.71 \mathrm{~m}(275 \mathrm{ft})$ \\
\hline Rotor Axis Height & $57.1 \mathrm{~m}(187 \mathrm{ft})$ \\
\hline Wind Velocities & \\
\hline Cut-In & $3.76 \mathrm{~m} / \mathrm{s}(8.41 \mathrm{MPH})$ \\
\hline Rated & $7.59 \mathrm{~m} / \mathrm{s}(16.98 \mathrm{MPH})$ \\
\hline Cut-out & $16.60 \mathrm{~m} / \mathrm{s}(37.13 \mathrm{MPH})$ \\
\hline $\begin{array}{l}\text { Annual Energy Production } \\
\text { (Design) }\end{array}$ & $5.21 \times 10^{6} \mathrm{KWh}$ \\
\hline
\end{tabular}

The choice of this machine design relates to the locations and wind regimes used in later portions of this study, as will be described further.

\subsubsection{STORAGE SYSTEM INTEGRATION AND INTERCONNECTION TO THE WIND ENERGY CONVERS ION SYSTEM}

The principal objective of this area of study investigation was to identify and assess major limitations or consequences that could be expected as a result of applying various energy storage methods in conjunction with a wind 
energy conversion system. The energy storage system was assumed to serve the wind system exclusively; therefcre, the power input to storage would be derived solely from that available from the wind system. Discharge of stored energy would occur as part of a combined wind-energy/storage system output to a utility network. The option of supplying a portion of the storage charging energy from the utility was also considered, but is treated later in this report in Section 3.6 on multiple-source charging. It may be noted that in general, this latter option tends to reduce the storage interface and integration problem, so that the storage system considerations discussed in this section are likely to be the most severe.

The situation to be considered is similar to other "process flow" problems in that the system components must work together compatibly to produce a desired output (in this case, electric power) without either damage to components or excessive efficiency losses.

The numerous criteria examined earlier in this study were re-considered by the study team in order to identify especially critical design or operational parameters. "Critical" in this case was defined as a condition resulting uniquely from the incorporation of energy storage with a wind system which might make the integrated concept unworkable or otherwise undesirable. The conditions of most concern were then investigated in more detail, considering representative sizing and input-output parameters. In addition, consultations were held with equipment designers to obtain the benefit of the ir experience on probable equipment limitations. The results of these investigations are described in the following sections for the various storage technologies. It should be recognized that due to the scope of investigations 
involved, only the more pressing concerns could be covered, and any future implementation of these storage methods should be predicated on more detailed investigation of specific designs.

Special concerns investigated were:

1. Consequences of wind system input interruption during storage charging.

2. Limitations imposed on basic system equipment.

3. Equipment rating problems

4. Possible sizes for modularization.

5. Potential impact of concept options on cost effectiveness and operational suitability.

\subsubsection{Pumped Hydro Storage}

Use of pumped hydro storage in conjunction with a wind turbine power plant could be treated either as part of an existing hydro facility (or extension of such a facility) or as a completely new installation. The cost and technical requirements would be quite different for the two situations. For study purposes, since some utilities have little or no hydro capability in place, the impact of adding such storage was assumed to be that of adding a pure pumped storage (PPS) facility to an existing utility network, independent of any conventional hydro-electric generation. A system assessment of the use of pumped storage in conjunction with a wind turbine array was made by: identifying critical design parameters; determining the existence of typical equipment; and evaluating the implications and impact of the variability and interruptibility of the wind-generated energy. No distinction need be made between above-ground and underground pumped hydro installations in this portion 
of the storage assessment, since the differences in pumping heads, costs, potential hazards, etc., have already been identified for both methods and discussed in Volume I of this report. The total wind energy output level of 375 MVA or about $10 \%$ wind system pentration has been used as a reference point in considering the application of pumped hydro and the other candidate concepts.

\section{Integrated System Concept}

A nominal pumped hydro system assessed for study purposes is shown in Figure 2.1-4. A reservoir having a maximum head of 1000 feet above the sump drives

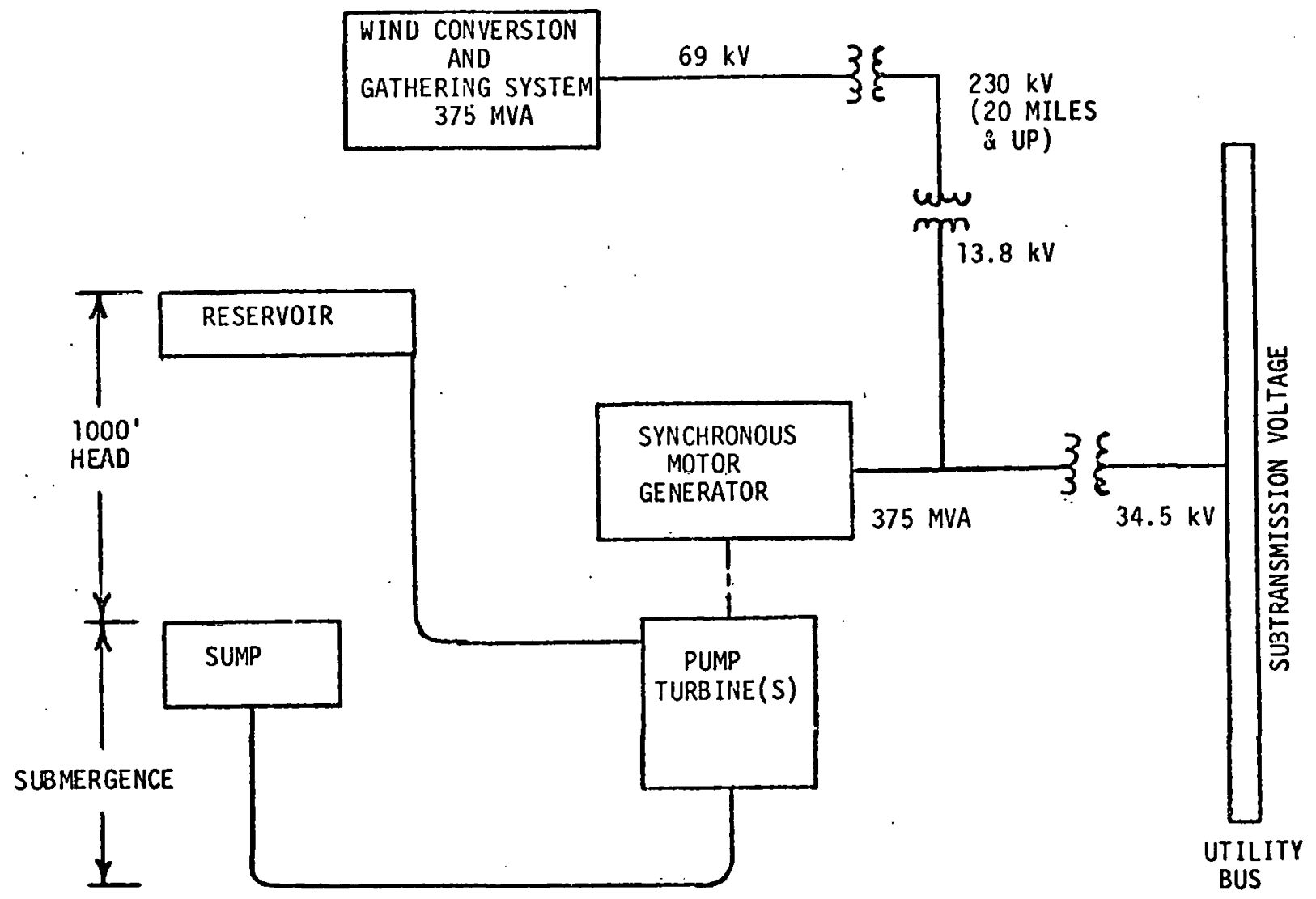

FIGURE 2.1-4. WIND ENERGY CONVERSION WITH PUMPED HYDRO STORAGEUTILITY APPLICATION 
a reversible pump-turbine with a flow rate sufficient to obtain approximately 375 MVA output from the reversible motor-generator which is synchronous with the utility. The discharge to the reservoir is dependent on the variability and presence of the wind energy source. The pump-turbine is set somewhat below the sump to prevent pump-turbine cavitation.

This system is predicated on constant speed operation and operates in the following manner when charging from a wind energy conversion systeli. (Discharge per se is not directly affected by the energy source, although it is part of the averall system consideration with respect to operational modes).

When the reservoir head is low, the pump, driven by the constant speed motor with maximum horsepower input, pumps at its maximum flow rate. As the reservoir head rises but still with maximum horsepower input, the flow rate decreases. If the power input to the pump is reduced, due to the variability of the energy source, the flow rate also decreases.

\section{Functional Assessment}

Hydraulic generator/motors can be found in the 375,000 KVA rating size, with a speed range of 72 to $200 \mathrm{rpm}$, normal full-1oad efficiency of $97.6 \%$ at $0.9 \mathrm{PF}$, and an output of 13,800 volts.

The power required to drive this generator is:

$$
\begin{aligned}
\text { Power } & =\frac{\text { KVA } \times P F \times 1.341}{\text { Efficiency }}(\mathrm{hp} / \mathrm{kW}) \\
& =\frac{375,000 \times 0.9 \times 1.341}{0.976} \\
& =463,716 \text { horsepower }
\end{aligned}
$$


If this is taken to be the brake horsepower input to the pump, the flow rate in gallons per minute which is possible against a total head (static and dynamic) would be:

$$
\begin{aligned}
Q_{1} & =\frac{n p \times \eta_{P} \times 3960}{H_{T} \times S . G .} \\
& =\frac{463,716 \times 0.7 \times 3960}{1000 \times 1.0} \\
& =1,285,423 \mathrm{gpm} \approx 1.3 \times 10^{6} \mathrm{gpm}
\end{aligned}
$$

where

$$
\begin{aligned}
& \eta_{p}=0.7 \text { (assumed) } \\
& \text { S.G. }=1.0 \\
& H_{T}=\text { Total Head }
\end{aligned}
$$

Hydraulic Turbines, Inc., HTI, was consulted to determine the practicality nf nbtaining a pump turbine operating in the 200-RPM speed range capable of this million gallon per minute flow rate. All pumped hydro systems are custom designed but it was determined that the system described is well within existing experience. The IEEE paper, "Survey of Pumped Storage Projects in the United States and Canada to 1975"* shows that for turbine heads in the 200-300 meter ranges $\left(600-1000^{\prime}\right) 2$ to 8 units are used, with individual generators rated at from 125 MVA to 333 MVA, with speeds from 200 to 360 RPM, and voltages of 13.8 to $17 \mathrm{KV}$. Eight methods for starting the pump (motor) are given and for the head of interest here, the "Pony Motor" start is the most prevalent choice.

* IEEE Transactions on Power Apparatus and Systems, Volume PAS-95, No. 3, May/June 1976. 
On the question of energy source variability, HTI advised that pump manufacturers do not recommend operation of the pumps below. $50 \%$ load because of efficiency, stability and possible cavitation. Below $50 \%$ load the efficiency of the system decreases significantily and without a proper flow rate, the turbine unit vibrates excessively and cavitation can occur which may damage the purnp. Although the unit submergence should preclude cavitation, minimum unit submergence is desirable as it is a cost consideration which is very site dependent. Usually, model testing is performed to determine the minimum unit submergence required for a given installation.

It may be noted that in a conventional hydro storage operation, the on/off cycling amounts to perhaps 20-30 cycles/month. With wind system use, and assuming appropriate procedural constraints, it was decided the consequences of a much higher rate of cycling should be considered. On-off switching rates of up to 8-10/day pose no special problem for pumped hydro systems. In Europe these systems are reportedly turned on and off without concern many more thar: 8 times/day.

It is believed that existing or obtainable site wind data could be used to establish, for a given location, the likelihood of achieving satisfactory hydro pumping operation within the cycle range indicated above. A more detailed investigation of the absolute limits for pump-turbine cycling under wind system operation should be performed in conjunction with any. specific application designs.

With respect to the impact on the wind energy system itself due to loss of load, there is no new impact consequent to operation with a pumped hydro 
system. Each wind turbine must operate autonomously such that upon sensing a loss of load at its own output terminals, it will redirect any excess energy, usually by "feathering" the rotor blades.

For switching considerations, the advice of GE's Industrial Control Products Department was sought. The "limit/amp" motor starter produced by this department was cited as an example of device power rating limitations in that it is not offered for voltages above $7.2 \mathrm{KV}$. It was recommended that power circuit breakers be used for the $13.8 \mathrm{KV}$ voltage level. From review of switchgear data, it can be shown that such circuit breakers will meet current, voltage, and interrupting ratings with no parts replacement for a repetitive duty of 5000 operations, provided they are operated at no load, with control vol tage at 90 to $100 \%$ of rated, and are serviced at every 2000 operations. If a frequency of 8-10 operations a day is assumed, the breakers should be serviced about every 6 months and overhauled about every year and a half. The no-load mechanical limit has been selected as the principal constraint, since for normal operation of the wind energy system, it is expected that the circuit breakers will be closed before the energy source delivers significant power (slightly greater than no-load) and will be opened only after the power delivered by the energy source decreases to slightly more than no load.

The physical size of a 375 MVA wind energy system implies that the interconnections required to form the gathering system to collect the power must be cost effective. This assumption was not tested in this assessment, but is believed to be a significant consideration for any specific array configuration. 
The manufacturer's recommendation that the hydraulic pumps should not be cperated below 50\% load imposes some additional considerations on the wind energy system. Presumably the $50 \%$ pump load would be equated to the minimum desirable operating conditions for the energy source; so that when maximum operating conditions are occurring, provision must be made to channel the excess power elsewhere. If the system design requires that whatever wind power is available must be supplemented by utility power for pumping, then some means of proportioning the pump load between the utility and the wind system source would be required. The load proportioning must accurately determine the capability of contribution in order to achieve the most efficient utilization of energy. The choice of using integrated units as opposed to separate pumps, turbines and motors would be a system design option, although Francis pump-turbines are predominantly used at the present time.

\section{Conclusions}

1. The choice of an above or underground hydro system is significant in terms of heads, equipment ratings, sizing, site availability and cost, but these are not necessarily significant limitations to the use of pumped hydro with wind energy systems.

2. Interruptibility and cycling of hydro pumping operations is a location-dependent design consideration, but is not an unsurmountable problem.

3. Where suitable sites are available, pumped hydro is a technically desirable method of energy storage. 
4. Use of auxiliary power (from the utility) for pumping during low wind periods is a logisal alternative. Integrated windutility pumping may also be desirable to reduce equipment module requirements. Other hybrid operating concepts are also feasible and attractive possibilities. ${ }^{2}$

\subsubsection{Underground Compressed Air Storage}

The possible use of compressed air in an underground cavern or enclosure as a method of storing wind generated energy was considered in the light of current concepts for underground compressed air storage.

The assessment and discussion which follows describes wind system use of the compressed air storage concept in basic terms; identifies critical system design parameters; examines availability or existence of typical equipment; and evaluates the probable impact of the variable and interruptible nature of the wind energy source.

\section{Integrated System Concept}

The compressed air storage system operating with a wind energy source of electric power is diagrammed in Figure 2.1-5. The system shown is unfired (no fuel combustor) and various methods of improving the system by way of heat exchangers and auxiliary turbo machinery are not shown ${ }^{3}$. The compressor, motor generator, and expander are all on the same shaft which oferates at constant speed both on charging and discharging the storage volume of compressed air. The discharge of the storage volume through the expander is the same, regardless of the manner in which the volume is charged provided that proper consideration has been given to allotting sufficient wind turbine capacity to supply the demand. To charge the system, the compressor running at 


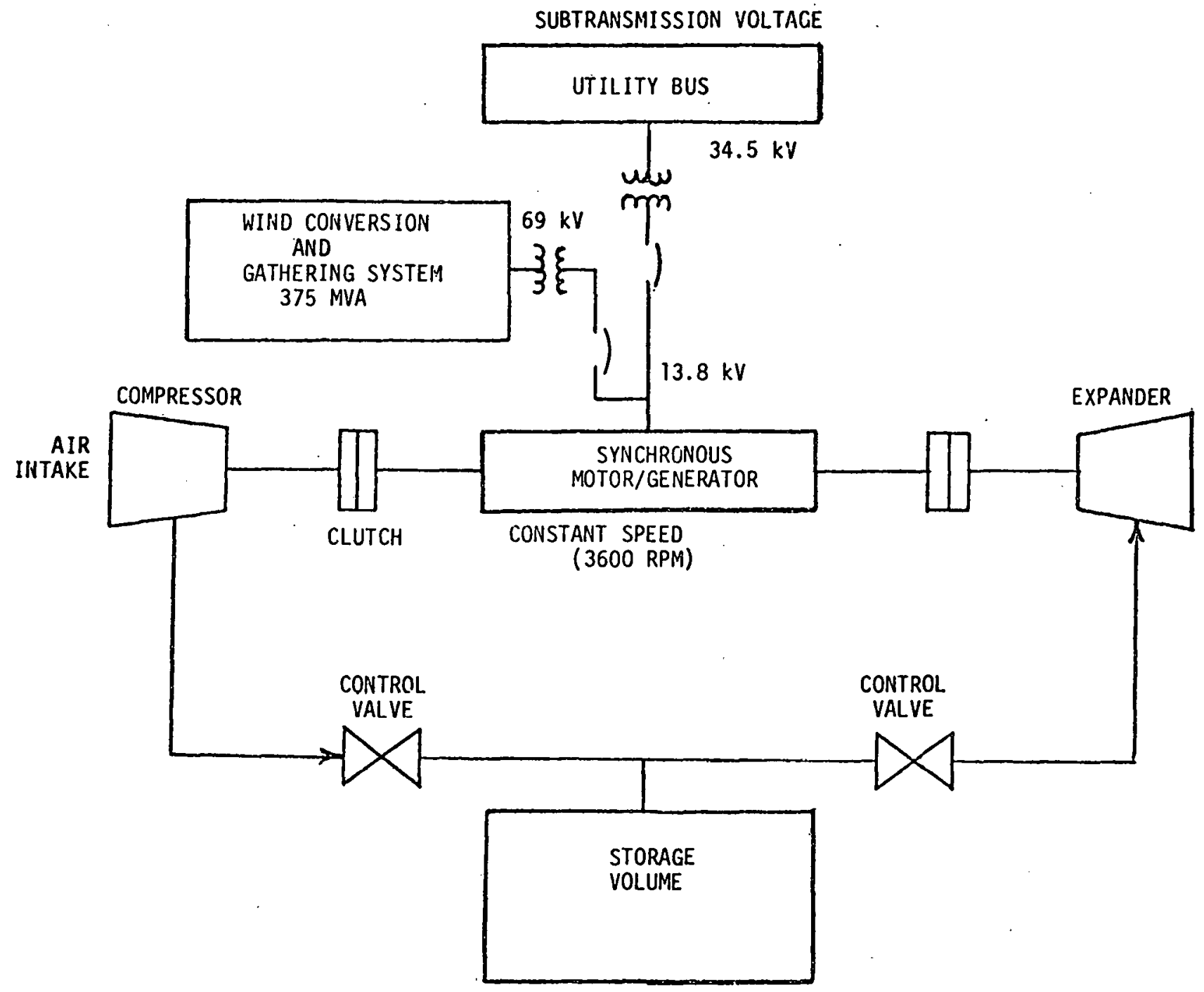

FIGURE 2.1-5. WIND ENERGY CONVERSION WITH COMPRESSED AIR STORAGEUTILITY APPLICATION

constant speed input provides a flow rate (lbs. of air/sec) dependent upon the pressure in the storage volume. The flow rate will decrease as the pressure in the storage volume increases to a pressure matching the power input. An increase in storage pressure will then require an increase of input power. The operation of the compressor is generally described in terms of the pressure ratio and the power input to the compressor. 
A clutch is shown on both sides of the motor generator to indicate versitility. The single shaft system can be operated independently of the storage volume (in case of failure) and the compressor or expander can be operated indepenciently with the storage volume.

\section{Functional Assessment}

Table 2.1-2 below was taken from the ERDA report ${ }^{3}$ of the GE Study on compressed air storage. From this table it can be seen that since the turbine expander speed is $3600 \mathrm{rpm}$ ( $3000 \mathrm{rpm}$ is European use) the motor-generator and compressor are also $3600 \mathrm{rpm}$ and no gear boxes are required. Synchronous motor-generators of this size (375 MVA) and speed present no problems.

TABLE 2.1-2. CHARACTERISTICS OF COMBUSTION TURBINES FOR COMPRESSED AIR STORAGE

\begin{tabular}{|c|l|l|l|l|l|}
\hline $\begin{array}{c}\text { PRESSURE } \\
\text { RATI0 }\end{array}$ & $\begin{array}{l}\text { INI.FT } \\
\text { TEMP. } \\
\left({ }^{\circ} \mathrm{F}\right)\end{array}$ & $\begin{array}{l}\text { SPECIFIC } \\
\text { TURBIINE } \\
\text { FLOW } \\
\text { (LB- } \\
\text { AIR/kWh) }\end{array}$ & $\begin{array}{l}\text { SPEED } \\
\text { (RPM) }\end{array}$ & $\begin{array}{l}\text { OUTPUT } \\
\text { (MW) }\end{array}$ & $\begin{array}{l}\text { HEAT } \\
\text { RATE } \\
(\mathrm{Btu} / \mathrm{kWh})\end{array}$ \\
\hline $10: 1$ & 1850 & 14 & 3600 & 168 & 6200 \\
$1.1: 1$ & - & - & 3600 & 169 & 4600 \\
$40: 1$ & 2000 & 11 & 3600 & - & 4000 \\
$43: 1$ & 1470 & 13 & 3000 & 220 & 4770 \\
$25: 1$ & 1650 & 13 & 3000 & 232 & 5370 \\
$4.5: 1$ & 1022 & 11.4 & 3000 & 290 & 5560 \\
& & & & & \\
\hline
\end{tabular}

The power required to drive the expander is a function of the air flow (lb/ sec) and the adiabatic head Lad. The adiabatic head is given by:

$$
L_{a d}=\frac{1545 T_{1}\left(R_{c}^{\sigma}-1\right)}{\bar{m} \sigma}
$$


where:

$$
\begin{aligned}
R_{c}= & \text { ratio of compression (say 10.3) } \\
T_{1}= & \text { absolute temperature for an inlet temperature } \\
& \text { of } 1985^{\circ} \mathrm{F} T_{1}=2445 \\
\bar{m}= & \text { molecular weight of air }(28.96) \\
\sigma^{\prime}= & \frac{k-1}{k} \text { where } k=\frac{\text { spec. ht. O const. press. }}{\text { spec. ht. O const. vol. }} \\
& \text { for air } k=1.4 \\
L_{a d} & \frac{1545(2445)(10.3 .2857}{(28.96)}(0.2857) \\
= & 432,363 \text { feet }
\end{aligned}
$$

The power to drive the turbo machinery is given by:

$$
P=\frac{F l o w(1 b / s e c) \times \text { Head }(f t)}{550(\mathrm{ft}-1 \mathrm{~b} / \mathrm{sec}) \times \text { Turbine Effic. }}
$$

or Flow $(1 \mathrm{~b} / \mathrm{hr})=\frac{\mathrm{P}(\mathrm{bhp}) \times 550 \times \text { Effic. } \times \mathrm{sec} / \mathrm{hr}}{\text { Head }}$

$=$ KVA $X$ PF $\times$ Gen. Effic. $X$ hp/kW $\times$ ft-lb/hp $\times$ sec/hr $\times$ Turbine Effic.

$=\frac{(375,000)(.9)(.97)(1.341)(550)(3600) \times \text { Turbine Effic. }}{(432,363)}$

$\cong 2 \times 10^{6} \mathrm{~Tb} / \mathrm{hr} \times$ Turbine Effic.

The GE Gas Turbine Division was contacted as to the availability of compressors capable of this flow rate; and provided the information shown in Table 2.1-3. 
TABLE 2.1-3. GE COMPRESSOR DATA

\begin{tabular}{|c|c|c|c|r|}
\hline MOUEL & SPEED (RPM) & \# OF SHAFTS & $\begin{array}{l}\text { AIR FLOW } \\
\text { (LB/HR) }\end{array}$ & $\begin{array}{c}\text { PRESSURE } \\
\text { RATI0 }\end{array}$ \\
\hline MS 3000 & 7100 & & & $7: 1$ \\
MS 5000 & 5100 & 1 or 2 & $1,000,000$ & $8: 1$ \\
MS 7000 & 7600 & 1 & $2,200,000$ & $10: 1$ \\
\hline
\end{tabular}

They also recommended possible further contacts for information. Further consultations determined that a minimum pressure residual must be maintained: 12 atmospheres (407 ft. of water) was suggested. Initial startup is usually proposed as a "boot strapping" of the expander by using a motor rated at $10 \%$ of power olltput to spin up the turbine, after which the expander is operated as a gas turbine to accelerate the system to synchronous speed. At synchronous speed, the synchronous motor generator would be used to drive the compressor and the starting equipment turned off.

It was reported that all systens considered thus far have been constant speed-variable power systems and consideration of a variable speed, variable power energy source vould require new study for a concept design. For a constant speed system, the system would stall once the power input to the compressor matched the pressure in the storage volume or when the power decreased beiow a matching pressure. It was suggested that a multiple conpressor (say three) multiple shaft system could be considered. 'With this modular concept, as more wind power was available, a second and then a third compressor could be brought up to speed each independently feeding the storage volume. Alternatively, the compressor could be selected on the minimum power available from the wind energy system and when excess power 
is available, it could be pumped back into the utility. Of course, the compressor could be selected on some other proportion of power less than the maximum available and the utility power could be used to supplement the wind source. Present pumped air storage systems are primarily being considered as utility load levelers. Work conducted to date indicates that little treatment has been given to the control systems required, and this area is likely to be quite complicated. Wot enough engineering has yet been applied to this problem.

With respect to stall power level, it seems likely a minimum pressure ratio of 5.1 should be maintained and if avallatile power is insufficient to obtain this pressure ratio, the compressor(s) should be disconnected.

From the preceding it is clear that the fundamental pumped air system is considerably like a pumped hydro storage system so far as use with a wind entrgy system is concerned. Other observations on pumped hydro with respect to switching, interconnections and loss of load apply as well to pumped air.

\section{Conclusions}

1. An underground compressed air system can be designed to work in conjunction with a wind energy system.

2. The sizing, consequences of interruption, and site-related characteristics of compressed air storage for wind energy system use are very similar in nature to these same considerations for pumped hydro st.orage. 
3. A hybrid operation in conjunction with other utility power generation storage charging sources is a more likely application approach. This method could avoid or reduce equipment modularity requirements that would otherwise be encountered in designing a wind-only system with efficient component sizes.

\subsubsection{Battery Storage Sys tems}

Both lead-acid batteries and a number of advanced batteries now under development $t^{4,5}$ are potentially compatible with the concept of an integrated wind-energy storage and conversion system. Extensive studies have been done, and estimates made for lead-acid batteries. ${ }^{6,7,8}$ Assessments of expected results for advanced batteries have also been made, and a major test program, the Battery Energy Storage Test Program, 9, 10,11 has been organized. Since the above types of data are readily available, and battery operation in general is well understood, the purpose of this section is primarily to assess the major consequences of interfacing this type of storage with a wind conversion system. It will be assumed in this discussion that any successful advanced battery will meet or exceed the key performance characteristics of a lead-acid battery; therefore, attention will be directed at the operational results to be expected with lead-acid batteries as the storage system for wind energy conversion. Fundamental considerations such as placement of power conversion equipment and typical voltages and currents will be discussed.

\section{Integrated Wind Conversion System Concept}

A lead-acid battery storage system for utility use with a wind system is shown in Figure 2.1-6. The preliminary design data shown for the wind energy 


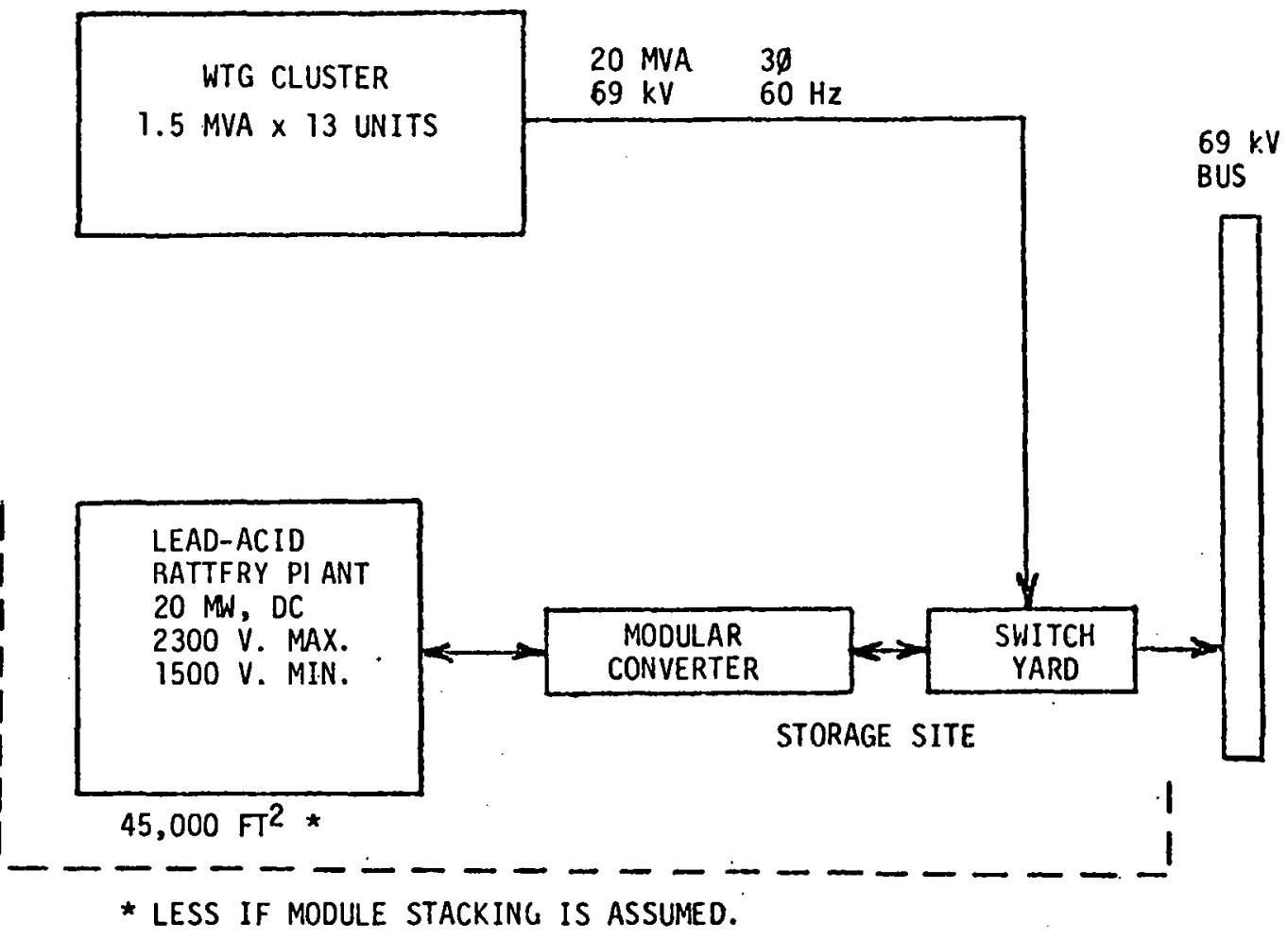

FIGURE 2.1-6. WIND ENERGY CONVERSION WITH LEAD-ACID BATTERY STORAGEUT ILITY APPLICATION

system was taken from a recent GE-ERDA study. ${ }^{12}$ The information shown for the lead-acid storage system was extracted from and/or based on the EPRI Workshop report on "Lead-Acid Batteries for Utility Application". 4

The discharging of the storage system per se is not directly affected by the wind energy source, and is not included in this portion of thediscussion.

For the wind system as shown, no accounting of losses or effect of capacity factor is indicated. The power outputs indicated are maximums. If a 
capacity factor of $40 \%$ is assumed for the wind turbine generators (WTG), an average power output of 8 MVA can be relied upon to charge the batteries. Since the equipment for the storage system is selected on a power basis, several system alternatives should be considered for determining the equipment complement of the storage system, as described below.

\section{Functional Assessment}

Storage equipment can be selected so that the power ratings are correlated to the maximum power available from the energy source. The system would then have poor efficiency because the average power level is much less than rated. Electrical equipment is more efficient at rated conditions and the efficiency at rated conditions improves the higher the power and voltage ratings (i.e., with size). Also, for inverter units in the 20 MVA size, stable operation is not possible for low power (around 10\%) input. Regardless of size, cooling of inverter/converter equipment must be varied as a function of load for inpreved efficiency. This condition may be improved by the alternative of modularizing the power conditioning equipment into, for example, three sets of $30 \%$ power capability each. Thus, depending upon the power output from the wind source, only $1 / 3$ of the power conditioning equipment is operated at less than rated conditions. Each of the power conditioning modules would be less efficient at full load than a single unit but the system efficiency should be better than that of operating one large unit in the 20 to $50 \%$ efficiency range. An actual design trade-off would be required before the advantage of modularizing could be established. It must be kept in mind, however, that modulariziing will impact reliability and will also severely affect cost effectiveness. A third alternative is to select a wind source power rating 
such that the average power output is correlated to the storage rieed. For this alternative, some other options must in turn be exercised when the source is providing maximum, and in this case, excess power. The power could be dissipated bj' inefficient operation of the energy source, pumped back into the utility system or, again, the storage system could be modularized. Modularization, as before, will increase complexity and decrease cost effectiveness.

In conjunction with the first alternative, an option for maintaining charging power for storage at a constant level is to supplement the wind power with utility power. For specific utility systems, this option may have merit, but the determination is strongly defendent on the particular utility operating situations, and has, to date, been the subject of much discussion, both for and against this option.

\section{Conclusions}

It may be readily shown that the fower ratings of the wind conversion system with respect to the power ratings of the storage system may be approached by one of three alternatives:

1. Modularization

2. Overrating

3. Supplemental energy supply

Firm conclusions regarding optimum configurations and equipment sizing could only be made after specific preliminary svstem designs were carried to the point where system performance could be traded-off against system cost effectiveness; however, certain observations can be made: 
1. With regard to cost effectiveness, the unit cost of an inverter rises disproportionately as the size or power rating is decreased, but the cost of gathering interconnections will always be a much larger percentage of system cost for multiple unit clusters than will the inverter equipment. Therefore, the cost effectiveness of the wind conversion and storage system will be drastically affected by the degree of modularization.

2. A wind conversion system with its power output variation will offer some design challenges in obtaining the best match of power ratings. Trade-offs with unit efficiencies must be expected.

3. Battery storage systems inherently offer the possibility for distributed unit location and are flexible in their physical arrangement. Interruption of the charging cycle merely exercises the switching devices and their associated instrumentation. Restart of the charging process does not involve the same problems of inertia associated with large rotaiting machinery. Thus, a significant aspect of energy storage being associated uniquely with a variable output source, such as wind, is reduced to a minimal problem. Conversely, the battery system can be expected to provide an instantaneous and variable-magnitude discharge response when called upon to meet a changing load demand.

4. A dc wind turbine output could be traded off against the dual conversion to and from the battery; however, a conversion to ac would obviously be necessary someplace in the system prior to supplying energy to the utility grid. Prior investigations of this 
option have generaliy les to a designer's preference for ac WTG output.

\subsubsection{Flywheel Energy Storage}

Flywheel storage with wind energy conversion systems at the utility scale of usage is covered in this Section. Assessment is made by describing a representative system in fundamental terms, so that the critical system parameters can be identified. The impact and implications of charging the storage via a variable and interruptible wind energy conversion source are included in the discussion.

\section{Integrated System Concept}

The fundamental flywheel storage system is shown in figure 2.1-7. The system consist.s of: a flywheel which stores kinetic energy, a constant speed motor/ generator, and avariable speed coupling (or a variable frequency converter). Since the mass of the flywheel is fixed, the kinetic energy of the flywheel can only be charged or discharged by changing the flywheel speed. For utility use, a synchronous motor/generator would provide the most desirable interface to the utility bus. That is, it would be desirable to have the flywheel discharge via a constant speed generator synchronized to the utility bus. Conversely, for charging, the constant speed machine would be used as a motor to charge the flywlieel. In order to accomplish this, it is necessary to interpose a variable speed coupling between the constant speed machine and the variable speed flywheel. This variable speed coupling (during charging) must accept power (torque $X$ speed) from the constant speed machine, which is equivalent to the variable wind source output and, in turn, raise the then 


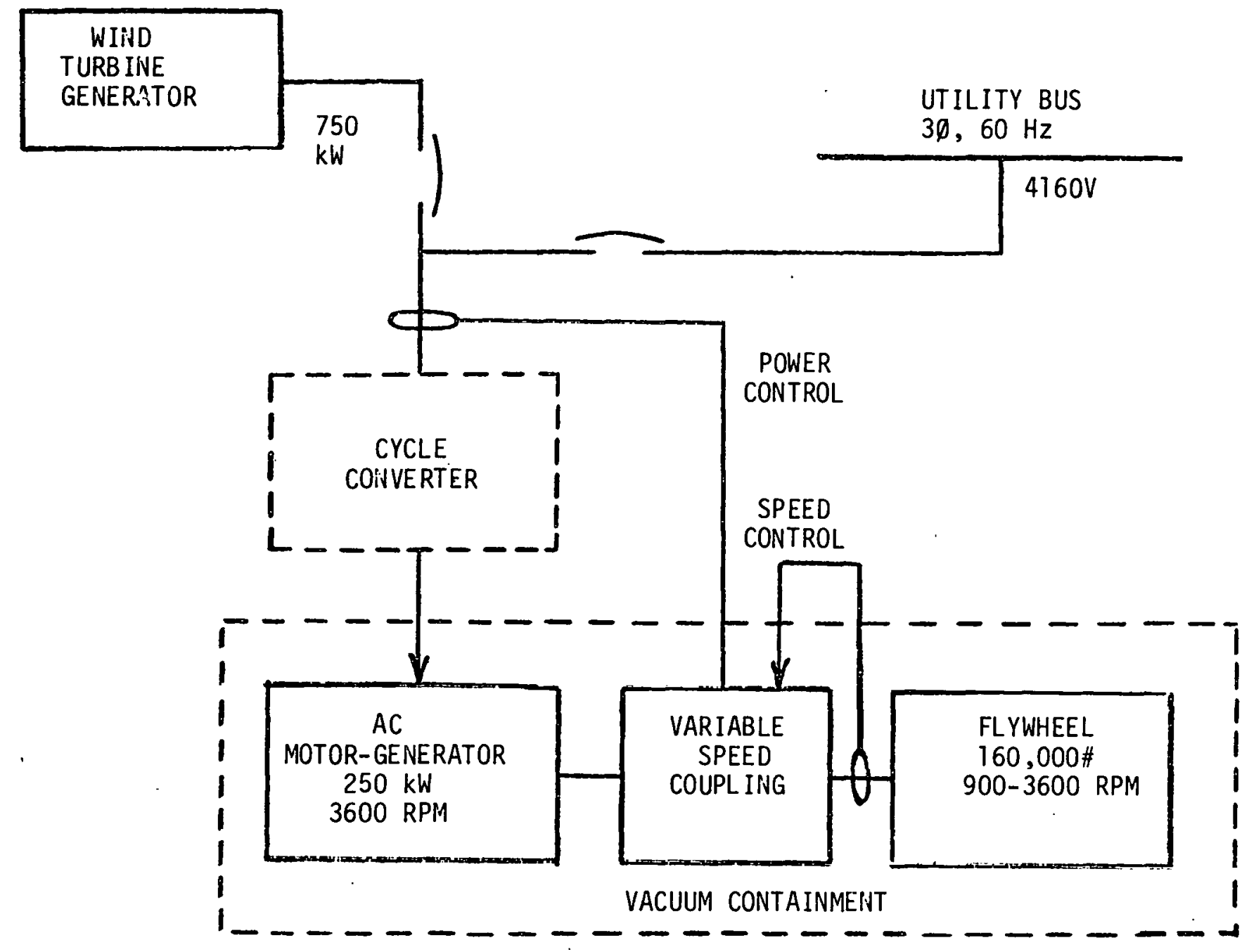

FIGURE 2.7-7. WIND ENERGY CONVERSION WITH FLYWHEEL ENERGY STORAGEUT IL ITY APPL ICATION

existing speed of the flywheel to a still greater speed. In order to fully utilize the available energy source power, the: coupling must be controlled on the basis of sensed power. In discharging into the utility grid, the source is open circuited and the coupling is controlled on the bas is of scheduled power out of the synchronous generator. That is, the discharge power is a selected value and the variable speed coupling is controlled so as to maintain the selected output. 
An alternative scheme using a cycle converter (shown dotted in Figure 2.1-7) may also be employed to modulate the input/output speed of the ac motorgenerator to charge/discharge the flywheel. For this option, the frequency on the utility side of the converter must be constant and the frequency on the mator/generator side must be controlled for charge/discharge and power level. When charging from the variable power level wind turbine source, the frequency out of the cycle converter must be increased until the speed of the motor is greater than the speed then existing on the flywheel. Conversely, when discharging, the power and frequency from the cycle converter to the utility must be maintained constant as the ac generator, being driven by the flywheel, is constantly slowing down.

In order to minimize idling or standby losses due to friction and windage losses of the flywheel, the high speed units are generally enclosed in a chamber evacuated of air or other gases and mounted on very efficient bearings.

As with other storage systems considered, the charging cycle is the key portion of the system operation which needs be considered to assess the hardware design impact of the wind conversion -flywheel system interface. The discharge cycle is unaffected, provided proper energy balance has been allocated, since the storage system effectively isolates the load (during discharge) from the variations of the source. 


\section{Functional Assessment}

An ERDA studyl3 describes a basic flywheel rotor module for utility application. This flywheel is a 160,000 pound 185 inch rotor capable of delivering 2.5 MWh (10 hour discharge) and has a maximum speed of 3,600 RPM. When connected to a 3600 RPM synchronous generator, the variable speed transmission allows flywheel speeds from 3600 to $900 \mathrm{RFM}$. The configured systems as described in the above study (Section 5.3) assume constant (rated $250 \mathrm{~kW})$ power input during charge and discharge. For a wind energy conversion source with a capacity factor of about $33 \%$, assume a power rating of $750 \mathrm{~kW}$. With the variable speed coupling system, the operation of the motorgenerator would be as for any normal application, and the generator efficiency would be close to $95 \%$ from $50 \%$ load to full load, dropping sharply below the $50 \%$ load point. The variable speed coupling, however, would have poor efficiency except at rated (or low slip) conditions.

To illustrate, consider the operation of some type of slip clutch while the system is charging and assume the flywheel is spinning at 900 RPM and $15 \%$ of the source power or $125 \mathrm{~kW}$ are available. The generator at $50 \%$ load will be turning at 3600 RPM and since the power output of the generator is a constant $125 \mathrm{~kW}$ there is a constant torque of:

$$
\begin{aligned}
Q & =\frac{125 \mathrm{~kW}}{3600 \mathrm{RPM}} \quad 3413 \frac{\mathrm{Btu}}{\mathrm{kWh}} \quad 778 \frac{\mathrm{ft}-1 \mathrm{~b}}{\mathrm{Btu}} \quad \frac{1 \mathrm{~h}}{60 \mathrm{~min}} \quad \frac{1}{2 \pi} \frac{\mathrm{Rev}}{\operatorname{Rad}} \\
& =244.5 \mathrm{lb}-\mathrm{ft} .
\end{aligned}
$$

applied at the input. Since there is no loss of torque through the clutch, the power into the flywheel is given as

$$
P=125 \times\left(\frac{900}{3600}\right)=31.2 \mathrm{~kW} .
$$


Therefore, about $95 \mathrm{~kW}$ must be dissipated in the variable coupling device as the flywheel is accelerated from 900 to 3600 RPM as illustrated in Figure 2.1-8. Ignoring the damping and shaft spring parameters of the system (which should be negligible), the time constant for the flywheel under constant torque from the motor is:

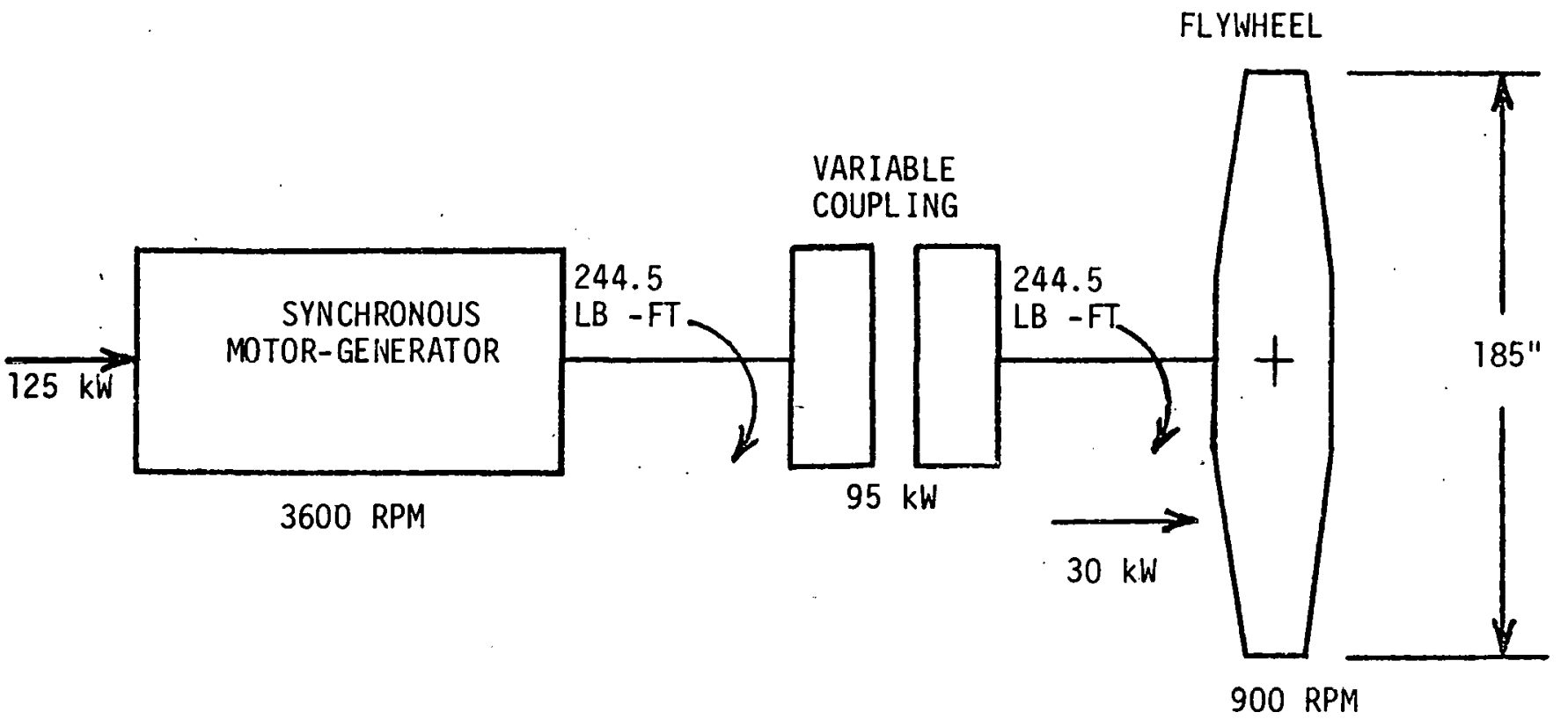

FIGURE 2.1-8. SLIP POWER DISSIPATION IN VARIABLE SPEED COUPLING 


$$
d t=J \frac{d \omega}{Q}
$$

where

$$
\begin{aligned}
\mathrm{J} & =1 / 2 \mathrm{MR}^{2} \quad \text { (assumes right circular cylinder) } \\
& =\left(\frac{1}{2}\right)\left(\frac{160,000}{32.2} ;\left(\frac{185}{(2)(12)}\right)^{2}\right. \\
& =1.47 \times 10^{5} \text { slug-ft }{ }^{2} \\
\mathrm{~d} u & =\frac{3600-900(2 \pi)}{60} \\
& =282.7 \mathrm{Rad} / \mathrm{Sec} \\
\mathrm{dt} & =\frac{(1.47 \times 10)^{5}(282.7)}{244.5} \\
& =169,993 \mathrm{sec} \\
& =47.2 \mathrm{hrs} . \\
& =1.97 \mathrm{days}
\end{aligned}
$$

As the flywheel speeds up to the same speed as the motor, less puwer is dissipated in the coupling. The total energy lost in accelerating the flywheel is the integral of the slip characteristic of the coupling device over the period of acceleration.

It has been suggested in the previously-mentioned report, that this dissipative situation can be ameliorated considerably through the use of automotive type transmission systems, one such being the Trancor constant velocity transmission (CVT). Essentially, this CVT would continuously minimize the speed ratio between the constant speed motor and the variable speed flywheel. The result would be high accelerating torques applied to the discharged 
flywheel but little power being dissipated in the transmission. Units of $250 \mathrm{Hp}(186 \mathrm{~kW})$ have been built, but they are still developmental. For state-of-the-art, eddy-current clutches have been suggested for utility applications. Eddy-current clutches were also considered by GE Advanced Energy Programs personnel for use with the Mod-1 Wind Turbine Generator. The size of these clutches is about the same size as an 1800 RPM synchronous machine or slightly larger.

If the variable speed motor/generator option is considered, the variable speed coupling is replaced by a fixed coupling and the frequency range for the cycle converter is $3: 1$. Down conversion of frequency is simpler than the up conversion inferred by the arrangement shown in Figure 2.1-7. In any case, the cycle converter will be operated with variable power input, such that a single unit will not be very efficient. The efficiency of the cycle converter would be improved by modularizing units to a fraction of the total load then switching modules in and out such that all but one module was operated at full load. The system complexity will be increased in this case, and therefore the reliability of the system will decrease somewhat with modularization.

\section{Conclusions}

1. Flywheel storage systems can be interfaced with a variable power source such as a wind energy system. The degree of success, however, will be dependent- upon the satisfactory development of the flywheel itself and also a large variable speed transmission system, capable of long life with a relatively large number of operating cycles. In addition, suitable bearirigs and enclosures must be availdble. 
2. Alternative designs may introduce requirements for modularity which would increase the complexity and cost of the system. A design trade-off would be required to select a preferred sys ten.

\subsubsection{Hydrogen Gas Generation and Storage System}

This Section provides a brief practical assessment of a system using fuel cells to generate hydrogen for storage, with subsequent utilization of the stored energy by burning the hydrogen in a fuel cell to produce electricity. The system energy input requirements are supplied by a wind energy source and the generated electricity is supplied at utility level and scale. A candidate $\mathrm{H}_{2}$ system will be described along with the identification of critical system parameters and evaluation of the probable results of interruption or variation in the wind energy input.

\section{Integrated System Concept}

A basic hydrogen generation and storage system is shown in figure 2.1-9, based on information contained in a supporting study performed for this program by General Electric Direct Energy Conversion Programs (DECP). ${ }^{14}$ In the figure, electrical lines are shown solid, and plumbing lines are shown dotted. In assessing this storage system for the Impact of interfacing with a wind energy source, it is not necessary to consider the discharge of the storage system since it should be presumed that the storage system has been appropriately scaled to supply specific utility needs, and the storage device effectively isolates the utility demand from the variability of the wind energy source. The essentials of the hydrogen generation system which 


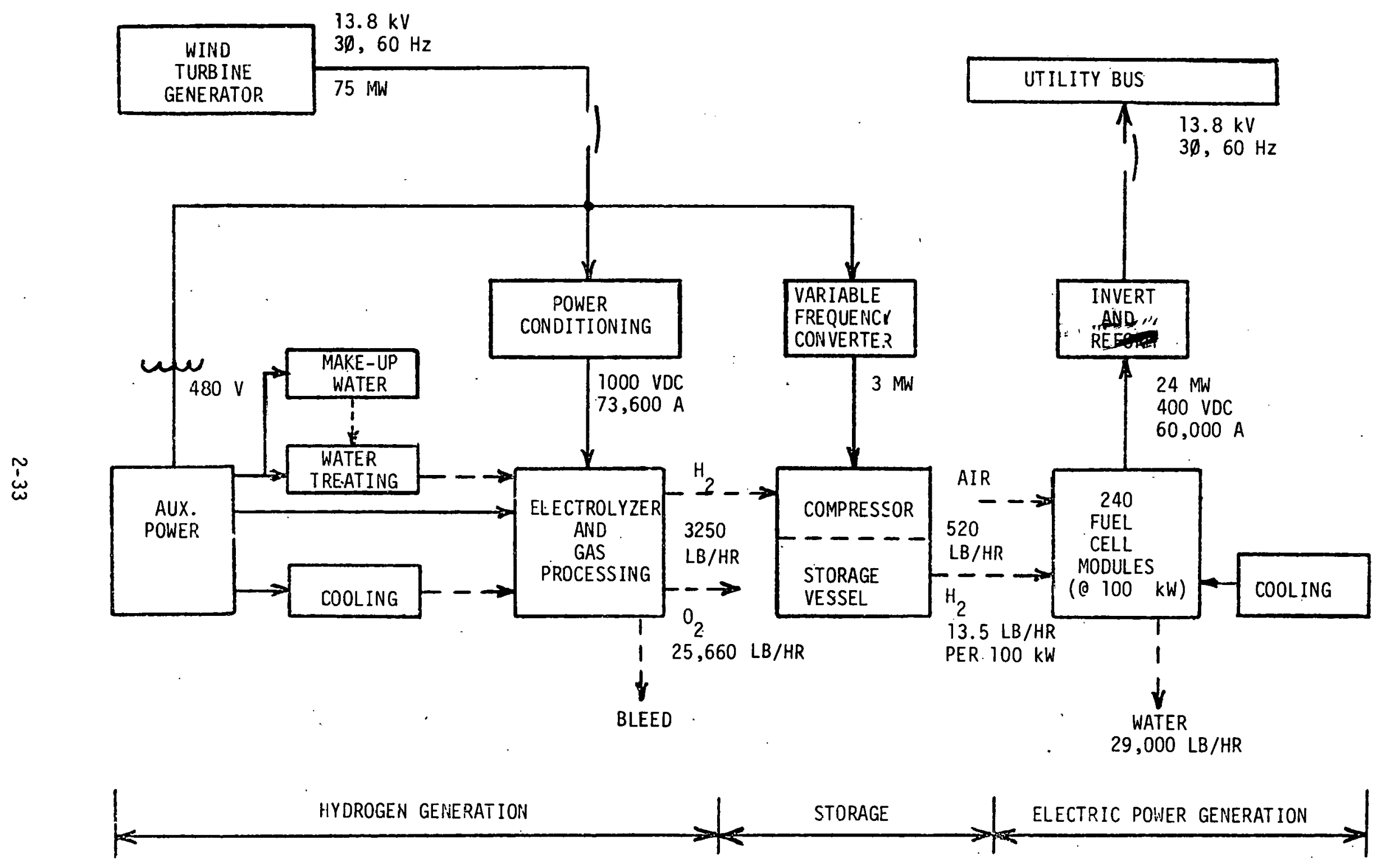

FIGURE 2.1-9. WIND ENERGY CONVERSION WITH HYDROGEN GENERATION AND STORAGE SYSTEM - UTILITY APPLICATION 
charges the storage system are as follows: The Electrolyzer which provides the hydrogen (and incidental oxygen) must be provided with a constant voltage direct current source. The output flow rate of hydrogen is then proportional to the amount of current (power, in effect, since the voltage is constant.) provided with a constant voltage direct current source. Treated water is fed into the electrolyzer in a recycle with continuous flow rate and at a controlled pressure and provides the "raw material" for the electrolysis. The gases formed by the electrolysis are then processed by separat.ors, dryers and associated components which are not affected per se by the flow rate. However, heat exchangers required for the electrolys is and gas processing, are affected by flow rate, since the main reaction and other processing must be done at controlled temperatures. Therefore, the flow rate of cooling liquids must be varied as a function of the rate of hydrogen production which increases as the power provided by the wind energy system increases. Similarly, the flow rate of make up water must in orease as power (dc current) increases, in order to suppldit the watcr that has been decomposed by electrolysis.

The hydrogen generated by the electrolysis is generally stored under pressure and is available to generate electrical power via a fuel cell for either utility peaking requirements or base load requirements. Based on the DECP study, and an assumption that it is desirable to have as many fuel cells as the maximum hydrogen flow out of the electrolyzer will allow, it is noted that $75 \mathrm{MW}$ of input power to the storage system from the wind energy source will provide approximately 25 MW of fuel cell output. 


\section{Functional Assessment}

A fundamental. consideration for the hydrogen storage system is the manner in which the hydrogen (once it has been generated) is stored. Of the three methods of storage discussed in the DECP report: compressed gas, liquid, or metal hydride, the compressed gas is assessed as the most near term (See Table 2.1-4). The metal hydride system of storage is promising, but is developmental and the liquid hydrogen storage method has high charge/discharge cost ana only a fair intermittent operation capability. The assessment of

TABLE 2.1-4. COMPARISON OF HYORUGEN STURAGE METHODS

\begin{tabular}{|c|c|c|c|}
\hline POINT OF COMPARISON & $\begin{array}{l}\text { METAL } \\
\text { HYDRIDE }\end{array}$ & LIQUID & $\begin{array}{l}\text { COMPRESSED } \\
\text { GAS }\end{array}$ \\
\hline Equipment Cost, $\$ / 1000 \mathrm{SCF}$ & $350-530$ & $1000-1300$ & $550-1200$ \\
\hline Energy Expenditure, $\mathrm{kWh} / \mathrm{lb} \mathrm{H}_{2} /$ Storage Cycle & $0.8-1$ & $4-5$ & $0.5-1$ \\
\hline Intermittent Operation Capability & Good & Fair & Good \\
\hline Hydrogen Volume per Container Volume & Medium & High & Low \\
\hline $\begin{array}{l}\text { Storage Vessel Cost as Percentage of } \\
\text { Total Storage Cost }\end{array}$ & Mcdium & Low & High \\
\hline $\begin{array}{l}\text { Equipment cost Required to Induct } \\
\text { Hydrogen in or out of Storage as } \\
\text { Percentage of Total Storage Cost }\end{array}$ & Medium & High & Low \\
\hline
\end{tabular}

the storage method and the system for use with wind generated input power was discussed further with DECP personnel. The basic compressed gas storage system requires: a pressure vessel, a reciprocating compressor, and a large ac powered motor drive of low synchronous speed. This system is shown in 
Figure 2.1-10. The drive horsepower required for a three-stage compressor is $1.79 \times 10^{-4}$ times the standard cubic feet per day of hydrogen processed, $\left(V_{b}\right)$. For continuous 24 , hour operation at rated output:

$$
\begin{aligned}
V_{b} & =3250 \mathrm{lb} \text { of } \mathrm{H}_{2} / \mathrm{hr} \times 1 / .0052 \mathrm{ft}^{3} / \mathrm{lb} \times 24 \mathrm{hr} / \text { day } \\
& =15 \times 10^{6} \mathrm{ft}^{3} / \text { day }
\end{aligned}
$$

then:

Drive Power $=1.791 \times 10^{-4} \quad V_{b}=2686.5 \mathrm{hp} \cong 2000 \mathrm{~kW}$
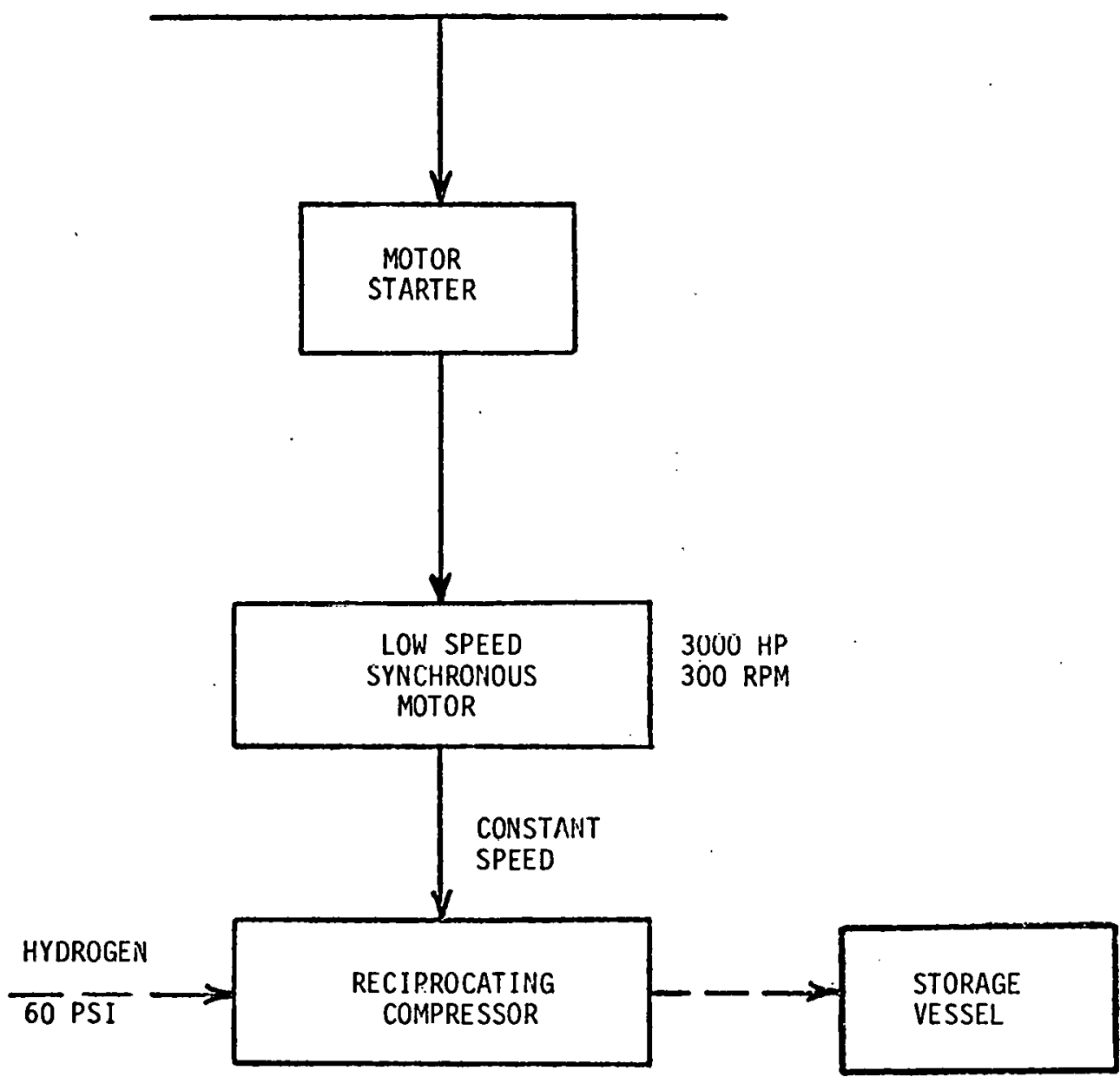

1295 PSI

FI.GURE 2.1-10. COMPRESSED GAS STORAGE SUBSYSTEM 
The significance of this system configuration is that a constant speed motor is driving a reciprocating compressor. This combination has essentially the same output at any pressure within the capability of the driver and the compressor, butithe capacity (flow rate) varies due to wind energy variability, so this system cannot operate at constant speed. As shown in Figure 2.1-9, a variable frequency converter is required to drive the positive displacement compressor at a speed correlated to the hydrogen flow rate. DECP has suggested elimination of the compressor by operating the electrolyzer at higher water pressure since the recycled water can have a constant flow rate. This scheme; shown in Figure 2.1-11, transfers the variable speed requirement to the pump supplying the make-up water, and requires a heavier electrolyzer unit.

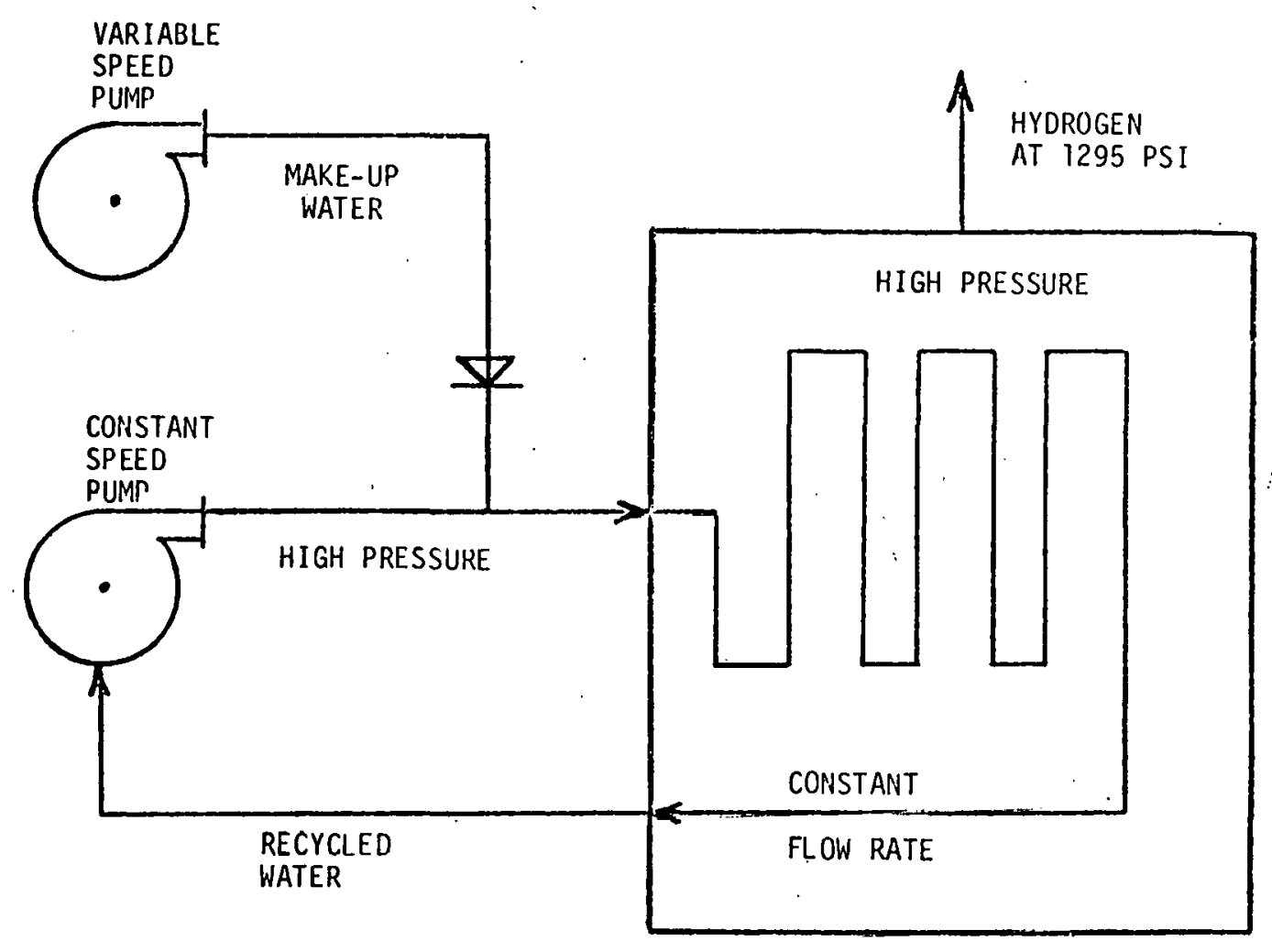

ÉLECTROLYZER

FIGURE 2.1-11. ELECTROLYZER CONFIGURATION WITH COMPRESSOR ELIMINATED 
With regard to the interruptibility of the hydrogen generation process, there are no unusual design or process problems associated with periods of inoperation, except for the impact on cycle life of switching elements.

As for variability of energy source, the range of power variability will as previously stated, require variable speed drives to vary the cooling fluid flow rate as a function of the rate of hydrogen generation. It has also been suggested by DECP that cooling flow be stopped for power input to the electrolyzer below $10 \%$.

The selection of variable speed pump(s) for the make-up feed water is a design problem not under consideration here, but a system is conceivable whereby the hydrogen generation can continue for very small (less than 10\%) power into the electrolyzer.

Because of power conditioning requlremeits for the clectrolyzer, it is doubtful that efficient operation can be obtained unless the power conditioner is modularized (e.g., 10 units each rated at 10\% of maximum power). The power conditioners, as most electrical equipment, operate most efficiently at or near rated power. The efficiency decreases drastically below about $50 \%$ of rated load.

The hydrogen storage system is basically amenable to dedicated operation with wind energy systems but at severe cost to efficient operation. The definitive course for improvement of operation efficiency appears to be to completely modularize all aspects of hydrogen generation and power generation, but the 
consequences of the resultant complexity may seriously affect utility requirements for reliability and availability.

It is noted that the low voltage levels associated with the power input to the electrolyzer and also out of the fuel cells results in very high currents, Clearly, exceptional care must be taken in the design of all interconnecting conductors to minimize resistances and consequent power losses and cooling problems.

\section{Conclusions}

1. A hydrogen generation and storage system can be made to perform satisfactorily in conjunction with a wind energy conversion system for charging power.

2. The precise operating characteristics of such a system would require a design analysis for a specific system.

3. For the near term, a compressed gas storage system presents the least complications. Other storage methods may be introduced at a later time. Hydride storage appears to offer the most desirable possibility for the long term future. 


\subsection{RESIDENT IAL SYSTEMS}

\subsubsection{BASIC ENERGY CONVERSION SYSTEM}

The basic energy producing unit assumed for the residential wind energy conversion application was a horizontal axis wind turbine generator rated at a nominal $10 \mathrm{~kW}$ output. Such a system would be located on the premises of the owner and adjacent to the residence structure or as close thereto as practical. The system output would normally be connected for residence use via additional control system and power cabling and the conventional residential load center. Additional terminal enclosures at the load center would be required. The siting, interconnection, and operational procedures would require conformance with applicable codes. Specific designs for homeowner or architect selection would be necessary. Particular attention would be required with respect to standardization of equipment and implementation practices in order to accommodate large-scale use of such systems. While only a single WTG unit is considered here, there are clearly options to use smaller units or to combine units at the $10 \mathrm{~kW}$ rating or larger ratings to serve more than une residence. Also, both vertical and horizontal axis windmills have been studied by others and either could be applied.

\subsubsection{WIND CONVERSION SYSTEM OPERATION}

Alternatirig current output WTG units were assumed based on prior assessments 15,16 of the impact of providing ac vs. dc power for residential use. Table 2.2-1 gives the major WTG parameters of immediate interest. The machine design parameters were selected to match the wind output levels at selected sites. These sites and their associated wind regimes are discussed in Section 3. 
TABLE 2.2-1. $10 \mathrm{~kW}$ WIND GENERATOR SYSTEM CHARACTERISTICS

\begin{tabular}{|l|l|}
\hline Rated Power & $10 \mathrm{~kW}$ \\
Design Wind Velocity & $5.36 \mathrm{~m} / \mathrm{s}(12 \mathrm{MPH})$ \\
Generator Parameters & $\begin{array}{l}\text { Synchronous, } 10 \mathrm{~kW}, 120 / 240 \mathrm{VAC}, \\
60 \mathrm{~Hz}, 1-\mathrm{Phase}, 1800 \mathrm{RPM}\end{array}$ \\
$2 \mathrm{Blade}, 150.5 \mathrm{RPM}$ \\
Rotor & $9.28 \mathrm{~m}(30 \mathrm{ft})$ \\
Rotor Diameter & $19.9 \mathrm{~m}(65 \mathrm{ft})$ \\
Rotor Axis Height & \\
Wind Velocities: & $3.56 \mathrm{~m} / \mathrm{s}(7.96 \mathrm{MPH})$ \\
$\quad$ Cut-in & $7 / 49 \mathrm{~m} / \mathrm{s}(16.75 \mathrm{MPH})$ \\
Rated & $15.01 \mathrm{~m} / \mathrm{s}(33.58 \mathrm{MPH})$ \\
Cut-out & $36.4 \times 10^{3} \mathrm{kWh}$ \\
\hline $\begin{array}{l}\text { Annual Energy Production } \\
\text { (Design) }\end{array}$ & \\
\hline
\end{tabular}

\subsubsection{STORAGE SYSTEM INTEGRATION AND INTERCONNECTION TO THE WIND ENERGY . CONVERSION SYSTEM}

- I he basic WTG unit with energy storage added was considered on a case-by-case basis with respect to the probable consequences of being interconnected with various storage systems. By virtue of previous suitability screening as described in Volume I of this report, the use of systems other than batteries, flywheels, and small-scale pneumatic (compressed air) storage were ruled out for further consideration in this study. However the possible alternative of a conventional (hot water) thermal system at the residential level is included in this Section. 


\subsubsection{Battery System Storage}

Most recently, the primary emphas is on battery storage development has been directed at utility applications and vehicular transportation needs. While advanced versions of present lead-acid batteries and also various other types of "advanced" batteries are actively being pursued 5,17 , the prime utility interest cited above indicates why very little firm data exists upon which to base an assessment of residential -scale wind system battery storage hardware interface problems with advanced batteries. However, it is well known that alternative lead-acid battery sizes and scalings are possible. Modenn residential battery storage systems could readily use the lead-acid technology of motive power batteries now available to industry. Residential use of advanced batteries must remain dependent on the current R\&D efforts leading to a sound product and the subsequent resolution of issues relating to maintenance requirements, potential hazards, and the ownership responsibilities which are as yet unknown and/or undefined. The discussion which follows, therefore, is based on lead-acid battery technology and the assumption that eventually one or more so-called "advanced" batteries will be available with performance characteristics at least as favorable as those for lead-acid batteries.

\section{Integrated System Concept}

Figure 2.2-1 shows a concept for a wind energy system with lead-acid storage batteries, and identifies the principal components involved. The values given relate to a single battery size $(43 \mathrm{kWh})$. Figure $2.2-2$ shows the physical dimensions of such a battery as proposed by C\&D Batteries, Div., of Eltra Corp., during the course of a supporting study for this energy storage investigation. Table 2.2-2 gives other proposed characteristics of such a battery. 


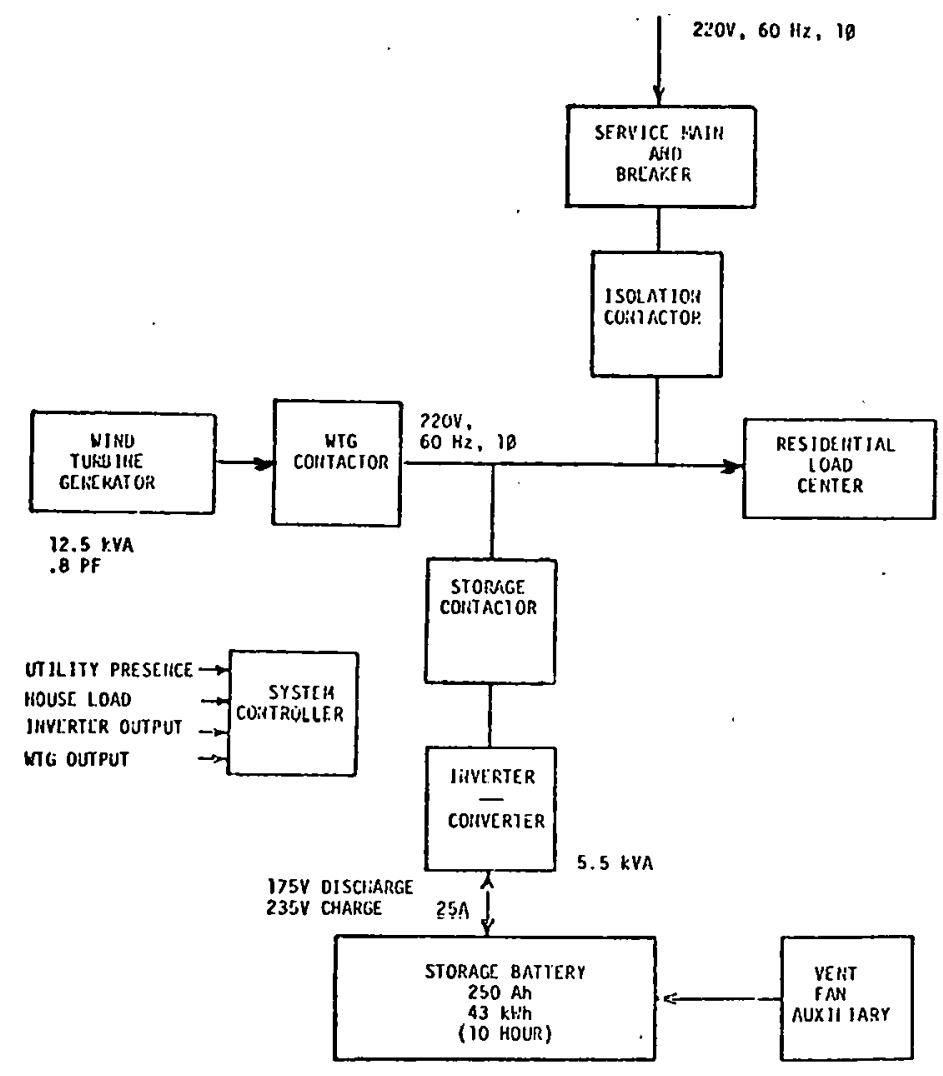

FIGURE 2.2-1. RESIDENT IAL BATTERY ENERGY STORAGE SYSTEMWIND ENERGY CONVERSION

TABLE 2.2-2. REPRESENTATIVE RESIDENTIAL LEAD-ACID BATTERY CHARACTERISTICS

Capability

$10 \mathrm{Hr}$ System Power

Number of Cells

Ampere Hours per Cell

Physical Dimensions One of 4 Modules

Weight per Module

Hydrogen Evolution

Recommended Charge Voltage

Discharge Voltage

(End of Life)

Water Consumption

Gal./Cycie/Cell
$4.3 \mathrm{~kW}$ Peak

$43 \mathrm{kWh}$

96 Series

225 AH (Derated 333 AH)

$22.5^{\prime \prime} \mathrm{L} \times 27^{\prime \prime} \mathrm{W} \times 23^{\prime \prime} \mathrm{H}$

1410 Pounds

$0.145 \mathrm{Ft}^{3} / \mathrm{Ce}$. $11 /$ C.ycle (Niew Cel1)

2.45 Volts per Cell

1.83 Volts per Cell

$0.0008 \mathrm{Gal}$. 


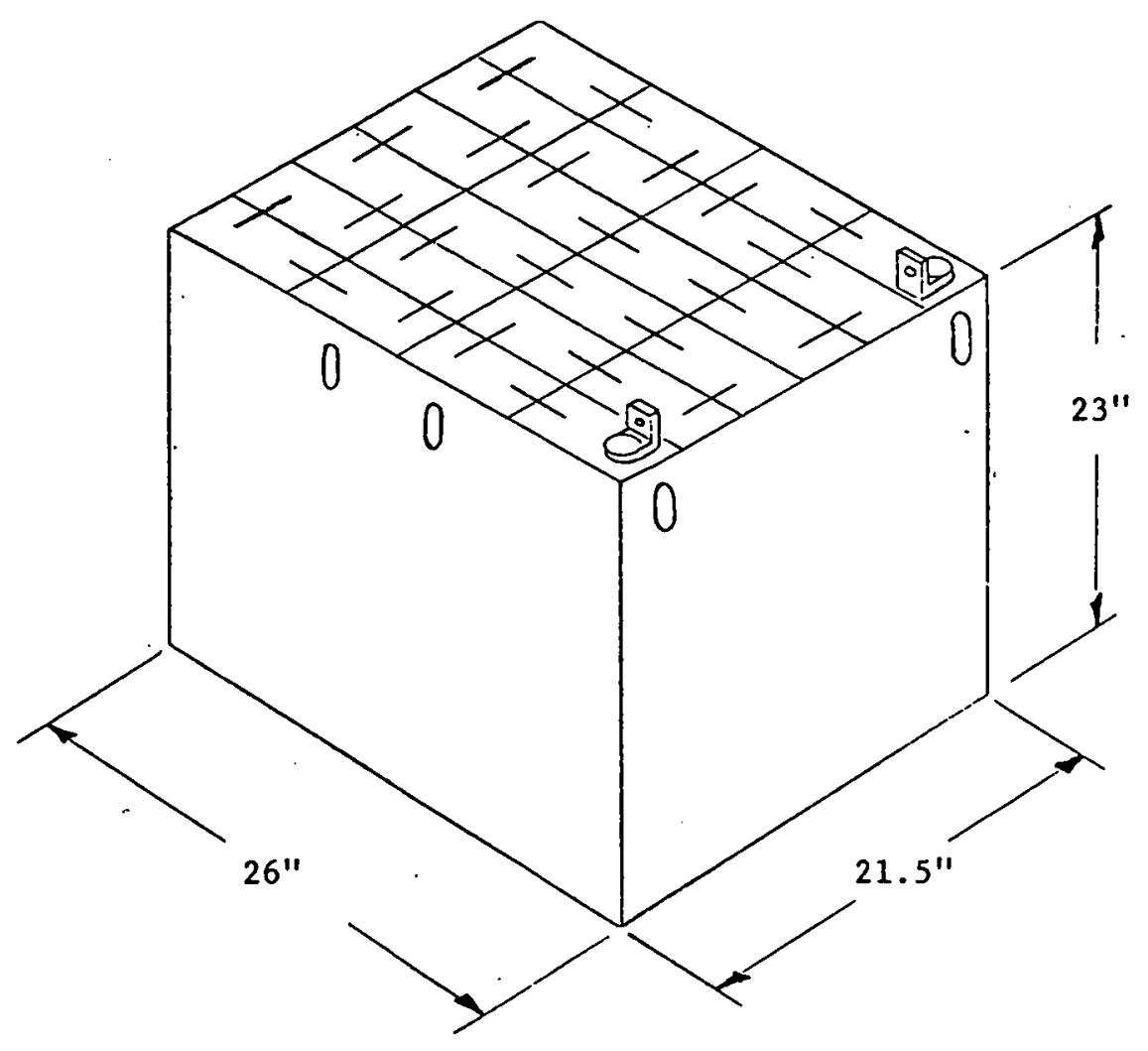

FIGURE 2.2-2. REPRESENTATIVE LEAD-ACID BATTERY MODULE FOR A RESIDENTIAL STORAGE SYSTEM

The concept shown provides for isolation of the utility, WTG, and storage system via contactor units. Normally, the house loads would be met first by the directly usable wind system output and supplemented as necessary by the utility power. During periods of low wind energy, the battery, charged previously with excess energy, would provide load power, again, backed up by the utility. During times when more than one s'ource is supplying the load, synchronism of the ac outputs must be assured by the control system. In event of a fault on the utility lines, isolation is required to prevent unwanted power feedback from the residential wind energy conversion system to the utility. 


\section{Functional Assessment}

The system components required for a residential wind energy conversion system with battery energy storage are not specifically available in the sense of "tailored" designs and sizes for this particular application. The: technology required, however, including manufacturing facilities and processes is available. It would be possible to assemble such systems on an individual basis using existing equipment for power conversion and interconnection. The control system would require that specific engineering and design be accomplished. In most cases, local codes and utility regulations would require prior coordination and approval for connection and operation of such systems. The system engineering and design requirements would at present make individual installations very costly and only a degree of product-line standardization could alleviate this problem. At the residential level, particular attention would be required to avoid operational protlems or hazards arising from carelessness with respect to battery water replenishment, prevention of hydrogen accumulation, and failure to properly secure the storage area. (The latter most likely would be within the residence structure). It should also be recognized that not only will present wind turbine designs not be practical for many densely populated neighborhoods, but in addition, many existing residences would lack a suitable area for a battery storage system to be added without extensive modification. Nevertheless, the problems cited appear reconcilable provided a substantial comnitment to a residential energy storage program were to be made by industry and government agencies.

\section{Conclusions}

1. There are no functional barriers of a technical nature that would prevent use of an integrated wind energy-lead-acid battery storage system at the residential level. 
2. The availability and acceptability of any type of "advanced" battery for residential use is hypothetical at the present time and judgment should be reserved until enough technical data is available to permit preliminary design of such a system.

3. A responsible homeowner attitude would be essential and maintenance support must be locally available.

\subsubsection{Flywheel Storage Systems}

Sinall flywheel stcrage systems presently exist for limited applications in the transportation and industrial fields. These applications are based on use of various shapes of steel flywheels. They have serious limitations to scale-up for advanced energy storage requirements due to need for higher energy density materials for the flywheel, and also need for improved bearings and enclosure systems. By-passing these considerations, however, the use of a flywheel system with a residential size wind turbine system may be examined to deternine the functional compatibility of the combination.

\section{Integrated System Concept}

Figure 2.2-3 shows the principal components needed for a residential system. The operational mode would include having the wind system supply the house load directly whenever possible. When the wind system generates excess power, the storage contactor is closed to permit the flywheel to be charged. Any further wind energy above these needs would be dissipated' by other means. House loads may be met by storage discharge alone or in combination with WTG output. The utility serves as backup and may be isolated by a contactor device. A system controller (not shown in the figure) is required to sense 


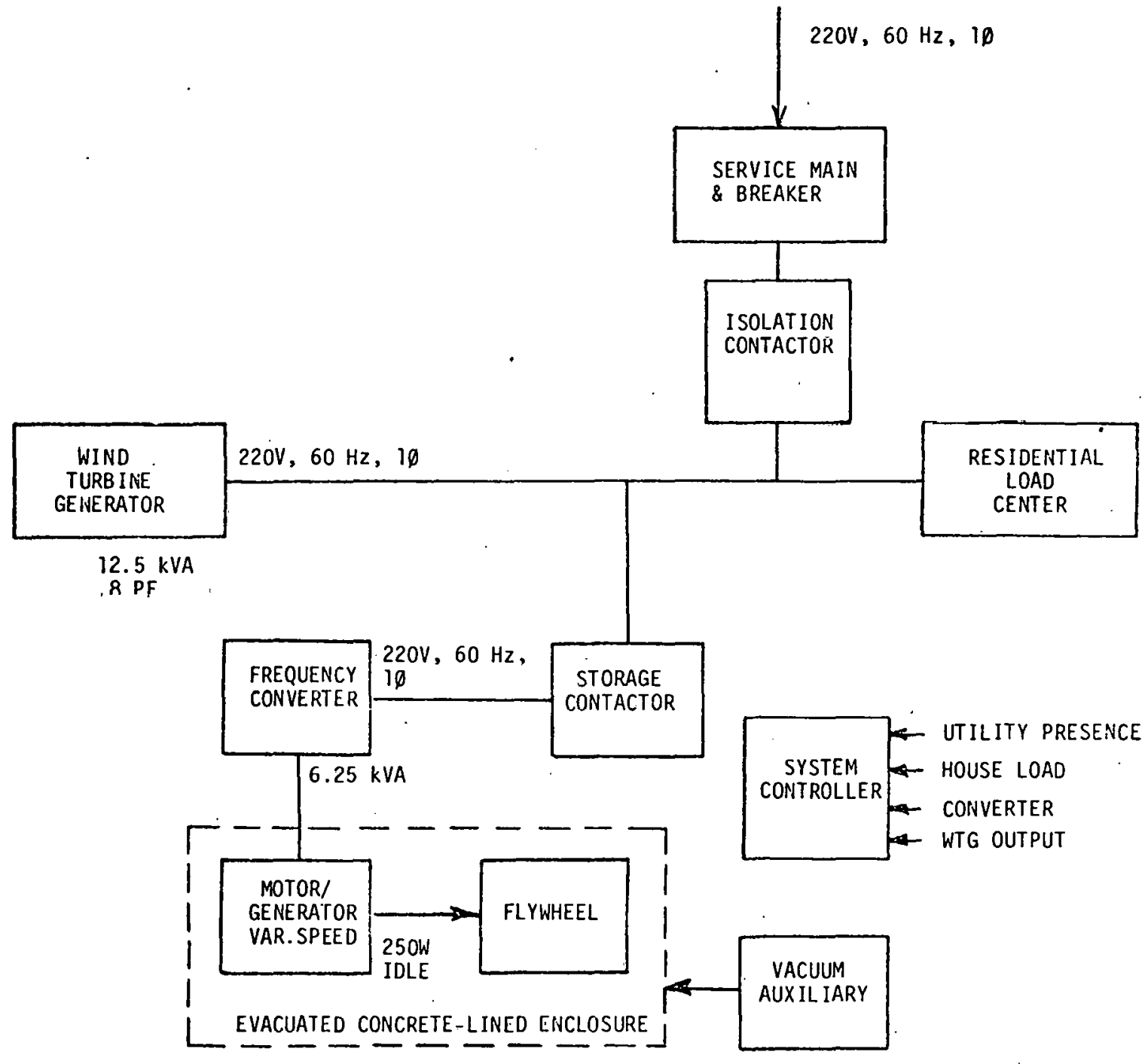

FIGURE 2.2-3. RESIDENT IAL FLYWHEEL ENERGY STORAGE SYSTEMWIND EISERGY CONVERSION

volitages and currents to assure proper operational sequence and the synchronous operation of the ac systems. The motor-generator and frequency converter are variable speed ac machines. For flywheel charging, the speed of the ac motor is determined by the frequency converter which changes a constant frequency power input to variable frequency power output. During dischargc, the varying frequency power output of the generator is converted to a constant frequency 
by the frequency converter, making it compatible with the normal utility power which serves the residential loads. The necessary speed-frequency conversion can also be accomplished mechanically by a variable speed transmission interposed between the flywheel and motor generator.

\section{Functional Assessment}

The components required for flywheel system use are not readily available in the sizes and configurations that would be needed. The flywheel itself, a lorig with bearings and enclosure system require further developmental work. Rockwe $11^{13}$ reported on a $5 \mathrm{kWh}$ flywheel as at the "forseeable" technology level using advanced flywheel technology. Such a system would have a composite rotor design with precision quality bearings, but short of the quality of those for space vehicle use. Early in this study, a residential design was projected on the basis of a conventional steel flywheel and up to $48 \mathrm{kWh}$ storage capacity, but was found to have costs in oxcess of $\$ 250 / \mathrm{kWh}$ of storage capacity.

\section{Conclusions}

1. A residential fiywheel system requires components that are either not available at the residential market level and/or require further advanced development.

2. From an operational standpoint, a system of this type has undesirably high standby or charge maintenance losses which must be considered. 
3. The amount and complexity of equipment involved combines to cause expectation of high cost and in all probability owner maintenance difficulties.

4. There is no technical reason why a flywheel system cannot be functionally integrated with a wind conversion system at the residential level.

5. Noise generated by the system is a problem requiring design attention.

\subsubsection{Pneumatic Energy Storage}

This form of energy storage was of interest at the residential level as a counterpart to the large-scale underground compressed air storage for utility use. Significant work on this type of storage concept was not found in earlier literature searches and consequently a specific investigation of major requirements was undertaken. The system aspects are discussed in the succeeding faragraphs.

\section{Integrated System Concept}

Figure 2.2-4 shovis the major elements which would be required for this type of energy storage. Air compression to about 700 psig was estimated as appropriate to the desired discharge level for a storage size of about $50 \mathrm{kWh}$. Compression would be accomplished by a multi-stage piston compressor driven by an ac motor. The discharge of the compressed air tank. would be used to drive an air turbine and a small alternator. The connection to the residenttal load center is not shown, but would be similar to other residential systems in that controls and contactor devices would be required to isolate the utility 


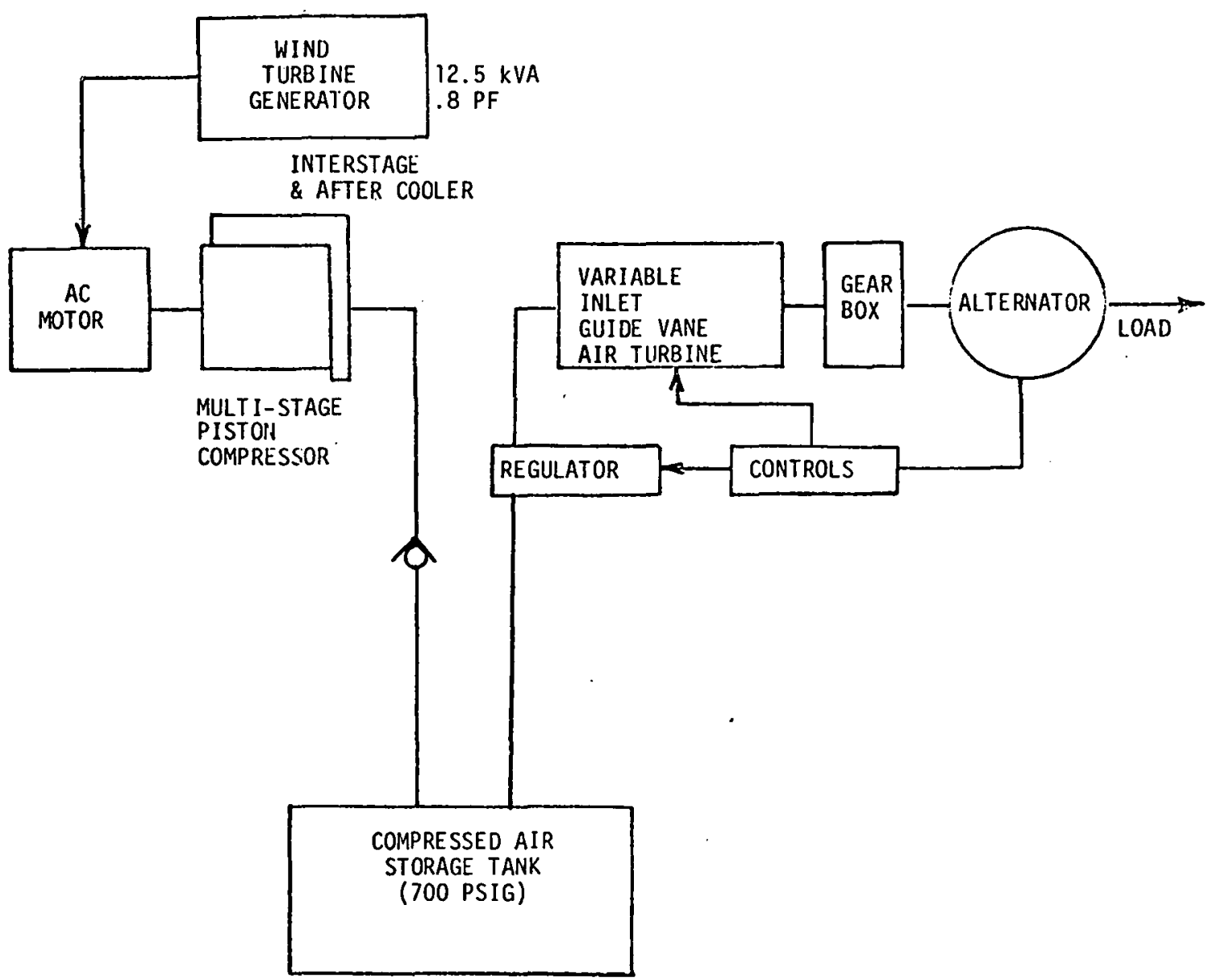

FIGURE 2.2-4. RESIDENTIAL. PNEUMATIC ENERGY STORAGE SYSTEM WIND ENERGY CONVERSION

power, the storage system and the wind turbine under various operating conditions. The ac outputs from these sources would require synchronization as well.

\section{Functional Assessment}

As can be seen from the diagram, a considerable amount of equipment is required for this concept. Some items are not readily available at present, although the AiResearch Manufacturing Division of Garrett Corp. 18 is fabricating an air-turbine driven alternator system rated at $80 \mathrm{~kW}$. This 
unit, however, is only intended for use as part of a Canadian proof-of concept experiment. 19 The efficiency of this concept was estimated to be in the order of $60 \%$ which is not particularly attractive. Another major problem with this concept is the weight and volume of the tankage. It is very conceivable that the 12 foot diameter, 15,000 1b tank estimated for the $50 \mathrm{kWh}$ of storage could be placed outside the residence, underground. Also, selection of a small storage capacity would obviously help reduce this problem. The other major factors that detract from the residence use of such a system would include the obvious hazard of the high pressure air tank, noise from the mechanical components, and high temperature ( $\sim 1000^{\circ} \mathrm{F}$ ) at the compressor discharge. The concern about interiuptibility that was identified with utility underground compressed air storage is reduced to small proportions at the scale of operation involved in the residence case. Proper design for motor disconnection under low WTG output conditions should essentially resolve this item.

\section{Conclus ions}

1. Off-the-shelf components arc not presenlly avallable to produce pneumatic storage systerns on a quantity basis, but could likely be made available within present technology. The air turbine performance results on the Canadian project would be a key item to monitor.

2. The pneumatic storage system as conceived can be integrated technically with a wind turbine generator system but has a number of very negative features. At the present time these do not appear. readily resolvable in the context of a residential scale system. 


\subsubsection{Thermal System Storage}

Although thermal-oil and thermal-steam types of energy storage were not found attractive for integrated use with wind systems, additional consideration is offered here with respect to conventional hot water systems for residential scale use. A major reason for further investigation of the residential thermal storage possibilities is that the major portion of the residential loads are thermal in nature, involving space heating and hot water heating.

\section{Integrated System Concept}

A number of storage mediums have been proposed, and some have been tried with varying degrees of success reported. Among these are hot water systems, heated rock storage and others. Figure 2.2-5 shows the major components of such a system based on use of a fluid heat exchange and energy storage system.

The wind energy output 111 lhis case would be used to provide power to residential electrical loads directly whenever possible. Utility power provides the remainder of the residence electrical needs. Excess wind system energy would be used to heat the thermal storage fluid, probably water, suitably enclosed in an insulated tank or similar device. The energy thus stored would not be reconverted to electricity but could be delivered via hot water or hot air distribution systems to directly serve home heating and hot water needs. 


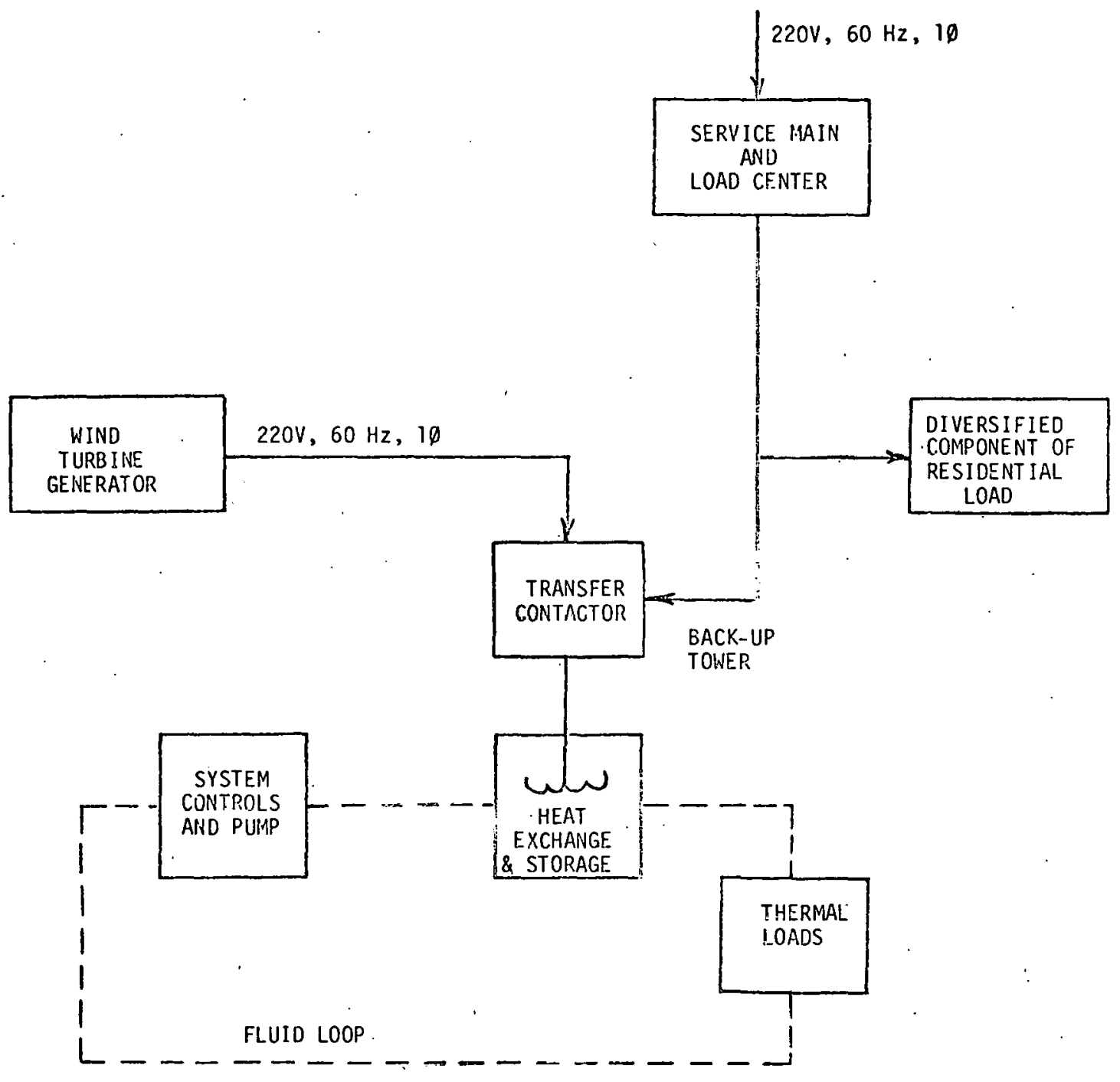

FIGURE 2.2-5. RESIDENTIAL. THERMAL ENERGY STORAGE SYSTTMM -

WIND ENERGY CONVERSION

\section{Functional Assessment}

The efficiency of conversion from electricity to thermal energy would be very high $(.95-1.0)$ so that the system. losses overall would depend only on the insulation of the storage device and the distribution system and the amount of time between storage and use. The equipment requirements would generally include punps, valves, fans and other mechanical equipment which 
would yield to fairly low technology development and production where existing equipment was not adequate. Further investigation and sizing of such a system was beyond the intended scope of this study, but should not be difficult to accomplish as related work has been done in the field.

\section{Conclusions}

1. This process of charging storage is highly amenable to unplanned interruptions, and interface problems would be relatively simple.

2. The attractiveness of such a system would require formulation of a detailed design and a detailed cost estimate.

3. The economic desirability of the value of such a system would require a direct comparison with results obtainable with all electric systems on a cost per Btu basis. 


\subsection{INTERMEDIATE SYSTEMS}

\subsubsection{BASIC ENERGY CONVERSION SYSTEM}

A $500 \mathrm{~kW}$ wind turbine generator was used as the basic unit for the intermediate category of wind energy storage system applications. Figure 2.3-1 shows the block diagram for such a system. Multiple units of this size WTG would be a suitable means of meeting load demands of the larger intermediate applications. For study purposes, however, the single $500 \mathrm{~kW}$ unit was used.

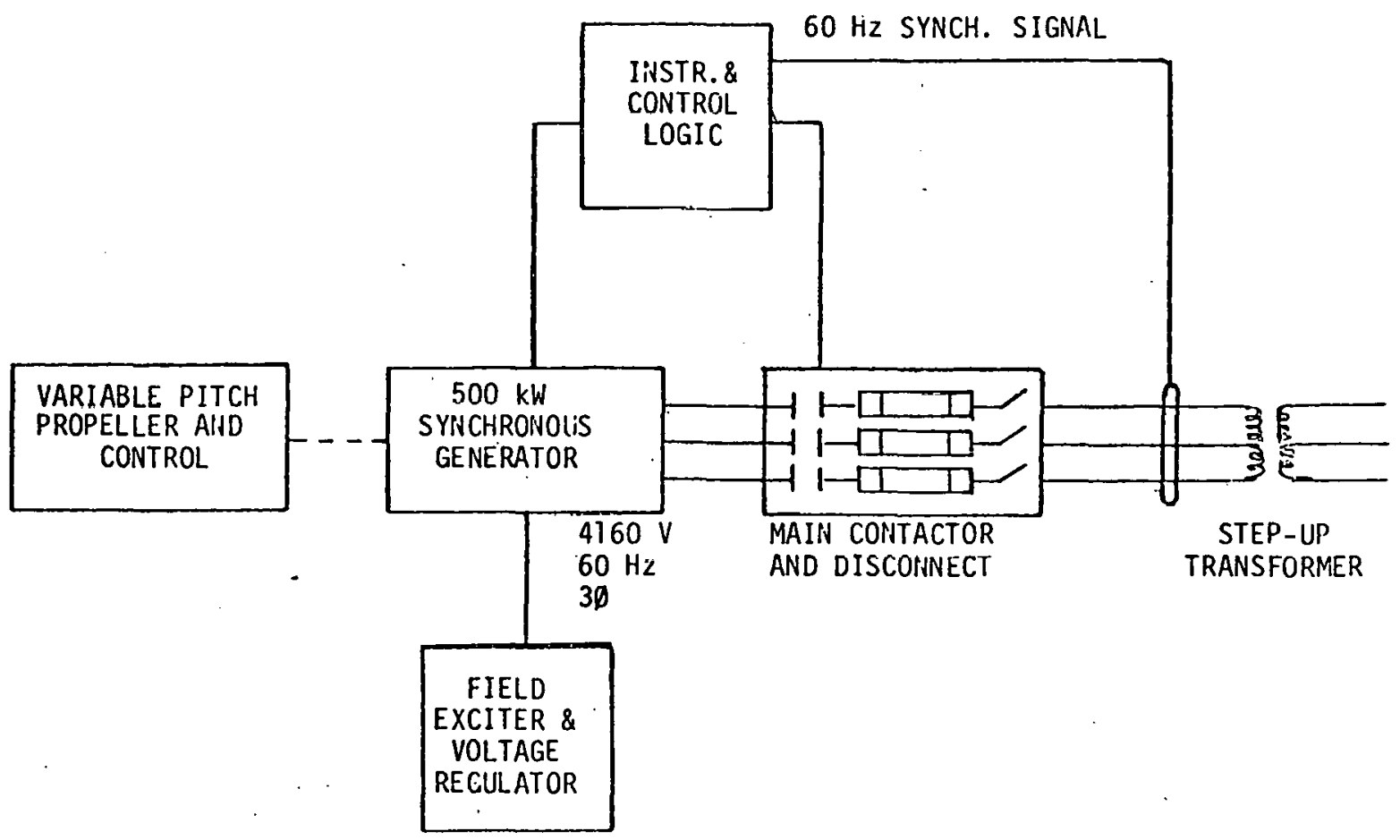

FIGURE 2.3-1. BASEL INE 500 MW WINO ENERGY CONVERSION SYSTEM BLOCK DIAGRAM 


\subsubsection{OVERALL WIND CONVERSION SYSTEM OPERATION}

WTG system output was assumed to be alternating current electric power, as discussed in earlier sections.

The same wind site locations were used as for the residential and utility applications. Principal parameters of interest are given in Table 2.3-1 for the $500 \mathrm{~kW}$ machine operating in the selected wind regimes.

TABLE 2.3- 1. $500 \mathrm{~kW}$ WIN D GENERATOR SYSTEM CHARACTER ISTICS ${ }^{1,12}$

\begin{tabular}{|l|l|}
\hline Rated Power & $500 \mathrm{~kW}$ \\
Design Wind Velocity & $5.36 \mathrm{~m} / \mathrm{s}(12 \mathrm{MPH})$ \\
Generator Parameters & $\begin{array}{l}\text { Synchronous, 500 kW, 4160 VAC, } \\
60 \mathrm{~Hz}, 3-\mathrm{Phase}, 1800 \mathrm{RPM}\end{array}$ \\
$2-B 1 \mathrm{ade}, 29.3 \mathrm{RPM}$ \\
Rotor & $55.29 \mathrm{~m}(181 \mathrm{ft})$ \\
Rotor Diameter & $42.9 \mathrm{~m}(141 \mathrm{ft})$ \\
Rotor Axis Height & \\
Wịnd Velocities & $3.55 \mathrm{~m} / \mathrm{s}(7.94 \mathrm{MPH})$ \\
$\quad$ Cut-in & $7.32 \mathrm{~m} / \mathrm{s}(16.37 \mathrm{MPH})$ \\
Rated & $15.7 \mathrm{~m} / \mathrm{s}(35.12 \mathrm{MPH})$ \\
Cut-out & $1.86 \times 10^{6} \mathrm{kWh}$ \\
Annual Energy Production & \\
\hline
\end{tabular}

\subsubsection{STORAGE SYSTEM INTEGRATION AND INTERCONNECTIOH TO THE WIND ENERGY CONVERSION SYSTEM}

The internediate applications for wind energy conversion and storage systems will require physical, electrical and operational approaches which relate to 
those aiready described for the utility and residential usages. The principal determining factor will be one of application scale. In some cases, a hybrid situation would be appropriate. The principal matter of concern here, however, was whether hardware or other technical barriers could be expected, unique to the intermediate application,which would prevent satisfactory system integration using various storage concepts.

No major new equipment constraints were identified with the intermediate system, although a range of component sizes will be needed. General technical considerations relating to installation and use will be quite different in some respects. Examples of these include:

1. Compatible adjacent location of WTG units .

2. Compatible locations for storage units.

3. Planning, design and/or modifications of plant or facility layouts to accommodate interconnection with utility power.

Some non-technical considerations will also be very significant in certain applications:

1. The management of the additional facilities and equipment pose additional responsibilities for owners and operators. A particular case in point would be that of a shopping center having general management by the ownership and individual billing or allocation of costs to each business enterprise within the complex.

2. Negotiation of service contracts with local service organization.

3. Negotiation of rates with the area utility company. 
Thes? examples of other problems are cited here as a reminder that the technical designs are still highly dependent on other operational questions. On the surface the latter may appear simple, but in reality, they may not be easily resolved. This class of implementation constraint should not be overlooked.

The previous discussion of utility and residential concept technical interface issues are generally applicable to the intermediate application situation. No additional problems should be encountered as a result of intermediate sizing provided suitable system scaling is employed. 


\section{SECTION 3}

\section{WIND ENERGY STORAGE ASSESSMENT}

\subsection{GENERAL}

This portion of the study was directed at determination of appropriate cost goals for the effective use of energy storage with wind energy conversion systems. Appiications of energy storage to systems sized for residential, intermediate and utility use were considered. The economic benefit from storage for the utility case includes both net fuel cost savings and credits derived from reduced requirements for conventional generating equipment and for transmission and distribution facilities. For the residential and intermediate cases, the principal economic benefit defined was the potential saving in the consumer's cost of electricity, although other less tangible benefits were considered. As part of the basic benefits analysis, it was also desired to determine the effects of the following factors relative to storage capacity and cost goàls:

1. Location/Wind Regime

2. Effect of various rates of fuel escalations and general inflation

3. Storage system efficiency

4. Peiletration of wind energy relative to total system capacity. (Utility case only)

The following special cases were also investigated:

1. Multiple source charging

2. Effect of transient wind system output smoothing.

The results of these investigations were translated into summary curves for use in relating a range of alternative conditions to the effect on allowable break-even capital cost and optimum storage capacity. Further conclusions 
were drawn concerning economic viability of various storage methods, which in turn were used to refine the results of initial program evaluations of various storage concepts.

\subsection{METHOD OF ANALYSIS}

\subsubsection{UTILITY APPLICATIONS}

Several possible approaches were considered as a means of projecting the value of adding storage to a wind system. It was decided for the purposes of this study, to measure the value increase when various levels of storage were added to a specific no-storage baseline system. This method inherently results in maximizing the amount which a utility might be willing to pay for dedicated storage, since none of the storage benefit is used to increase the worth of the basic wind generation. The potential for the storage system to aid overall wind system viability is then assessed in the light of cost goals derived for storage on its own merits.

\subsubsection{Basic Procedure.}

The following comprise the general steps involved in this portion of the Study:

1. Wind turbine power output was computed for Great Falls, Montana, Lubbock, Texas and Blue Hill (Boston) Mass. Actual hour by hour wind velocities were obtained for these locations from a recently prepared tape made available by SANDIA Laboratories. ${ }^{20}$ The computations matched the wind velocities to the machine design characteristics for a $1500 \mathrm{~kW}$ wind turbine generator providing ac power output. 
2. A representative utility system hourly load profile was compiled based on Representative System " $B$ " defined in a recent study by Public Service Electric and Gas Company of Newark, N.J. (PSE\&G). ${ }^{21}$ As System "B" is more representative of summer peaking systems, Representative System "B'" was selected for a winter-peaking case (Great Falls). Seasonal load duration curves were used to more accurately assess loads over the entire year modeled.

3. A generalized system model was established and cost strata were assigned for energy generation by various types of equipment.

4. Computer runs were utilized to match the load with wind turbine outputs, and establish the baseline "no-storage" case fuel costs.

5. Energy storage was added and employed to reduce fuel costs, according to pre-determined energy management cycles for charging and dispatch of stored energy.

6. The amount of displaced generation (i.e., conventional utility generation supplanted by wind system output) was assessed and, in turn, the break-even costs based on fuel savings plus applicable "credits" were computed.

\subsubsection{RESIDENTIAL APPLICATIONS}

The residential analysis was necessarily different from the above although similar techniques were employed. Similarities and differences are discussed below.

\subsubsection{Basic Procedure}

1. Step one from Section 3.2.1.1 above was followed except that a single $10 \mathrm{~kW}$ wind turbine generator was uttlized. 
2. Representative residential loads were selected for use with each of the same three locations.

3. Computer runs were made to match the wind turbine output energy to the load on an hour by hour basis for a one-year period. Required utility energy purchases were computed for this time period.

4. Energy storage was added and used to store wind turbine excess energy for later use. New values of required utility purchased energy were computed.

5. Residential break-even costs were computed based on the reduction in purchased energy due to use of storage. Analysis was performed for each location and case variation of interest.

\subsubsection{INTERMEDIATE APPLICATIONS}

The intermediate application analysis method was slmildr lo the one uscd for the residence case, but with the following modifications.

1. A single $500 \mathrm{~kW}$ wind turbine was utilized.

2. A load profile was assumed based on a shopping center type of operation with fixed hours and a stable load pattern.

3. The effects of a sizeable increase or decrease in load were examined to provide results analogous to the utility penetration effect. 


\subsection{ANALYSIS AND PROJECTION OF COST GOALS IN UTILITY APPLICATIONS}

\subsubsection{EHERGY MANAGEMENT}

\subsubsection{Allocation of Wind System Energy Contribution}

For the utility case it can be shown that a very high percentage of any wind energy system output can be immediately and directly used on line by the utility. This is so in part because of the fact that the total utility load is projected as being much larger than the wind system output, thus eliminating most of the "excess" that would be experienced in a case where the load was smaller than the wind system output. The possibility of enhancing the value of wind energy by using storage depends, in the utility case, on being able to employ energy sturage at times wien the wind system output, even if it could be used by the load, would be of relatively low value to the utility. Figure 3.3-1 illustrates the desired "relocation" of wind energy from off-peak to peak load times when it will have more value to the utility in terms of cost-of-generation.
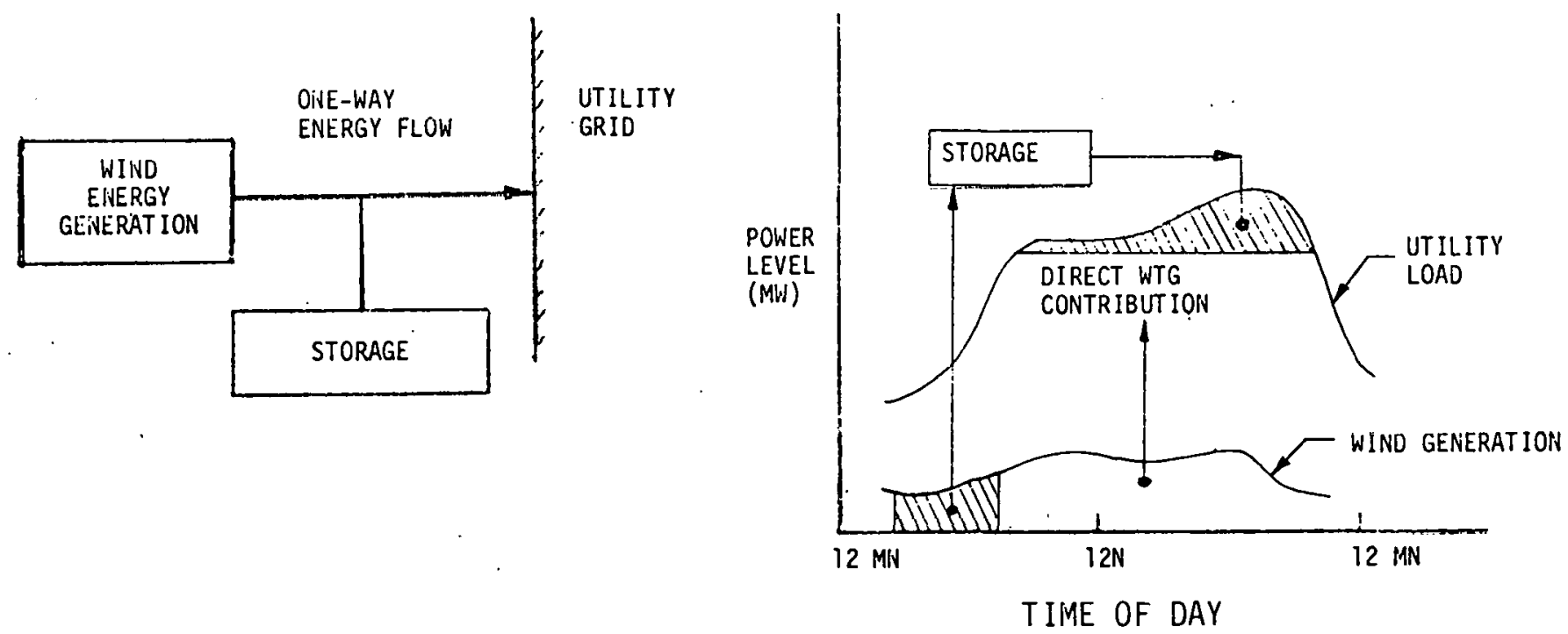

FIGURE 3.3-1. WIND ENERGY WITH DEDICATED ENERGY STORAGE FOR UTILITY APPL.ICATIONS 
It is also significant to point out the one-way nature of the power flow to the utility grid, as the charging of the storage system is entirely dependent, in this case, on the wind system. As will be shown later, the effect of this arrangement is to lessen the storage utilization and in turn its value as compared with other configurations. It should also be noted that there is a large, but not total coincidence of the available wind energy with the utility peak load times. Whenever load demand matches well with wind energy availability, storage can be avoided and consequently the storage efficiency losses also. To the extent that the wind energy direct-to-load component and the stored energy contribution can be reliably delivered, both conventional generation and generation capacity may be reduced.

In terms of a utility system load duration curve as portrayed in figure 3.3-2, the economic usefulness of the wind-direct and stored contributions can be depicted within each cost-of-generation strata.

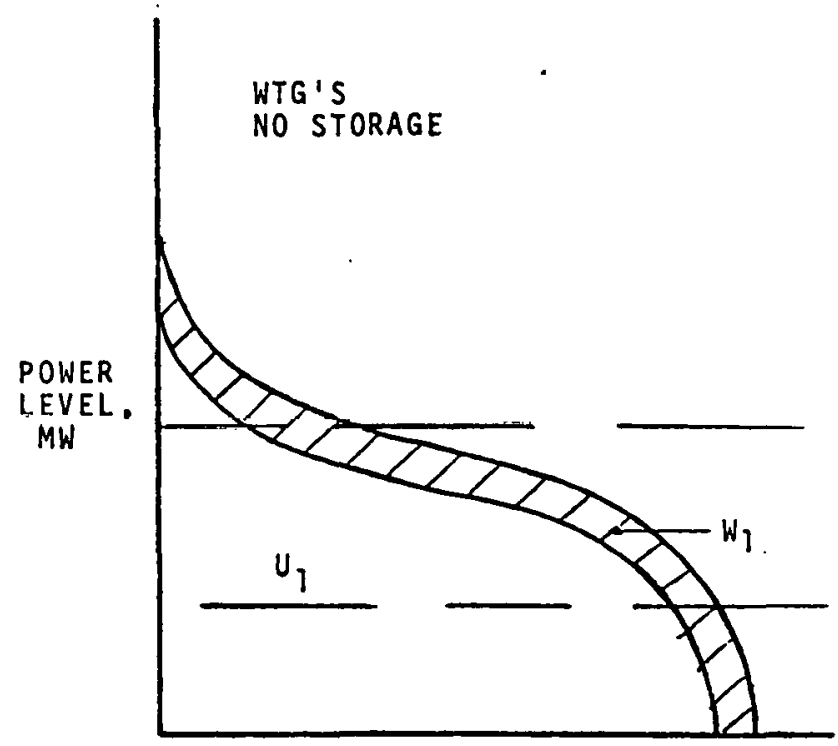

HOURS

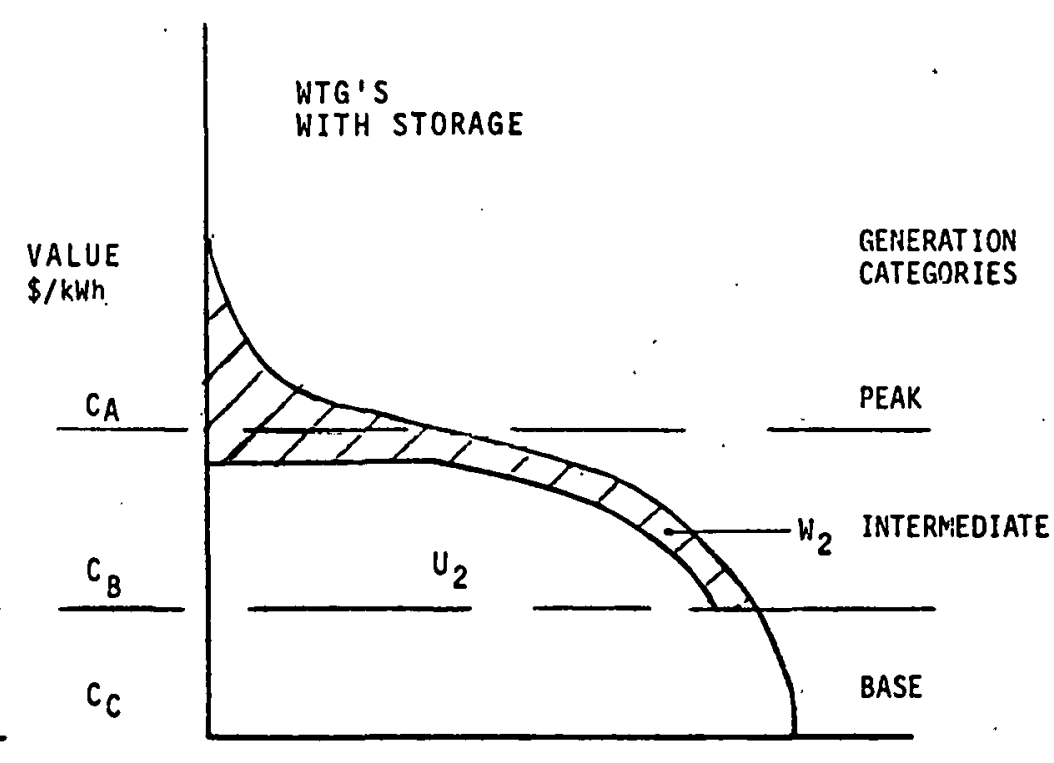

HOURS

FIGURE 3.3-2 WIND ENERGY RE-DISTRIBUTION UTILIZING ENERGY STORAGE - UTILITY APPLICATION 
Wind energy without storage may be contributed in either the peak, intermediate or base generation portions of the load duration curve, or may be spread throughout (as shown) depending on the time of day when the wind blows. The wind contribution without storage couid be concentrated in only one region of the load duration curve, but this would be unlikely based on examination of representative wind distribution patterns. Storage can be used to re-arrange a portion of the wind energy to the peak and/or intermediate regions while reducing or eliminating contributions in the base load region. Since the total external load on the utility grid is unchanged by the source of the energy contributions, for any one region:

$$
\begin{aligned}
& U_{1}+W_{1}=U_{2}+W_{2} \\
& \Delta \cos t=C\left(U_{1}-U_{2}\right)=C\left(W_{2}-W_{1}\right)
\end{aligned}
$$

where

$$
\begin{aligned}
U_{2}, U_{1}= & \text { utility contribution to load with and without storage } \\
w_{2}, w_{1}= & \begin{array}{l}
\text { wind system energy contribution to load with and without } \\
\text { storage }
\end{array} \\
C= & \text { incremental cost of generation per unit load (e.g. } \$ / \mathrm{kWh})
\end{aligned}
$$

Summing the $\Delta$ cost for all regions yields the total equivalent fuel saving benefit of adding storage to the wind system. In the base-load region, the value goes negative and must be subtracted. This is because the utility must now deliver more energy in the base load region, since the wind energy contribution has been "relocated" to the higher cost regions.

The above described generation cost saving can be easily capitalized to determine the maximum amount one would be willing to pay for a storage system based on fuel savings alone. 


\subsubsection{Theoretical Maximum Value of Storage - Utility Application}

Computation of the theoretical maximum value or worth of energy storage is a reiatively simple task with a very useful output - a standard against which the effectiveness of storage operational strategies can be measured. The theoretical maximum value is identical for dedicated and multi-source charging, the former merely falls much shorter of the maximum due to the variability of the wind. Assume 1 kilowatt-hour of storage capacity with an overall input-output efficiency of $\eta$. Let:

$$
\begin{aligned}
V_{p} & =\text { value or incremental cost of peaking energy }-\$ / \mathrm{kWh} \\
V_{b} & =\text { value or incremental cost of base load energy }-\$ / \mathrm{kWh} \\
N & =\text { number of storage cycles per year } \\
F C R & =\text { fixed charge rate } \\
M_{f} & =\text { fuel savings multiplier }
\end{aligned}
$$

Maximum value per cycle is achieved when energy is stored at the lowest value (base load) and discharged when energy is most costly (peaking). The energy cost savings $\left(A_{E}\right)$ for full capacity operation becomes simply:

$$
A_{E}=N\left(V_{p}-V_{b} / \eta\right)
$$

Levelizing with the fuel multiplier and dividing by FCR to capitalize yields:

$$
\begin{aligned}
& \text { Capitalized Energy Credit (Value of storage as an energy saver) } \\
& \qquad C_{E}=M_{f} N\left(V_{p}-V_{b} / \eta\right) / F C R \quad \$ / k W h
\end{aligned}
$$

Figure 3.3-3 presents $C_{E}$ versus the incremental costs of base load and peaking energy for storage efficiency of $75 \%$, fixed charge rate of .18 and 250 annual operational cycles. The latter figure is a typical annual business 


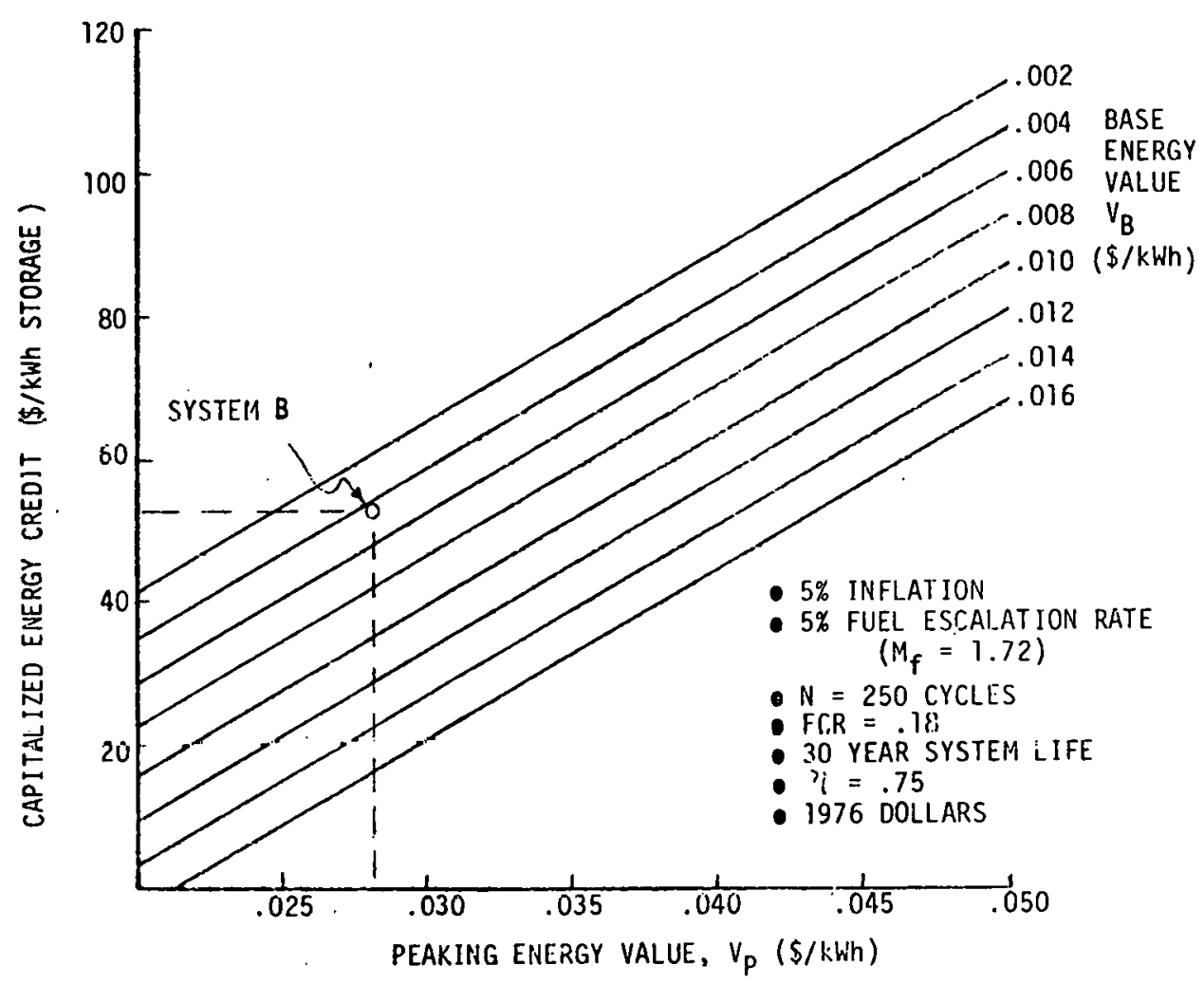

FIGURE 3.3-3. THEORETICAL MAXIMUM ENERGY CREDIT FOR STORAGE-UTILITY APPLICATION

day figure when allowances are made for weekends and holidays. Inflation and fuel price escalation rates of $5 \%$ correspond to zero differential fuel price escalation. Shown on the curve is the theoretical maximum energy credit for the representative utility system "B" cited earlier in this report. Comparison of the theoretical maximum for another set of utility costs with the cost computed with rates assumed for this study and the system "B" load (point shown in Figure 3.3-3) will enable a rough extrapolation of the report results to the other utility system. It is obvious from Figure 3.3-3 that the energy credit is a strong function of the system energy cost characteristics. 
Capacity credit and transmission and distribution credit, where applicable, must be added to the capitalized energy credit to obtain the total storage break-even cost. For example, taking capacity credit of $140 \$ / \mathrm{kW}$ for assumed gas turbine displacement and a T\&D credit of $45 \$ / \mathrm{kW}$ (for battery systems only) gives the following theoretical maximum break-even cost results for a system "B" type load:

\begin{tabular}{|c|c|c|}
\hline & $\begin{array}{l}5 \text { Hour } \\
\text { System }\end{array}$ & $\begin{array}{l}10 \text { Hour } \\
\text { System }\end{array}$ \\
\hline $\begin{array}{l}\text { Energy Credit } \\
\text { Capacity Credit } \\
\text { T\&D Credit (Batteries only) }\end{array}$ & $\begin{array}{r}\$ 53.35 \\
28.00 \\
9.00 \\
\end{array}$ & $\begin{array}{r}\$ 53.35 \\
14.00 \\
4.50 \\
\end{array}$ \\
\hline $\begin{array}{l}\text { Break-even Costs (except batteries) } \\
\text { Break-even Costs (batteries) }\end{array}$ & $\begin{array}{l}\$ 81.35 \\
\$ 90.35\end{array}$ & $\begin{array}{l}\$ 67.35 \\
\$ 71.85\end{array}$ \\
\hline
\end{tabular}

These represent the maximum storage break-even costs for a $5 \%$ energy price escalation rate. Figure 3.3-4 can be easily used to extrapolate the energy credit portion of the above break-even costs to other escalation rates and various start years.

For example, a 1988 start with $8 \%$ escalation gives about 2.0 times the levelized energy savings of the base $5 \%$ case. Maximum break-even cost for a 5 hour battery would then become (using the same credits):

Energy Credit

Capacity Credit

T\&D Credit

$$
\begin{array}{r}
\$ 106.70 \\
28.00 \\
9.00 \\
\$ 143.70 \text { / kWh }
\end{array}
$$

This represented a $59 \%$ increase in break-even cost over the base $5 \%$ escalation case. 


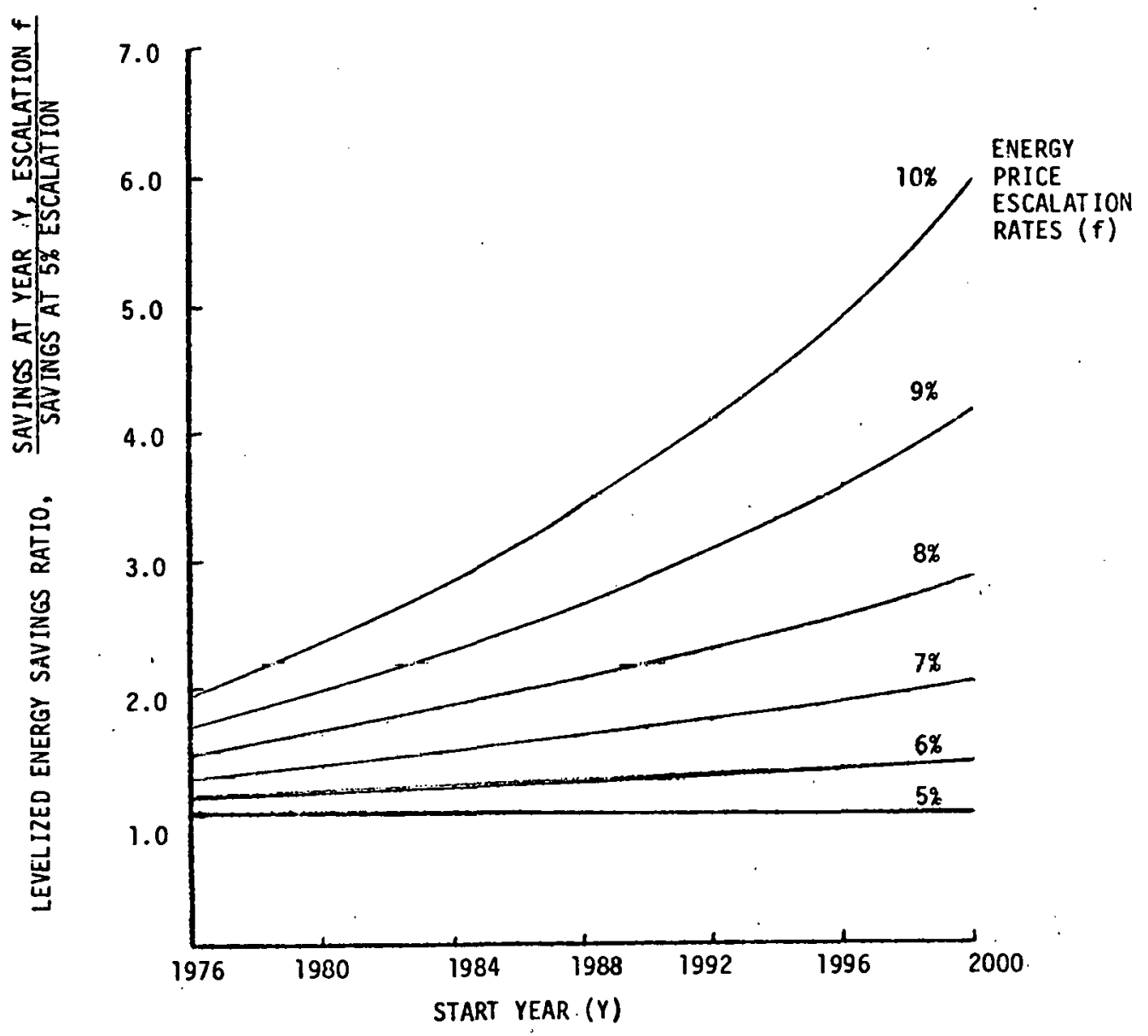

FIGURE 3.3-4. EFFECTS OF START YEAR AND ENERGY PRICE ESCALATION RATE ON LEVELIZED ENERGY SAVINGS-UTILITY APPLICATION.

Practical Limits to Storage Value

There are several reasons why the theoretical maximum energy credit cannot be achieved in practice. Operation and maintenance requirements, component replacement costs and interest during construction must be considered. These factors are concept-dependent and, for some systems, substantialiy affect the net savings. System efficiency varies among concepts. The principal limitation on energy credit, however, is that only at very small storage sizes can energy be continually moved from the lowest cost level(base load) to the 
highest level (peaking). U tility system " $B$ "loads, used in the majority of the utility analysis in this report, has four main levels of generation costs, to which the following values were assigned:

$$
\text { Level Incremental cost }
$$

$\begin{array}{lll}\text { A } & .0281 \quad \$ / k W h & \begin{array}{l}\text { More discussion } \\ \text { B }\end{array} \\ C & .0215 & \text { of this subject } \\ \text { D } & .0120 & \text { will be found in } \\ \text { Section 3.3-4. }\end{array}$

The savings in moving a kilowatt hour from one level to another was shown in the previous section to be equal to:

Savings per cycle; $S_{c}=V_{\text {discharge }}-\frac{V_{\text {charge }}}{\text { Efficiency }}$ where

$V_{\text {discharge }}$ and $V_{\text {charge }}$ are values or incremental costs at the levels of discharge and charge respectively. Using the costs assigned, $\mathrm{S}_{\mathrm{C}}$ can be calculated for exchange between any two levels: (o 75\% efficiency).

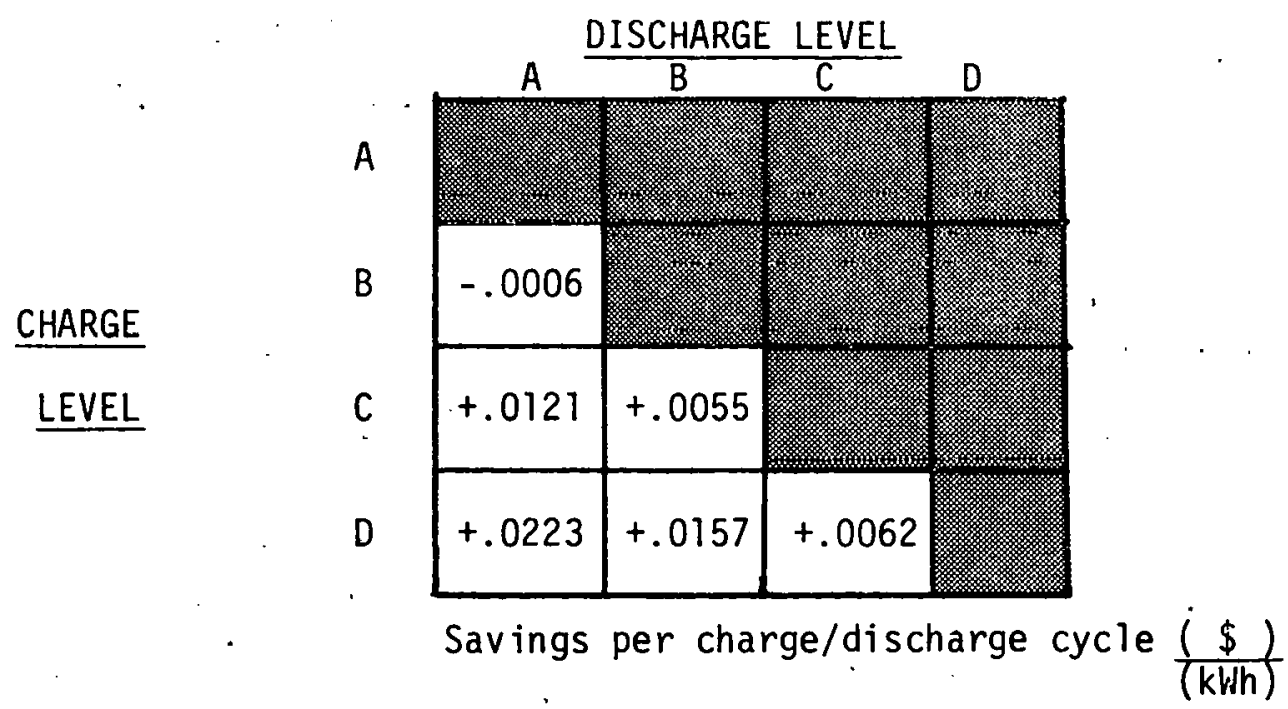

Note that discharge to a level at or above the charge level was eliminated 
and, in addition, transfer from level $B$ to level. A proved uneconomic. The rapid fall off in value when a level $D$ to level A transfer cannot be made is evident. A level $D$ to $B$ transfer is worth $30 \%$ less and a leve $C$ to $A$ about $46 \%$ less.

The characteristics of system " $B$ " demonstrate the typical manner in which storage value falls off as size is increased:

1. For a small amount of storage (less than $100 \mathrm{MWh}$ for this example) the storage can cycle year round between levels $D$ and $A$, and thus closely achieve maximum value.

2. As storage size is increased, the spring and fall peaks are eliminated and additional storage energy is forced to transfer to level $B$.

3. A further increase in size will eliminate the winter peaks, resulting in more level $D$ to level $B$ transfer.

4. At some level of storage size, the capacity for base load charging is depleted and level $C$ must be used (or costs must be incurred to increase base load charging capacity). Level $C$ can discharge to the peaking or "A" level only in the summer and is forced to displace $B$ level energy the remainder of the year which provides a very low storage benefit.

A winter peaking utility system would see a similar pattern. Some utility characteristics may result in depletion of base load charging ability before peaks are eliminated, but the net effect is identical - a steady decrease in storage value per kilowatt-hour as storage size is increased.

This does not say that low storage size is most economic. Net savings, considering the actual cost of storage, will determine optimum economic storage size. Once storage is economic, further cost reductions increase the optimum size of storage in terms of MWh capacity. 


\subsubsection{WIND ENERGY AVAILABILITY AND CONVERSION}

\subsubsection{Wind Energy Patterns}

Prior studies of wind characteristics including velocities, variability and cyclic modes have resulted in a much clearer understanding of some of the key factors which need to be dealt with in harnessing this source of energy. Since the power available from the wind has a direct cube function relationship to velocity $\left(P=1 / 2 \rho v^{3}\right)$, geographic site selection is of importance. In addition, some cyclic general patterns of wind behavior have been defined. These relate primarily to daily, seasonal, and annual or long term variations. Since the timing of wind energy availability is critical to the optimum use and/or storage of such energy, the general trends in wind behavior should be kept in mind. Figures 3.3-5 and 3.3-6 present some previously identified diurnal and seasonal patterns. ${ }^{12}$ Wind regimes are identified as high, moderate and low. These categories are further defined in Figure 3.3-7. 


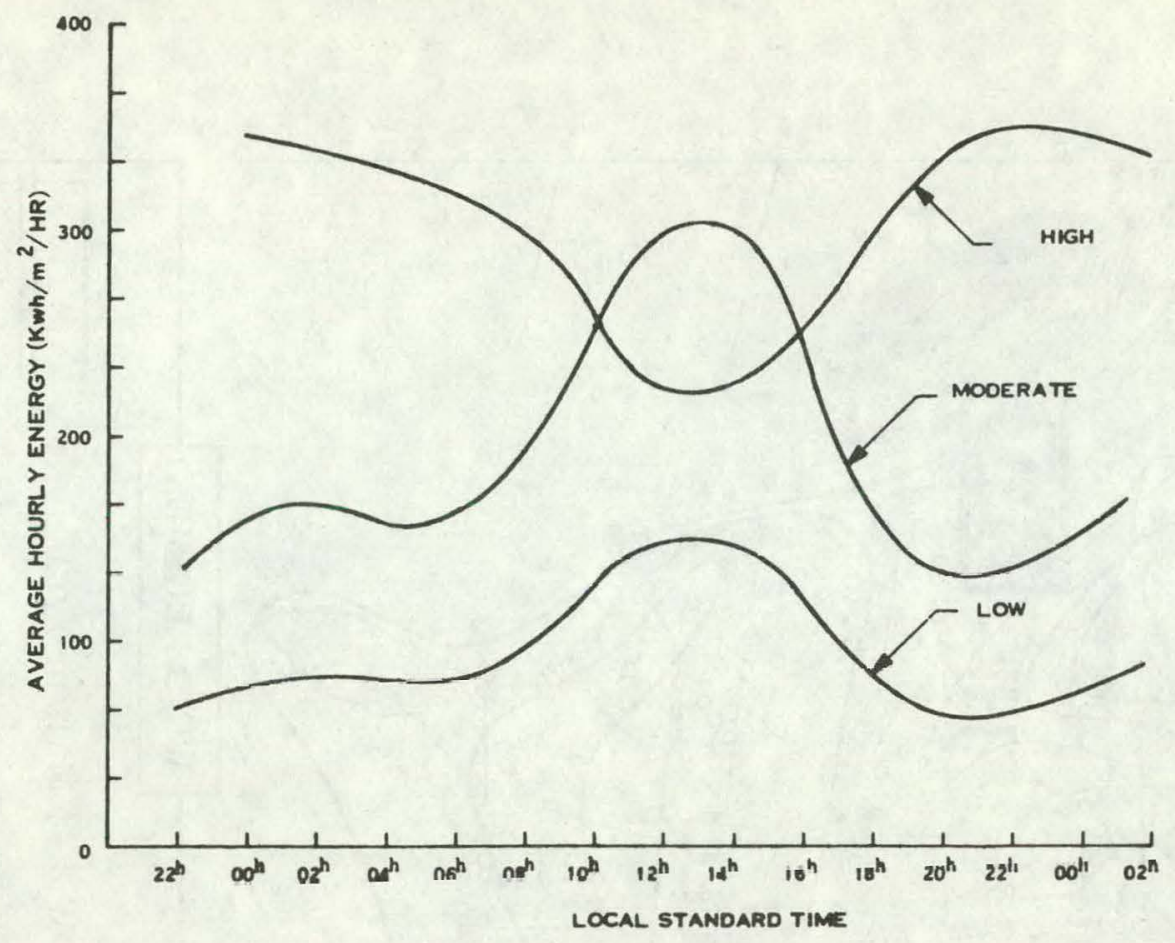

FIGURE 3.3-5. DIURNAL VARIATION MODEL OF WIND ENERGY IN THE THREE FAVORABLE WIND REGIMES

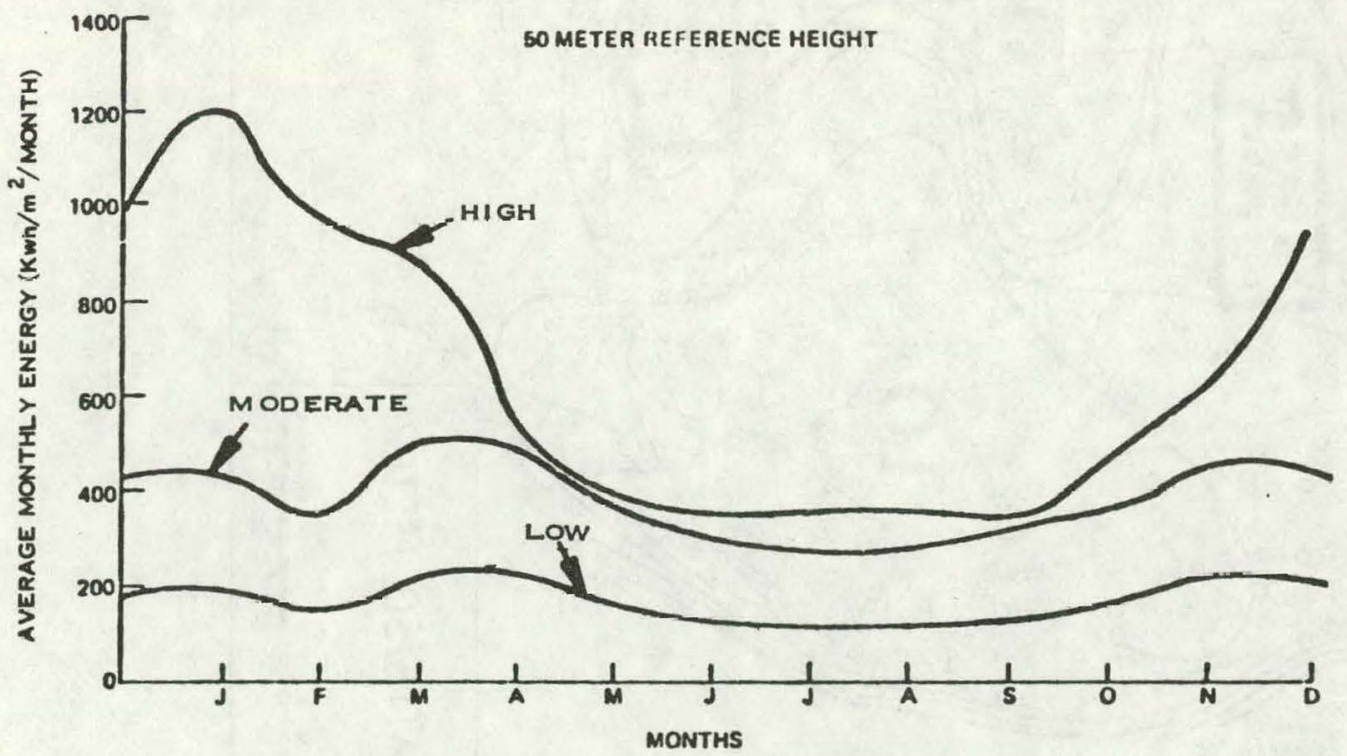

FIGLIRE 3.3-6. SEASONAL VARIATIONS MODEL OF WIND ENERGY IN THE FAVORABLE WIND REGIMES 


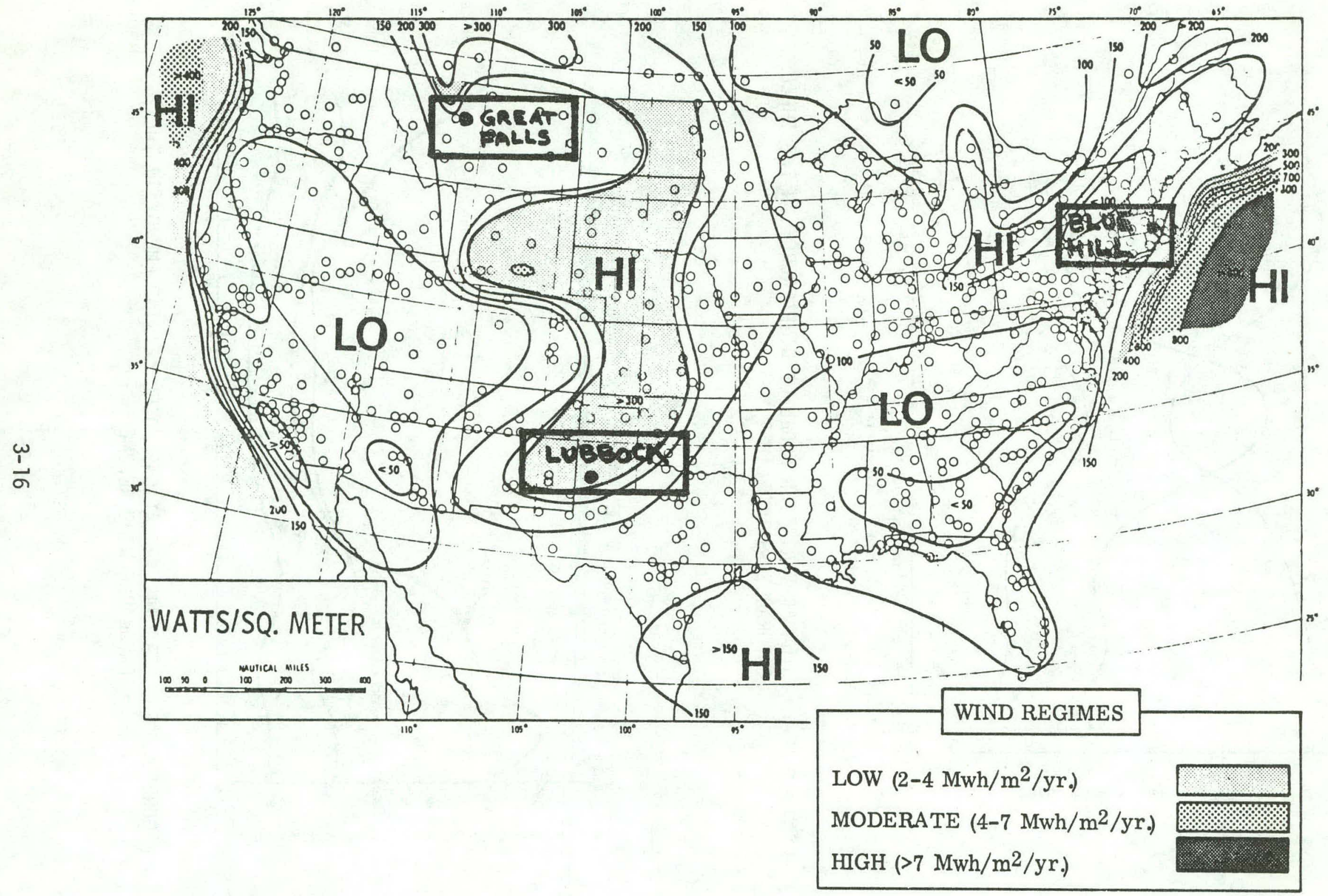

FIGURE 3.3-7. WIND DATA SITES VS. REGIONAL WIND REGIMES (AFTER REED22) 
As can be noted from the preceding figures, there are tendencies for higher wind outputs during mid-day in the moderate and low wind regimes which comprise most of the geographic land area of the United States. Also, there are seasonal lows, notably in summer months. The general impact of the foregoing on the use of energy storage are:

1. Most wind energy may be available at times of day when present consumer loads make direct use, rather than storage, both feasible and desirable.

2. The seasonal lows make the concept of long term, large quantity storage of energy appear attractive.

An additional wind characteristic not shown here, but one which will be discussed in a subsequent section, is short term variability. This characteristic can result in large increases or decreases in the power available to drive a wind turbine rotor, and necessitates consideration of energy storage device ability to follow. WTG output variations.

\subsubsection{Selection of Data Sites}

For purposes of assuming a representative range of conditions under which storage might be attractive, data was selected from three different locations. Each location was to be representative of different climate, terrain, wind conditions, geographic region and costs of fuel and electricity. Recent work by SANDIA Laboratories resulted in an hour-by-hour data tape containing pertinent wind information for some 19 sites. Thesc tapes were made available for this study and were found to contain the needed information. Useful information on the data tape included mean wind speed, tower height, latitude, temperature and air density. The variable items in this list were given for each hour for a full year (1962). Data for Lubbock, Tx., 
Great Falls, Mt., and Blue Hill, Ma. was selected for use in response to the range of representation described above. Figure 3.3-7 shows the selected locations relative to regional wind regimes defined in prior studies. 12

\subsubsection{Wind Turbine Output}

The machine design characteristics for application of a wind turbine generator are normally selected knowing the wind regime and wind velocities or wind profiles likely to be encountered for the particular site and installation. As an example, for Lubbock, Tx., a wind regime defined by previous wind area mapping as $2-4 \mathrm{MWh} / \mathrm{m}^{2} / \mathrm{Yr}$ is involved. Based on experience with ranges of wind velocity within this regime, WTG designs ${ }^{1}$ in the $12-13 \mathrm{mph}$ range are indicated. This analysis utilizes a $13 \mathrm{mph}$ design with output power characteristics as depicted in Figure 3.3-8.

To establish the annudl WTG output profile for Lubbock winds, the hour by hour annual wind velocity data for Lubbock was matched against the WTG characteristic curve. Figure 3.3-9 presents the results of this computation for Lubbock, and Figures 3.3-10 and 3.3-11 show the comparable results for Great Falls and Blue Hill, respectively. It should be noted that the figures show the cumulative hourly WTG outputs for the entire year for each of the 24 daily hours. The annual outputs for the three locations show a certain degree of correlation of daytime maximums with lower night time generation-basically the reverse of what might be desired for low-cost utility charging of storage. The daytime peaks do, however, permit more direct use of wind turbine output at utility peak load times. Great Falls and $\mathrm{Blue} \mathrm{Hill}$ are in the next higher wind regime $\left(4-7 \mathrm{MWh} / \mathrm{m}^{2} / \mathrm{Yr}\right.$ ) than Lubbock, 
and the data from these locations showed annual WTG output results about $1 \%$ and $13.5 \%$ higher, respectively.

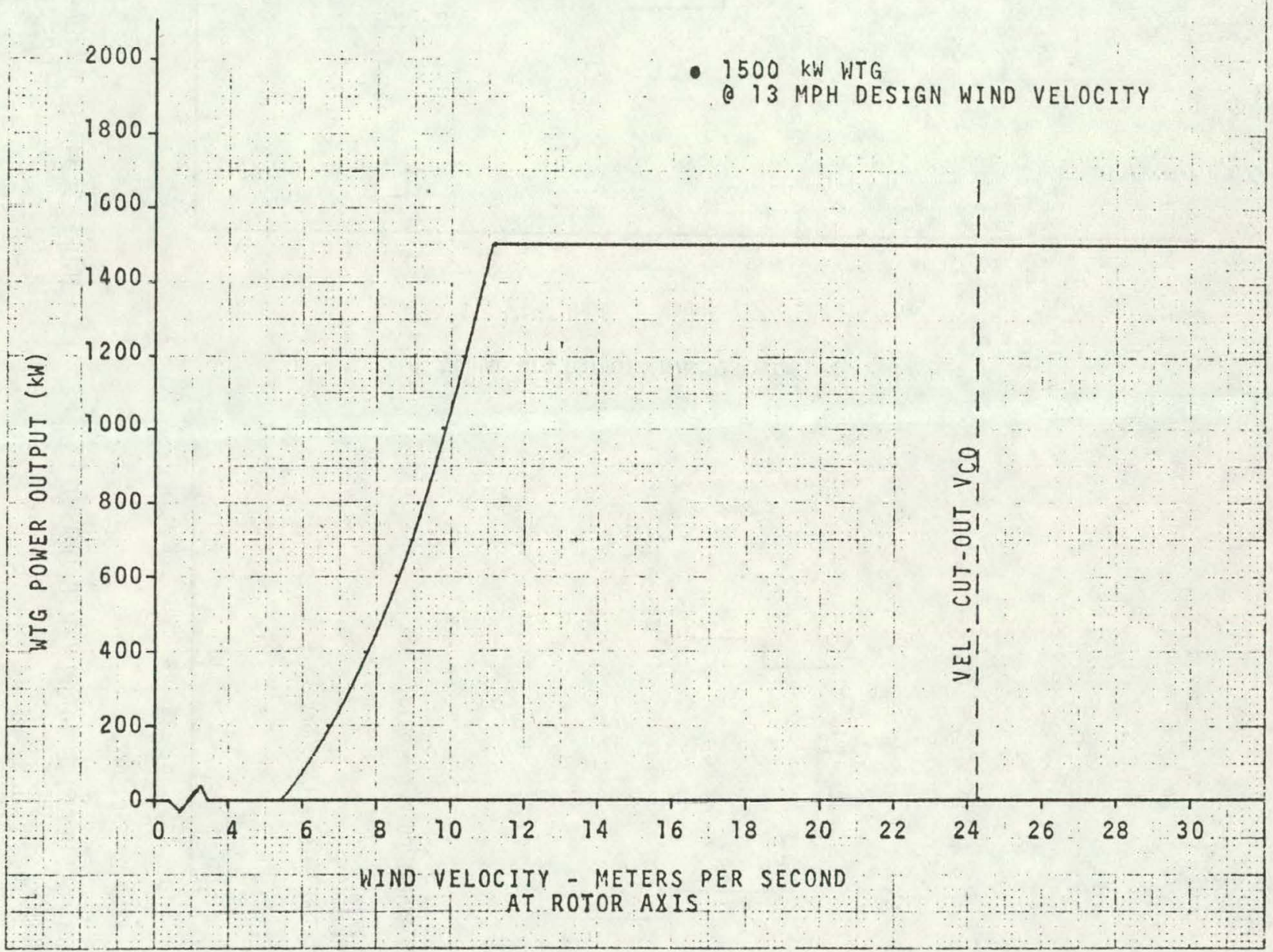

FIGURE 3.3-8 WIND TURBINE POWER OUTPUT FOR VARIOUS WIND VELOCITIES 


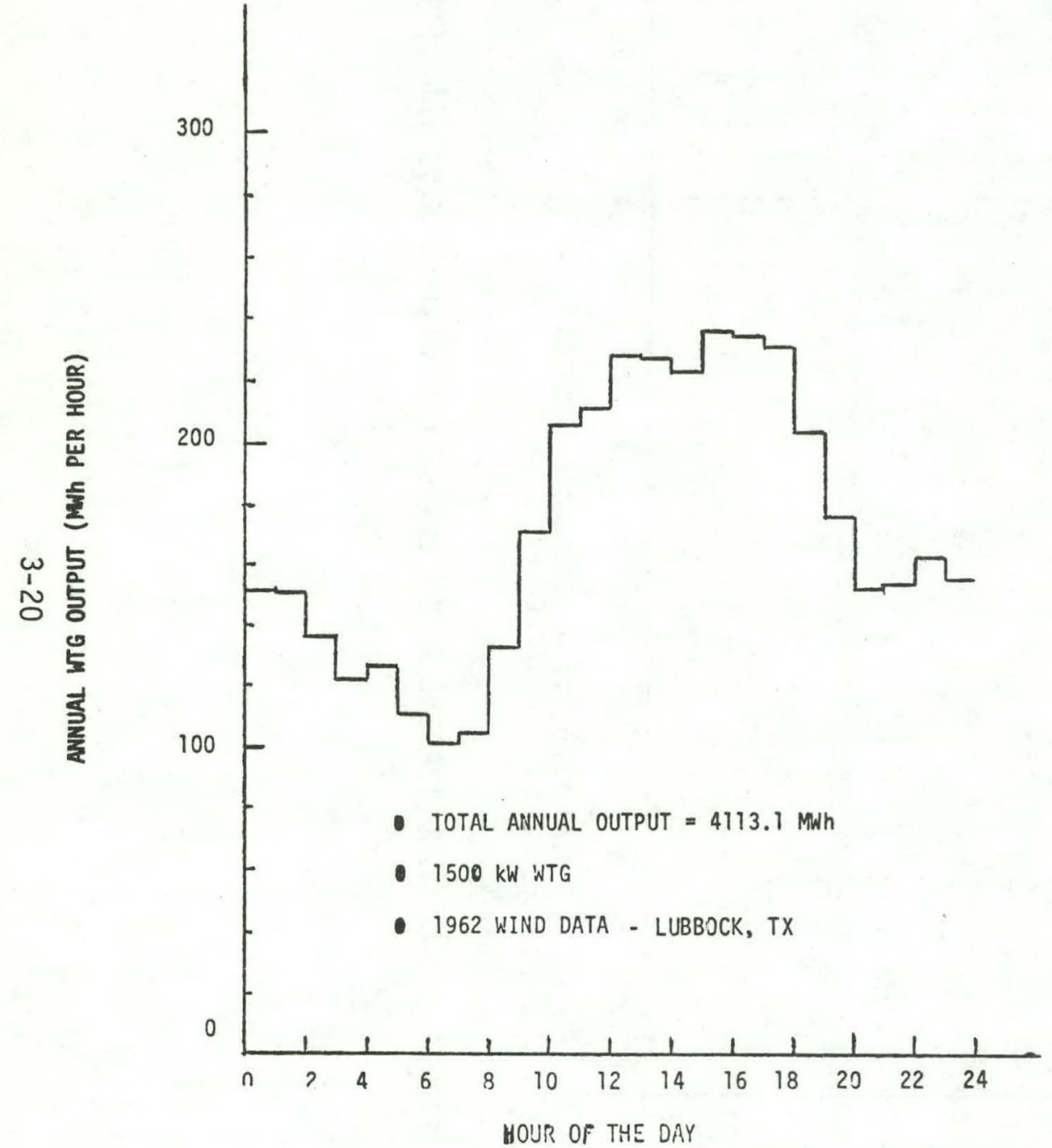

FIGURE 3.3-9. ANIUUAL CUMULATIVE HOURLY WTà OUTPUT (LUBBOCK, TX)

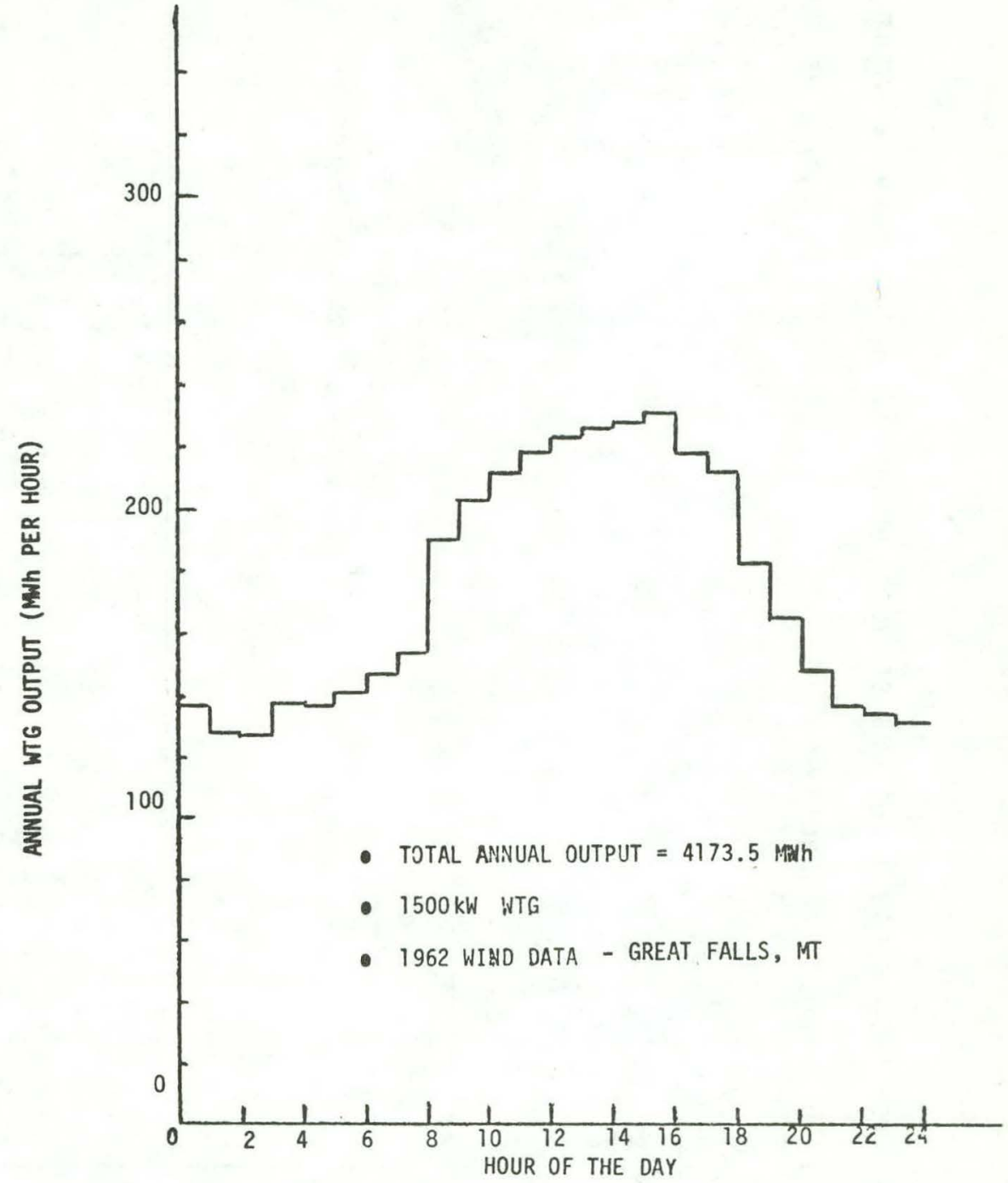

FIGURE 3.3-10. ANNUAL CUMULATIVE HOURLY WTG OUTPUT (GREAT FALLS, MT) 


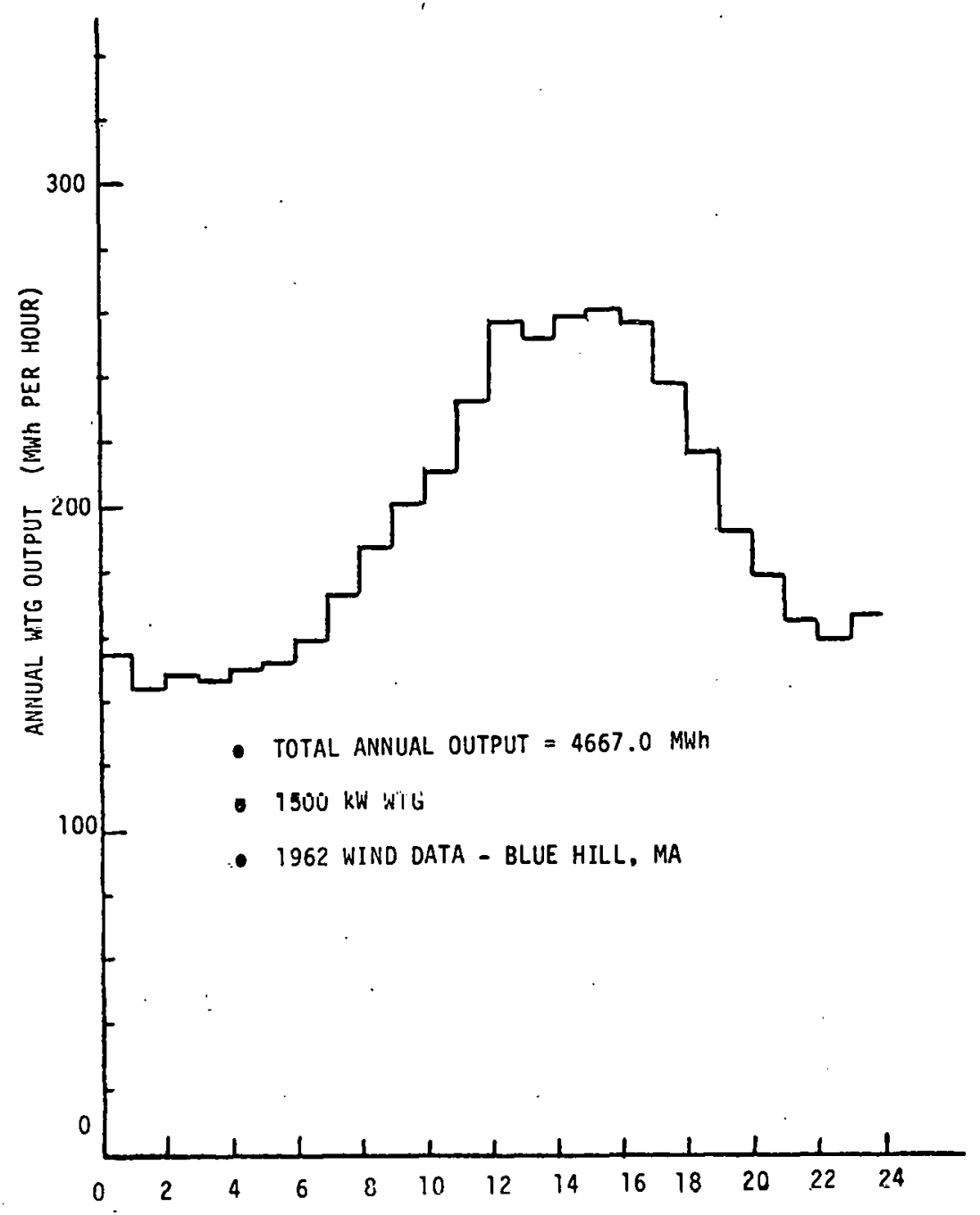

FIGURE 3.3-11 ANNUAL CUMULATIVE HOURLY WTG OUTPUT (BLUE HILL, MA.)

\subsubsection{UTILITY LOAD DEMANDS}

\subsubsection{Load Selection}

The objectives of this area of the study were directed toward the effect energy storage might have on the worth of wind supplied energy in a utility application. Consequently, it was desired to assess the effects of different parameters pertinent to wind and storage system use while serving a representative load. To accomplish the latter, system hourly load data was obtained for the most representative utility loads for summer and winter 
peaking systems. These representative systems were selected based on results of an exhaustive analysis in a recent study performed by Public Service Electric and Gas Company of Newark, N.J. ${ }^{21}$ The systems used are designated "B" and "B'"respectively. Figure 3.3-12 shows the approximate load shape of system "B" for a representative one week period, with summer load peaks superimposed.

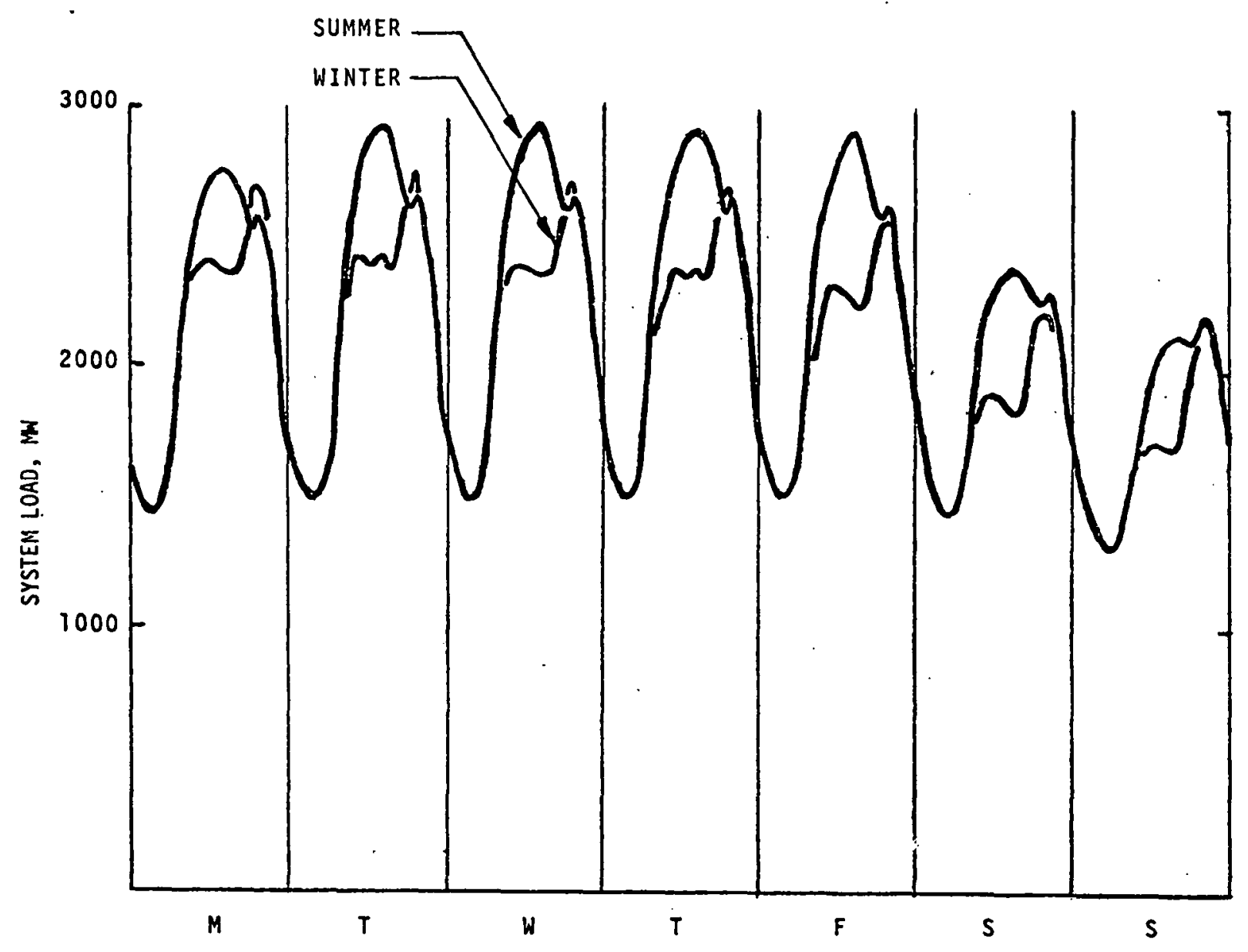

FIGURE 3.3-12 REPRESENTATIVE WEEK - SYSTEM "B" LOAD DEMAND 
Originally, it was planned to examine only one or perhaps several "representative weeks". It became obvious, however, that such an approach might leave many unanswered questions, therefore, with the help of a computer model, a full year or 8760 hours was examined with a minimum of difficulty.

\subsubsection{Load Duration Curves}

Seasonal load duration curves were plotted and examined in order to establish operating cost strata for use in further modeling. Figures 3.3-13 and 3.3-14 show the summer and winter seasonal load curves for systems "B" and "B" ", respectively.

\subsubsection{Generation Mix}

Due to the generalized results desired for the storage worth analysis, it was decided that mix of generation be considered only to the extent necessary to establish modeling assumptions. Tables 3.3-1 and 3.3-2 give the assumed generation mix and energy allocations for use with the loads typified by system "B". Note that this mix is not intended to reflect any specific current system mix but rather a possible mix which could deliver energy to meet the general load shape of the representative system. 


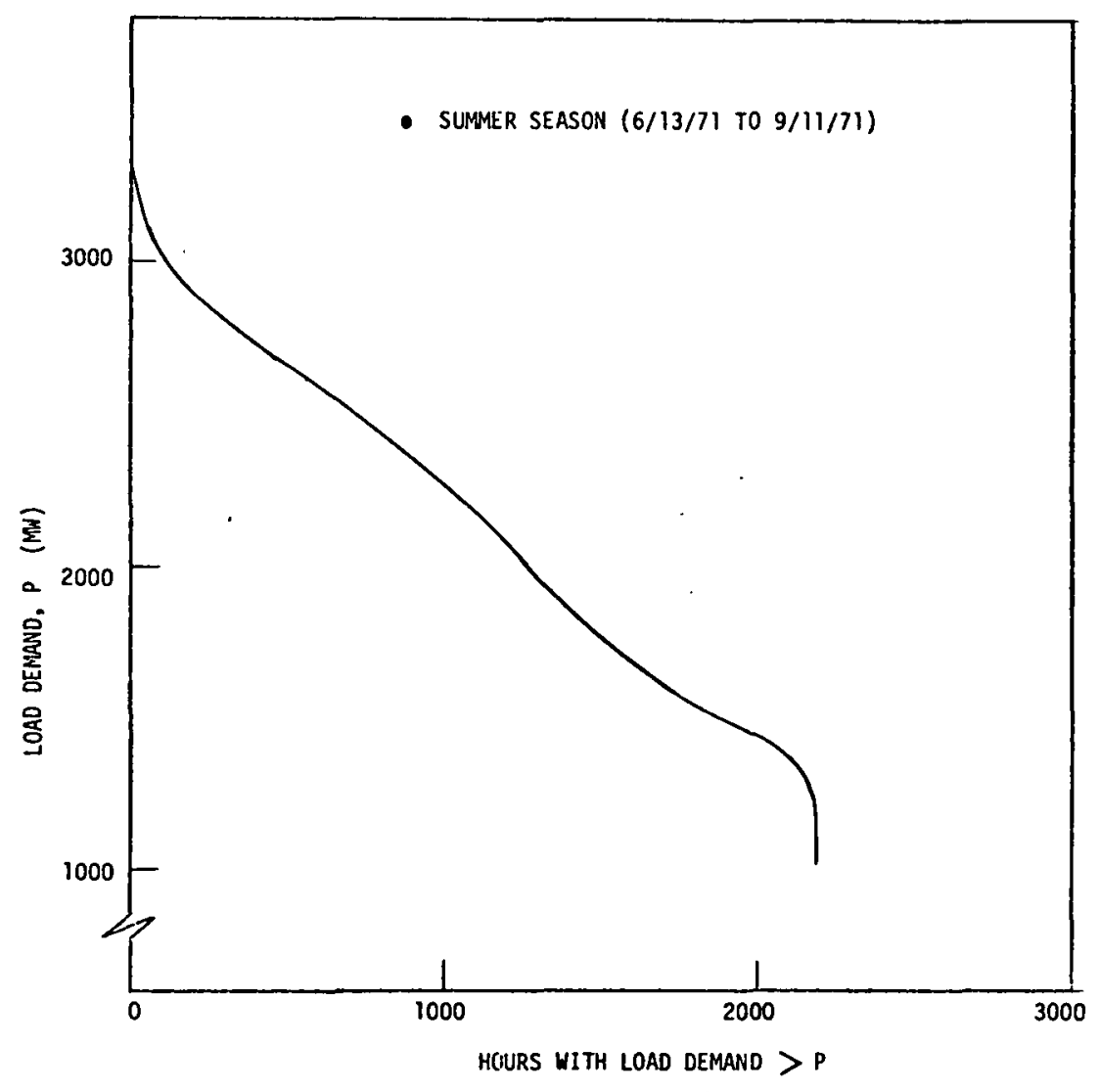

FIGURE 3.3-13. SUMMER SEASON LOAD DURATION CURVE FOR SYSTEM "B"

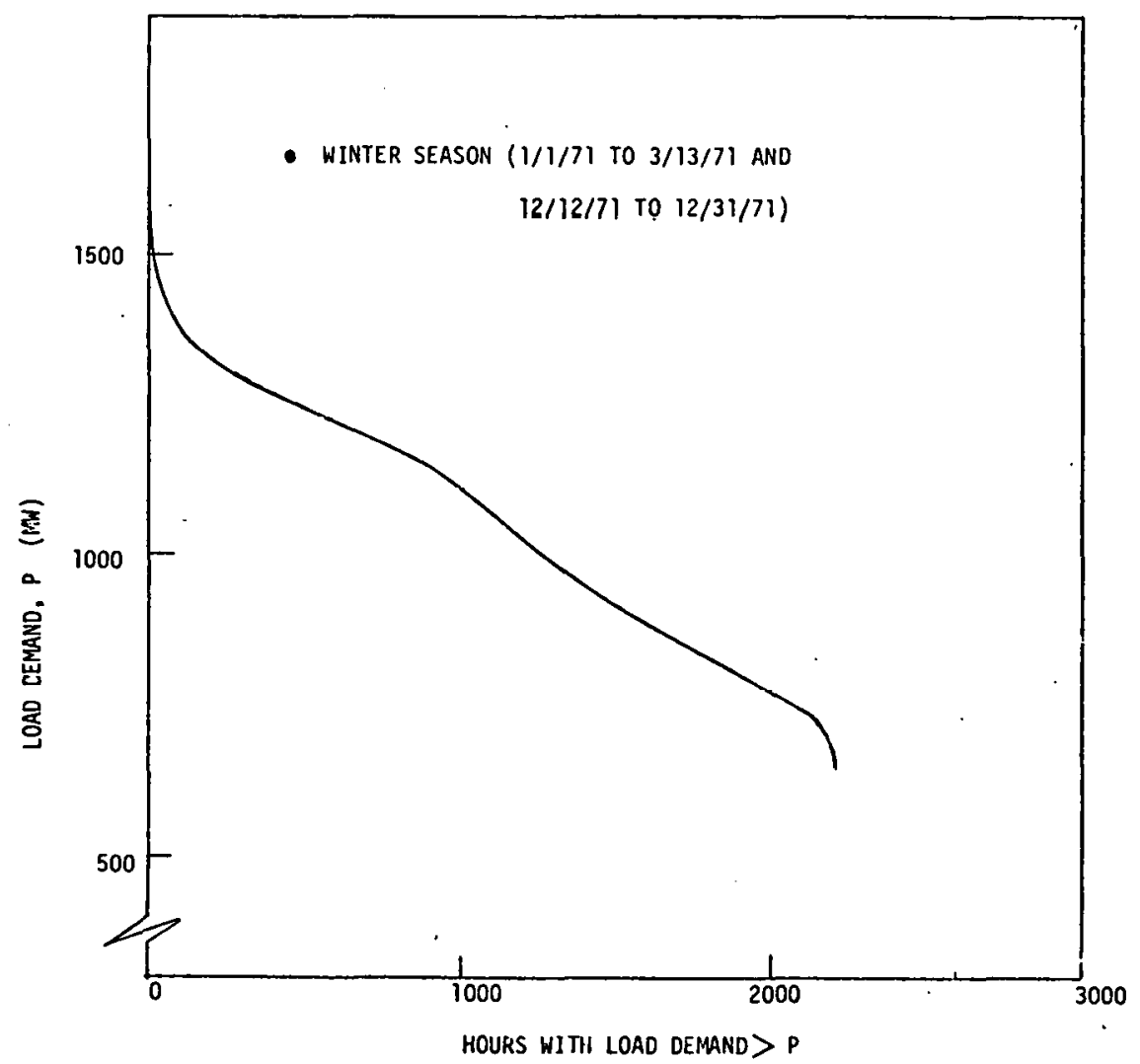

FIGURE 3.3-14. WINTER SEASON LOAD DURATION CURVE FOR SYSTEM " $B$ " 
TABLE 3.3-1 ASSUMED GENERATION MIX FOR SYSTEM "B" TYPE LOAD PROFILE

\begin{tabular}{|c|c|c|c|c|c|c|c|c|}
\hline \multirow[b]{2}{*}{$\begin{array}{l}\text { TYPE OF } \\
\text { GENERATION }\end{array}$} & \multicolumn{2}{|c|}{ WINTER } & \multicolumn{2}{|c|}{ SPRING } & \multicolumn{2}{|c|}{ SUMMER } & \multicolumn{2}{|c|}{ FALL } \\
\hline & $\begin{array}{l}\text { Cut-In } \\
\text { Load } \\
\text { Level } \\
\text { MW }\end{array}$ & $\begin{array}{c}\text { In } \\
\text { Service } \\
\text { Capability } \\
\text { MW }\end{array}$ & $\begin{array}{l}\text { Cut-In } \\
\text { Load } \\
\text { Level } \\
\text { MW }\end{array}$ & $\begin{array}{c}\text { In } \\
\text { Service } \\
\text { Capability } \\
\text { MW }\end{array}$ & $\begin{array}{l}\text { Cut-In } \\
\text { Load } \\
\text { Level } \\
\text { MW }\end{array}$ & $\begin{array}{c}\text { In } \\
\text { Service } \\
\text { Capability } \\
\text { MW }\end{array}$ & $\begin{array}{l}\text { Cut-In } \\
\text { Load } \\
\text { Level } \\
\text { MW }\end{array}$ & $\begin{array}{c}\text { In } \\
\text { Service } \\
\text { Capability } \\
\text { MW }\end{array}$ \\
\hline Gas Turbines & 2500 & 480 & 2350 & 266 & 2850 & 458 & 2650 & 780 \\
\hline $0 i 1$ - Steam & 2300 & 200 & 2200 & 150 & 2500 & 350 & 2300 & 350 \\
\hline Coal - Steam & 1900 & 400 & 1900 & 300 & 1300 & 600 & 1900 & 400 \\
\hline Nuclear - Steain & 700 & 1200 & 700 & 1200 & $? 00$ & 1200 & 700 & 1200 \\
\hline $\begin{array}{l}\text { Minimum Out- } \\
\text { Put Leve } 1\end{array}$ & 0 & 700 & 0 & 700 & 0 & 700 & 0 & 700 \\
\hline
\end{tabular}

心

TABLE 3.3-2. ENERGY ALLOCATION FOR ASSUMED GENERATION MIX SYSTEM "B" LOAD SHAPE

\begin{tabular}{|l|r|r|r|r|r|}
\hline \multirow{2}{*}{$\begin{array}{l}\text { TYPE OF } \\
\text { GENERATION }\end{array}$} & \multicolumn{5}{|c|}{ ENERGY SUPPLIED - MECAWATT HOURS } \\
\cline { 2 - 6 } GINTER Turbines & 36,882 & 19,311 & 41,203 & 45,111 & 142,507 \\
Oil-Steam & 92,909 & 89,394 & 170,952 & 170,225 & 523,480 \\
Coal-Steam & 407,180 & 285,357 & 672,875 & 432,083 & $1,767,495$ \\
Nuclear-Steam & $2,330,383$ & $2,230,057$ & $2,352,689$ & $2,351,142$ & $9,274,271$ \\
Minimum Out- & $1,545,600$ & $1,528,800$ & $1,528,800$ & $1,528,800$ & $6,132,000$ \\
Put Level & $4,412,954$ & $4,152,919$ & $4,7<6,519$ & $4,527,361$ & $17,839,753$ \\
TOTALS & & & & \\
\hline
\end{tabular}




\subsubsection{GENERATION AND LOAD MATCHING}

\subsubsection{Analytical Computer Model}

The large number of computations involved required the use of a functional computer model as diagrammed in Figure 3.3-15.

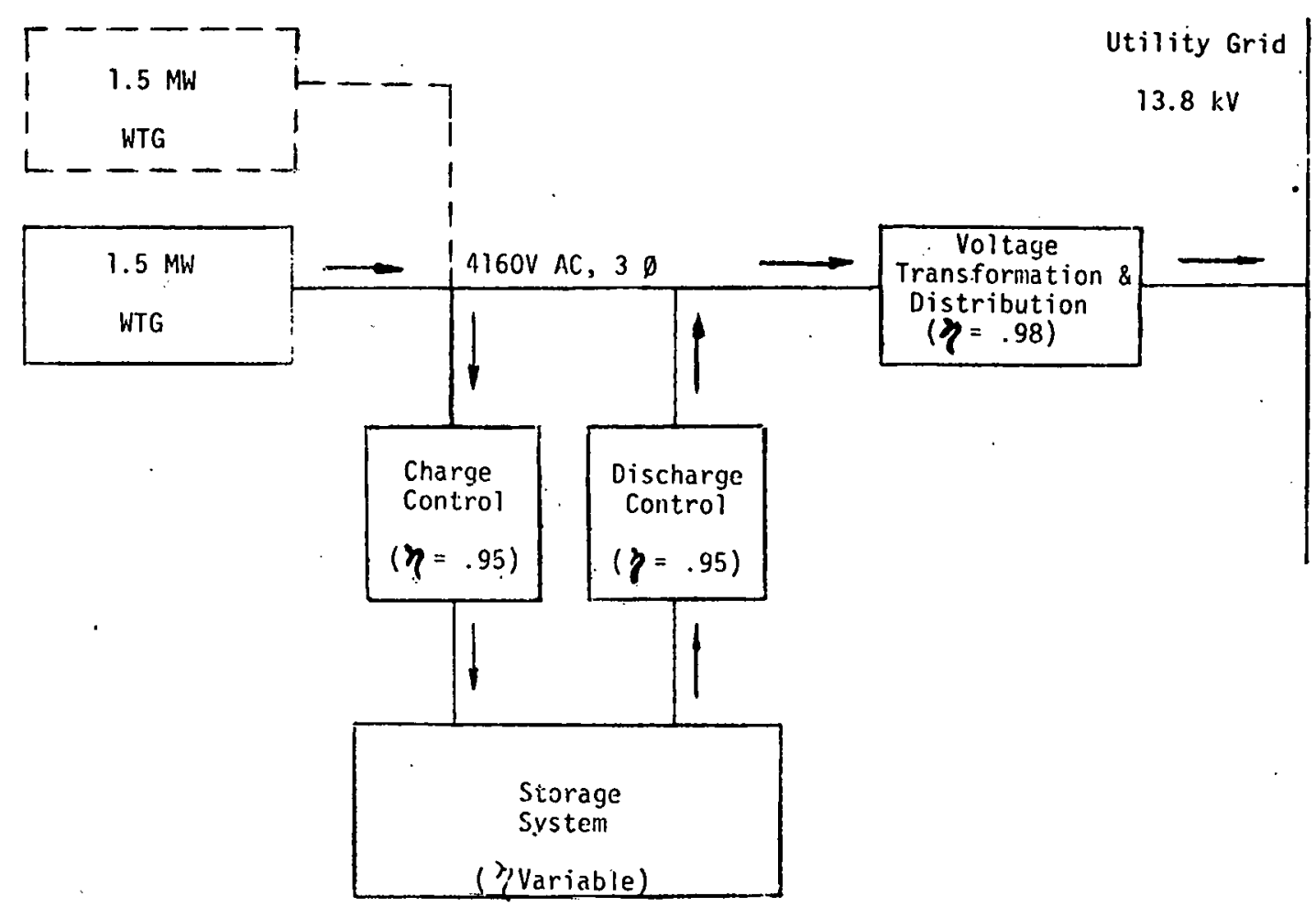

FIGURE 3.3-15. COMPUTER MODEL LOGIC DIAGRAM - WIND

ENERGY CONVERSION - UTILITY APPLICATION 
The basic wind energy conversion unit was a 1.5 MW Wind Turbine Generator. Multiples of this size WTG were added as indicated by the dotted second unit in the diagram to simulate penetrations of 10,20 and $30 \%$ of the utility installed generation capacity ( $4000 \mathrm{MW}$ nominal). The arrows in the diagram represent the allowable directions for energy flow. For this dedicated storage configuration, energy flow from the utility grid for use in charging the storage system was not permitted. The charge and discharge power handling devices were each assigned a $95 \%$ efficiency as noted in the figure. These devices were also considered to be power limited and this limit was considered as an input parameter in the evaluation of system performance.

A storage system overall energy efficiency was assigned for each data run and treated as an independent variable in the investigation of system performance. An additional in-line efficiency of $98 \%$ was included to account for voltage transformation and distribution losses between the non-conventional energy sources under investigation and the point of measurement of the utility system load demand. This latter loss did not disturb the overall evaluation of the benefits of storage since the same loss allowance was included in both the storage evaluation runs and in the nostorage base case.

\subsubsection{Generation and Load Matching Without Storage}

To establish a reference baseline for each set of storage run conditions, the wind system output was matched directly to the load demand on an hour by hour basis for an entire year of use ( 8760 hours). This course was 
chosen as a means of reducing the potential bias that could result from selection of some shorter span of time which might in actuality be less than "representative". (It is, of course, recognized that different annual wind data or longer terms than one year might be even more desirable than the time period chosen). During the zero storage run, no WTG energy was allowed to pass through the storage system. The conventional energy displacement, resulting from use of the wind power to serve a portion of the load, was tabulated for each hour and summed to monthly and annual totals for subsequent analysis. Basically, any energy which the wind turbine delivers to meet load demands goes on line regardless of the time of day, and it is assumed that any required adjustment of total utility system output will be accomplished without cutting off the wind turbines.

\subsubsection{Generation and Load Matching Incorporating Storage}

For purposes nf romputing the energy displacement effects of adding storage, all the blocks in Figure 3.3-15 become operative. Increasing amounts of storage system capacity (MWh) were assigned to the sturage block as successive data computations were taken. A storage efficiency of $75 \%$ was assumed for the majority of the cases, with alternative cases taken at 60 and $90 \%$ efficiency to determine the efficiency effect on output results. The utility system load is met by a combination of directly supplied WTG energy, energy delivered from storage and a net make-up furnished by the conventional generation plant. The computer logic required to carry out the incorporation of storage is described in the following section. 


\subsubsection{Storage Charging and Dispatch Logic}

The energy management of the charge-discharge cycle employs an operating strategy based on the following ground rules:

1. Charging of storage will only occur when source output would otherwise displace the lowest value energy category (designated in the model as category $D$ ).

2. Storage dispatch will be permitted only to displace load quality of category $C$ or higher.

3. No storage discharge will occur on weekends or holidays.

4. The storage system state-of-charge (SOC) is managed on a weekly basis to provide a near-optimum displacement of the highest quality energy. To this end the program logic determines, on a daily basis, that value of system load which is required to drive the $S O C$ to an alluwalue value for each day. This value of minimum allowable SOC is a function of the day-ofthe-week according to the following algorithm.

$$
\mathrm{SOC}_{A}=\frac{(5-I) S O C_{M}+\mathrm{SOC}_{L}}{6-I}
$$

where

$$
\begin{aligned}
\text {SOC}_{A} & =\text { allowable minimum SOC for the day } \\
I & =\text { day-of-the-week number (Monday }=1 \text { ) } \\
\text { SOC } L & =\text { low } 1 \text { imit on storage system SOC } \\
\text { SOCM } & =\text { SOC at midnight of the preceding day. }
\end{aligned}
$$

These constraints were arrived at after trial runs in which daily vs weekty cycles were tested as were the results of raising the chargedischarge cut-off point higher on the load duration curve. The analysis assumes ability to fully predict and manage hourly source output and load demand on a daily basis to drive the storage system SOC to the pre-determined minimum allowable value for each day.

\subsubsection{Computational Format and Typical Load Matching Results}

Table 3.3-3 lists a typical computer data output format for a storage analysis run. 
TABLE 3.3-3 TYPICAL COMPUTER RUN FORMAT, WIND SYSTEM STORAGE CHARGING - UTILITY APPLICATION

\section{0\% PENETRATION \\ 1000 MWh STORAGE CAPACITY \\ GREAT FALLS, MT}

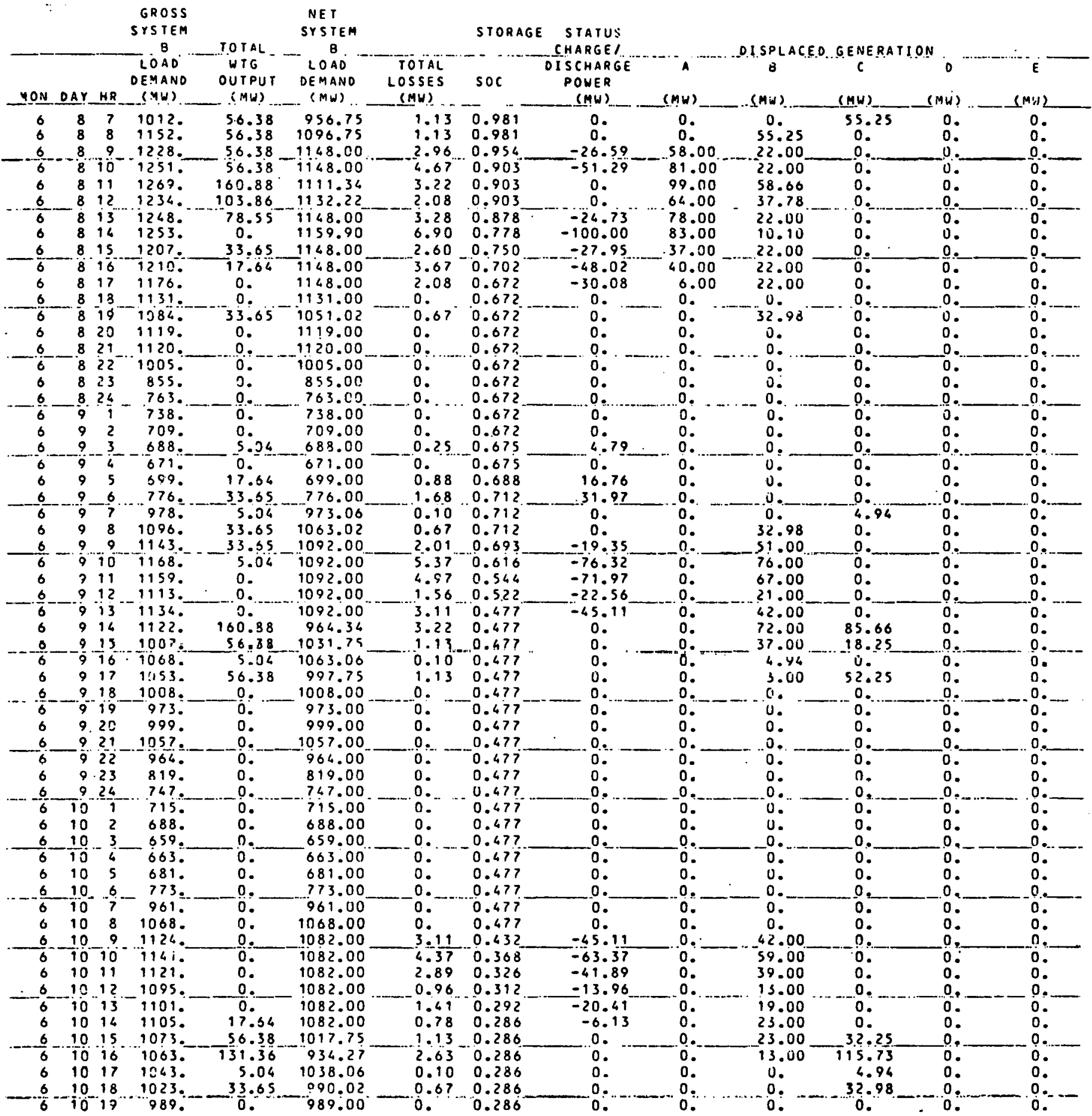


A typical profile resulting from the dispatch technique selected is shown in Figure 3.3-16. As shown by the state-of-charge curve, storage is dispatched to meet the early evening peak load. Direct contributions from the WTG output are taken as available during the heavier load periods and can be seen segregated at the bottom of the plot.

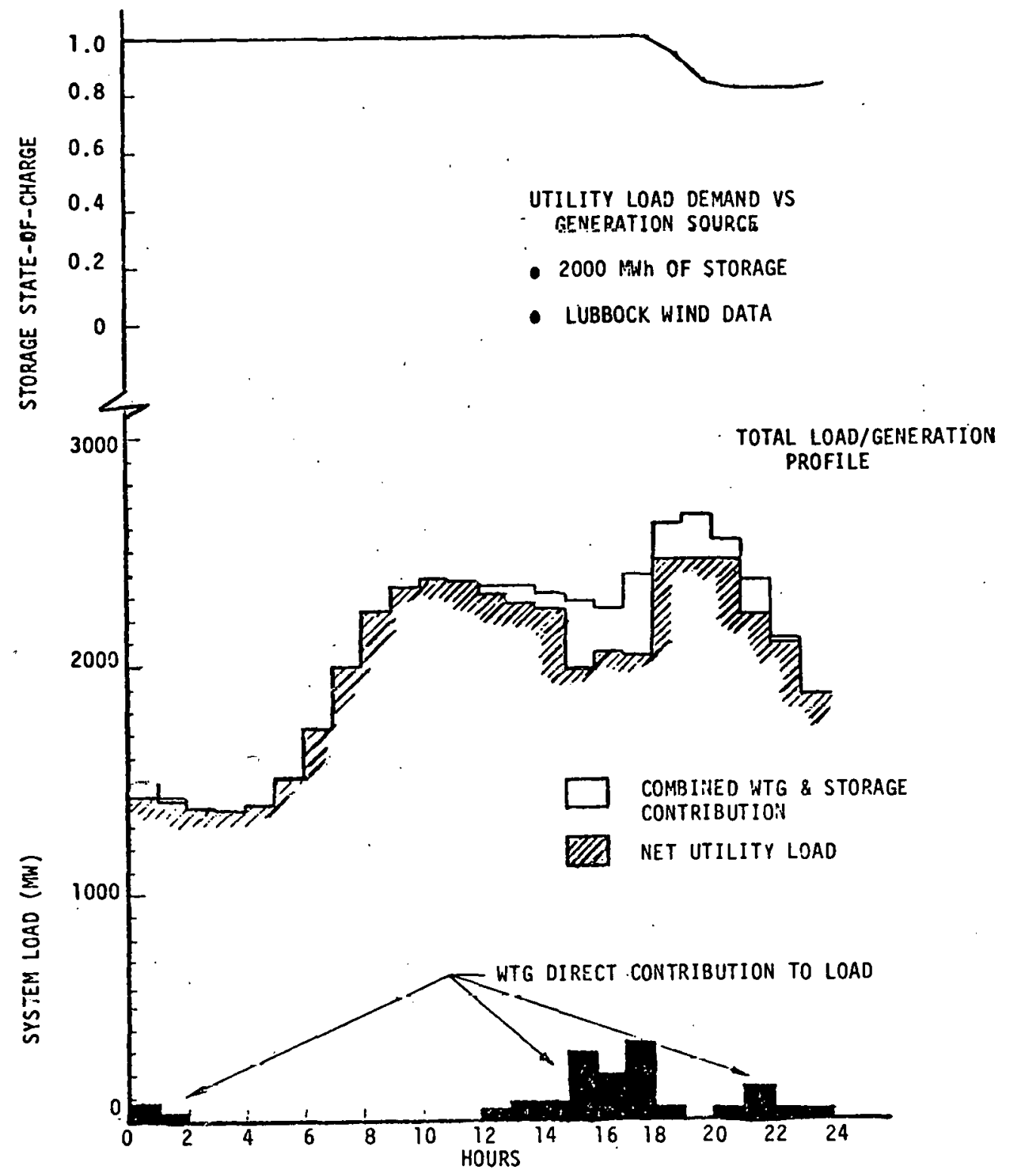

FIGURE 3.3-16 TYPICAL DAILY PROFILE OF LOAD AND GENERATION MATCHING RESULTS. 
Figure 3.3-17 shows similar data taken over a representative week. The dashed lines in Figure 3.3-17 divide the various cost-of-energy-generation regions. Comparison with the state-of-charge curve above the load/generation profile reveals the storage response to peak load demands as "dips". At week's end, the last (and lowest) dip reaches the 0.1 low limit on state-of-charge as a result of the storage dispatch strategy. It then rises as a result of weekend recharging.

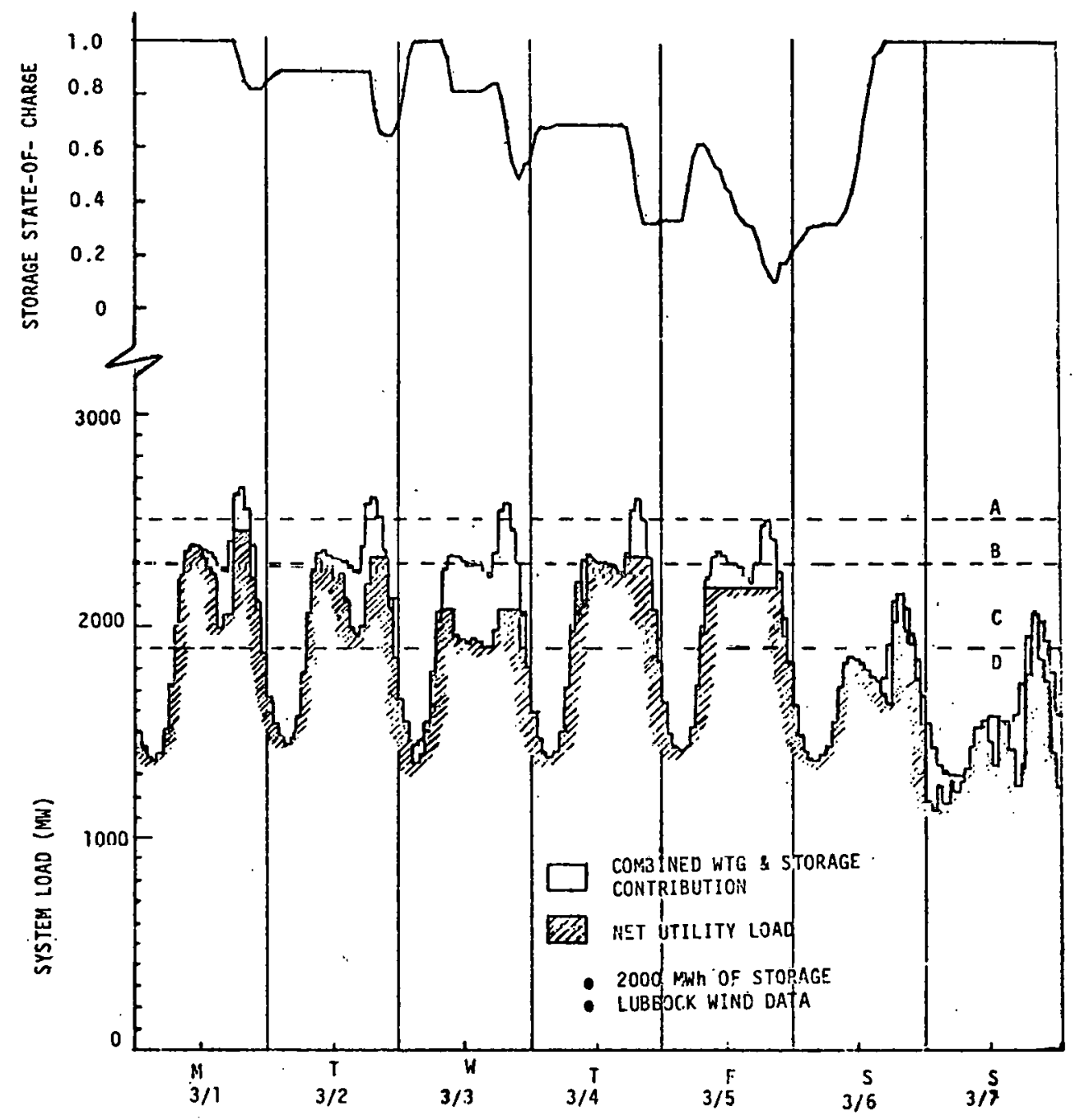

FIGURE 3.3-17 TYPICAL WEEKLY PROFILE OF LOAD AND GENERATION MATCHING RESULTS 
As can be seen in Figure 3.3-17, the storage operating ground rules chosen assure a fairly equal distribution over the week of the displacement of the highest quality energy. This operating strategy does not account for the unequal distribution of the source generation over the entire week. This influence is revealed by the larger total system displacement on Wednesday in the above figure when WTG energy output was very high. If the storage system dispatch could be managed to account for such weekly variation in source capability, it might be possible to slightly improve the value of the displaced energy. An investigation of the feasibility of such operation was beyond the scope of this study, but the results nhtained suggest that opcrating logic opliums would be a usefui area for additional investigation.

The month by month results of modeling the wind turbine and storage contributions are shown for a representative case in Figure 3.3-18. The plot on the right hand side of the figure shows the change in delivered energy by cost of generation region which results from the addition of 2000 MWh of storage to the wind turbine-only results shown to the left.

While the total wind turbine output is the same in both cases, the right hand plot contains a lower amount of total energy due to losses in charging and utilizing storage. A careful inspection, however, will reveal that categories $A, B$, and $C$ increase in area with addition of storage while category $D$ decreases. This reflects the upgrading of the value of energy which the wind turbine alone would have to deliver at the lower value.

It may also be noted that the two curves are a direct reflection of the 

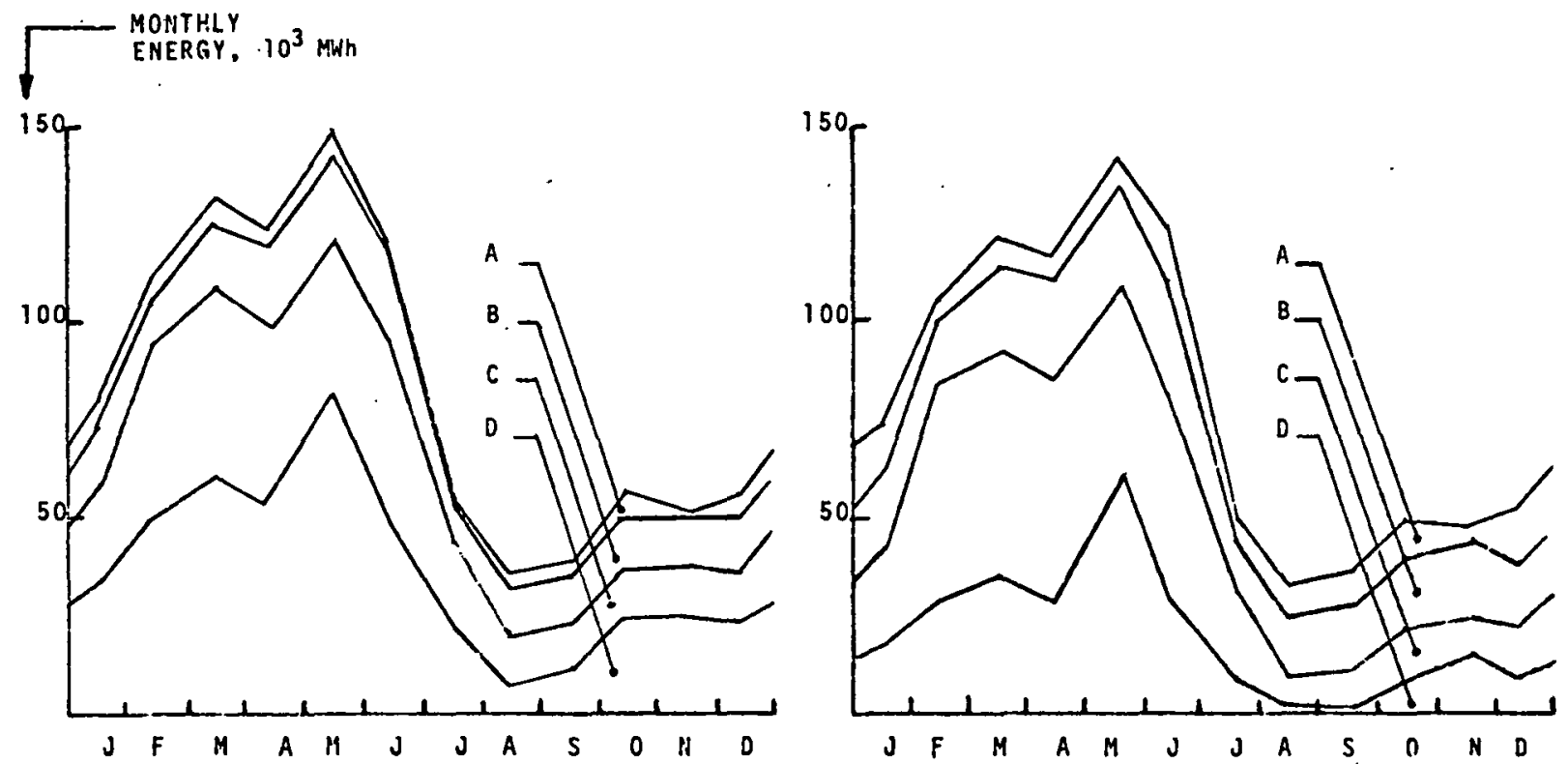

FIGURE 3.3-18 DELIVERED ENERGY PERFORMANCE WITH AND WITHOUT ENERGY STORAGE (LUBBOCK, TEXAS, WIND DATA)

availahilit.y of wind during the year. A pronounced low in the summer months of July and August significantly affects savings over that time period.

\subsubsection{BREAK-EVEN COST METHODOLOGY}

The numerics required to carry out the analysis of the utility cost goal evaluation are developed and the results presented in this section based on the methods, operating strategy, and other assumptions previously described.

\subsubsection{Determination of Energy Storage Break-Even Costs}

The process of determining a bottom-line energy storage break-even cost involves not only the analysis of the energy dispatch reflected in Figure 3.3-2 
as it applies to cost of generation savings (fuel) but also other applicable savings. The latter include credits for displaced generating units and/or spinning reserve units which might be shut down. Savings in transmission and distribution (T\&D) equipment is a further potential benefit of certain storage technologies.

Break-even cost determination employed the following basic steps:

1. Selection of: Wind conversion system, Load profile, WTG penetration, and Storage capacity

2. Determination of system annual performance:

a. Wi thout storage

b. With energy storage.

3. Determination of representative values of fucl-related energy cust $(\$ / k W h)$ for the various levels of power generation.

4. Computation of annual energy benefit due to addition of storage.

5. Determination of capitalized value of annual energy benefits.

6. Estimate of storage 08M costs (capitalized and deducted from capitalized energy benefits.)

7. Adjustment of net credit above to account for interest during construction.

8. Estimate of net capacity credit and other applicable credits, which add to adjusted net credit above, to yield storage break-even cost.

9. Comparison of storage system break-even cost with actual or estimated storage system costs.

\subsubsection{Cost Regions}

It was necessary to assign cost-of-generation values for the various portions of the system load based on the fuel cost differences which occur because utilities typically use a combination of different types of generating units to meet various segments of the system load. Utility data available for the Washington, D.C. area and for Phoenix, Arizona and Miami, Florida were examined and used as the basis for establishing these cost-of-generation dollar values. Table 3.3-4 provides this data in 
summary form. The variation across this geographic spread was very small and therefore an average value was taken for fuel cost for each type of generation. Multiplied by a representative heat rate for each type of generation, a dollars-per-megawatt-hour cost of generation figure results as shown.

TABLE 3.3-4 REPRESENTATIVE COSTS OF GENERATION*

\begin{tabular}{|c|c|c|c|c|c|c|}
\hline \multirow{2}{*}{$\begin{array}{l}\text { GENERATION } \\
\text { TYPE }\end{array}$} & \multicolumn{4}{|c|}{ FUEL COST \$/MBTU** } & \multirow{2}{*}{$\begin{array}{l}\text { HEAT RATE } \\
\text { MBTU/MWh }\end{array}$} & \multirow{2}{*}{$\begin{array}{c}\text { FUEL COST OF } \\
\text { GENERATION } \\
\$ / M W h \star \star\end{array}$} \\
\hline & W & $P$ & $M$ & AVG & & \\
\hline GAS TURBINE & 2.26 & 2.36 & 2.41 & 2.34 & 12 & 28.10 \\
\hline OIL-STEAM & 2.00 & 2.20 & 2.00 & 2.07 & 10.4 & 21.50 \\
\hline COAL-STEAM & 1.31 & .79 & 1.36 & 1.15 & 10.4 & 12.00 \\
\hline NUCLEAR-STEAM & .42 & .42 & .42 & .42 & 10.4 & 4.35 \\
\hline
\end{tabular}

*Based on Utility Data for Washington, D.C., Phoenix, and Miami **1976 Dollars

Figure 3.3-19 relates these costs of generation to the areas under the "Representative System B" load curve where they might typically apply. The separation levels shown were selected to provide about 1000 hours of annual peaking duty and a base load set just slightly above the normal "valleys" of the annual load curve. The intermediate levels were likewise set to reflect typical capacity factors for the applicable types of generation equipment. 
In a specific system case study, utility operating data and experience would be used directly. As indicated by the column heading of Figure 3.3-19 the cost-of-generation figures can also be considered as the "worth" per MWh of any energy provided subsequently by wind and/or storage. Levels were set for each season since the differences are significant in strata A and B. No further consideration of generation mix details is involved beyond this point in the analysis.

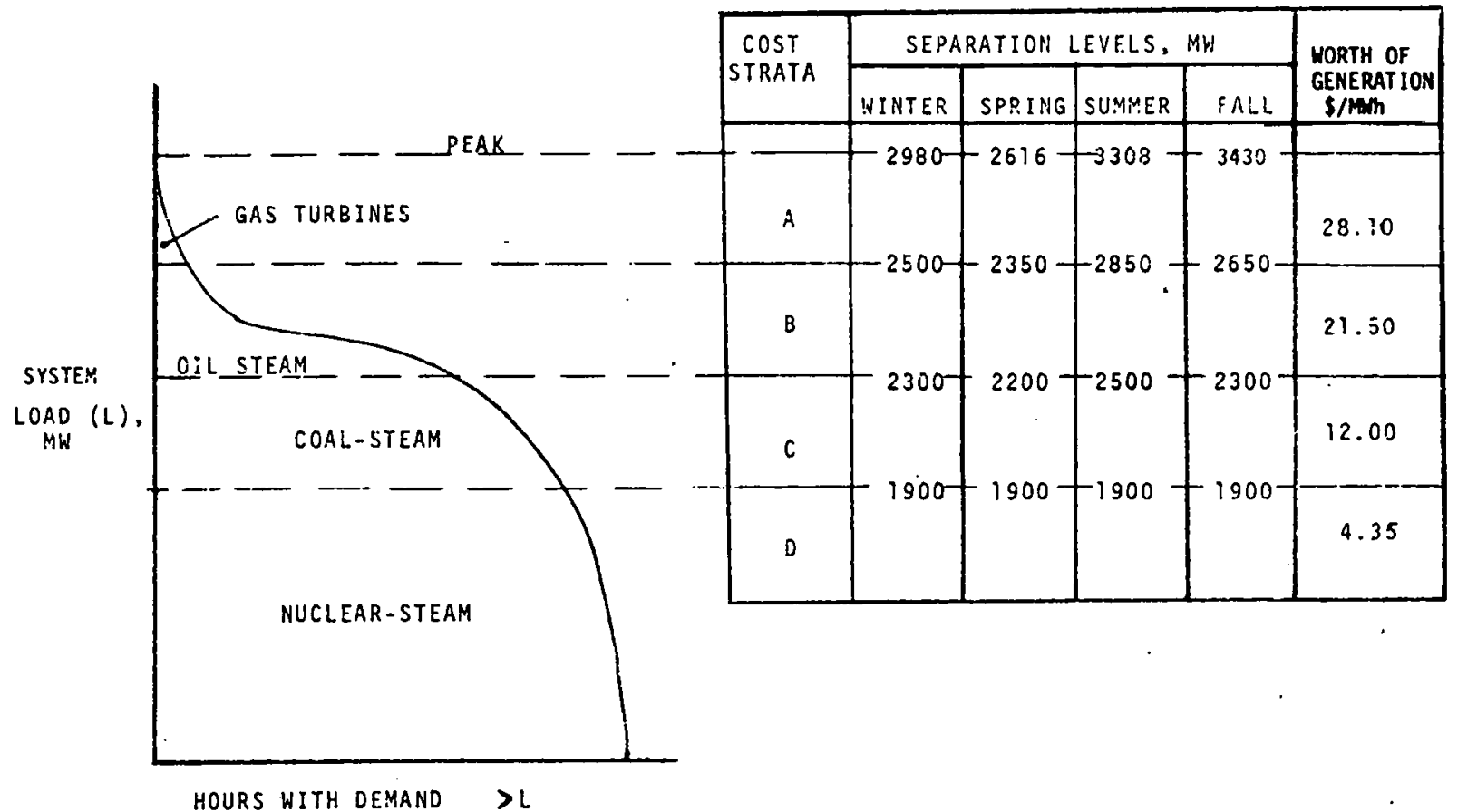

FIGURE 3.3-19 COST-OF-GENERATION STRATA VS ANNUAL UTILITY SYSTEM LOAD 


\subsubsection{Energy Credit}

The fuel saving or "energy credit" achieved, based on use of 2000 MWh of storage with a discharge limit of 10 hours at $75 \%$ storage device efficiency, a $10 \%$ penetration of wind generation and representative System "B" annual load is further reviewed in this section as an example case.

Table 3.3-5 shows a comparison of the annual benefit of wind energy without storage and with 2000 MWh of storage added.

TABLE 3.3-5 ANNUAL ENERGY BENEFIT (CREDIT) OF STORAGE (2000 MWh) (WTG CHARGING) (LUBBOCK, TX)

\begin{tabular}{|c|c|c|c|c|c|}
\hline \multirow[b]{2}{*}{$\begin{array}{l}\text { GENERATION } \\
\text { STRATA OR } \\
\text { "WORTH } \\
\text { CATEGORY" }\end{array}$} & \multirow[b]{2}{*}{$\begin{array}{l}\text { ENERGY } \\
\text { WORTH } \\
\$ / M W h\end{array}$} & \multicolumn{2}{|c|}{ WITHOUT STORAGE } & \multicolumn{2}{|c|}{ WITH STORAGE } \\
\hline & & $\begin{array}{c}\text { ANNUAL ENERGY } \\
\text { DI ŞPLACED } \\
10^{3} \mathrm{MWh}\end{array}$ & $\begin{array}{l}\text { ANNUAL } \\
\text { WORTH } \\
10^{6} \$\end{array}$ & $\begin{array}{c}\text { ANNUAL ENERGY } \\
\text { DIŞPLACED } \\
103 \text { MWh }\end{array}$ & $\begin{array}{l}\text { ANNUAL } \\
\text { WORTH } \\
10^{6} \$\end{array}$ \\
\hline A & 28.10 & 50 & 1.405 & 78 & 2.192 \\
\hline B & 21.50 & 182 & 3.913 & 238 & 5.117 \\
\hline c & 12.00 & 330 & 3.960 & 381 & 4.572 \\
\hline D & 4.35 & 446 & 1.940 & 246 & 1.070 \\
\hline TOTALS & $\cdots$ & 1,008 & 11.218 & 943 & 12.951 \\
\hline
\end{tabular}


The value of the increase resulting from use of storage is found as shown below:

Annual Energy Benefit of Storage $=(12.951-11.218) \times 10^{6}=$ $\$ 1.733$ million

$=\$ 1,722,000 / 2,000,000 \mathrm{kWh}$ of storage capacity

$=\$ .8665 / \mathrm{kWh}$ of storage capacity

Figure 3.3-20 shows the monthly value of WTG dedicated charging with 2000 MWh of storage.

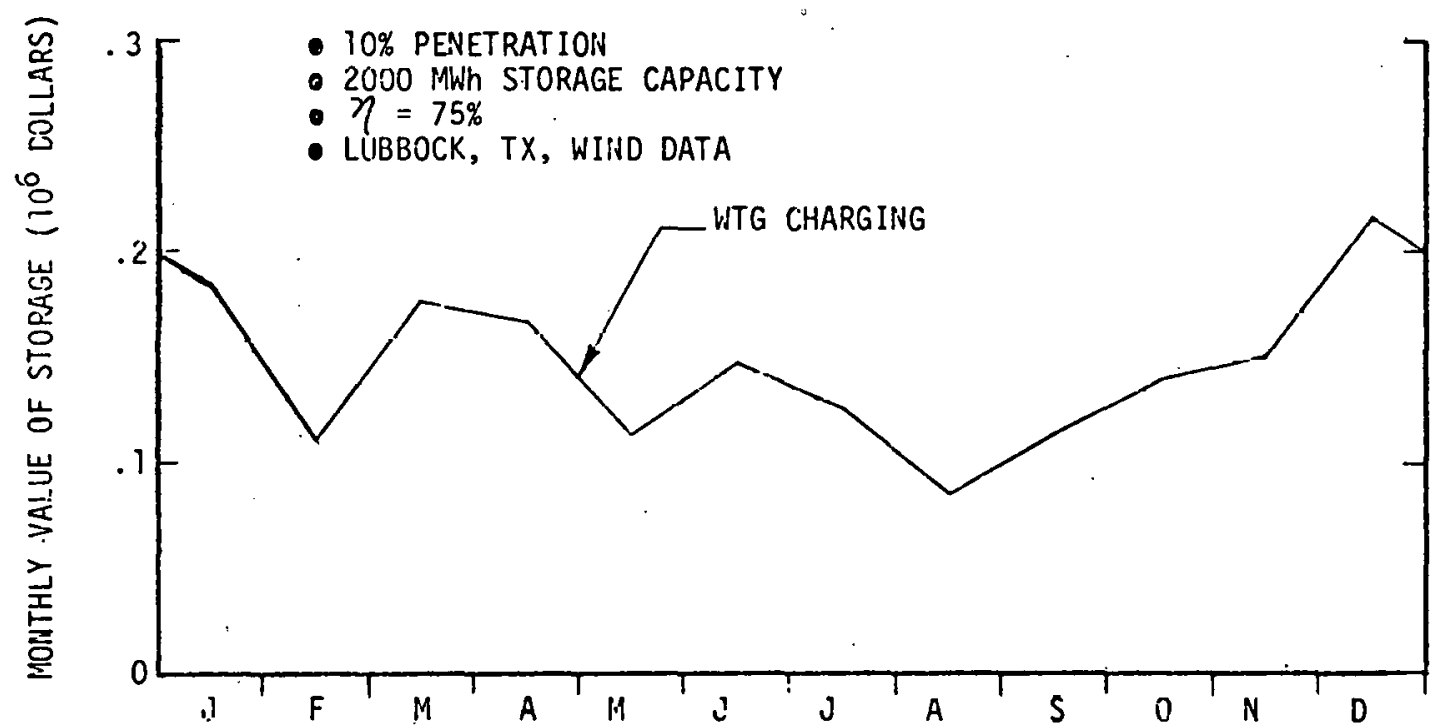

FIGURE 3.3-20. MONTHLY VALUE OF STORAGE WITH WTG CHARGING 
The energy displacement effect of adding storage at capacity levels other than 2000 MWh was also investigated. Figures 3.3-21 and 3.3-22 show the annual fuel savings benefit results of these investigations.

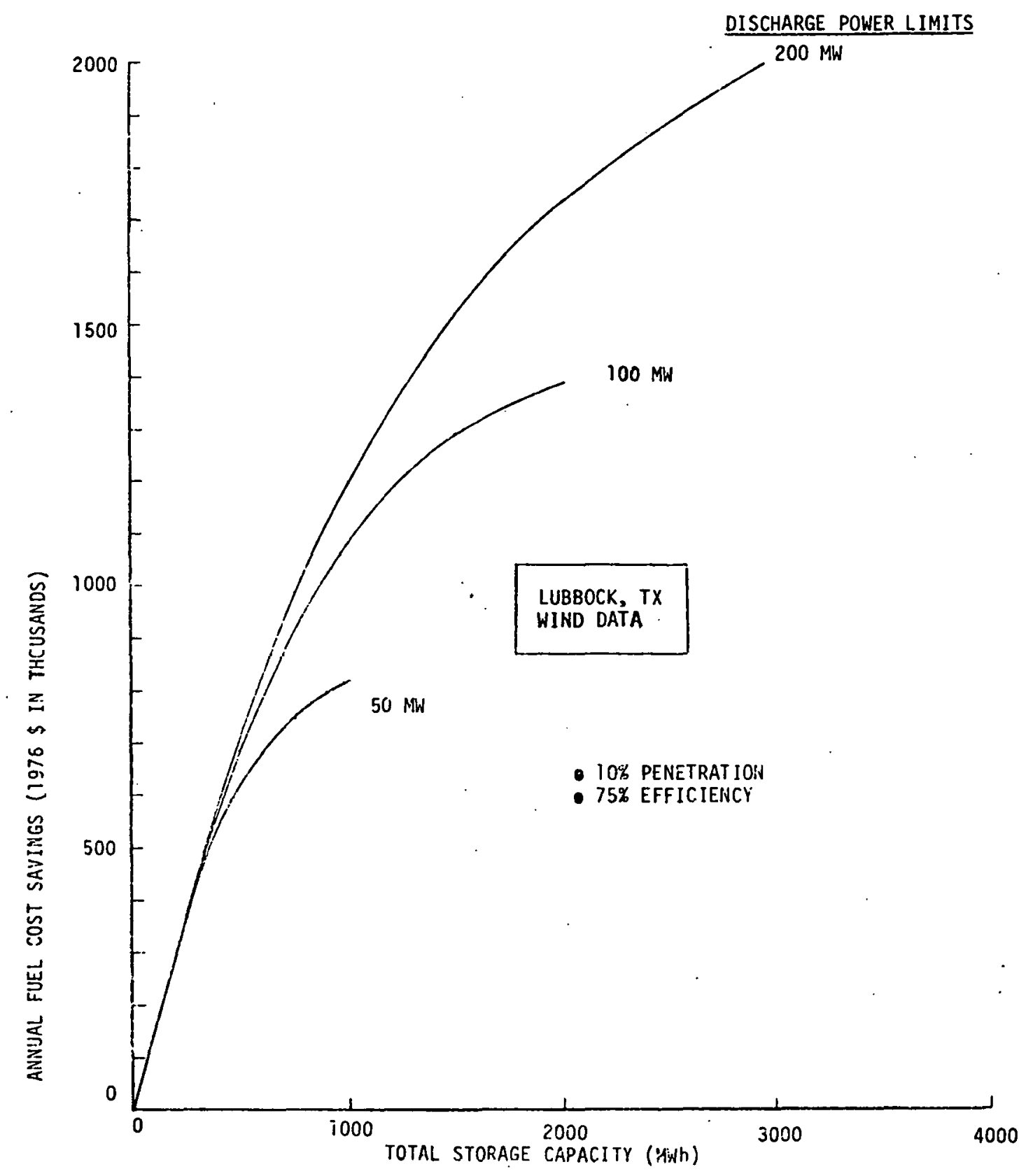

FIGURE 3.3-21. ANNUAL FUEL COST SAVINGS WITH STORAGE FOR LUBBOCK, TX AT 10 PERCENT PENETRATION 


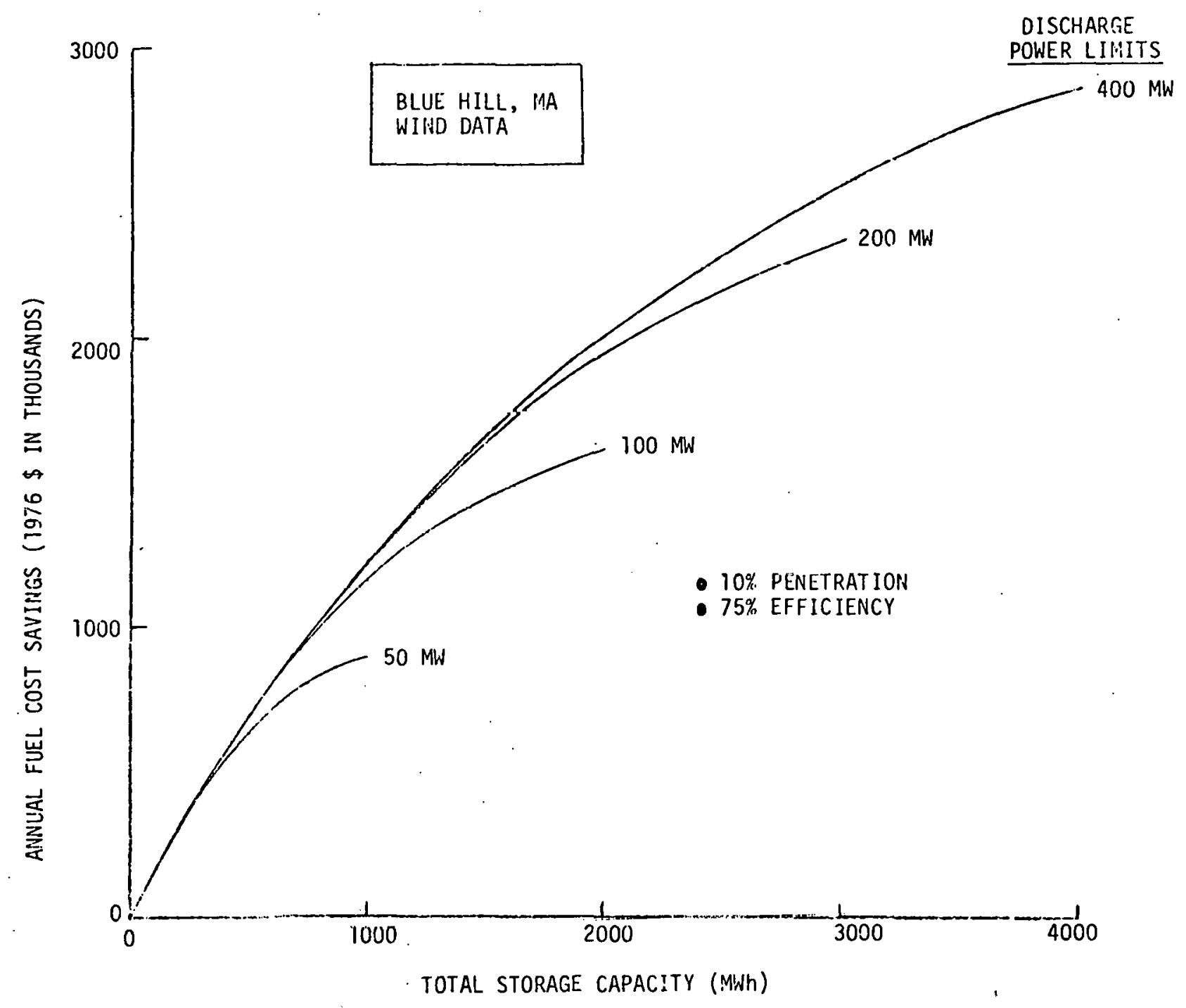

FIGURE 3.3-22. ANNUAL FUEL C.OST SAVINGS WITH STORAGE

FOR BLUE HILL, MA, AT 10 PERCENT PENFTRATION 


\subsubsection{Capacity Credit}

Energy storage, within a utility generation mix, will actually reduce requirements for conventional generating capacity and thus derive capacity credit. It was desired that an appropriate and relatively simple method be employed for estillating capacity credit of storage systems. For this purpose, use is made of Garver's equation ${ }^{15}$ which defines effective capacity for a new unit as follows:

$$
C^{*}=C-m \text { In }\left(1.0-R+R e^{c / m}\right)
$$

where

$$
\begin{aligned}
& C^{*}=\text { effective load carrying capability } \\
& C=\text { rated power capacity } \\
& R=\text { Unit's forced outage rate ( } \text { isk) } \\
& m=\text { Characteristic slope of the generating system. }
\end{aligned}
$$

The slope $r_{i}$ is a measure of the system LOLP sensitivity to changes in its peak load deniand. It is the load change that will change LOLP by 2.178 times or the value of "e", the base of the natural logarithmic system. Values of " $\mathrm{m}$ " for typical utilities fall in the range of 500 to $700 \mathrm{flW}$.

A value for $R$ was determined by comparing the energy displacement results of baseload charging of storage vs. WTG charging of storage. The method is as follows:

1. Storage cr.arged with off-peak utility power each day is assumed to have an availability factor of one. 
2. With wind energy charging of storage, the long-term (annual) storage displacement has been found to be about ore-third as great as in Step 1. The ratios of the energy for these two conditions (for the same amount of storage capacity) are then taken as a measure of the degree to which a dedicated windcharged storage system could fulfill a capacity replacement commi tment.

Putting this in risk terms:

$R \equiv$ Forced Outage Rate $\cong 1-\frac{E_{D W}}{E_{D U}}$

where $E_{D W}$ is the annual energy displaced by WTG storage charging and $E_{D U}$ is the annual energy displaced by comparable utility off-peak storage charging. Table 3.3-6 shows computed values of $\mathrm{R}$ for various storage capacities and discharge rates. 
TABLE 3.3-6. RISK FACTOR FOR VARIOUS ENERGY STORAGE DISPLACEMENTS*

\begin{tabular}{|c|c|c|c|c|}
\hline $\begin{array}{l}\text { HOURLY DIS- } \\
\text { CHARGE RATE } \\
\text { LJMIT (HRS) }\end{array}$ & $\begin{array}{c}\text { STORAGE } \\
\text { CAPACITY } \\
\text { (MWh) }\end{array}$ & $\begin{array}{l}E_{\text {DW }} \\
\text { (MWh) }\end{array}$ & $\begin{array}{c}E_{\text {DU }} \\
\text { (MWh) }\end{array}$ & $R$ \\
\hline \multirow{2}{*}{10} & 250 & 22,632 & 51,350 & .559 \\
& 500 & 42,795 & 101,053 & .572 \\
& 1000 & 79,190 & 194,897 & .594 \\
& 2000 & 135,263 & 361,459 & .626 \\
5 & 250 & 23,381 & 74,676 & .687 \\
& 500 & 44,915 & 146,985 & .695 \\
\hline
\end{tabular}

* WTG charging data for Lubbock, TX, 10\% wind system penetration, 75\% efficiency.

The value of $c *$ based on the algebraic relationships of Garver's equation may be determined as shown below, using a value of 500 for " $m$ ". This value was selected based on examination of typical numbers from utility studies 23 . For a storage capacity of 2000 MWh and a discharge rate limit of 10 hours, the power rated capacity is:

$$
C=200 \mathrm{MW}
$$

From Table 3.3-6, the risk factor is:

$$
\mathrm{R}=.626
$$

and the effective capacity $C^{*}$ (using Garver's equation) is

$$
C^{\star}=65.8 \mathrm{MW}
$$

The effective load carrying capacity, $C^{*}$, thus determined is used as a m!eans of establishing a consistent value for a capacity credit that might fairly reflect the ability of dedicated storage to meet load demands. A dollar value for this credit is determined by multiplying the value of $c^{\star}$ by an amount, 
$\bar{C}$ reflecting the cost of the conventional generation equipment most likely to be displaced. Based on a representative value of $\$ 140 / \mathrm{kW}$ for gas turbine peaking units (See Table 3.3-7), a resultant capacity credit for the example shown would be:

$$
C C=C^{\star} \cdot \bar{C}=65.8 \times 10^{3} \cdot 140=\$ 9.21 \times 10^{6} \text { or } \$ 46 / \mathrm{kW} .
$$

It should be noted that even though energy displacement from storage occurs in several regions, the most likely capacity displacement. is the peaking generation units. Very large scale storage systems could be expected to also displace sulle higher valued intermediate load capacity, but the value would be partially offset by the increased interest during construction of the large systems. Thus the $140 \$ / \mathrm{kW}$ was used as a realistic yet conservative capacity credit.

TABLE 3.3-7. REPRESENTATIVE GENERAT ING EQUIPMENT COSTS

\begin{tabular}{|l|c|}
\hline LOCATION & $\begin{array}{c}\text { GAS TURB INE PEAKING } \\
\text { UNIT CAPITAL COST15 } \\
(\$ / \mathrm{kW})\end{array}$ \\
\hline Miami & 150 \\
Wash., D.C. & 130 \\
Phoenix & 130 \\
Average & 140 \\
\hline
\end{tabular}




\subsubsection{0ther Cost Factors}

\section{Operatior and Maintenance Costs}

0\& $M$ costs may be either fixed or variable in nature and both elements may be present, depending on the type of storage and the form of operation and maintenance needs. Fixed 0\&M costs are essentially incurred by virtue of ownership of an in-place system regardless of the amount of use. The total amount of such fixed costs relate to the storage system power rating or may be converted from $\$ / \mathrm{kW} / \mathrm{Yr}$ to $\$ / \mathrm{kWh} / \mathrm{Yr}$ if a storage discharge rate is specified. The variable portion of $08 / 1$ costs are a function of the amount of use of a storage system and may be presented in terms of dollars per kilowatt hour of discharge energy. In computing storage system benefits, the latter must be reduced by the amount of the 0\&M costs as will be shown in break-even computations in the next section.

\section{Other Generation, Transmission and Distribution Credits}

Transmission and distribution credits for an energy storage system may be appropriate in certain cases. These credits result from system re-arrangements or alternative planning which allows strategic placement of storage units so as to reduce or eliminate the need for larger tie lines, substations or other high capital cost items. Evaluation of credits for such cost reductions is dependent on specific information for cases of interest. Only those storage systems which have a relatively small physical size and the flexibility of module/generating system interconnection to make distributed siting practical should receive such credits. Battery systems appear to offer the most possibility for distributed siting. It is conceivable but less clear that inertial storage systems might also qualify. The amount of such credits as discussed by others 21,24 who have considered this factor 
ranges from $\$ 0-\$ 75 \mathrm{~kW}$ or more. In computing the final adjusted breakeven costs for battery systems, a nominal allowance $(45 \$ / \mathrm{kW})$ for transmission and distribution credits has been added to indicate the effect that this benefit could have on viability.

An energy storage system could also add value due to shutdown of spinning reserve units as a fuel saving measure (but not necessarily as a capital cost saving), and for improvement of system reliability and/or voltage control and stability. Very large combined credits for these and other $i$ tems discussed above have been projected by some sources ${ }^{25}$. It is recommended here, however, that the mattcr of credtis be either made the subject of specific evaluations for several actual operating cases or left to the discretion of individual utility planning operations when new storage systems are actually incorporated in a utility system.

\subsubsection{Break-Even Cost Sample Calculation}

Break-even costs resulting from investigations of a dedicated wind/utility use of storage are preserted in this section. A sample calculation is given below for pumped hydro-storage. A "capitalized" cost approach is used for convenience in handling lhe energy and capacity credits while at the same time obtaining answers in familiar capital outlay terms. 26,27 


\section{Specific Conditions}

- $10 \%$ wind-system penetration ( $375 \mathrm{MW}$ )

- 2000 MWh - pumped hydro storage

- 10 hour cischarge rate

- $5 \%$ inflation rate, $g$

- $10 \%$ fuel escalation rate, $f$

- 30 year system life, $n$

- $9 \%$ discount rate, $r$

- $75 \%$ storage efficiency

- Fixed charge rate, $\mathrm{FCR}=.18$

- Annual 08M cost, $A_{0 M}=\$ 1.68 \mathrm{~kW}$ of storage power rating $/ \mathrm{Yr}$ (fixed)

- Annual Energy Credit, $A_{E}^{0}=\$ 1.67$ million

(representative U.S. mean value at 2000 MWh - See Figure 3.3-26).

- $C^{*}=85 \mathrm{MW}$ (representative mean value o $2000 \mathrm{MWh}$ - See Figure 3.3-28).

- Year 2000 start

- Kesults in 1976 dollars. 
The first step involves capitalization of the annual energy credit, $A_{E}$ and the annual 0\&M cost, $A_{O M}$. This is accomplished by introducing the parameters $M_{g}$ and $M_{f}$, the levelizing values for an escalating cost stream, defined as:

$$
M_{g}=\frac{r(1+g)}{r-g}\left[\frac{(1+r)^{n}-(1+g)^{n}}{(1+r)^{n}-1}\right]
$$

and

$$
M_{f}=\frac{r(1+f)}{r-f}\left[\frac{(1+r)^{n}-(1+f)^{n}}{(1+r)^{n}-1}\right]
$$

where

$$
\begin{aligned}
& g=\text { general inflation rate } \\
& f=\text { fuel price escalation rate } \\
& r=\text { discount rate } \\
& n=\text { storage system life, years. }
\end{aligned}
$$

Note that when $f$ (or $g$ ) is equal to $r$, the levelizing multiplier is:

$$
M_{f}=\frac{n r(1+r)^{n}}{(1+r)^{n}-1}
$$

The capitalized values for $A_{E}$ and $A_{O M}$ become:

$$
\begin{aligned}
& C_{E}^{0}=\left(\frac{1+f}{1+g}\right)^{\delta} \frac{M_{f}}{F C R} \quad A_{E}^{0} \text { (capitalized energy credit based on } \\
& \text { fuel savings) }
\end{aligned}
$$


where $\delta$ is the number of years from 1976 to the start year and FCR is the fixed charge rate applicable to the particular storage system. Superscript " 0 " refers to values obtained for $75 \%$ storage efficiency. A correction factor $C$ ? adjusts for efficiency other than $75 \%$. (See Figure 3.3-24).

The break-even cost, $\bar{C}_{B E}$, adjusted for efficiency effects and the cost of money during construction is given by:

$$
\bar{C}_{\mathrm{BE}}=\frac{\mathrm{C}_{\eta} C_{E}^{0}-C_{O M}}{\mathrm{CCF}} \quad \text { (without credits) }
$$

where the factor CCF accounts for interest during construction and is storage system related. The capacity credit, CC, and any applicable transmission and distribution credits, TDC, are then added to obtain total break-even $\cos t, \mathrm{C}_{\mathrm{BE}}$.

$$
r_{B E}=\bar{C}_{B E}+C C+T D C
$$

Using the input data given, $M_{f}=3.3746, M_{g}=1.7228$ and TDC $=0$ for pumped hydro.

$$
\begin{aligned}
C_{E}^{0} & =\left(\frac{1.1}{1.05}\right)^{2000-1976}\left(\frac{3.3746}{.18}\right) \quad(\$ 1,670,000) \\
& =\$ 95.6 \text { million or } \$ 47.81 / \mathrm{kWh} \text { for } 2000 \mathrm{MWh} \\
C_{O M} & =\frac{1.7228}{.18} \quad(\$ .168 / \mathrm{kWh})=\$ 1.608 / \mathrm{kWh}
\end{aligned}
$$


$c_{\eta}=1$ since $?=75 \%$ and $C C F=1.4$ for pumped hydro storage.

$$
\bar{C}_{B E}=\frac{1.0(47.81)-1.608}{1.4}=\$ 33.00 / \mathrm{kWh}
$$

capacity credit:

$$
C C=\$ 140 / \mathrm{kW} \times 85000 \mathrm{~kW}=\$ 11.9 \text { million }
$$

and

$$
C_{B E}=33.00+\frac{11,900,000}{2,000,000}=\$ 38.95 / \mathrm{kWh}
$$

\subsubsection{COST GOALS AND PARAMETRIC ANALYSIS}

\subsubsection{General}

This section presents the findings of wind/utility storage analyses based on the techniques described in the preceding sections. The effects of wind regime/location, start year, fuel price escalation rate, wind system penetration, storage discharge rate and storage efficiency are presented in terms of break-even capital costs of storage versus storage capacity. Data developed from the previously described modeling is specifically translated into projected economic results for the following types of energy storage systems:

1. Pumped Hydro

a. above ground

b. underground.

2. Underground Compressed Air

3. Batteries
a. lead-acid
b. advanced

4. Inertial (Flywheel)

5. Hydrogen 
For discussion of the implications of these analyses with respect to preferred storage systems for dedicated wind system use, reference should be inade t.o Section 1.1.

\subsubsection{Factors Affecting Annual Energy Credits}

\section{Effect of Location}

The results of the analysis in terms of annual energy credits resulting from energy storage are depicted in Figure 3.3-23. As can be seen from the figure, value ranking by location is:

1. Blue Hill

2. Lubbock

3. Great Falls

While the wind generator energy output was slightly greater for Great Falls than for Lubbock, this difference was more than offset by load matching effects. The difference between these two locations would have been even more pronounced had local costs of generation been used rather than an average, since availability of hydro power in the Great Falis area makes it a relatively low cost power region 28 . Nevertheless, the major difference, which gives the highest credit to Blue Hill, would appear to be the larger amount of wind energy.

\section{Effect of Penetration}

As can also be seen, the effect of wind system penetration on storage energy credit is relatively small. A saturation effect seems to occur such that with respect to storage, higher penetration may not necessarily yield higher credits. The complexities of the generation mix and dispatch make interpretation of this result difficult. In any case, the energy credit variation due to penetration is small. 


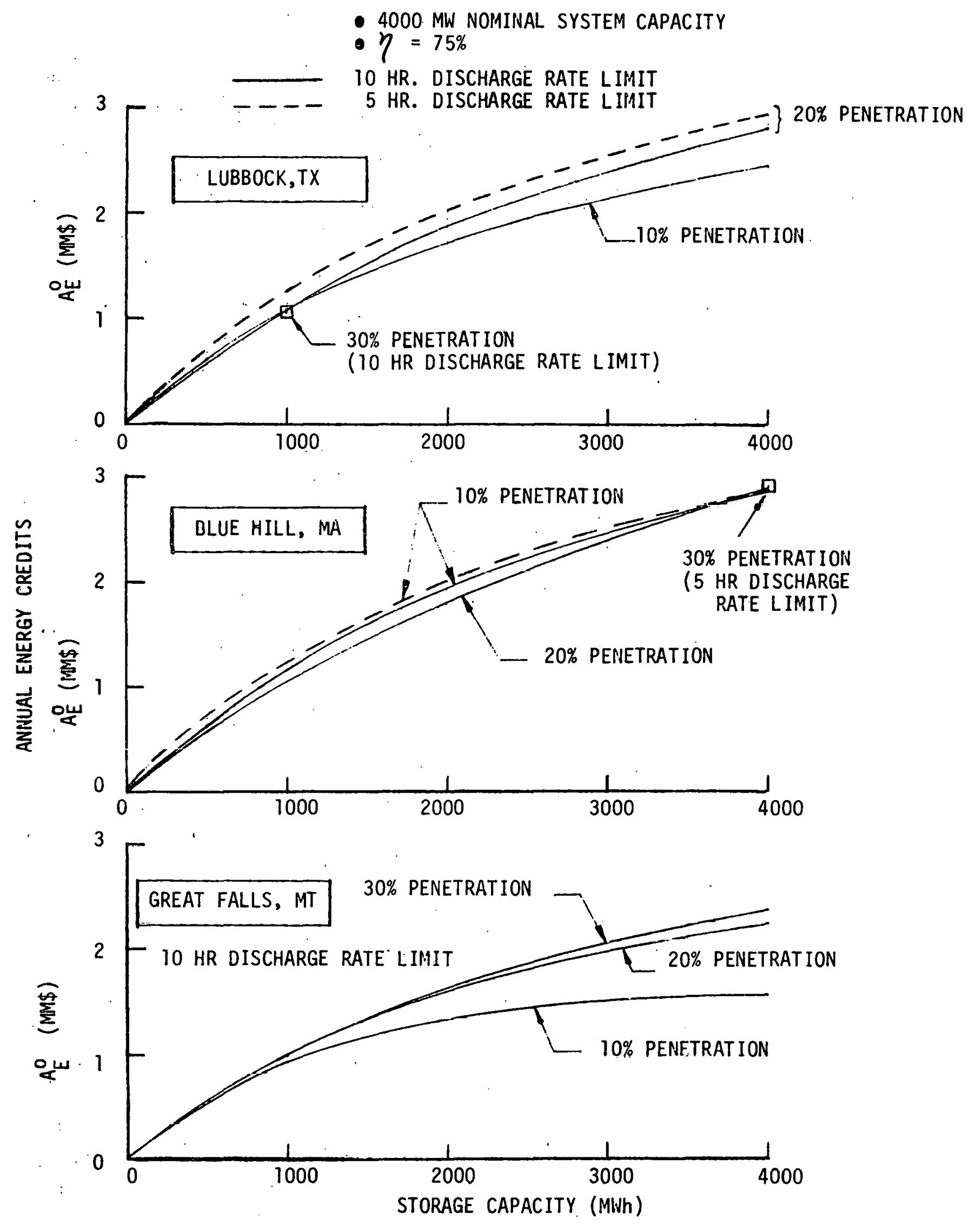

FIGURE 3.3-23. LOCATION, PENETRATION AND STORAGE DISCHARGE RATE EFFECTS, WIND ENERGY CONVERSION - UTILITY APPLICATION 


\section{Effect of Discharge Rate}

The 5 hour discharge rate seemed to improve the credit over a ten hour rate as indicated in Figure 3.3-23, and this was interpreted as a more effective use (cycling) of storage capacity at the 5 hour rate. As expected, overall annual energy credit increased with storage capacity but decreased on a per-unit-of-storage basis as will be seen in subsequent plots.

\section{Effect of Storage Efficiency}

The computer model was run for several values of storage efficiency ranging from 60 to $90 \%$. Figure $3.3-24$ shows the range of effects on annual energy credit for the Blue $\mathrm{Hill}$ and Lubbock wind data.

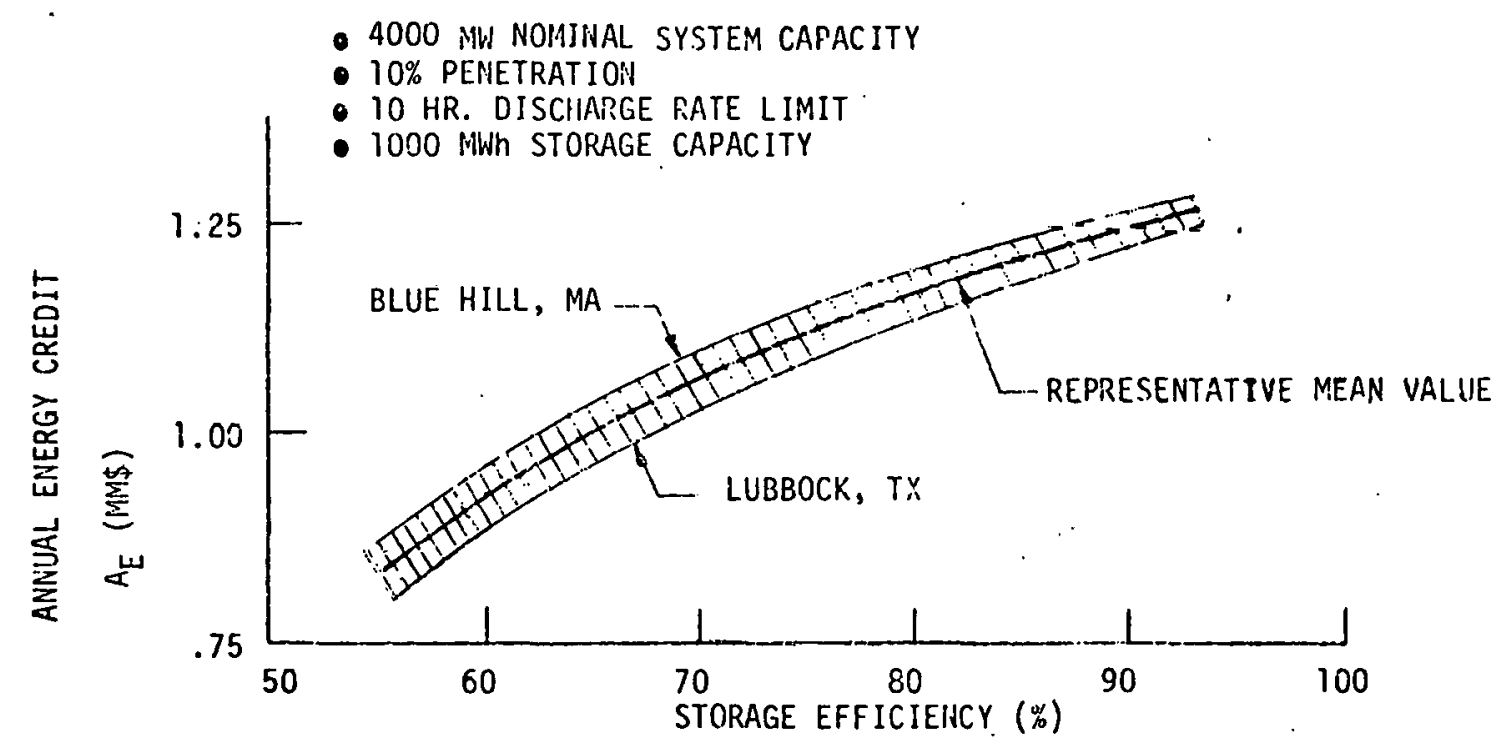

FIGURE 3.3-24. AINNUAL ENERGY CREDIT COMPARISON FOR VARIOUS EFFICIENCIES 
A representative mean value for the annual energy credit as a function of storage efficiency was used to generate a correction factor for the efficiency effect. This correction factor, denoted as $\mathrm{C}_{6}$, is defined by:

$$
C_{\eta}=A_{E} / A_{E}^{0}
$$

where $A_{E}^{0}$ is the annual energy credit at $75 \%$ efficiency. Figure $3.3-25$ illustrates $C_{\eta}$ versus storage efficiency.

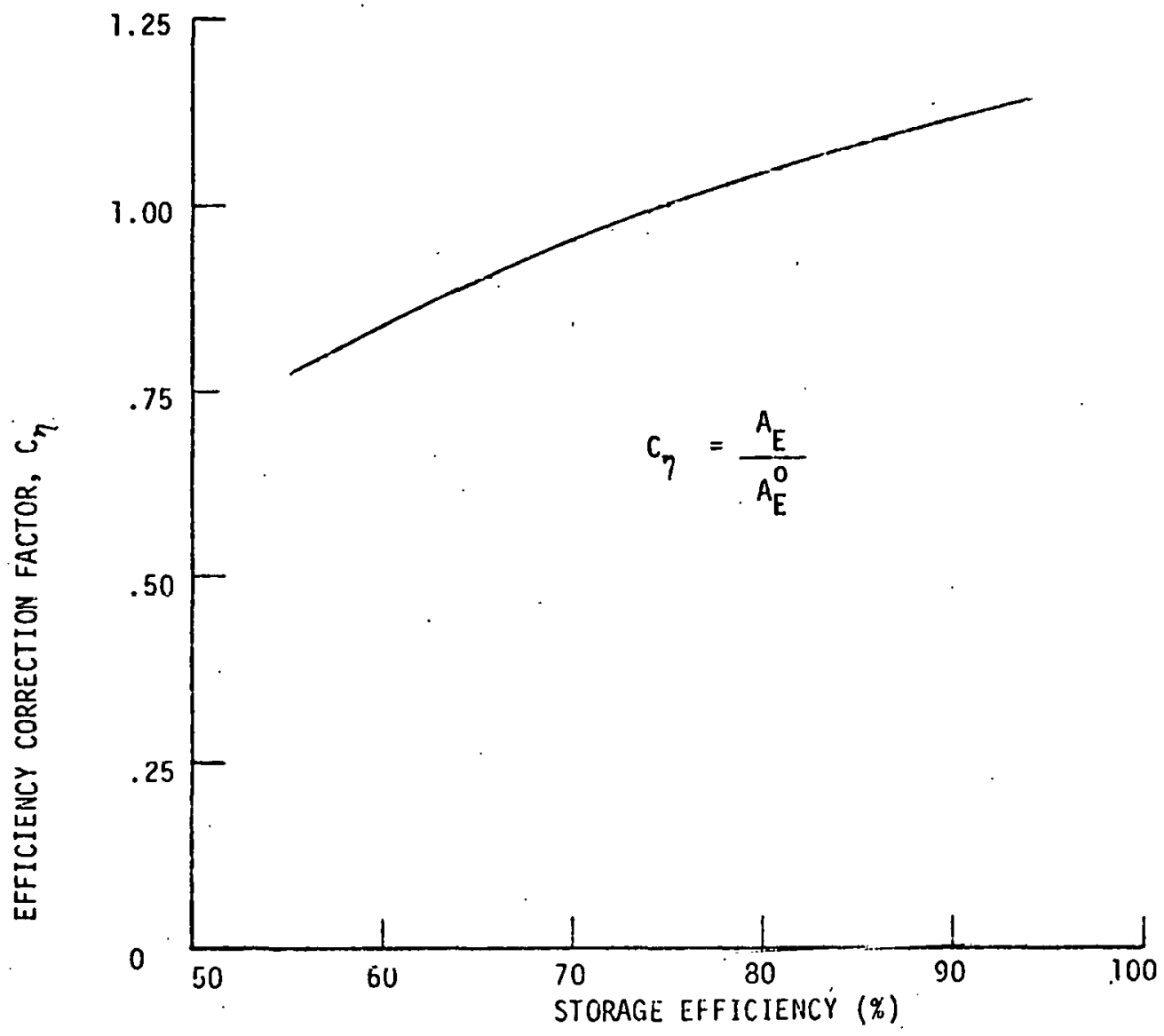

FIGURE 3.3-25. STORAGE EFFICIENCY CORRECTION FACTOR, WIND ENERGY CONVERSION - UTILITY APPLICATION 


\subsubsection{Correlation of Effects on Annual Energy Credits}

As can be seen from Figure 3.3-23, the further analys is and interpreation of the various factors affecting energy storage economics could involve a very large number of variables or "degrees of freedom". A representative mean value approach was evolved in order to simplify and narrow this process to manageable proportions and assist in meaningful interpretation of the results. Figure 3.3-26 shows the upper and lower bounds of annual energy credit as shown in Figure 3.3-23, along with the representative mean value that was used in the subsequent analysis on the utility application of wind energy storage.

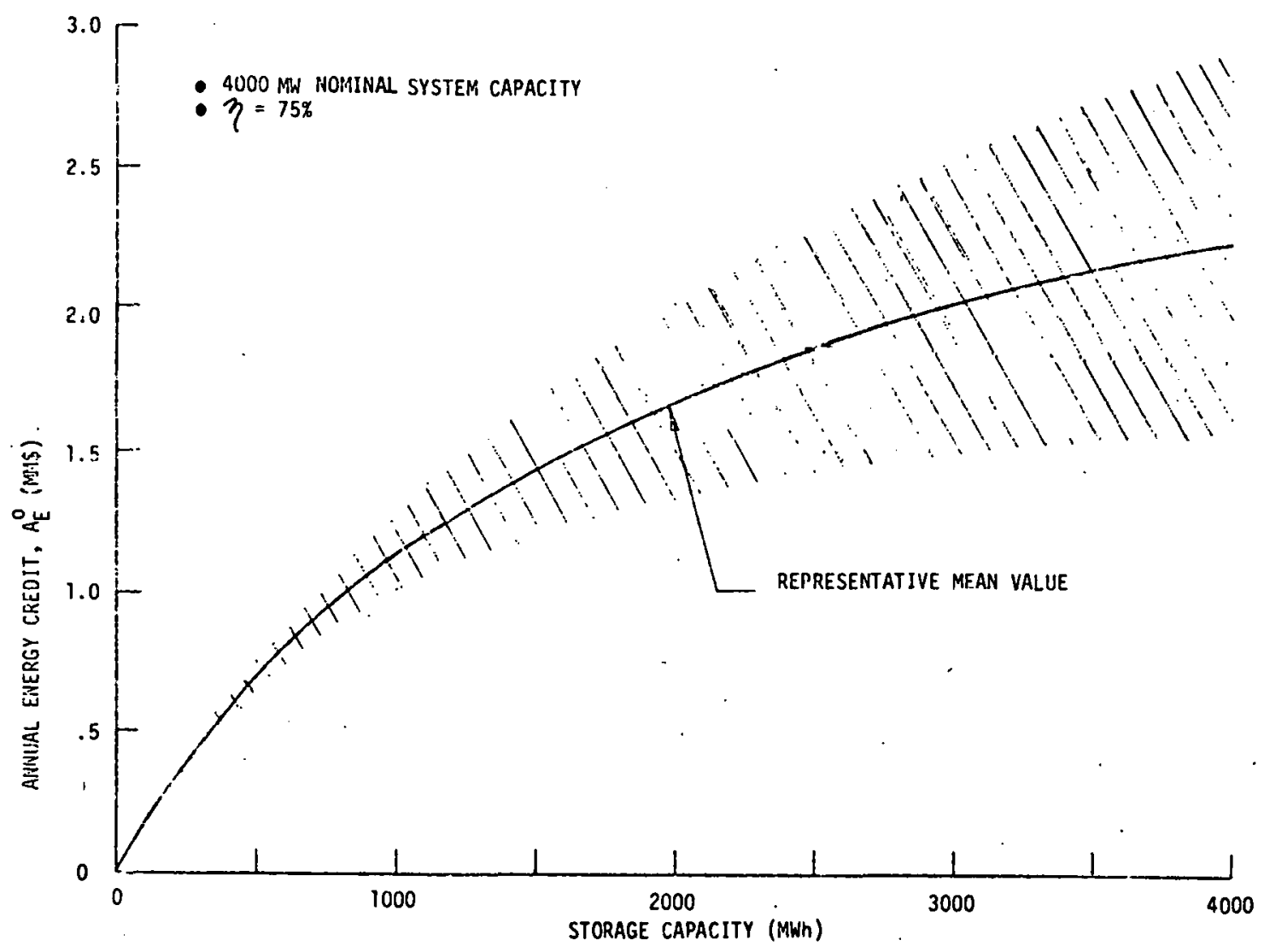

FIGURE 3.3-26. COMPOSITE ENERGY CREDIT, WIND ENERGY CONVERSION UT IL ITY APPLICATION 
The capitalization of the annual energy credit, $A_{E}^{0}$, was discussed in Section 3.3.5.6 with the capitalized energy credit $\left(C_{E}^{0}\right)$ expression repeated here as:

$$
C_{E}^{0}=\left(\frac{1+f}{1+g}\right)^{S} M_{f} \quad \frac{A_{E}^{0}}{F C R}
$$

A table of the quantity $\left(\frac{1+f}{1+g}\right) \leqslant \quad M_{f}$ for the utility application is presented below as a function of start year and fuel escalation rate ( $f$ ).

TABLE 3.3-8. ANNUAL ENERGY CREDIT MULTIPLIER - UTTILITY APFLICATIONN

\begin{tabular}{|c|c|c|c|c|c|c|c|}
\hline \multirow{2}{*}{$\begin{array}{l}\text { START } \\
\text { YEAR }\end{array}$} & \multirow{2}{*}{$\delta$} & \multicolumn{6}{|c|}{$\left(\frac{1+f}{1+g} \delta^{\delta} M_{f} \quad(g=5 \%)\right.$} \\
\hline & & $f=5 \%$ & $6 \%$ & $7 \%$ & $8 \%$ & $9 \%$ & $10 \%$ \\
\hline $\begin{array}{l}1976 \\
1979 \\
1982 \\
1985 \\
1988 \\
1991 \\
1994 \\
1997 \\
2000\end{array}$ & $\begin{array}{r}0 \\
3 \\
6 \\
9 \\
12 \\
15 \\
18 \\
21 \\
24\end{array}$ & 1.7227 & $\begin{array}{l}1.9504 \\
2.0067 \\
2.0645 \\
2.1241 \\
2.1854 \\
2.2484 \\
2.3133 \\
2.3780 \\
2.4486\end{array}$ & $\begin{array}{l}2.2197 \\
2.3490 \\
2.4858 \\
2.6306 \\
2.7838 \\
2.9459 \\
3.1175 \\
3.2990 \\
3.4912\end{array}$ & $\begin{array}{l}2.5159 \\
2.7378 \\
2.9792 \\
3.2419 \\
3.5278 \\
3.8389 \\
4.1775 \\
4.5458 \\
4.9467\end{array}$ & $\begin{array}{l}2.9200 \\
3.2667 \\
3.6544 \\
4.0882 \\
4.5734 \\
5.1163 \\
5.7235 \\
6.4029 \\
7.1629\end{array}$ & \begin{tabular}{|r}
3.3746 \\
3.8801 \\
4.4612 \\
5.1293 \\
5.8975 \\
6.7808 \\
7.7963 \\
8.9639 \\
10.3064
\end{tabular} \\
\hline
\end{tabular}

Storage break-even cost complitations for all of the storage systems considered in this study were adjusted to account for the major differences in concept-peculiar parameters; such as efficiency, operation and maintenance and component replacement requirements. The replacement requirements effect is accounted for in adjusted fixed charge rates (FCR) for the affected systems. For a detailed explanation of how FCR was determined, 
see Volume I Appendices. In addition, the cost of money during construction is accounted for through the application of the construction cost factor $(C C F)^{21,29}$. Table 3.3-9 lists the values for CCF and FCR for each of the 7 storage systems.

TABLE 3.3-9. CONSTRUCTION COST FACTORS AND FIXED CHARGE RATES UT ILITY APPLICATION

\begin{tabular}{|l|c|c|c|}
\hline \multicolumn{1}{|c|}{ STORAGE SYSTEM } & $\begin{array}{c}\text { NOMINAL } \\
\text { EXPECTED } \\
\text { LIFE (YRS) }\end{array}$ & CCF & $F^{*}$ \\
\hline $\begin{array}{l}\text { Pumped Hydro } \\
\text { Above-Ground } \\
\text { Underground }\end{array}$ & 50 & 1.40 & .18 \\
$\begin{array}{l}\text { Underground } \\
\text { Compressed Air }\end{array}$ & 30 & 1.17 & .18 \\
$\begin{array}{l}\text { Batteries } \\
\text { Lead-Acid } \\
\text { Advanced } \\
\text { Inertial (Flywheel) }\end{array}$ & 10 & 1.05 & .22 \\
Hydrogen & 20 & 1.05 & .19 \\
\hline
\end{tabular}

*Provides adjustment for comparison of all systems on a common 30 year basis.

\subsubsection{Estimation of Annual 08M Costs}

The best available data for estimating operation and maintenance costs of various storage technologies were used in conjunction with computer model results to compute annual $0 \& M$ costs, $A_{O M}$. Fixed and/or variable component of $0 \& M$ cost are applicable, depending on the type of storage. For the 
variable component, the energy storage discharge energy was used as the basis of estimation according to:

$$
A_{O M}(\text { variable })={ }^{a} O M \times A S D E,
$$

where $\mathrm{a}_{O M}$ is the variable storage 0\&M cost in $\$ / \mathrm{kWh}$ of discharge energy (See Table 5.3-1 in Volume I) and ASDE is the annual sțorage discharge energy. Again, a representative mean value of ASDE, shown in Figure 3.3-27 was used in the conputation of $A_{O M}$.

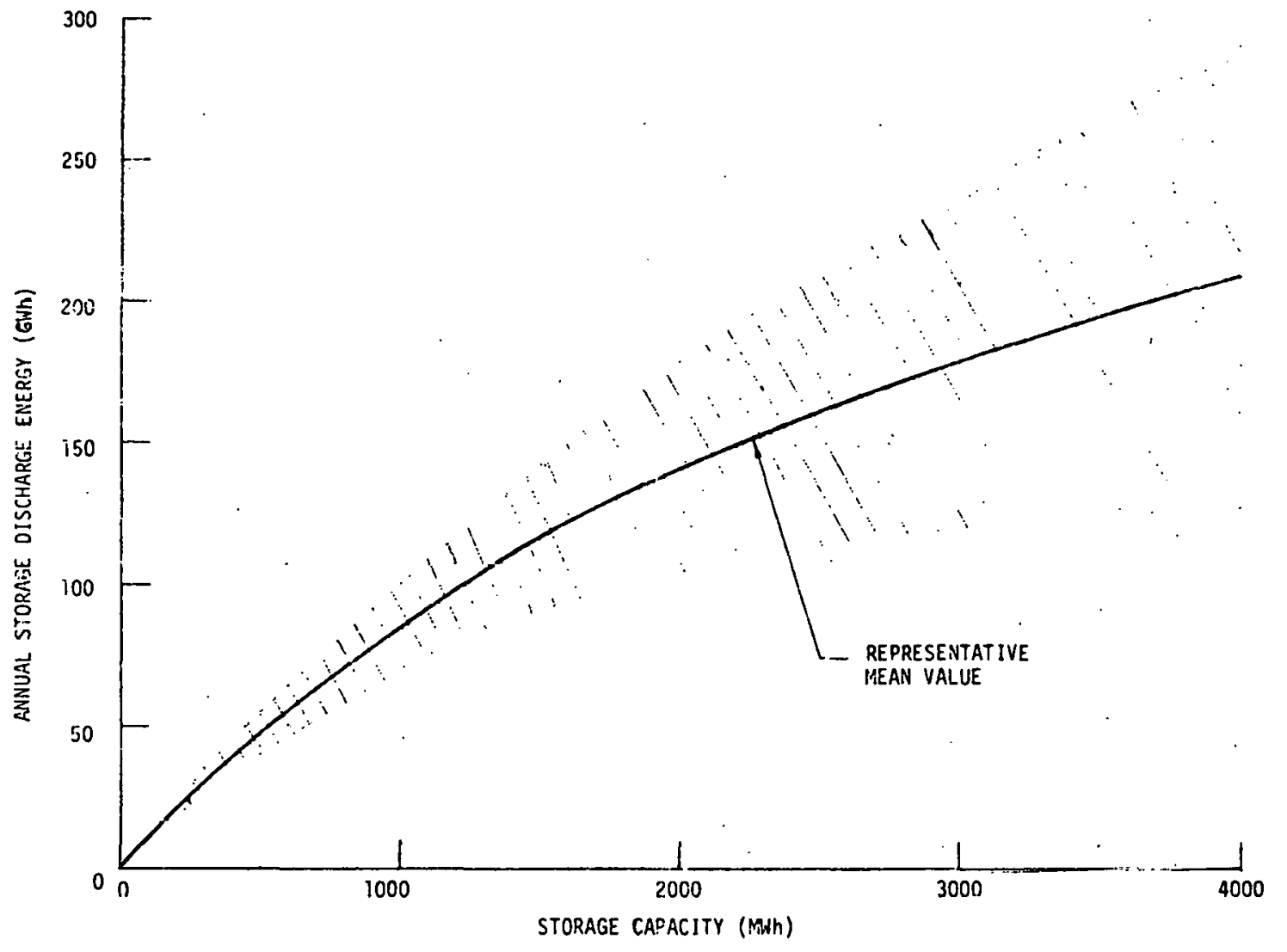

FIGURE 3.3-27. MEAN VALUE OF STORAGE DISCHARGE ENERGY - UTILITY APPLICATION 
Table 3.3-10 below lists the. computed annual 08M costs for each of the storage systems investigated at 1000 MWh storage capacity and 10 hour discharge rate limit.

TABLE 3.3-10. ANNUAL STORAGE OPERATION AND MAINTENANCE COSTS (1000 MWh)

\begin{tabular}{|l|c|}
\hline STORAGE SYSTEM & $A_{O M}(1976 \$ / \mathrm{kWh})$ \\
\hline $\begin{array}{l}\text { Underground } \\
\text { Pumped Hydro }\end{array}$ & $.168^{\star}$ \\
$\begin{array}{l}\text { Above-ground } \\
\text { Pumped Hydro }\end{array}$ & $.168^{\star}$ \\
$\begin{array}{l}\text { Underground } \\
\text { Compressed Air } \\
\text { Lead-Acid }\end{array}$ & .473 \\
Batteries & .043 \\
Advarced Batteries & .255 \\
Inertial (Flywheel) & .473 \\
Hydrogen & .240 \\
\hline
\end{tabular}

*Fixed Component only ( 10 hour discharge rate limit)

\subsubsection{Capacity Credit Effects}

The energy storage capacity credit for the utility application was estimated using the expression:

$$
C C=C * \times 140 \$ / \mathrm{kW}
$$

where $C^{\star}$ is the effective capacity rating of the dedicated storage system and $\$ 140 / \mathrm{kW}$ corresponds to the cost of peaking generation equipment (gas turbines). Although some storage systerils in specific utility systems may displace some higher-valued intermediate capacity, the $\$ 140 / \mathrm{kW}$ is a conservative but realistic estimate. 
Figure 3.3-28 illustrates the variation of $C^{*}$ with storage capacity and shaws the representative mean value employed in further analyses.

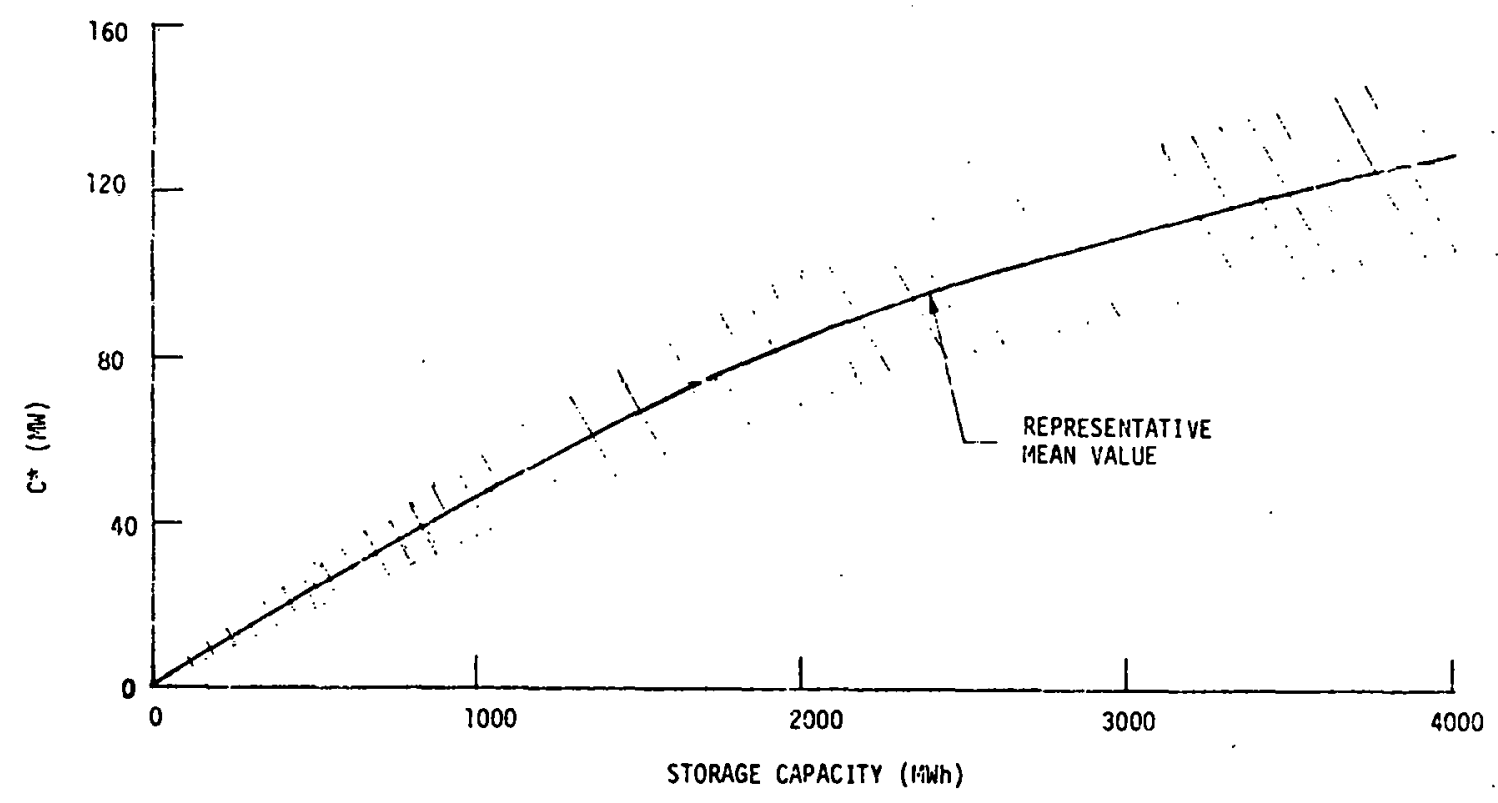

FIGURE 3.3-28. ESTIMATED EFFECTIVE LOAD CARRYING CAPACITY FOR DEDICATED WIND CHARGING OF ENERGY STORAGE-UTILITY APPLICATION

\subsubsection{Capital Cost Comparisons}

Break-even capital costs and projected system costs were first computed for one set of conditions for each of the storage types considered in the study. This was done in order to provide more insight into the rankings based on levelized annual cost (Section 1.1). Adjusted break-even costs were computed for 1000 Wh of storage capacity, 10 hour discharge rate and the extreme economic conditions of $10 \%$ fuel price escalation rate and 
2000 start year. Comparison with system cost estinates is presented in Table 3.3-11 which provides a measure of relative economic potential.

TABLE 3;3-11. BREAK-EVEN COSTS WITH WIND CHARGING COMPARED TO SYSTEM COST ESTIMATES - YEAR 2000, 10\% FUEL ESCALATION

\begin{tabular}{|l|c|c|c|c|}
\hline \multicolumn{1}{|c|}{ STORAGE CONCEPT } & $\begin{array}{l}\text { BREAK- } \\
\text { EVEN } \\
\text { COST }\end{array}$ & $\begin{array}{c}\text { COST * } \\
\text { ESTIMATE }\end{array}$ & $\triangle$ & $\begin{array}{c}\text { POTENT IAL } \\
\text { VIABILITY }\end{array}$ \\
\hline Underground Pumped Hydro & 547 & 230 & +317 & Yes \\
Above-Ground Pumped Hydro & 547 & 190 & +357 & Yes \\
Uncierground Compressed Air & 591 & 300 & +291 & Yes \\
Lead-Acid Batteries & 585 & 790 & -205 & No \\
Advanced Batteries & 594 & 310 & +284 & Yes \\
Inertial Storage (Flywhee1) & 647 & 1850 & -1203 & No \\
Hydrogen & 411 & 450 & -39 & No \\
\hline
\end{tabular}

All Costs in $1976 \$ / \mathrm{kW}$

* Figures include learning curve estimates from Vol. I, Section 5.3.3, and reflect most optimistic costs.

Capacity credit and transmission and distribution credits (where applicable) are included in the above data as part of the break-even cost goal. The results inaicate four systems of potential viability: both types of hydro, compressed air and advanced batteries. These four, plus lead-acid batteries (due to general interest in this technology) were selected for the detailed analysis which follows. The above screening affords maximum opportunity for a storage concept to demonstrate economic potential, with cost estimates 
taken from the year 2000 projected values of Figure 5.3-1. of Volume I. A broad range of comparative analyses were made for the five technologies of interest for the utility application: both types of Pumped Hydro, Underground Compressed air, Lead-acid Batteries and Advanced Batteries. For these cases, break-even costs at a nominal storage capacity of 1000 MWh are shown in Table 3.3-12 along with the capitalized values of energy credit, 0\&M, capacity credit, and (where applicable) a nominal T\&D credit.

TABLE $3.3-12$. BREAK-EVEN COST COMPONENTS

- 1000 MWh Storage Capacity

- 10 Hour Discharge Rate Limit

\begin{tabular}{|c|c|c|c|c|c|c|c|c|}
\hline \multirow[t]{2}{*}{$\begin{array}{c}\operatorname{COST} \\
(\$ / \mathrm{kW})\end{array}$} & \multicolumn{2}{|c|}{$\begin{array}{l}\text { PUMPED } \\
\text { HYDRO }\end{array}$} & \multicolumn{2}{|c|}{$\begin{array}{l}\text { UNDERGROUND } \\
\text { COMPRESSED AIR }\end{array}$} & \multicolumn{2}{|c|}{$\begin{array}{l}\text { LEAD-ACID } \\
\text { BATTERIES }\end{array}$} & \multicolumn{2}{|c|}{$\begin{array}{l}\text { ADVANCED } \\
\text { BATTERIES }\end{array}$} \\
\hline & $\begin{array}{l}1985 \\
f=6 \%\end{array}$ & $\begin{array}{l}2000 \\
f=10 \%\end{array}$ & $\begin{array}{l}1985 \\
f=6 \%\end{array}$ & $\begin{array}{r}2000 \\
f=10 \%\end{array}$ & $\begin{array}{c}1985 \\
f=6 \%\end{array}$ & $\begin{array}{r}2000 \\
f=10 \%\end{array}$ & $\begin{array}{l}1985 \\
f=6 \%\end{array}$ & $\begin{array}{l}2000 \\
f=10 \%\end{array}$ \\
\hline$C_{E}$ & 142 & 689 & 136 & 660 & 103 & 501 & 109 & 527 \\
\hline $\mathrm{C}_{\mathrm{OM}}$ & 16 & 16 & 45 & 45 & 3 & 3 & 20 & 20 \\
\hline $\begin{array}{c}C_{B E} \\
\text { (no } \\
\text { credits) }\end{array}$ & 90 & 480 & 78 & 525 & 95 & 474 & 85 & 483 \\
\hline CC & 66 & 66 & 66 & 66 & 66 & 66 & 66 & 66 \\
\hline TDC & 0 & 0 & 0. & 0 & 45 & 45 & 45 & 45 \\
\hline$C_{\mathrm{BE}}$ & 156 & 547 & 144 & 591 & 206 & 586 & 196 & 594 \\
\hline
\end{tabular}

The preceding table is principally useful in showing the relative magnitudes of the major factors affecting break-even cost. It also reveals the dominance 
of the energy credit with future start date and the higher rates of fuel escalation. Differences in results at 5 hour discharge rates v.s. 10 hour are treated further in data and discussions which follow.

Figures 3.3-29 and 3.3-30 show the break-even results vs. estimated system costs for a nominal $6 \%$ escalation case as well as for boundary cases of zero differential fuel escalation and a ten percent fuel escalation with a year 2000 start. The amount by which the break-even cost exceeds the system cost in each reflects the degree of economic viability, if any, for storage dedicated to wind system charging.

An important finding of the break-even analys is is that energy-saving credit alone is not sufficient to achieve early viability. There must be some form of benefit due to displacement of other equipment. Estimates of capacity credit have been developed in this study. Values for T\&D credits as developed by ulliers $21,24,25$ werc reviowed and a nnminal value of same has been added parametrically here to give a better indication of net effect of major storage system credits on break-even cost.

\subsubsection{Viability Comparison of the Selected Storage Systems}

For the four systems selected for more detailed comparison, Figure 3.3-31 presents the difference between break-even cost and system cost estimates versus storage capacity. A positive value indicates potential viability with the extreme 10\%, year 2000 conditions assumed as before. It can be seen that pumped hydro storage has the highest potential, although advanced batteries are close on a 5 hour basis. Lead-acid batteries do not achieve 


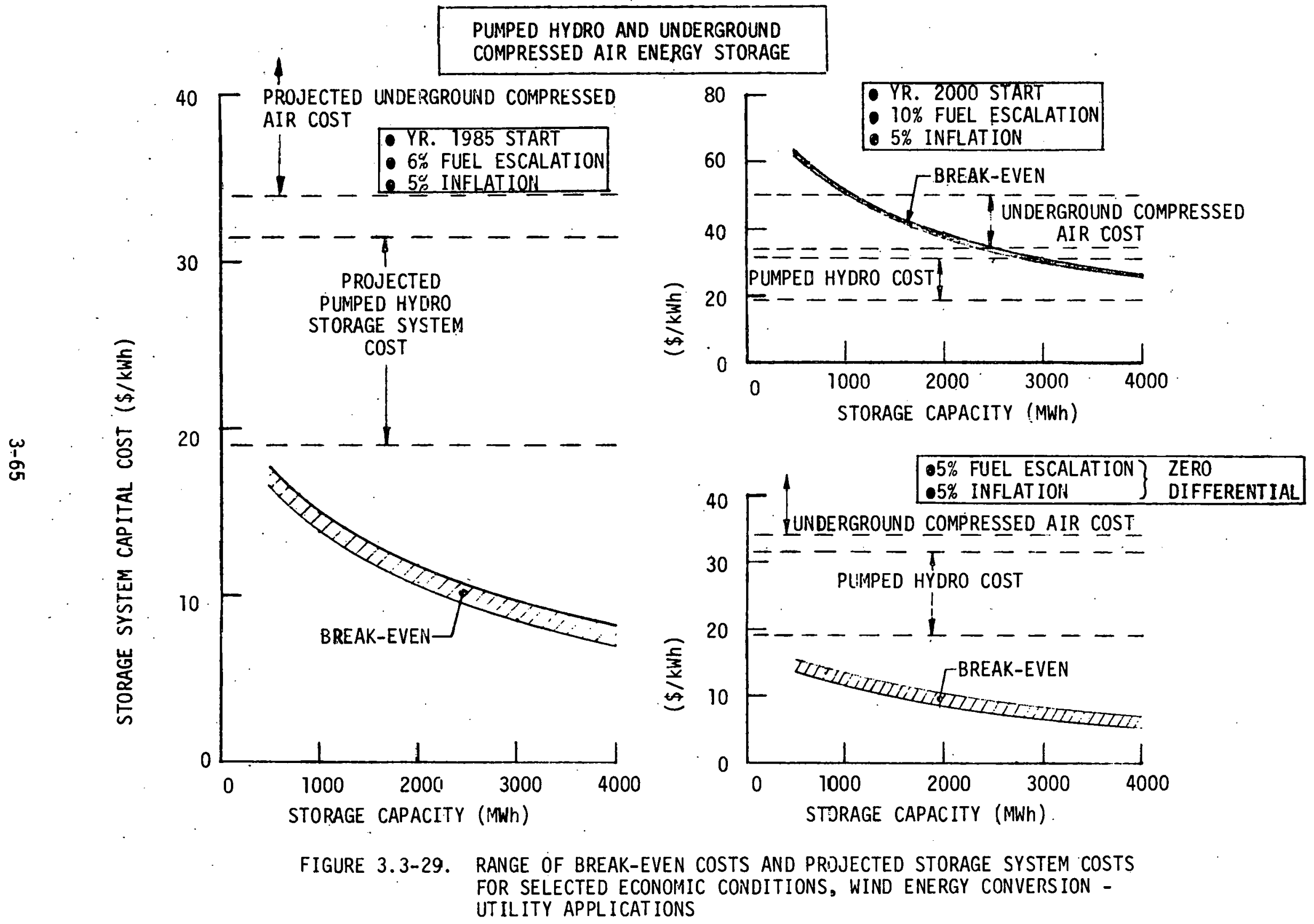




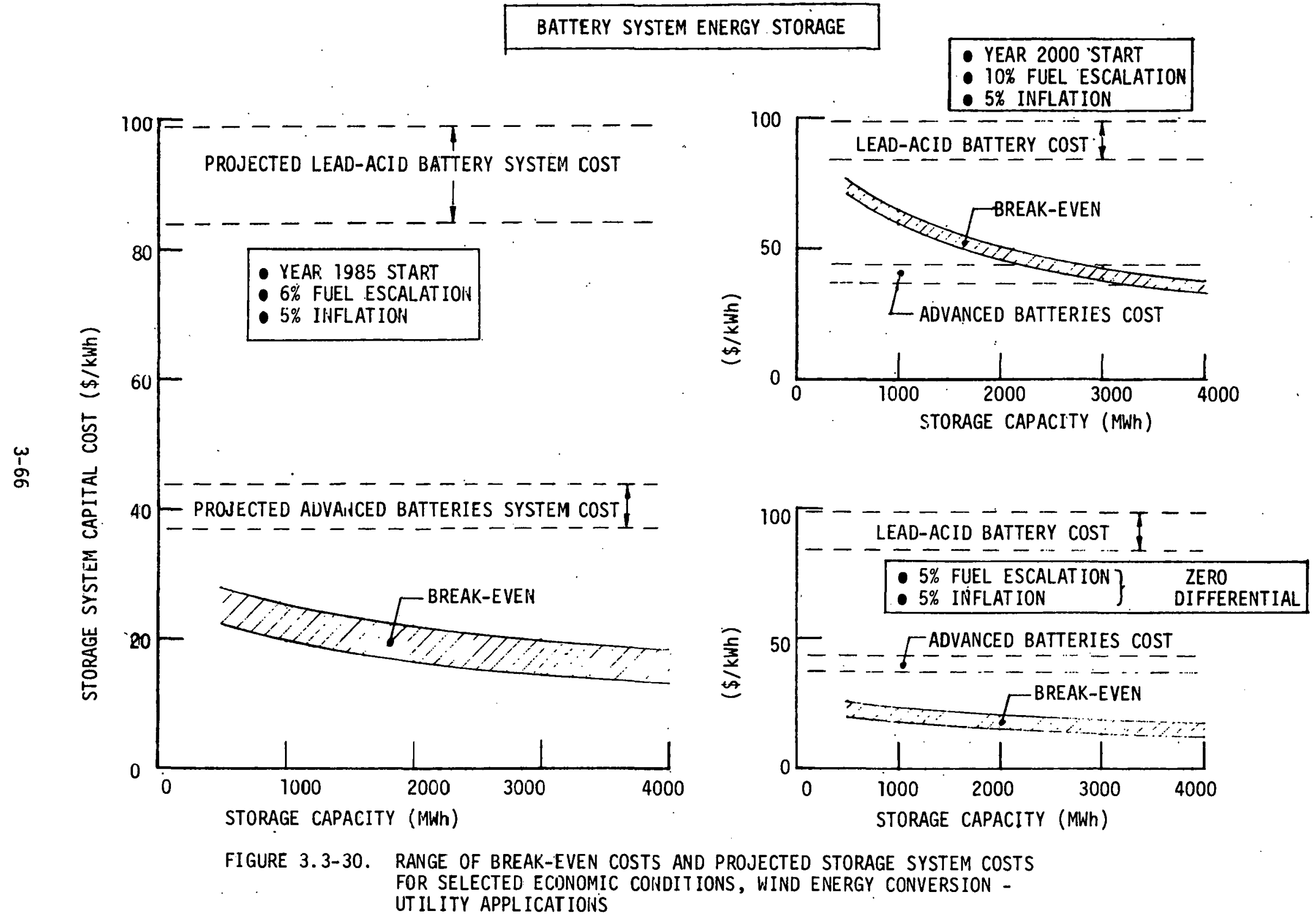




\begin{tabular}{l} 
- YEAR 2000 START \\
10\% FUEL ESCALATION \\
5\% INFLATION \\
POSITIVE VALUES INDICATE VIABILITY \\
\hline
\end{tabular}
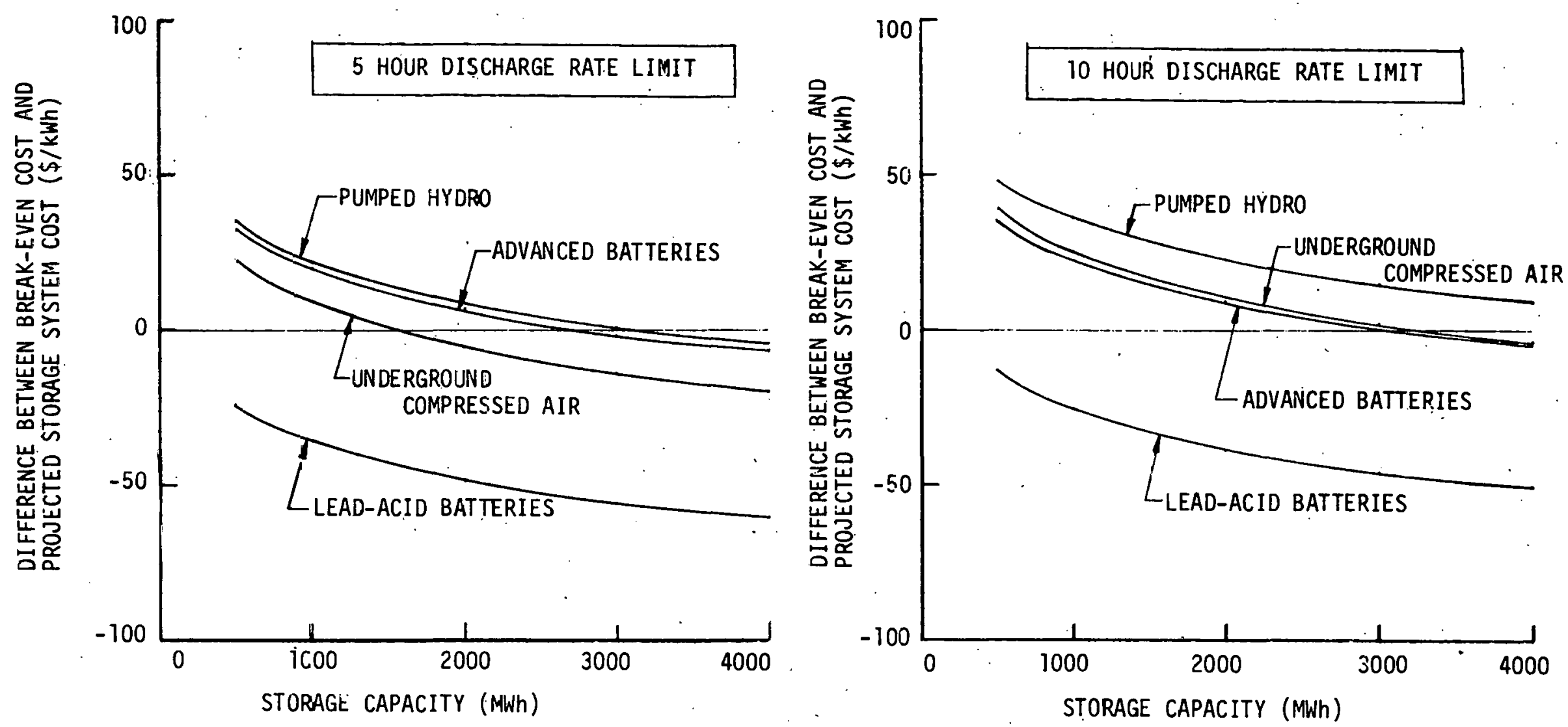

FIGURE 3.3-31. VIABILITY COMPARISONS FOR SELECTED ENERGY STORAGE TECHNOLOGIES, WIND ENERGY CONVERSION - UTILITY APPLICATIONS 
viability for dedicated utility wind system use under the conditions assumed here. There are obviously many escalation rate-start year combinations under which a given storage system will become economic. Figure 3.3-32 shows the break-even cost for pumped hydro and underground compressed air storage (which are virtually identical) plotted versus start year and fuel price escalation rate. Also shown are current cost estimates. Thus, if the escalation rate is $8 \%$, pumped hydro reaches viability by about 1981 but at $7 \%$ escalation would not be viable until 1990. The reader can test viability against any estimates of system cost, escalation rate and start year. Figure 3.3-33 is a similar chart for advanced batteries.

It should be pointed out that the break-even results of Figure 3.3-32 are those for pumped hydro. The compressed air break-even curves very nearly coincide with those for pumped hydro; therefore, it was convenient to show the system costs for both concepts on one plot.

\subsubsection{Optimum Storage Size}

The optimum size of energy storage is determined by finding the maximum difference between break-even value and total system cost. Table 3.3-13 below shows the process for advanced batteries ( 5 hour) at the $10 \%$, year 2000 condition. 
PUMPED HYDRO AND

UNDERGROUND COMPRESSED

AIR STORAGE

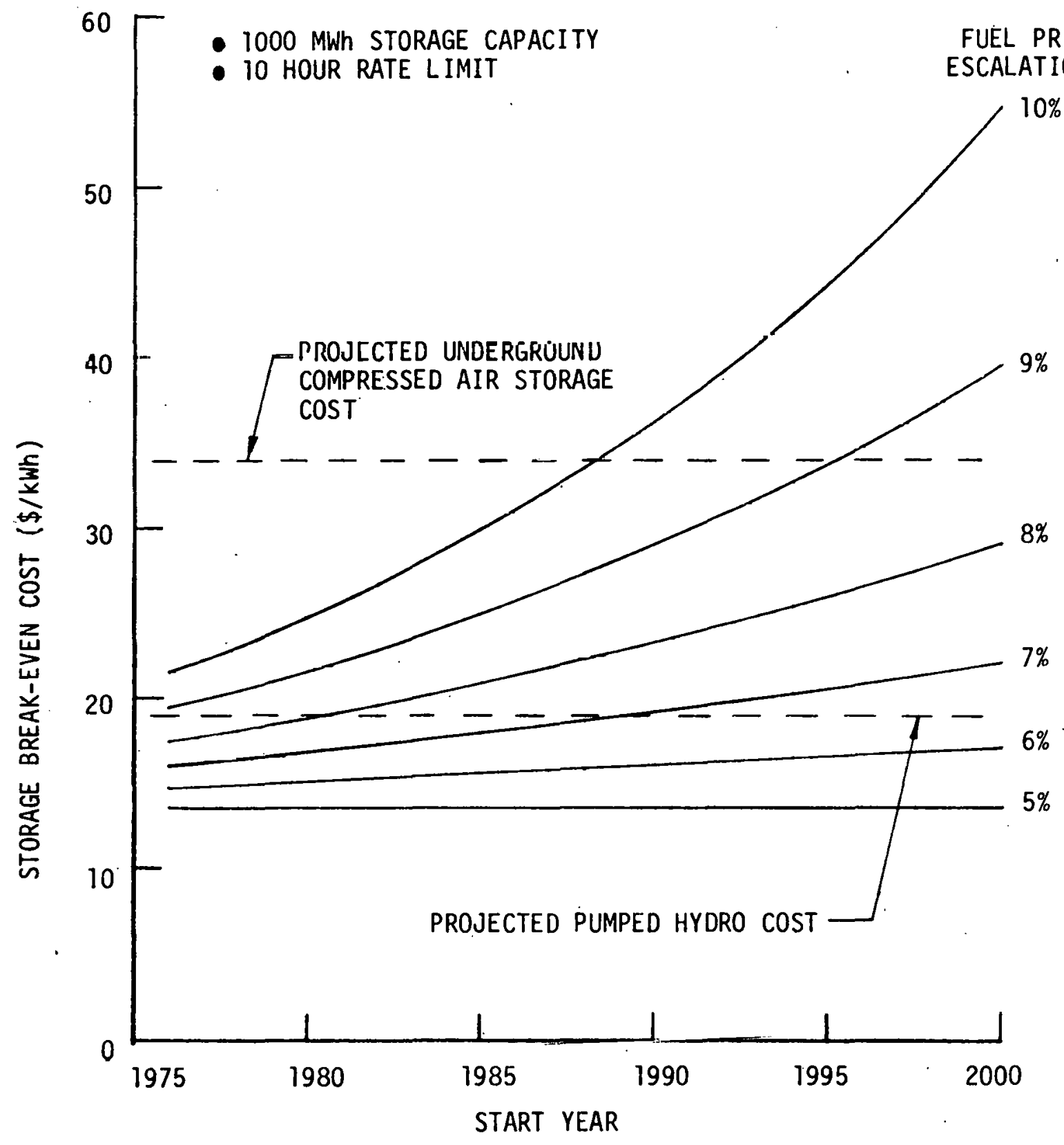

FIGURE 3.3-32. IMPACT OF START YEAR AND FUEL PRICE ESCALATION (COST OF GENERATION) ON STORAGE BREAK-EVEN COST GOALS, WIND ENERGY CONVERSION-UTILITY APPLICATION 


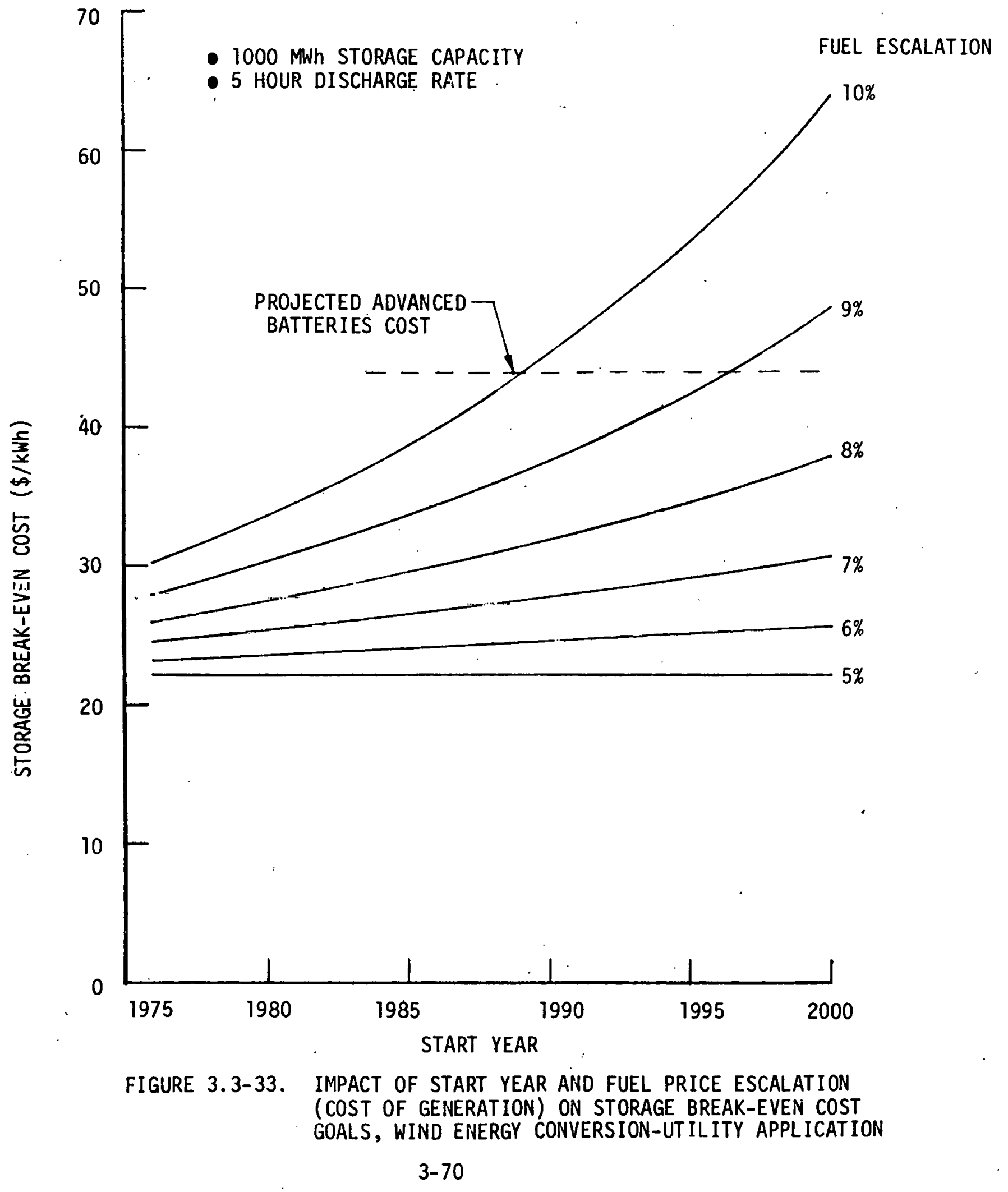


TABLE 3.3-13. STORAGE SIZE OPTIMIZATION VALUES - ADVANCED BATTERIES (5 HR)

\begin{tabular}{|c|c|c|c|c|}
\hline $\begin{array}{c}\text { STORAGE } \\
\text { SIZE } \\
(\text { MWh })\end{array}$ & $\begin{array}{c}\text { BREAK-EVEN } \\
\text { COST } \\
\$ / \mathrm{kWh})\end{array}$ & $\begin{array}{c}\text { SYSTEM } \\
\text { COST } \\
(\$ / \mathrm{kWh})\end{array}$ & $\begin{array}{c}\text { SAVINGS } \\
(\$ / \mathrm{kWh})\end{array}$ & $\begin{array}{c}\text { TOIAL } \\
\text { CAPITAL IZEP } \\
\text { SAVINGS }(10 \%\end{array}$ \\
\hline 500 & 76.4 & 44 & 32.4 & 16.2 \\
1000 & 63.9 & $\vdots$ & 19.9 & $19.9 *$ \\
1500 & 56.1 & $\vdots$ & 12.1 & 18.2 \\
2000 & 50.6 & & 6.6 & 13.2 \\
\hline
\end{tabular}

*Optimum

The above data is shown graphically in Figure 3.3-34, along with similar curves for underground compressed air and pumped hydro. Note that the better economics of pumped hydro seen in Figure 3.3-31 are reflected in a larger capacity when the system is optimized.

As fiuel price escalation rate increases and the start year is moved out further in time, storage economics obviously improve. This results in a steady increase in the optimum storage size. The effect is illustrated in Figlire 3.3-35 for pumped hydro storage. For example, at $9 \%$ fuel escalation about 800 MWh is cptimum for a 1985 start, but at year 2000 this has almost doubled to $1500 \mathrm{IWh}$. 
- YEAR 2000 START

- 10\% FUEL ESCALATION

- 5\% INFLATION
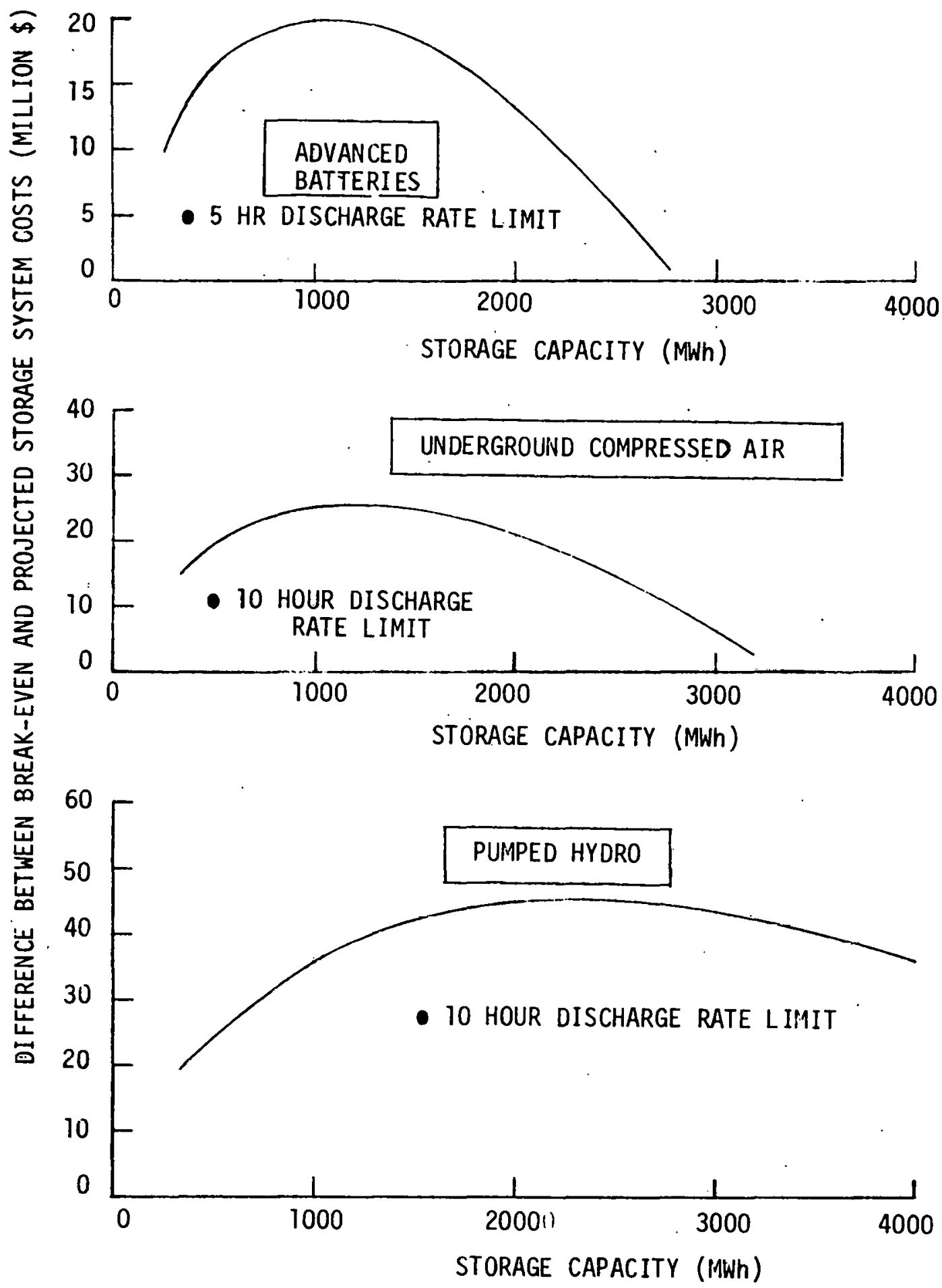

FIGURE 3.3-34. OPTIMUM (ECONOMIC) SYSTEM SIZES FOR SELECTED ENERGY STORAGE METHODS, WIND ENERGY CONVERSION, UTILITY APPLICA 


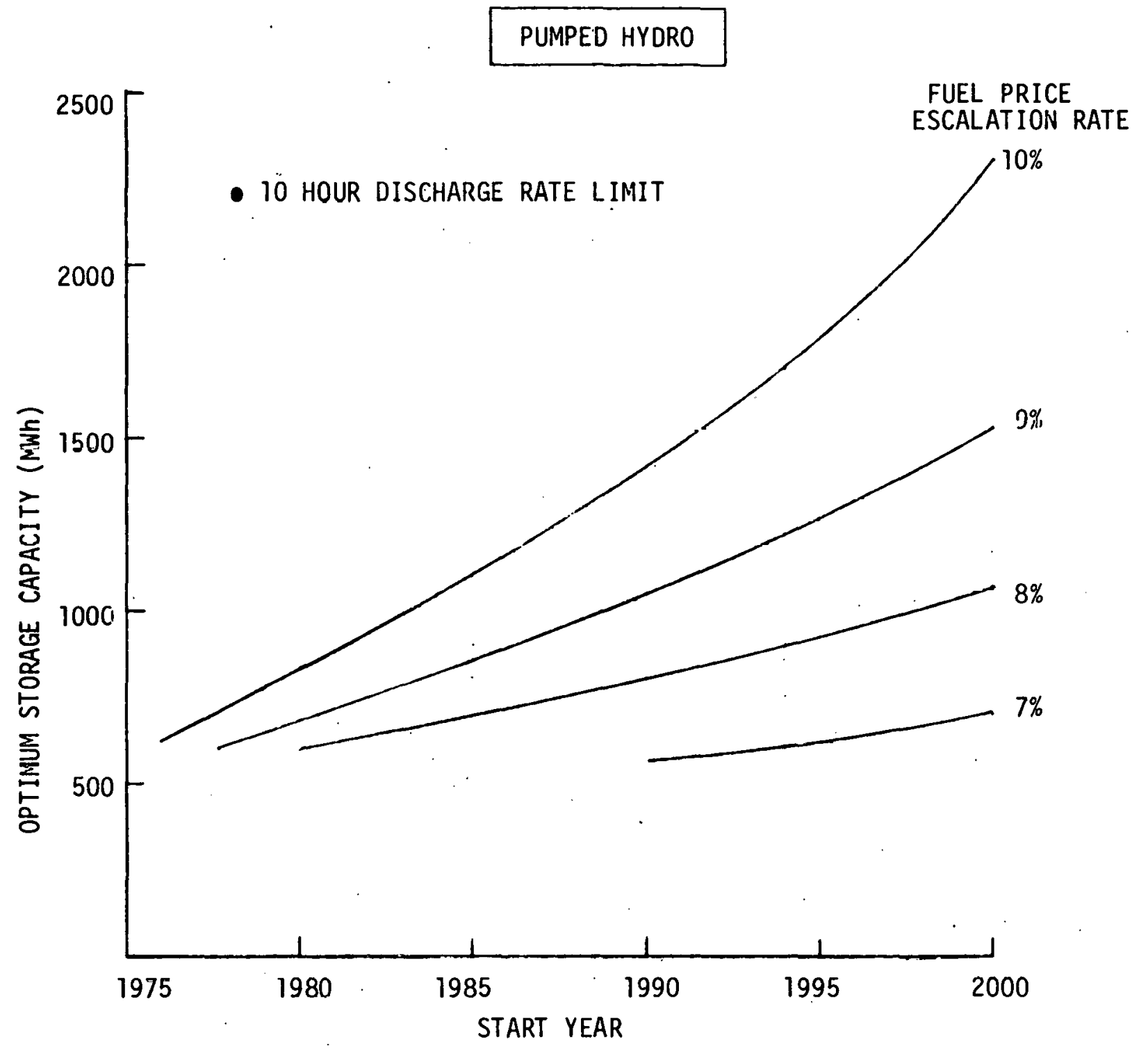

FIGURE 3.3-35. IMPACT OF START YEAR AND FUEL PRICE ESCALATION ON OPTIMUM ENERGY STORAGE SYSTEM CAPACITY, WIND ENERGY CONVERSION, UTILITY APPLICATION 


\subsubsection{UTILITY SYSTEM PLANNING ANALYSIS}

This section contains the analysis and results of a case study performed using a Monthly Energy Production Simulation program for a large utility pool. The overall purpose of this analysis was to determine the worth of energy storage based on a full scale utility planning simulation in which the generation mix effects and loss of load probabilities could be calculated. The results were used as a point of comparison with other data obtained during the overall energy storage study and also as a means of obtaining answers to other specific questions including energy source forecasting and load management effects. This case study was performed by General Electric Company's Electric Utility Systems Engineering Department, Schenectady, N.Y., in cooperation with GE-Advanced Energy Programs, Valley Forge, $\mathrm{Pa}$. The case selected is based on projected conditions of load, generation mix and other factors for the New England Power Pool in the year 1995. It should be noted that generally available information was used in this analysis and no inference is intended that the conditions postulated will in fact occur in the manner described. Dr. H. G. Sto11, A. L. Desell, and L. L. Iovinelli of GE-EUSED were the principal investigators for this work. 
POTENTIAL ENHANCEMENTS OF. STORAGE GENERATION TO WECS: A CASE STUDY. OF NEW ENGLAND POWER POOL IN 1995.

\subsection{GENERAL}

The specific objective of this study was to evaluate the benefits of storage to WECS on the New England Power Pool System. System representative data was gathered from Federal Power Commission reports. The WECS output characteristics of Boston, Massachusetts were developed by GE-Advanced Energy Programs. These characteristics were integrated into a power system analysis to determine the potential value of WECS and several storage devices.

\subsection{STUDY METHODOLOGY}

The Mnnthly Productiun SImulation and Single Area Reliability Programs have been modified to accept as input an hourly representation of WECS. This hourly incorporation of WECS enhances the utility power system simulation package. This model is illustrated in Figure 3.3.7-1.

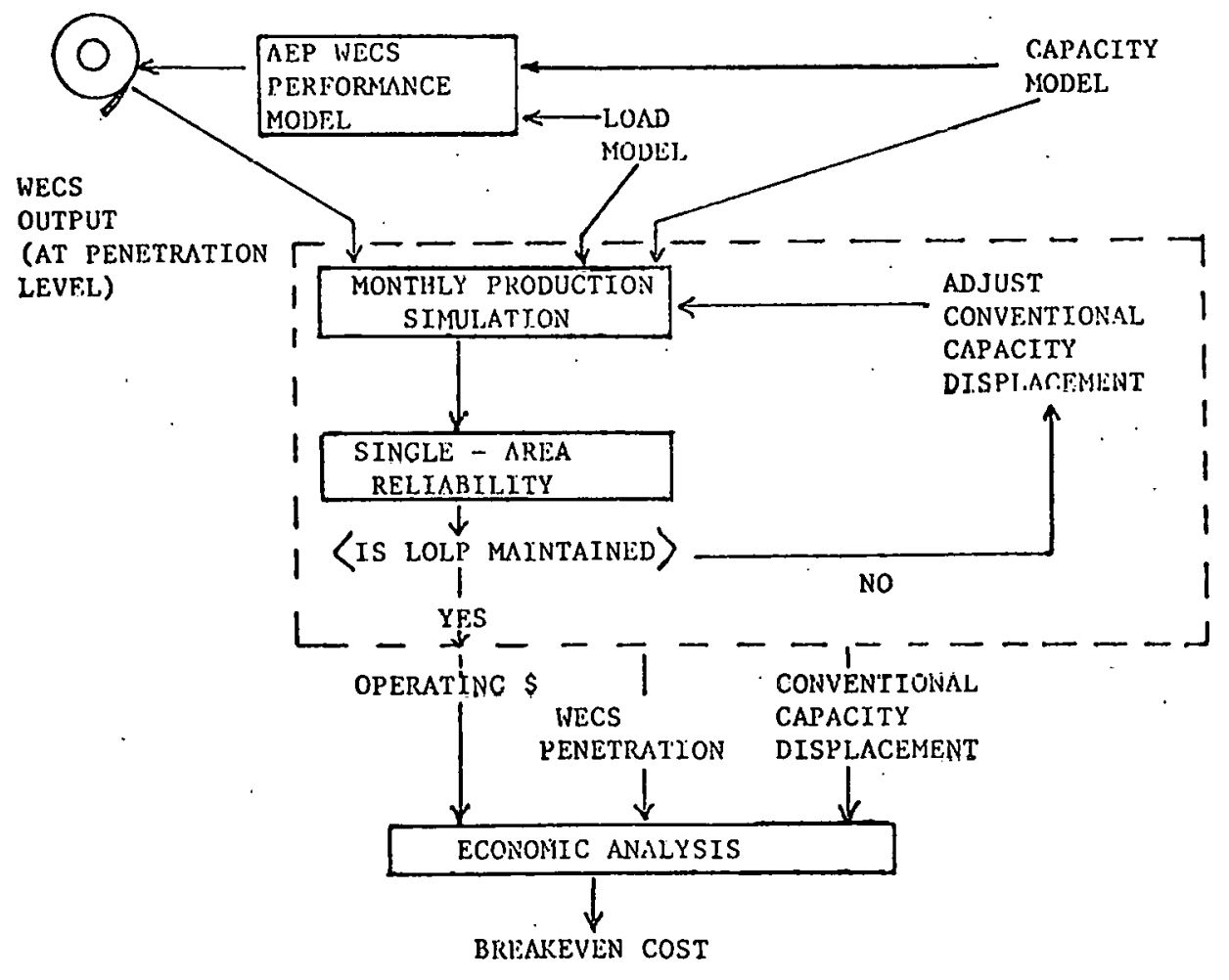

FIGURE $3.3 .7-1$ STUDY MNALYSIS TOOLS 
The chronological hour by hour power output of the WECS energy devices (obtained from GE-Valley Forge in this case) was input into the Monthly Production Simulation Program along with the utility load and capacity model. The utility/pool model is a chronological hour by hour description of the electricity demand of the utility/pool. The capacity model is a description of the capacity characteristics of the utility/pool including, capacity of units, fuel-type, forced and scheduled outage rates and heat rates. Also, input into the program is the WECS penetration and the amount of conventional capacity displacement as a result of the WECS penetration.

The results of the Monthly Production Simulation are a monthly and annual projection of the operating expenses of the utility for a given WECS penetration and corresponding conventional capacity displacement.

The Single Area Reliability Program performs an evaluation of the number of hours of expected shortage of capacity (LOLP) for a given penetration of WECS and correspunding conventional rapacity substitution.

The results of the production simulation (operating $\$$ ) can be combined with the capital costs of the capacity displaced by WECS for an economic analysis of the breakeven costs of the WECS and storage.

These two programs also have the capability to niodel system storage plants on an hour by hour basis, such as pumped storage hydro. This capability can be exploited when studying the applicability of storage systems with WECS. Activities of the storage device over typical weeks can be printed to illustrate the role of the storage device. 


\subsection{ILLUSTRATION OF STUDY ANALYSIS}

This section will illustrate how the models in Figure 3.3.7-1 may be utilized in evaluating the benefits of system storage in coordination with WECS.

Step 1. Base Case - No WECS. The power system is simulated in the horizon year, say 2000, without any penetration of WECS. The system mix is adjusted to an economic mix of generation types; nuclear, coal, gas turbine, combined cycle, and storage. The reliability for the system is measured (LOLP $=.1$ days/year). The levelized annual operating $\$$ of the power system results in $\$ 300$ million.

Step 2. 10\% WECS Penetration, 0\% Additional Storage. Since additional capacity is added to the system, in the form of $10 \%$ WECS penetration (for example $1000 \mathrm{MW})$, the system would be more reliable than the Base Case (i.e., .005 days/year LOLP). Since this is more reliable than the target criteria of .1 days/year LOLP, conventional capacity can be displaced. The choices of displacement capacity would be based on the utilities experience. This displaced capacity could be nuclear, coal, combined cycle, or gas turbine. Or, the displaced capacity could be a combination of all of these types. For this example, consider only the case of nuclear and gas turbine units being displaced.

Step 2A. Gas Turbine Displacement Only. In this step, gas turbine capacity is removed from the system until the system LOLP increases to the target level of .1 day/year (this may actually require 2 or 3 computer simulations of the Single Area Reliability Program to evaluate this MW quantity of gas 
turbines to be displaced). Suppose this answer is $500 \mathrm{MW}$ of gas turbines. The power system is then simulated using the complete analys is capability of Figure 3.3.7-1. The levelized production cost result is $\$ 250$ million.

The breakeven cost is evaluated as that capital cost of the WECS such that the production and investment charges are indifferent between the base case and the Step $2 A$ case. Suppose the capital cost of the gas turbines are 150 \$KW. The breakeven cost of the WECS is then (assuming 18\% fixed charge rate):

$$
\begin{aligned}
\$ 300= & \$ 250-.18 *(.150) * 500+\mathrm{BE}_{\text {WECS }} * .18 \\
\text { Then BE } & =353 \$ / \mathrm{kW}
\end{aligned}
$$

Step 2B. Gas Turbine-Nuclear Displacement. In this step rather than displacing $500 \mathrm{MW}$ of only gas turbines, $200 \mathrm{MW}$ of nuclear units are displaced and $350 \mathrm{MW}$ of gas turhines are displaced. (The actual amount of gas turbines displaced is evaluated using the Single Area Reliability Program and reducing gas turbines until the LOLP of .1 days/year is achieved). The levelized power system production cost is $\$ 260$ million.

The breakeven cost is then computed as (assume nuclear units have a capital cost of $600 \mathrm{KW})$ :

$\$ 300=\$ 260-.18 *(.150 * 350+.600 * 200)+B_{W E C S} * .18$

Then $\quad \mathrm{BE}_{\mathrm{WECS}}=395 \$ / \mathrm{KW}$ 
Step 2C. Gas Turbine-Nuclear Displacement. In this case more nuclear generation is displaced and another breakeven cost of WECS is computed. For example, $400 \mathrm{MW}$ of nuclear and $200 \mathrm{MW}$ of gas turbine. Suppose the breakeven cost is $300 \$ / \mathrm{kW}$.

Step 2D. Evaluation of Optimal Displacement. The three breakeven costs corresponding to the three capacity displacements can be graphed as is illustrated in Figure 3.3.7-2.

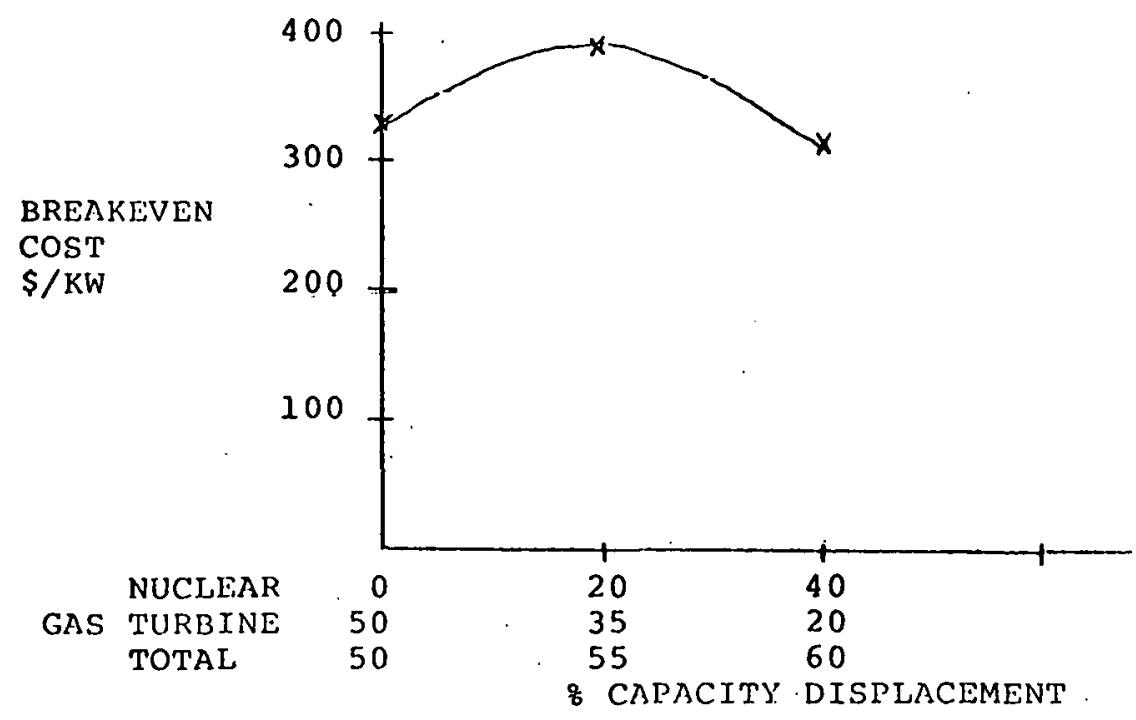

FIGURE 3.3.7-2 CAPACITY DISPLACEMENT RESULT

The point at which the maximum occurs is the optimal capacity displacement at a $10 \%$ WECS penetration. A greater MW amount of nuclear than gas turbines must be displaced to maintain the identical system reliability. Thus a greater total percent capacity displacement as more nuclear is chosen.

Step 3. 10\% WECS Pcnetration, 3\% (of System Capacity) Additional Storage 5 Hour Reservoir Storage.

In this case, the WECS are added as in Step 2 and also storage capacity is added. The same capacity displacement analysis similar to Step 2A, 2B, 2C 
and $2 D$ is performed. This is illustrated in Figure 3.3.7-3 for two values of storage plant capital cost.

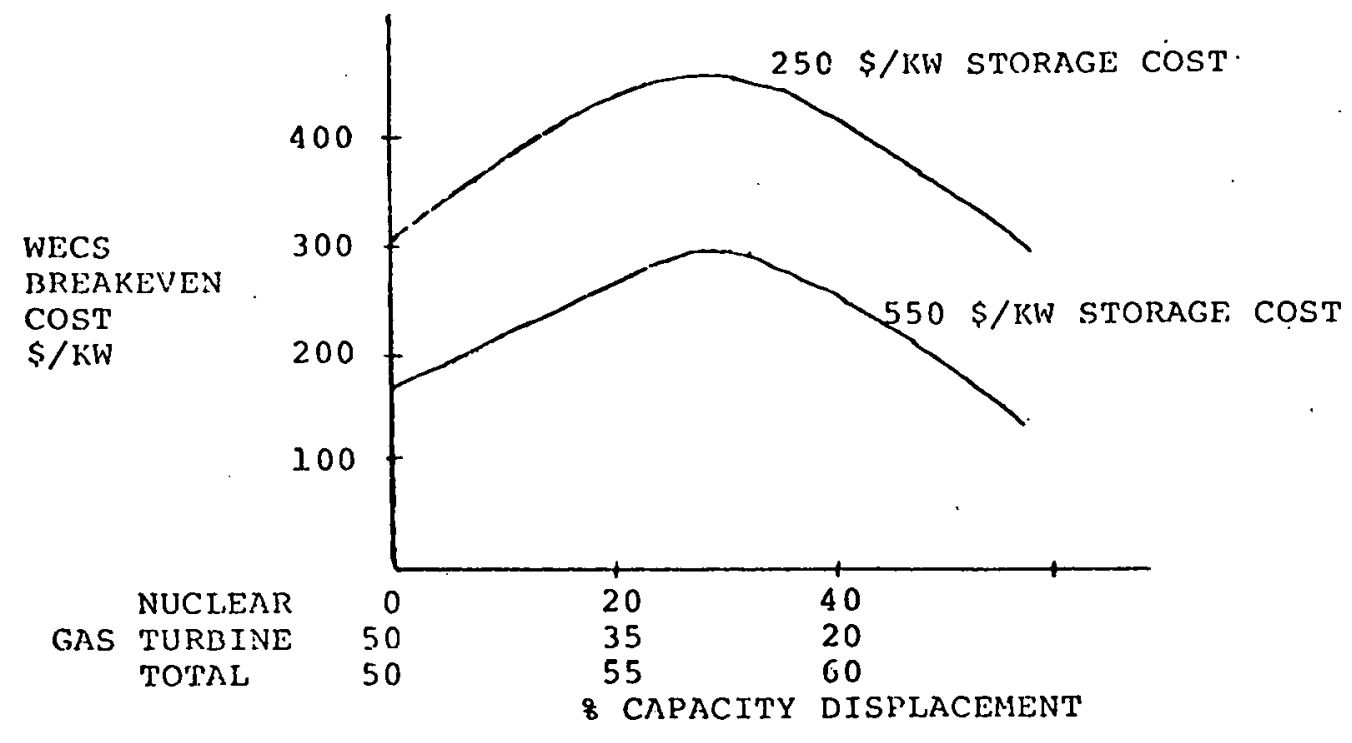

FIGURE 3.3.7-3 WECS BREAKEVEN COST WITH STORAGE

The breakeven value of storage can be computed by using the maximum value of the WECS breakeven cost in Figure 3.3.7-3 and plotting the result versus the capital cost of lie storage devire. This is illustrated in Figure 3.3.7-4.

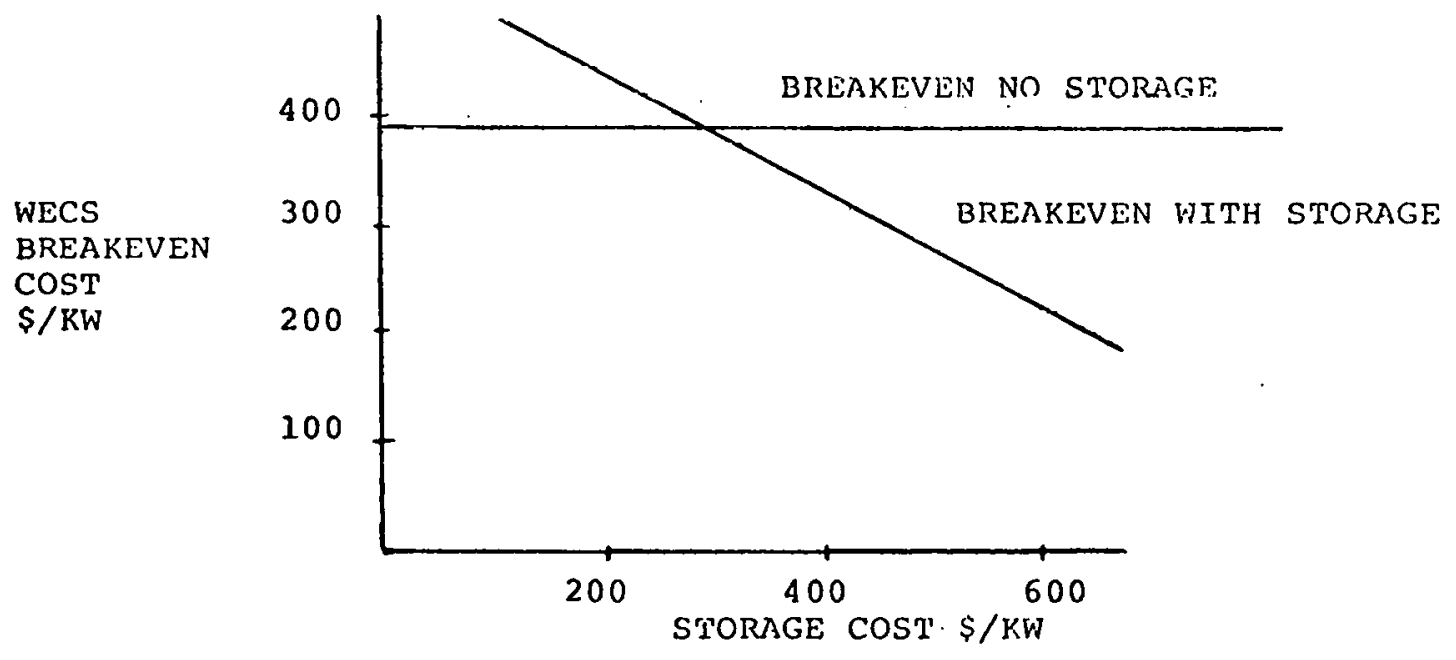

FIGURE 3.3.7-4 STORAGE BREAKEVEN VALUE CALCULATION 
Also plotted on Figure $3.3 .7-4$ is the breakeven cost of WECS with no storage (Step 2B). The breakeven value for storage of $300 \$ / \mathrm{KW}$ results when the two curves intersect.

Also from Figure 3.3.7-4, the added value of storage can be computed. The added value of storage is defined to be the difference between the breakeven cost and the actual equipment cost of storage. In this example, if the actual equipment cost were $250 \$ / \mathrm{KW}$, the added value of storage would be $300-250=50 \$ / \mathrm{KW}$.

The siilluldtion of storage devices can be performed in two ways; (1) storage dedicated to the WECS output, (2) power system wide storage. In dedicated storage, the power operation of the storage device and reservoir management is performed using only the energy from the WECS. Thus, if the WECS devices are not operative, then the storage plant will not recharge. On the other hand, system storage operates regardless of the WECS. In general, a storage device operated on a power system basis will be of greater value to the utility and, therefore, have a higher breakeven cost.

\subsection{POWER SYSTEM DATA}

Plant Costs ( $\$ / \mathrm{KW}$ Including Escalation \& AFDC)

$\begin{array}{ccc}(1980) & 1995 & \text { Escalation } \\ \$ / \mathrm{KW} & \$ / \mathrm{KW} & \% / \mathrm{YR}\end{array}$

$\begin{array}{llrl}\text { Nuclear } & 850 & 1767 & 5 \\ \text { Coal with scrubber } & 700 & 1455 & 5 \\ \text { Gas Turbine } & 190 & 395 & 5 \\ \text { Combined Cycle } & 400 & 831 & 5 \\ \text { Pumped Hydro } & 300 * & 623 & 5\end{array}$

* Note $70 \%$ efficiency of the PSH cycle 
Fixed Charge Rate

Present Worth Rate

Fuel costs

Nuclear

Coal

Residual Oil

Distilled Oil
$18.0 \%$

$10.0 \%$

\& MBTU

(1980)

\&/MBTU

(1995)

176

401

641

$72 \dot{2}$
Escalation

$\% / Y R$

6

6

6

6

operation and Maintenance costs

$\begin{array}{ccc}1980 & 1995 & \text { Escalation } \\ \$ / \mathrm{KW} / \mathrm{YR} & \$ / \mathrm{KW} / \mathrm{YR} & \% / \mathrm{YR}\end{array}$

Nuclear

Coal with Scrubber

15

25

Oil

Gas Turbine

Combined Cycle

Pumped Hydro
31

32

27

36

10

1
6
21

2
5
5
5
5
5
5

Availability of New Plants

(Accounting for Immaturity)

Average Availability

Nuclear

Coal steali

Gas Turbine

Combined Cycle

Pumped storage

oil steam

Peak Load

Peak Load INW

Load Factor \%

LOLP 6 HOURS/YEAR
68

73

88

86

98

78

$1980^{\circ}$

1995

Growth Rate

16850

37000

5.4

61.2 


\subsection{NEW ENGLAND GENERATION ADDITION PLANS}

New England Power Pool currently (end of 1975) has the following generating units on the power system.

$\begin{array}{lcccccc}\text { Nuclear coal } & \text { G.T. } & \begin{array}{c}\text { Oil } \\ \text { Steam }\end{array} & \text { Hydro } & \text { Combined } & \text { Cycle } & \text { Total } \\ 3460 & 485 & 1715 & 11025 & 2910 & 25 & 19595\end{array}$

The projected additions out to 1988 are listed below ("Data on Coordinated Regional Bulk Power Supply Programs", Northeast Power Coordinating Council, April 1977):

\begin{tabular}{|c|c|c|c|c|c|c|}
\hline & Nuclear & Coal & $\begin{array}{l}\text { Gas } \\
\text { Turbine }\end{array}$ & $\begin{array}{l}\text { Oil } \\
\text { steam }\end{array}$ & Hydro & $\begin{array}{l}\text { Combined } \\
\text { Cycle }\end{array}$ \\
\hline $\begin{array}{l}76 \\
77 \\
78\end{array}$ & 830 & & & $\begin{array}{r}960 \\
96 \\
600\end{array}$ & & \\
\hline $\begin{array}{l}79 \\
80\end{array}$ & & & & & & \\
\hline $\begin{array}{l}81 \\
82 \\
83\end{array}$ & $\begin{array}{l}1150 \\
1150\end{array}$ & & 205 & $\begin{array}{l}75 \\
75\end{array}$ & 12 & 270 \\
\hline $\begin{array}{l}84 \\
85\end{array}$ & 2380 & & & & & 147 \\
\hline $\begin{array}{l}86 \\
87\end{array}$ & 3450 & & & & & \\
\hline $\begin{array}{l}88 \\
\text { Capa- } \\
\text { bil1ty } \\
\text { Total } \\
1988\end{array}$ & 1150 & 485 & $1920^{\circ}$ & 12681 & 2922 & 452 \\
\hline
\end{tabular}

In developing the hase casc, consideration must be given to the amount of capacity that can be added from now until the horizon year, 1995. Lead time requirements of base load generation is a primary consideration. For nuclear units, which are the most economic units in NEPOOL, the lead time is approximately 10 to 11 years. Thus, the soonest a new nuclear unit could be placed 
in service, if decided upon today, would be 1988 and thereafter. Consequently, the maximum MW of nuclear capacity addition from 1988 to 1995 could be computed as

$\begin{array}{ll}\text { Peak Load } 1995 & =37000 \\ \text { Peak Load } 1987 & =25695 \\ \text { Load Growth } & =11304 \\ \text { Max. Nuclear Additions } & =\text { Load Growth } \times \text { Reserve Level } \\ 1987-1995 & =11304 \times 1.30=14,695\end{array}$

The maximum nuclear capacity in 1995 is approximately $14695+13570=38265$ MW

5.0 DETERMINATION OF THE OPTIMAL GENERATION EXPANSION THROUGH 1995

\subsection{INITIAL BASE CASE}

The composition of the generating system in 1995 is assumed to be based upon minimiziny lie power supply costs subject to the constraint that the system reliability measure, LOLP=2.5 days/year, is achieved. To determine the optimal composition requires that economic studies be made for various types of generation additions. In NEPOOL, these types would be nuclear, gas turbine and pumped storage hydro (PSH). Other types of generation additions were not considered largely because they would not be economic in NEPOOL or that their use would not be consistent with the national energy policy of reducing oil consumption.

As a basis upon which to proceed, one generation addition plan was postulated. In 1995 this plan had the following characteristics: 
1995 Capacity (MW)

Nuclear $\quad 25694$

Coal 337

Oil steam 12194

Gas Turbine $\quad 4635$

Combined Cycle $\quad 500$

PSH 2600

Pondage Hydro $\quad 1350$

1995 LOLP $=2.81$ Days $/$ Year

1995 Production costs

Fuel \$5656.05 MTLLION

O\&M \$1187.41 MILLION

TOTAL $\$ 6843.471$ MILLION

\subsection{ECONOMIC EVALUATIONS}

Generation equipment has a life of 30 to 50 years. Thus, an economic evaluation cannot be made entirely upon 1 year of economic evaluation. Rather, the evaluation should be made over several years. One method for accounting for the several year evaluation requirement is to compute a levelized annual cost that correctly factors into account inflation and present worthing.

Consider the matter of production costs. If one were to assume inflation increased at $6 \%$ per year and all costs were present worthed at 10\% per year, a $\$ 1.00$ production cost in 1995 would escalate in subsequent years as illustrated below. 
5 Year Inflation and Present Worth Example

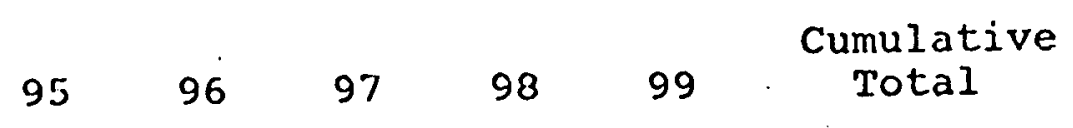

$\begin{array}{lcccccc}\text { Prod. Cost } & 1.00 & 1.06 & 1.12 & 1.19 & 1.26 & \\ \begin{array}{l}\text { Present Worth } \\ \text { Factor }\end{array} & 1.00 & .91 & .83 & .75 & .68 & 4.17 \\ \begin{array}{l}\text { Present Worth } \\ \text { Prod. Cost }\end{array} & 1.00 & .96 & .93 & .89 & .86 & 4.64\end{array}$

A levelized production cost is defined as that single production cost number which if it applied over the entire 5 year period would yield the same cumulative present worth total as the actual year by year present worth total. For the example above, the 5 year levelized production cost is

$$
4.64 / 4.17=\$ 1.11
$$

Intuitively, the levelized value is near the average of the yearly production cost values, but with a slight bias toward the edrly years as a result of the present worthing.

While 5 years was a good levelizing period for the above example, utilities will generally use a longer period of time. Utility practice ranges from a 10 year levelizing period to a 20 and 30 year period. While one might think that since the generation equipment has an expected. life of 40 years, a levelizing period of 40 years should be used. The thinking behind using a levelizing period less than the physical plant life in making economic evaluations is founded upon several arguments. Two of these are discussed as follows: 
(1) Levelizing over a long period (40 years) may lead to an alternative which does not payoff, or crossover, with competing alternatives until after 30 years. In this period, many of the economic projections made in justifying this long range decision may not be realized. Thus, one could make a decision which, if conditions are adverse, lead to an alternative never being economic.

(2) Expanding further upon argument 1, a decision which does not payoff for 30 years means that the added costs of that alternative in the near term will be borne by today's electric consumer. If a similar decision is made the next year, and the year after and so on, as is the case with a growing electric utility, it may be that the ultimate payoffs are always continued to be pushed out 30 years. Hence, what might look like a 30 year payoff in the case of 1 decision, actually may be a continually deferred payoff that is never achieved in the dynamic case of an expanding electric utility.

In this study, a 15 year levelizing period was chosen to represent an average of the utility industry practices.

In this case, the levelizing factor is 1.49 .

\subsection{BASE CASE OPTIMAL GFNERATION EXPANSION}

Several alternative generation expansion cases were made from the initial base case, described in 5.1. Table 3.3.7-1 presents the results. The results are presented relative to the initial base case. The costs are summarized in the last column. The first. item is the levelized (15 year) 
production cost. The second and third items are the levelized irivestment charges associated with the change in capacity from the base case. The last item for each case is the total decision cost.

In Case 2, nuclear generation is added and gas turbines are removed. This case shows a marked improvement over the initial base case.

In Cases 3 and 4, variations were made in the nuclear - PSH composition. These results illustrate that nuclear generation is more economic than PSH in the region of the initial base case.

In Case 5 , the sensitivity PSH and gas turbines were examined.

In Cases 6 and 7, the addition of nuclear and subtraction of gas turbines was further examined as an extension of Case 2 since Case 2 showed a marked economic gradient toward greater nuclear composition. Comparison of Cases 2, 6 and 7 reveal that the optimal nuclear - gas turbine tradeoff is with Case 6 .

On the basis of these simulations, it can be concluded that the base case from which all WECS storage cases should be run from is Case 6 . It is the case with the lowest economic cost. Furthermore, this case doesn't violate any nuclear construction constraints. Even though it does not lie exactly at the optimal point in the minimum cost, because a slight gradient exists for substituting PSH for gas turbines, on a practical basis the difference in cost between Case 6 and the mathematical exact optimal will be very small. 
TABLE 3:3.7-1. RESULTS SUMMARY

\section{\# Case \\ 1 Initial Base \\ 2 Add 1150 Nuclear Subtract $900 \mathrm{GT}$}

3 Subtract 1150 Nuc 24549 Add 800 PSH

\author{
25694 \\ 26844 \\ 24549
}

Description of IT Capacity Nuclear

\begin{abstract}
Add 800 PSH
\end{abstract}




\subsection{CONCLUSION}

Several alternative generation plans have been examined in the process of determining the base case generating composition of NEPOOL in the horizon year 1995. The base case was chosen as the economic optimal considering nuclear, gas turbines and PSH generating types.

\subsection{RESULTS AND ANALYSIS}

The base case of the simulated New England Power Pool was described in Section 3. The composition of the 1995 power system is:

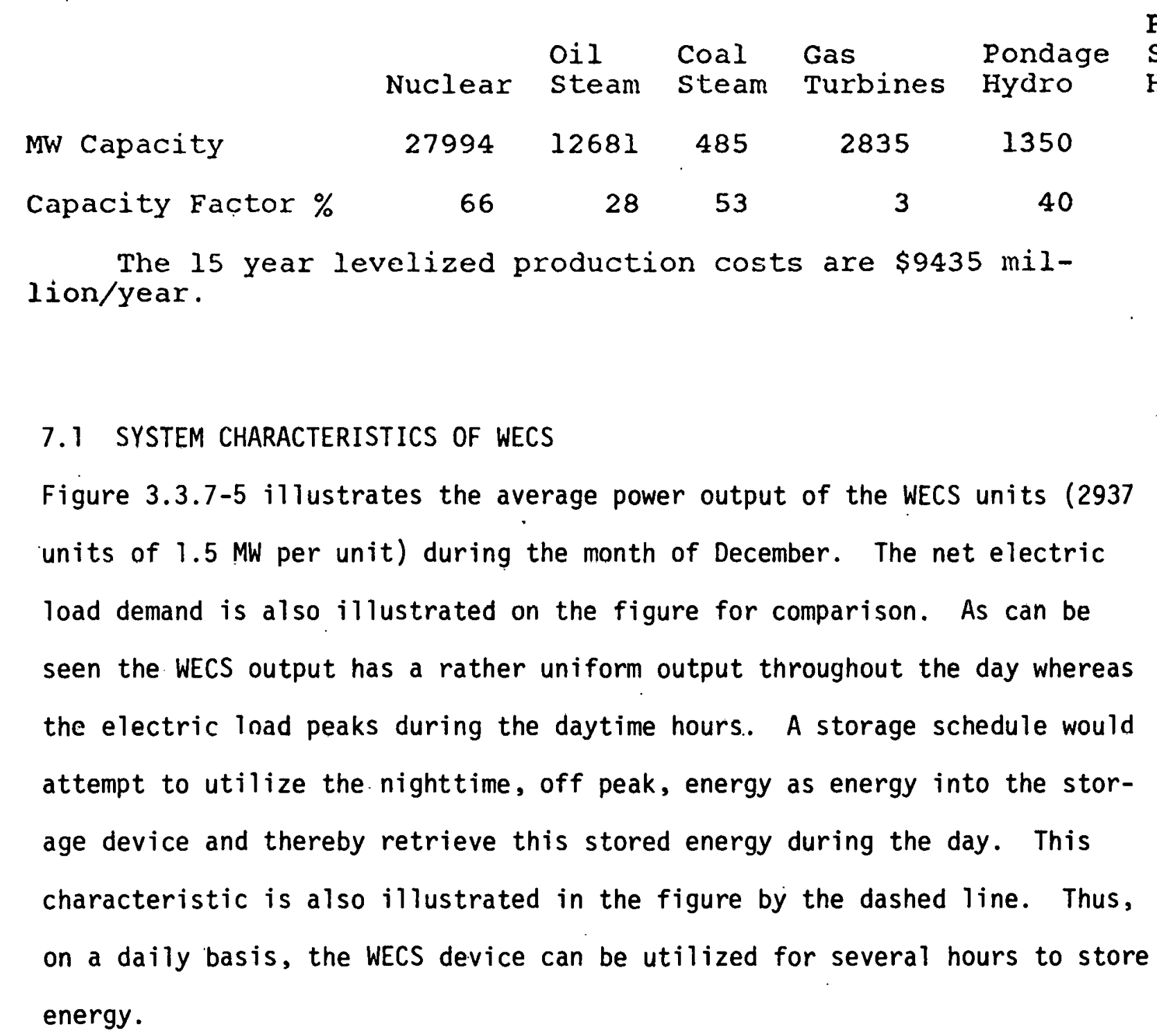




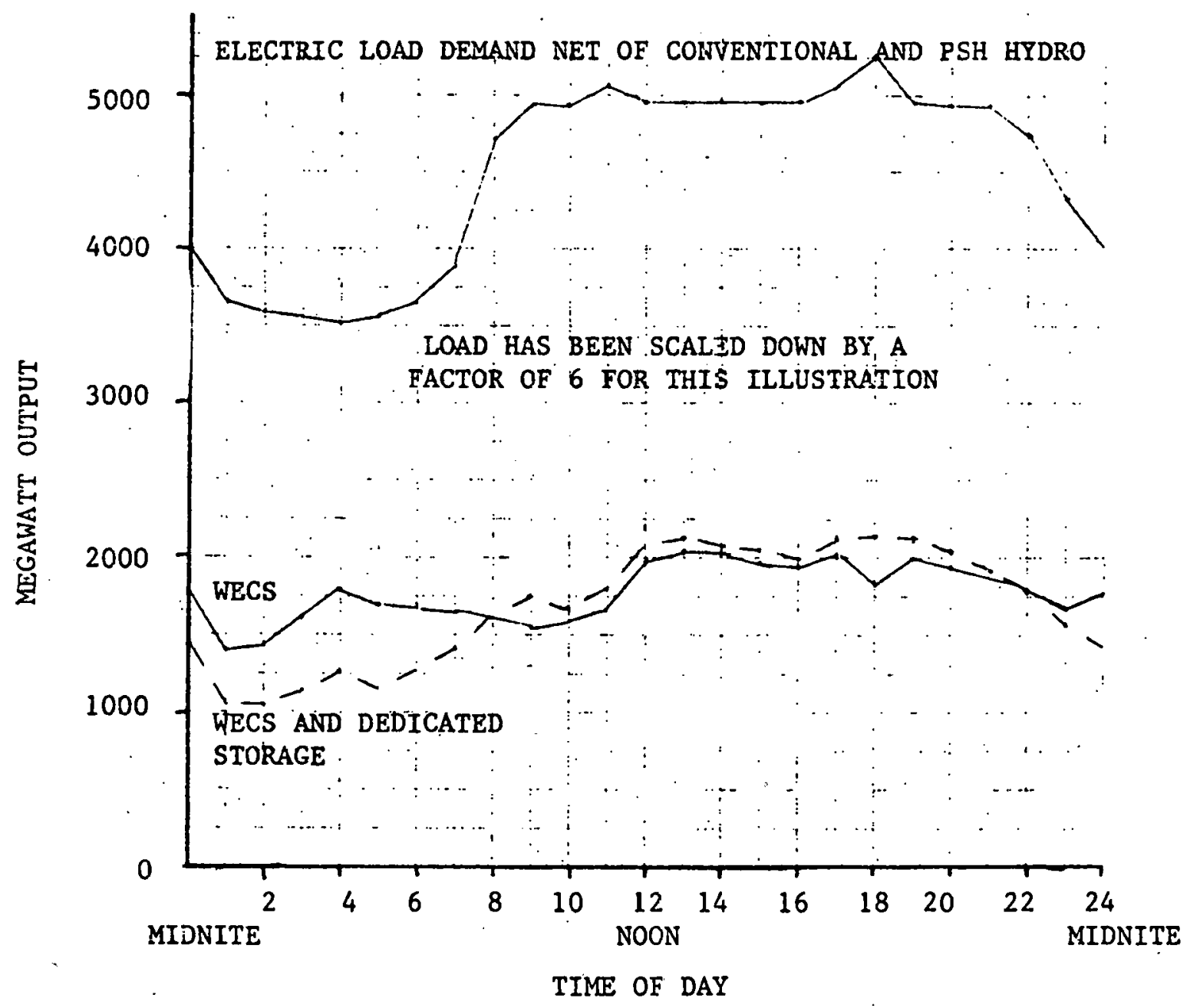

FIGURE 3.3.7-5. ILLUSTRATION OF WECS AND WECS WITH DEDICATED STORAGE FOR THE MONTH OF DECEMBER 


\subsection{DEDICATED VERSUS SYSTEM STORAGE}

The simulation of storage devices can be performed in two ways: (1) storage dedicated to the WECS output and (2) power system wide storage.

In dedicated storage, the storage device cannot operate unless the WECS device has supplied energy to it.

In system storage, the storage device may receive energy from either the WECS device or any other generating unit on the power system. This added flexibility renders system storage of greater value to the utility. However, since WECS are not deterministic devices whose output can be accurately predicted several days to a week ahead of time, WECS present some difficulties from system storage reservoir management viewpoint. In these system storage simulations of this study it was assumed that either (1) no weekly reservoir management advance planning would include consideration of WECS or (2) perfect weekly forecasting and advance planning of WECS. Neither these two cases are entirely accurate, but they do tend to bound the problem. Realistically, weather projections can be made one or two days in advance with some accuracy. Longer weather projections up to 1 week are needed, however, for storage reservoir planning. In the case of no forecasting of WECS, if WECS energy were available during an hour, the energy would be utilized for storage at the expense of some other type of energy, such as nuclear. For example, the reservoir's management plan would be developed assuming no WECS. Suppose as a result of this plan nuclear generation was to supply 1000 MWHR between 1 AM and 2 AM on Tuesday, May 5th. If the WECS output during this hour were 500 MWHR, the storage plan would be adjusted so that 500 MWHR of WECS and 500 MWHR of nuclear energy supplied the storage 
device. Furthermore, it was assumed that the storage device would have adequate storage capability to supply power during the peak load demand periods in the event that it was called upon to do so for system reliability purposes.

Figure 3.3.7-6 illustrates the differences between dedicated storage.

\subsection{WECS ANALYSIS}

Power system simulations were performed for the case of WECS with storage. The WECS capacity addition can lead to conventional capacity displacement of nurlear units, yds turbines or both. An economic analysis can be performed to evaluate which is more economic to the utility. The optimal type of capacity displaced will also lead to the largest breakeven value of WECS.

In this study a 10\% penetration of WECS was assumed (2937 units of $1.5 \mathrm{MW}$ ). Both nuclear and gas turbine capacity displacement was examined. The amount of capacity displaced was determined so as to maintain the same level of system reliability as the base case, in hours/year LOLP. Since nuclear units are generally added in integral sizes of $1150 \mathrm{MW}$, sometimes both nuclear and gas Lurbine capacity may be displaced, the gas turbine capacity being used to "trim" about the integral nuclear unit size.

The results of this analysis indicated that the capacity displacement could be either 1150 MW nuclear and 132 MW of gas lurbine or 910 MW gas turbine. (The reason that more nuclear capacity is displaced is because its effective capability in $\%$ of nameplate is less than that of gas turbines largely because its availability is less.) 


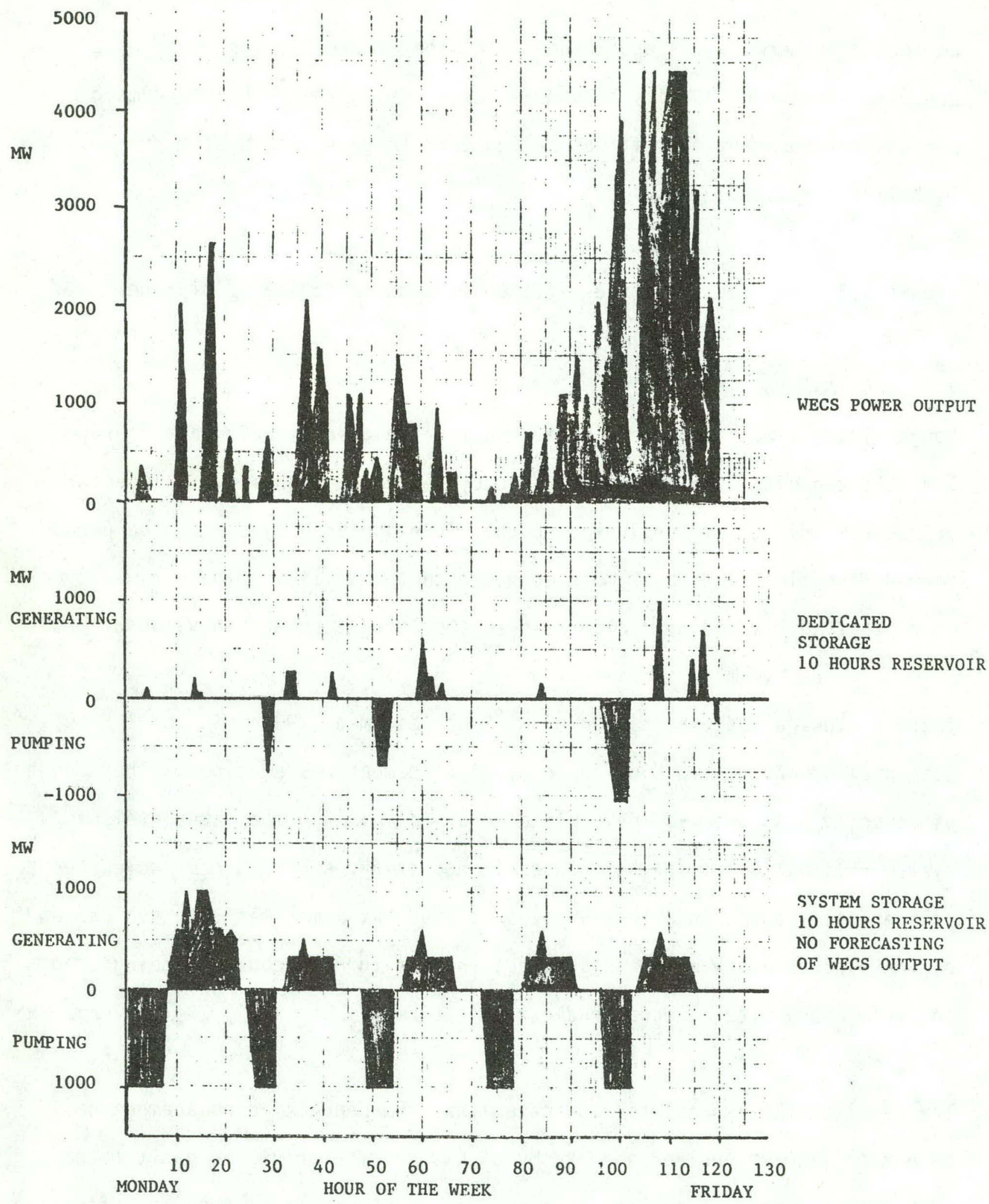

FIGURE 3.3.7-6 CONTRAST OF DEDICATED \& SYSTEM STORAGE FOR WECS 
The capacity credit for WECS is thus:

\begin{tabular}{lc}
\multicolumn{2}{c}{ WECS Capacity Displacement } \\
Gas Turbine $\%$ \\
$\begin{array}{cc}\text { Displacement } & \text { Nuclear } \\
21 \% & \text { Displacement }\end{array}$
\end{tabular}

The breakeven cost is illustrated in Figure 3.3.7-7. Displacing nuclear capacity is slightly better than gas turbines. The breakeven cost is characterized into two components, fuel and capacity. The fuel components result frum needing to burn less expensive fuel when WECS are installed. The capacity component arises from needing less conventional capacity when WECS are installed. The fuels saved as a result of the WECS additions are presented in the bottom section of Figure 3.3.7-7. The fuels saved are characterized in barrels of equivalent oil per year per KW of installed WECS. In NEPP, physical oil savings are a large contribution.

Since nuclear capacity was most economically displaced, subsequent work was based upon WECS capacity displacing nuclear generation. When storage is added to the power system additional benefits beyond that of WECS result. The $\$ / K W$ breakeven cost of the storage device can be calculated along with the types of fuels saved.

Figure 3.3.7-8 presents the breakeven cost of sturage for four applications. In the first application 1000 MW of PSH is added to the system (10,000 MWHR (a $60 \%$ efficiency) in which there is no WECS and 1100 MW of gas turbines are displaced by the PSH. The objective of this simulation is to determine the 


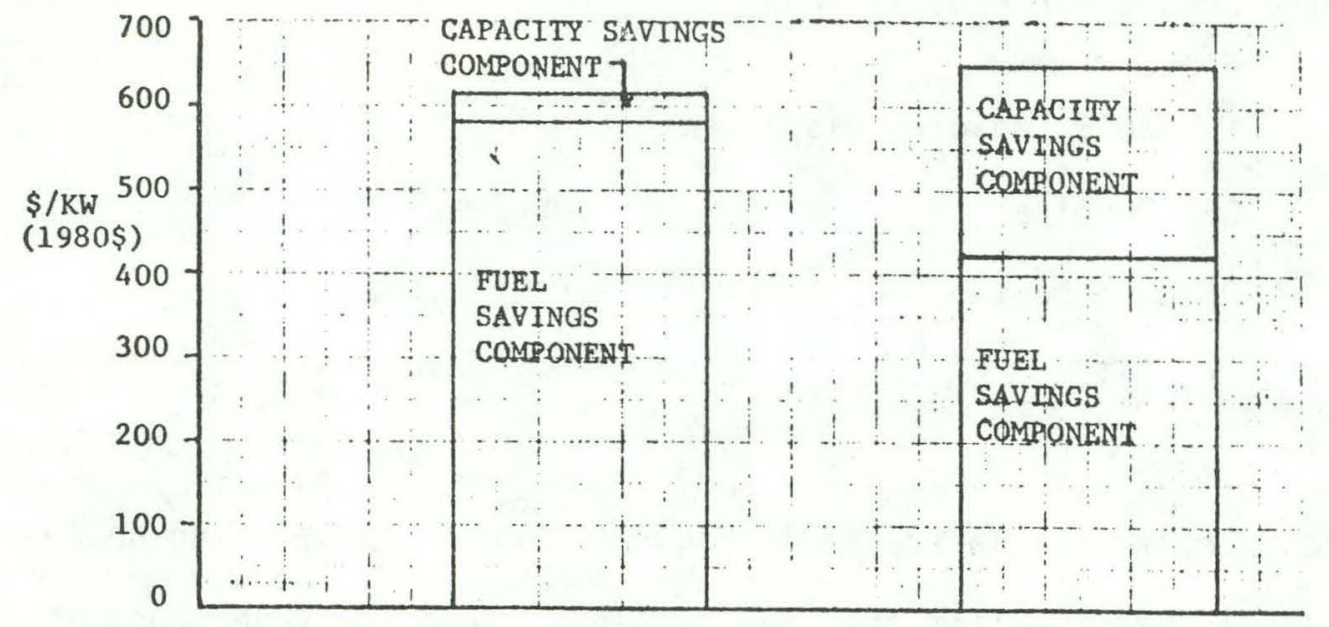

WECS

BREAKEVEN

COST IN

\$/KW (1980\$)

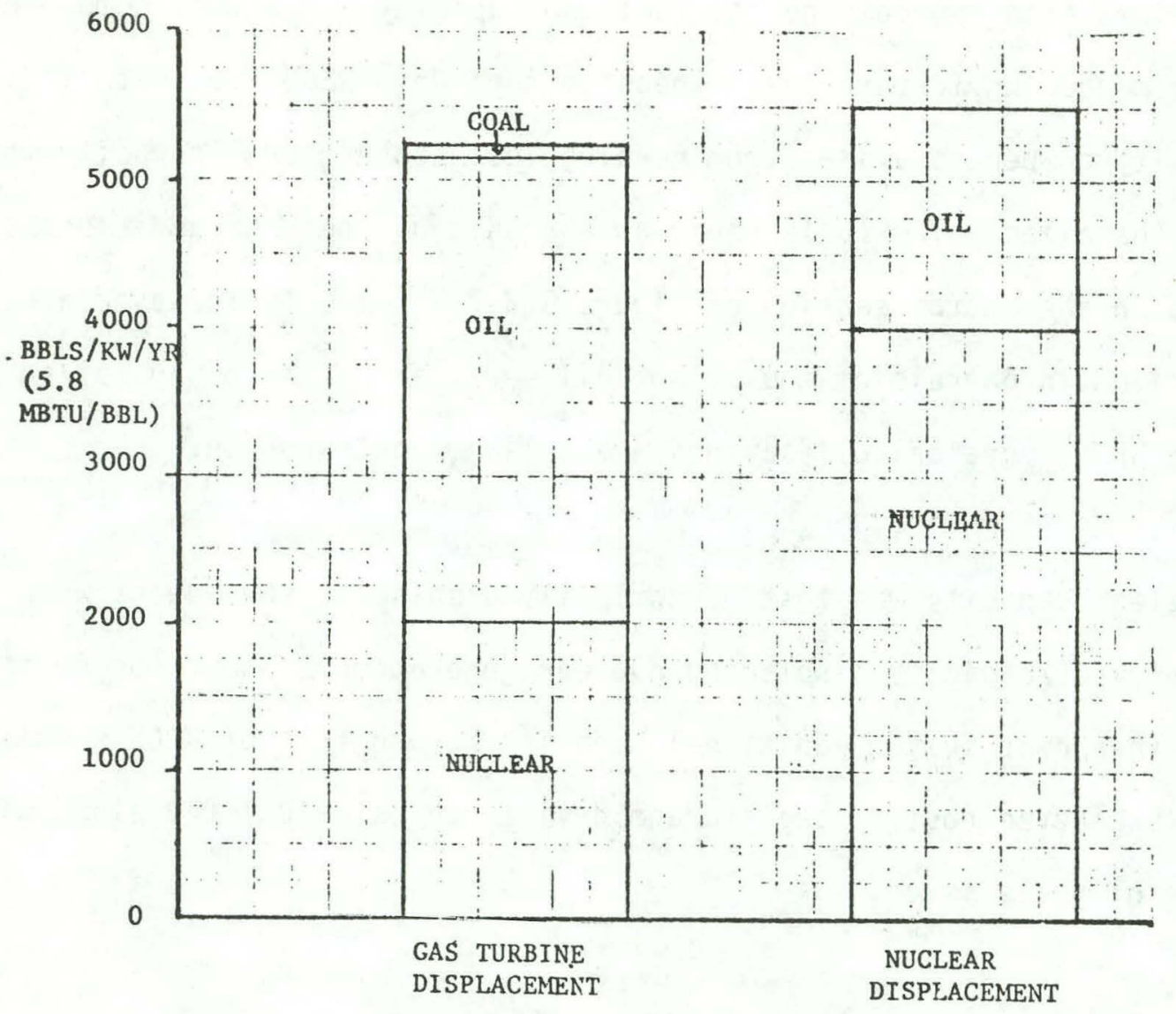

WECS

FUEL

DISPLACEMENT

IN EQUIVALENT

BARRELS OF

OIL PER YEAR

PER KW OF

INSTALLED WECS

FIGURE 3.3.7--7 CONTRAST OF WECS BREAKEVEN COST AND FUELS DISPLACEMENT FOR GAS TURBINE VS NUCLEAR DISPLACEMENT. 

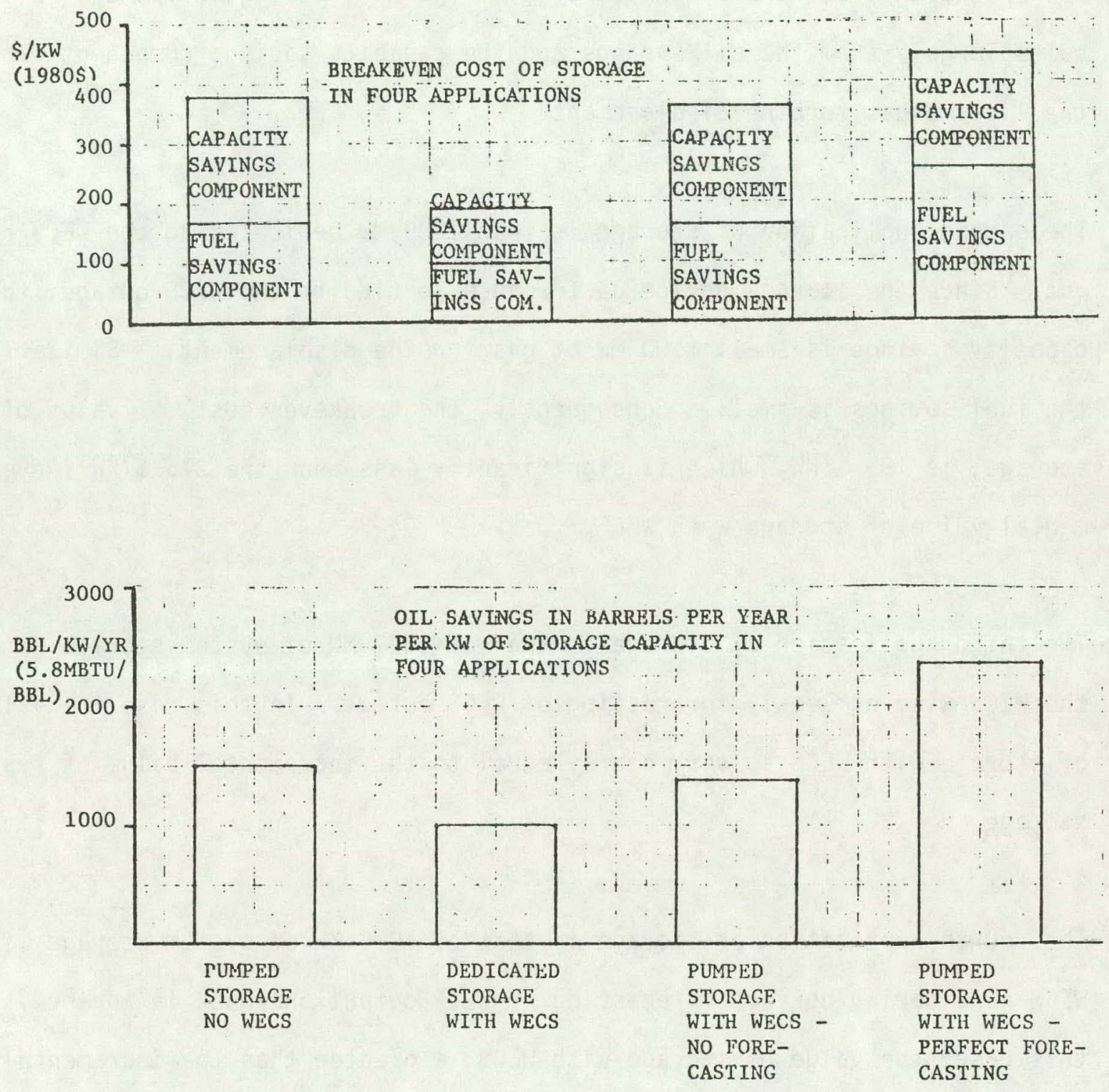

FIGURE 3.3.7-8 CONTRAST OF BREAKEVEN COST AND FUELS DISPLACEMENT OF WECS WITH STORAGE. 
breakeven cost of incremental system storage and thereby serve as a yardstick upon which to measure the value of storage when WECS is in the system. The breakeven cost is $375 \$ / \mathrm{KW}$ (1980 \$). The fuel savings component results largely from the oil savings and the capacity savings component from the 1100 MW gas turbine displacement.

The second application of storage is that 1000 MW dedicated to the WECS output. Since the storage device performance is tied to the WECS outage, the capacity savings is small (500 MW of gas turbine displacement). Similarly, the fuel savings is small. Consequently, the breakeven cost, or value of storage, is $195 \$ / \mathrm{KW}$, which is significantly less than the $375 \$ / \mathrm{KW}$ incremental value of storage with WECS.

The third application of storage is that of $1000 \mathrm{MW}$ of system storage with the WECS with no weekly forecasting of WECS output. In this case the value of storage with WECS is very nearly equal to the incremental value of system storage.

The fourth application of storage is that of $1000 \mathrm{MW}$ of system storage with WECS considering perfect forecasting of WECS output one week in advance. In this case, the value of storage with WECS is greater than the incremental value of storage. This is largely a result of being able to plan and most economically utilize the WECS output during the night to store energy. The increased value is largely attributable to increased fuel oil savings.

Conclusions drawn from these results are: 
1. Operating storage in a dedicated manner can lead to a significant economic penalty.

2. The value of system storage is not significantly different in the case of no, weekly forecasting of WECS than the value (cost) of system storage with no WECS.

3. The value of system storage in the case of perfect weekly forecasting of WECS is greater than the value (cost) of the storage device. Thu s in the case of perfect weekly forecasting of WECS output, storage can enhance the value of the WECS device.

\subsection{OVERALL CASE STUDY CONCLUS IONS FOR WECS W.ITH ENERGY STORAGE}

On the basis of the simulations conducted for New England Power Pool in 1995, the following conclusions were obtained

- Operating storage in a dedicated manner with WECS can lead to a significant economic penalty.

- There is a significant potential to improve the value of system storage in WECS applications by accurate weekly forecasting of WECS output.

- Storage has a greater potential application with WECS than with PVCS. This is because PVCS energy is available during the time of the utility peak. In this sense, PVCS approximately follows the utility load demand. (The PVCS analysis is presented in Volume II of this study report). 


\subsection{ANALYSIS AND PROJECTION OF \\ RESIDENT IAL STORAGE SYSTEM COST GOALS}

\subsubsection{ENERGY MANAGEMENT}

The residential application differs from the previously discussed utility case in several significant aspects. The power flow is in one direction; however, it feeds the house load directly rather than a power system grid. The utility is the backup energy source. Figure.3.4-1 schematically depicts system operation.
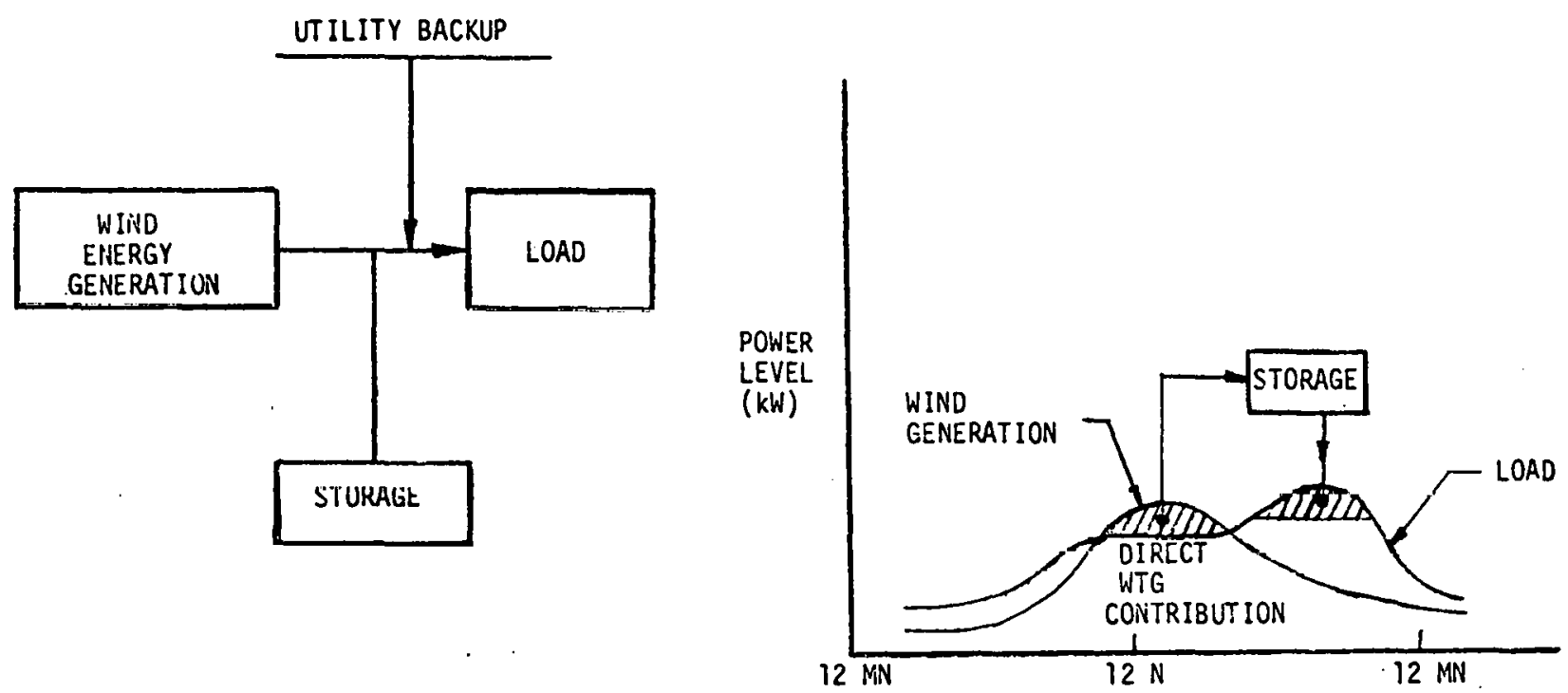

FIGURE 3.4-1. WIND ENERGY CONVERSION WITH DEDICATED STORAGE

The storage operational strategy is quite simple. When the wind turbine generator (WTG) output exceeds the load demand, the excess energy is put into storage and subsequently drawn out when the load exceeds ITT output. When the sum of WTG output and storage cannot meet the load, the utility backup is called upon. Figure 3.4-1 shows non-coincident WTG output and load peaks 
typical of many residential wind applications. For this situation, the role of energy storage is to accumulate the excess mid-day wind energy and dispense it during the late afternoon - early evening load peaks. Although these are typical wind output and load patterns, it should be noted that wide variations occur. An important option, not considered in this study, is utility "feedback", in which excess wind energy is fed back to the utility grid and credited at some pre-determined rate. This is an area which has been covered in other studies ${ }^{15}$ and should be considered as an alternative to onsite energy storage.

\subsubsection{WIND ENERGY AVAILABILITY AND CONVERSION}

The wind patterns described in Section 3.3.2 apply to the residential applications of wind energy as well as the utility applications. Wind data for the residential analys is was taken from Sandia-supplied tapes for three locations - Great Falls, Montana; Blue Hill, Massachusetts, and Lubbock, Texas.

A $10 \mathrm{~kW}$ wind generator system was selected for performance analysis using the wind velocities recorded for the above sites. Design characteristics for the basic wind generator system were derived from related prior work ${ }^{1,12}$ and are presented in Table 3.4-1. 
TABLE 3.4-1. $10 \mathrm{~kW}$ WIND GENERATOR SYSTEM CHARACTERISTICS

\begin{tabular}{|l|l|}
\hline & \multicolumn{1}{|c|}{ DESIGN VALUES } \\
\hline Rated Power & $10 \mathrm{~kW}$ \\
Design Velocity & $5.36 \mathrm{~m} / \mathrm{s}(12 \mathrm{MPH})$ \\
Generator & $\begin{array}{l}\text { Synchronous, 60 Hz } \\
\text { phase, 1800 RPM, 120/240 vac } \\
2 \mathrm{blade}, 150.5 \mathrm{RPM}\end{array}$ \\
Rotor & $9.28 \mathrm{~m}(30 \mathrm{ft})$ \\
Rotor Diameter & $19.9 \mathrm{~m}(65 \mathrm{ft})$ \\
Rotor Axis Height & $3.56 \mathrm{~m} / \mathrm{s}(7.96 \mathrm{MPH})$ \\
Cut-in Velocity & $7.49 \mathrm{~m} / \mathrm{s}(16.75 \mathrm{MPH})$ \\
Rated Velocity & $15.01 \mathrm{~m} / \mathrm{s}(33.58 \mathrm{MPH})$ \\
Cut-out Velocity & $36.4 \times 10^{3} \mathrm{kWh}$ \\
Annual Energy Production & \\
(al des ign velocity) & \\
\hline
\end{tabular}

Figure 3.4-2 presents the $10 \mathrm{~kW}$ WTG performance in terms of its kilowatt output versus wind velocity. 


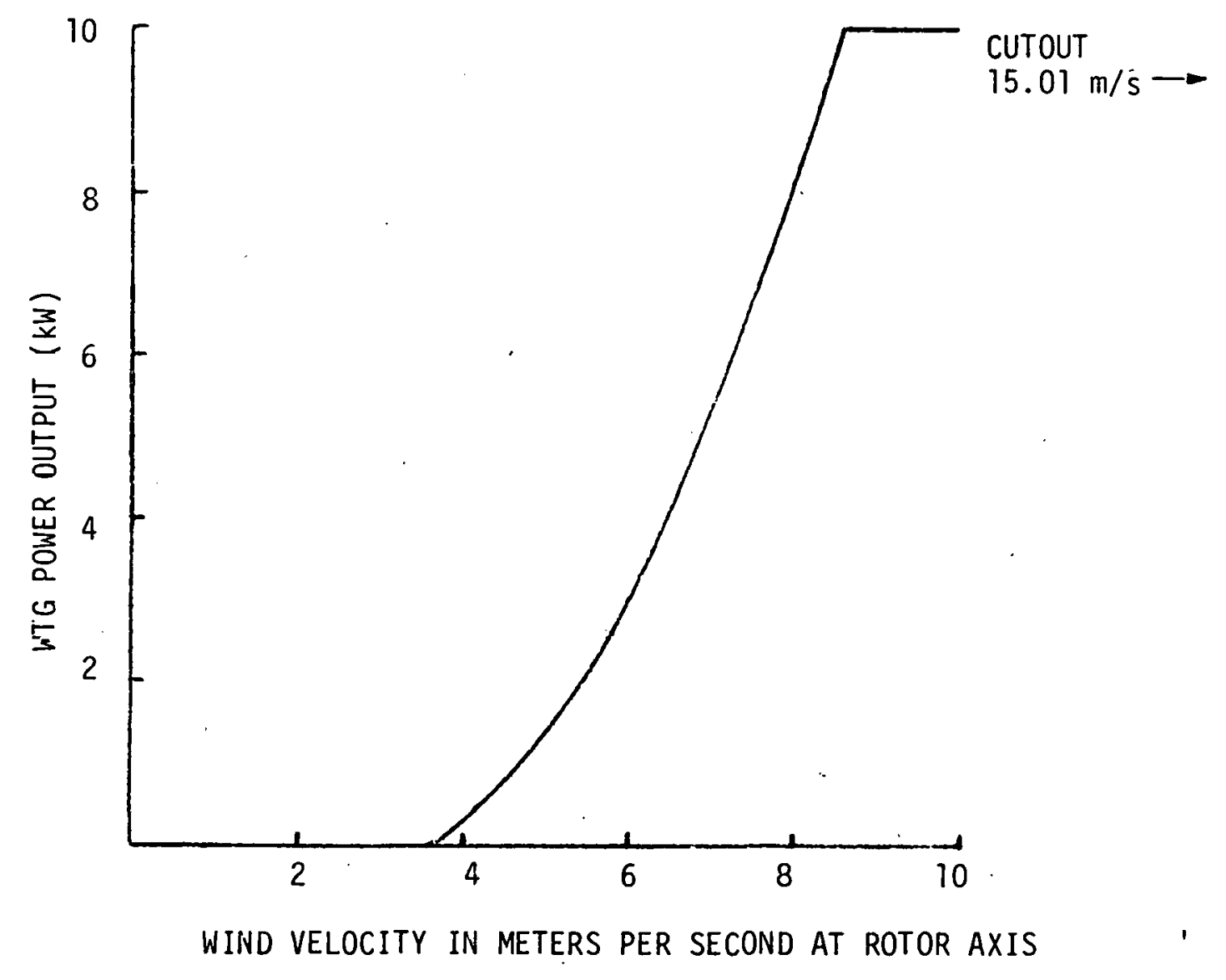

FIGURE 3.4-2. WIND TURBINE POWER OUTPUT VS. WIND VELOCITY $10 \mathrm{~kW}$ RESIDENTIAL UNIT

Combining the above performance curve with the wind tape data for each site yields hour by hour WTG output for 8760 hours or one year of projected operation. Table 3.4-2 presents the total annual output for the three residential locations. 
TABLE 3.4-2. $10 \mathrm{~kW}$ WIND TURBIINE ANINUAL ENERGY OUTPUT

\begin{tabular}{|l|l|}
\hline LOCATION & $\begin{array}{c}\text { ANNUAL OUTPUT } \\
\text { (klh) }\end{array}$ \\
\hline Great Falls, MT & 32,522 \\
Blue Hill, MA & 38,733 \\
Lubbock, TX & 34,747 \\
\hline
\end{tabular}

Obviously, the portion of the above energy that can be supplied directly to the load is a function of the absolute magnitude of the load and its phasing with WTG output.

\section{. 3.4 .3 LOAD DEMANDS}

The residential loads were selected from those established for representative cities during a prior study for NASA-Lew1s. 16,30 The loads are assoctated wtth an all-electric single family residence and include space heating/cooling, hot water heating and diversified house loads. The diversified load component included lighting, appliances and other miscellaneous household equipment. The hot water heating load pertains to representative domestic requirements. In order to simplify the analyses, both the diversified and hot water heating loads are assumed to have a fixed profile over the entire year. The space heating and cooling loads, which are clearly location sensitive, are computed separately on an hourly basis using the Building Tronsient Thermal Load (BTTL) program of reference 1. This program considers loads produced by: conduction heat losses/gains, infiltration losses/gains, internal sensible and latent 
heat gains from occupants, electrical appliances, showers and solar heat gains through windows. A standard residence area of $169 \mathrm{~m}^{2}\left(1819 \mathrm{ft}^{2}\right)$ was used for all sites. Conversion from thenial to electrical demani is based on the heat pump coefficient of performance treated as a function of outside ambient temperature.

The three major residential load components described above are summed to form the total load for each residential storage analysis.

Figures $3.4-3,3.4-4$ and $3.4-5$ show typical profiles for the three components of the residential load model. Table 3.4-3 lists the actual total combined loads for the three locations examined in this study.

TABLE $3.4-3$ RESIDENTIAL ANNUAL LOADS

\begin{tabular}{|l|l|l|l|l|l|}
\hline \multicolumn{1}{|c|}{ LOCATION } & $\begin{array}{l}\text { ANINUAL } \\
\text { HEATING } \\
\text { LOAD }\end{array}$ & $\begin{array}{l}\text { ANNUAL } \\
\text { COOLING } \\
\text { LOAD }\end{array}$ & $\begin{array}{l}\text { DIVERS IF IED } \\
\text { HOUSE } \\
\text { LOAD }\end{array}$ & $\begin{array}{l}\text { HOT WATER } \\
\text { HEATING } \\
\text { LOAD }\end{array}$ & $\begin{array}{l}\text { TOTAL } \\
\text { ANNUAL } \\
\text { LOAD }\end{array}$ \\
\hline $\begin{array}{l}\text { Great Fal1s, MT } \\
\text { Blue Hi11, MA }\end{array}$ & 19,944 & 312 & 7,665 & 5,110 & 33,031 \\
Lubbock, TX & 8,790 & 1,180 & $\downarrow$ & $\downarrow$ & $\begin{array}{l}\downarrow 2,745 \\
21,297\end{array}$ \\
\hline
\end{tabular}

All Values in $\mathrm{kWh}$ 


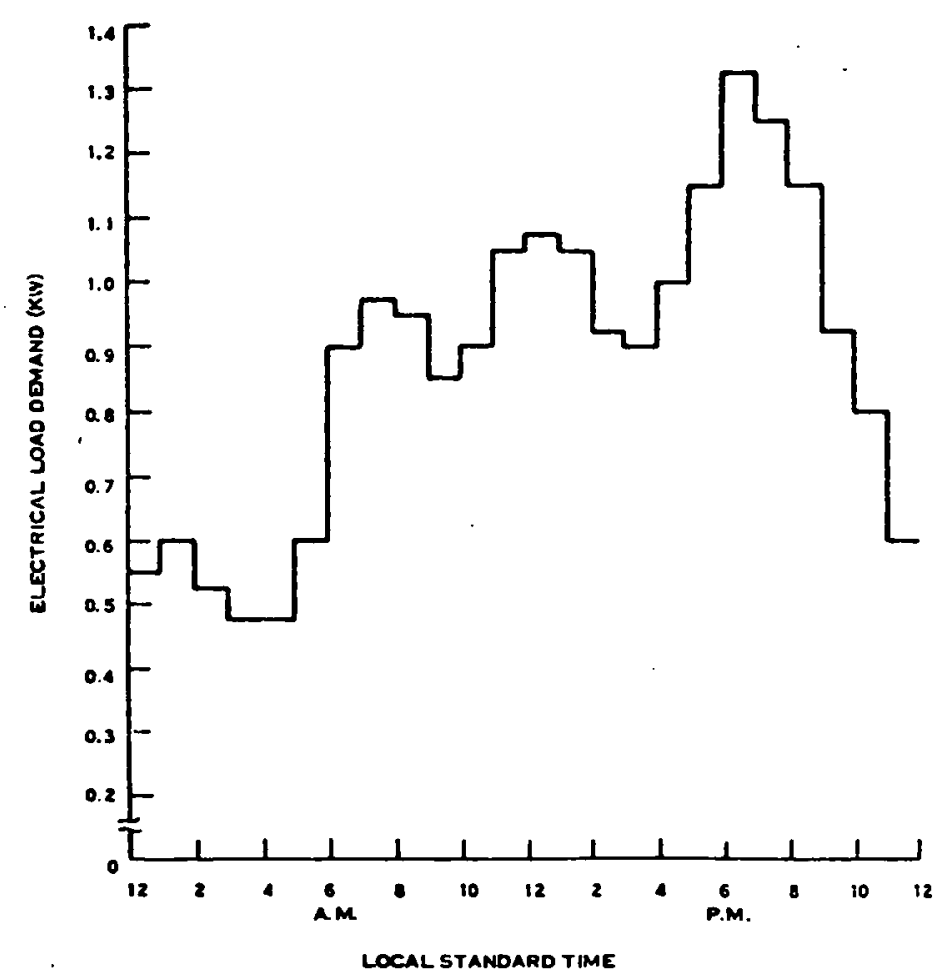

FIGURE 3.4-3. DIVERSIFIED RESIDENTIAL LOAD DEMAND PROFILE

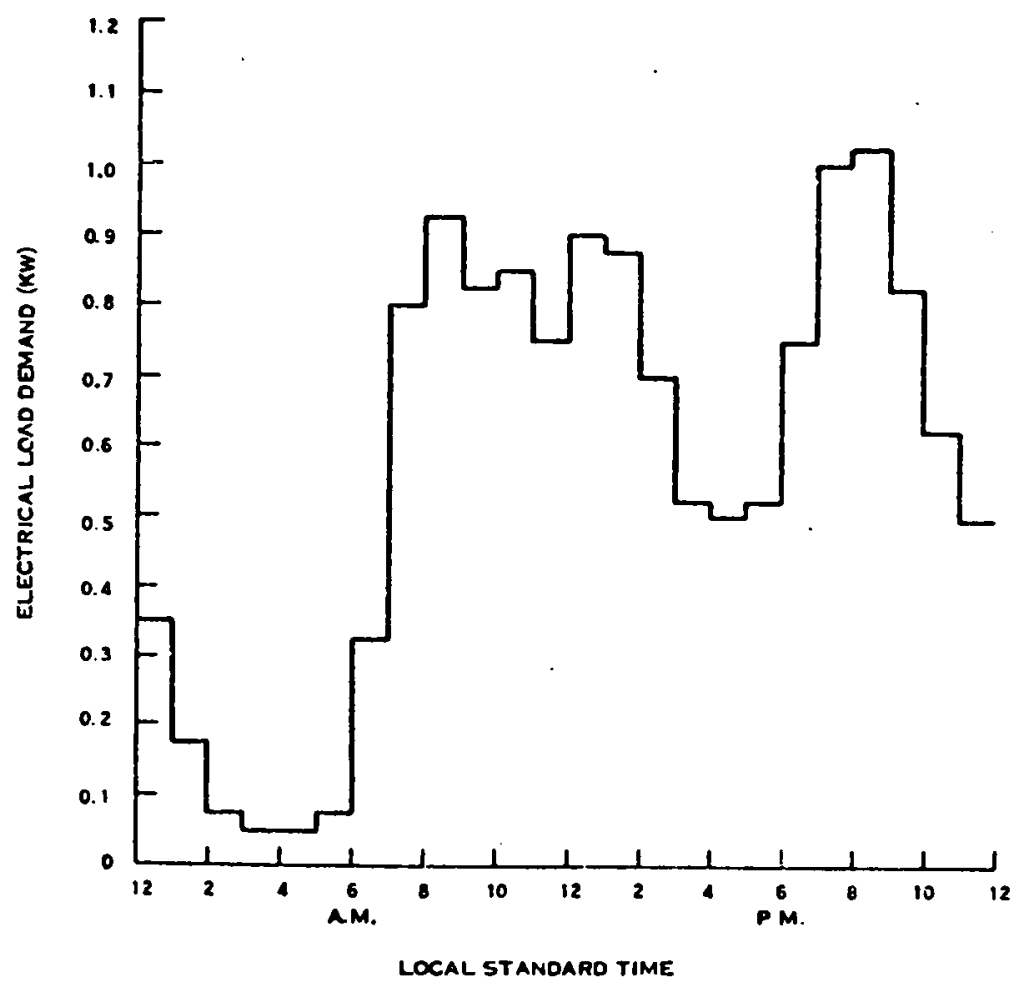

FIGURE 3.4-4. RESIDENTIAL HOT WATER HEATER ELECTRICAL LOAD DEMAND PROFILE

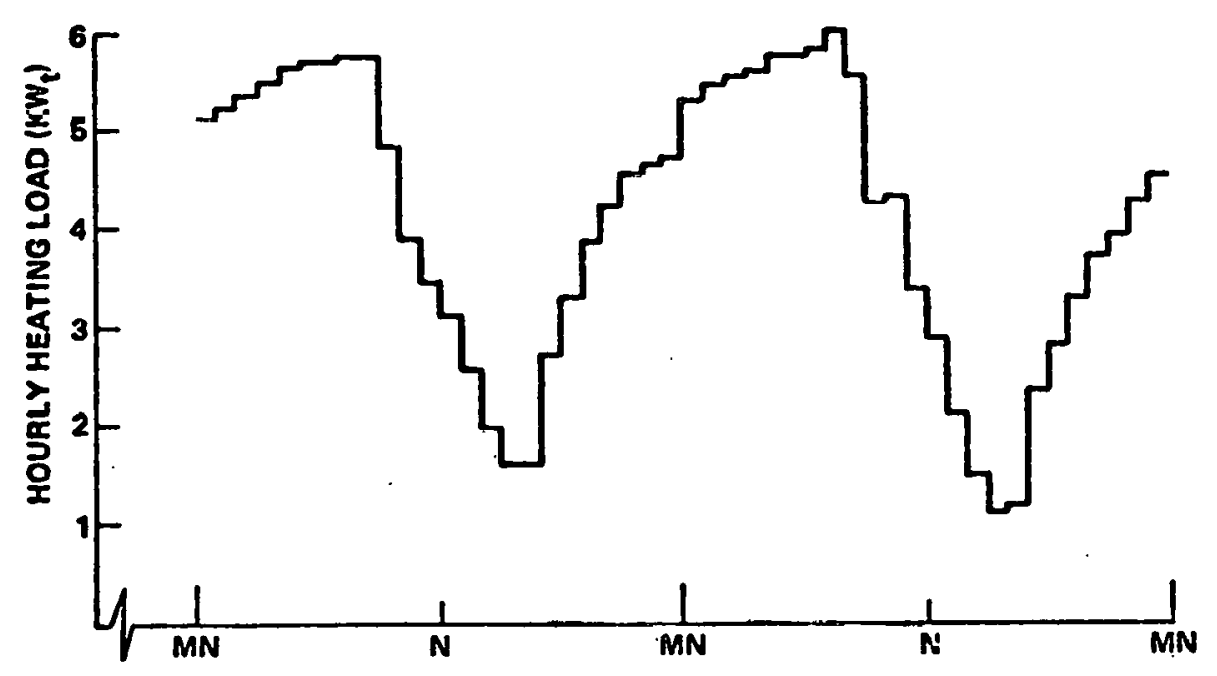

FIGURE 3.4-5. TYPICAL RESIDENTIAL WINTER HEATING DEMAND PROFILE 


\subsubsection{GENERATION AND LOAD MATCHING WITHOUT STORAGE}

A baseline no-storage case was computed initially for each residential location. The hour-by-hour tapes of wind turbine output and total residence electrical demands were compared by computer program to determine what portion of the WTG output could be supplied direct to the load. Excess WTG energy and required utility makeup energy were also computed and summed for the full 8760 hours. Results are presented in Table 3.4-4.

TABLE 3.4 4. RESIDENT IAL LOAD MATCHING $10 \mathrm{~kW}$ WTG - NO STORAGE

\begin{tabular}{|l|c|c|c|c|c|}
\hline LOCATION & DEMAND & $\begin{array}{c}\text { WTG } \\
\text { OUTPUT }\end{array}$ & $\begin{array}{c}\text { WTG } \\
\text { UT ILIZED }\end{array}$ & $\begin{array}{c}\text { WTG } \\
\text { EXCESS }\end{array}$ & $\begin{array}{l}\text { PURCHASED } \\
\text { ENERGY }\end{array}$ \\
\hline Great Falls & 33,031 & 32,522 & 15,588 & 16,934 & 17,443 \\
Blue Hill & 22,745 & 38,733 & 15,065 & 23,688 & 7,680 \\
Lubbock & 21,297 & 34,747 & 12,873 & 21,874 & 8,424 \\
\hline
\end{tabular}

All values in $\mathrm{kWh}$.

\subsubsection{GENERATIONI AND LOAD MATCHING INCORPORATING STORAGE}

The next step in the analys is was the addition of energy storage to use excess WTG energy to offset the remaining purchased electrical energy shown in Table 3.4-4. Storage was added in 12 kilowatt hour capacity increments and an hour-by-hour computer analysis performed as in the no storage case. System operational strategy is as follows: 
1. WTG output. is supplied directly to the load when it can be used.

2. When WTG output exceeds the load, excess is put into storage. When storage is full (completely charged), excess WTG output is dissipated.

3. When WTG output is less than the house load, storage output is used, within the constraints of the discharge rate limit and the minimum allowable state of charge.

4. When total load cannot be met with WTG output and/or storage output, utility makeup is permitted.

Inherent in the above strategy is the assumption that purchased electrical energy has a constant value throughout the day. Under several proposed peak load and time of day pricing schedules this would no longer be true, thus making some alternative storage operational strategy more economic. Such an alternate strategy might include utility off-peak charging if the rate differential was substantial.

Table 3.4-5 presents a sample hour-by-hour computer run using the four part operational strategy given above. Most of the column headings are selfexplanatory. SOC is storage state-of-charge representing the decimal fraction of total storage capacity ( $24 \mathrm{klWh}$ for the sample case) charged and available at any given time. Minimum allowable state of charge ( $\mathrm{SOC})$ is .1 , while only at the maximum SOC of 1.0. can excess WTG energy be dissipated. This 
TABLE 3.4-5. SAMPLE COMPUTER OUTPUT FOR RESIDENTIAL WIND STORAGE

\author{
24 kWh STORAGE CAPACITY \\ LUBBOCK, TX
}

\begin{tabular}{|c|c|c|c|c|c|c|c|c|c|c|c|}
\hline & & & $\begin{array}{c}\text { HO.T } \\
\text { WATER } \\
\vdots \\
\text { DIVER- } \\
\text { SIFIED }\end{array}$ & $\begin{array}{l}A / C \\
\text { OR } \\
\text { HEAT } \\
\text { PUMP }\end{array}$ & TOTAL & $\begin{array}{l}\text { WTG } \\
\text { OUTPUT }\end{array}$ & SOC & BATT & $A \cup X$ & EXCESS & PWR \\
\hline $\mathrm{MON}$ & DAY & tir & $\begin{array}{l}\text { LOAD } \\
(Y)\end{array}$ & $\begin{array}{l}1 O A D \\
(K: N)\end{array}$ & $\begin{array}{l}\text { LOAD } \\
(K W)\end{array}$ & $\begin{array}{l}P W R \\
(K W)\end{array}$ & - & $\begin{array}{l}P: R \\
(K W)\end{array}$ & $\begin{array}{l}P, R \\
(K W)\end{array}$ & $\begin{array}{l}\text { PWR } \\
(K W)\end{array}$ & $\begin{array}{l}\text { LOSS } \\
(K N)\end{array}$ \\
\hline 16 & 1 & 1) & 0.810 & 0 & C. 900 & 0 & 0.321 & -3.947 & 0 & 0 & 0.047 \\
\hline ר. ח & $!$ & 1 & 0.775 & 0. & 0.775 & c. & 0.587 & .0 .816 & 0. & 0. & 0.041 \\
\hline 10 & 1 & 2 & 0.600 & $\underline{n}$ & 0.6110 & 0 & 0.561 & -0.632 & 0. & 0. & 0.032 \\
\hline in & $i$ & 3 & 0.530 & 0. & 0.530 & 0.045 & 0.539 & -0.511 & 0 & 0 & \\
\hline 10 & 1 & 4 & 0.530 & 0 . & 0.530 & 4.674 & 0.362 & 3.937 & 0 & 0. & 07 \\
\hline 3 & i & 5 & $\therefore .675$ & 0. & 9.6 & 1.354 & 0.693 & 0.61 .5 & 0 . & 0 . & 134 \\
\hline is & $i$ & s & $1.2 ? 5$ & $\because$. & $1 . ? \geq 5$ & 2.420 & 0.718 & 1.135 & 0 & 0. & 0.060 \\
\hline & $?$ & $?$ & 1.775 & 0. & 1.775 & 1.354 & .703 & -0.4 & 0 . & 0. & 22 \\
\hline $1 ?$ & 1 & 5 & $1.5: c$ & 0 & 1.875 & 3.665 & 0.767 & 1.511 & 0. & 0 . & 0.080 \\
\hline 19 & 1 & 9 & 1.675 & 0.18 & 1.856 & 5.965 & 0.869 & 3.903 & 0. & 0. & \\
\hline 12 & 1 & 10 & 1.750 & 9.5 & 2.279 & 10.000 & 1.000 & 6.198 & 0. & 3.3 & \\
\hline ij & $?$ & 1: & $1.80 ?$ & 0.76 & 2.544 & 2.620 & 395 & -2.1 & $n$ & 0. & \\
\hline חבי & 1 & 12 & 9.793 & $1: .719$ & 2.754 & 0.6 & 0. & -2. & 0. & 0 . & \\
\hline$i=$ & 1 & $\because 3$ & $? .7 \geq 5$ & $1.2 ; 3$ & 2.9 .83 & 5.965 & 6.089 & 2.8 & ח: & 0. & 0.149 \\
\hline 19 & 1 & $i 4$ & $1.6: 5$ & 1.351 & 2.916 & 5.965 & $1 . \mathrm{col}$ & 0.344 & 0 & 2.626 & 0.018 \\
\hline$\theta$ & $i$ & 15 & 1.425 & 1.5 & 3.013 & 3.465 & 1.000 & 0. & 0. & 0.4 & \\
\hline 3 & 1 & 1 & כר. & $i .6$ & 108 & 54 & 923 & -1.846 & 0. & 0. & 0.392 \\
\hline i. & 1 & $: 7$ & 1.675 & 1.5 & 3.214 & 0.0 & 0.784 & -3.336 & c. & 0. & 167 \\
\hline 1!) & 1 & 18 & 2.075 & 0.5 & 2. & 0. & & -3. & 0. & 0. & 151 \\
\hline i2 & 1 & 16 & 2.850 & 0.4 & 2 & 0.61 & & -2 & 0. & 0. & 111 \\
\hline 13 & 1 & 20 & 2.175 & 0.16 & 2.337 & 0.0 & 0.665 & $-i$ & 0 . & 0 . & 121 \\
\hline 1) & 1 & 2 & 1.750 & 0 & 9.750 & 0.6 & 0.495 & -1 & 3. & 0. & 60 \\
\hline 1.7 & $\mathbf{i}$ & 22 & 1.425 & 0. & $? .425$ & 0.615 & 0.379 & -0.8 & 0 . & 0 . & c.r.4.3 \\
\hline $1 ?$ & 1 & 23 & 1.120 & 0. & $1.1 ! 0$ & 0. & 0.331 & -1. & 0. & 0. & 0.058 \\
\hline$i:$ & 2 & 0 & 0.950 & c. & 0.90 & 0.045 & 0.294 & -0.3 & 0. & 0 . & \\
\hline 19 & $?$ & 1 & 0.775 & 0. & 0.775 & 0. & 0.260 & -0.816 & 0. & 0. & 69 \\
\hline ? ? & ? & 2 & 0.600 & . & 0.60 & 0. & $233^{\circ}$ & -3.632 & 0. & 0. & 032 \\
\hline 0 & $?$ & 3 & $0.5 ? 0$ & 0. & & 0. & 10 & -0 & 0. & 0. & \\
\hline$\because$ & $?$ & $l_{i}$ & 0.330 & 0. & 0 & 0. & & & 0. & & \\
\hline$\because \because$ & $?$ & 5 & C.öis & $n$ & 0.0 .75 & 0.615 & is & -0 & 0. & פ. & $0 ?$ \\
\hline$\because:$ & ? & $\Rightarrow$ & $: .225$ & $?$. & 1. & 4 & & 123 & & . & 106 \\
\hline$\because$ & $\bar{\ddots}$ & 7 & $i . i: \vdots$ & 0. & 9.775 & 0.515 & 0.137 & -1.222 & 0. & C. & $6 i$ \\
\hline$\because$ & $\therefore$ & 3 & i.975 & 0. & 1.875 & 0.045 & 0. & -0.893 & 0.982 & 0 & 045 \\
\hline$: 0$ & 2 & 9 & $1.6 \% 5$ & 0. & 1.675 & 5.965 & 0. & 4.075 & 0. & 0 . & 214 \\
\hline$: 2$ & $\Xi$ & 10 &. .750 & $0 . j 6$ & & 4.6 & & & 0. & 0. & \\
\hline$: ?$ & $\because$ & 1 & חתים". & r. & & & & & 0. & 0. & 74 \\
\hline 9 & $\because$ & $1 i$ & 1.975 & 0.56 & & i. 3 & & -1 & 0. & 0 . & \\
\hline i) & $\Xi$ & 13 & $\therefore .25$ & 1. & 3 & 4.67 & & & 0 & 0 & 77 \\
\hline 9 & ? & 14 & $9.6 \geq 5$ & 1. & 3.0 .96 & 0. & 0.253 & $-3 \cdot ?$ & 0. & 0 . & 62 \\
\hline 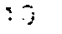 & 2 & 45 & 1.425 & 1. & 3.016 & 2.420 & 0.227 & -0.3 & 0. & 0. & \\
\hline !. & 2 & 16 & $1.5: 0$ & 1.64 & 3.14 & 2.420 & & -0.764 & 0. & 0. & 0.0 \\
\hline$i: ?$ & 2 & 17 & $1 . \therefore 7=$ & 1.58 & 3.239 & 0.615 & & -2.276 & 0.463 & 0 . & 0.116 \\
\hline 10 & 2 & 18. & 2.075 & 0.92 & 3.001 & 0. & & 0 & 3.001 & 0. & 0. \\
\hline$\therefore$ & ? & 18 & 2. $\geq 50$ & 0.6 & 2.035 & 0 . & & & & & 0 \\
\hline i? & ? & 20 & 2.175 & 0.43 & 2.510 & 0 & & 0 & 2.610 & 0 . & 0. \\
\hline 20 & 2 & 2 & 1.750 & & & 0. & & & & C. & c \\
\hline$a$ & $\because$ & $? 2$ & $i, 4 ? 5$ & C. 1.2 & כ.5. & 0.045 & & & $1.50 \mathrm{~s}$ & 0. & 0. \\
\hline 10 & $?$ & 23 & $i .: 30$ & 0. & 1.100 & 2.420 & & & 0 & 0 . & \\
\hline โ & 3 & 0 & 0.906 & e. & 0.900 & & & & 0. & 0. & 076 \\
\hline 10 & $j$ & 1 & 0.775 & 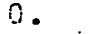 & 0.775 & & & & 0. & 0 . & 038 \\
\hline I. & 3 & 2 & 0.600 & 0 & 0.600 & 0.045 & 0.128 & -0.585 & 0. & & 0.029 \\
\hline
\end{tabular}


occurs at hours 10, 14 and 15 of day 1 in the example case. Conversion and power handling equipment efficiencies of .95 are assumed for charging and discharging of storage, in addition to the variable storage efficiency (.75 in the sample case). The AUX PWR column represents purchased utility energy, which is summed for the 8760 hour run, with results as shown in Table 3.4-6.

TABLE 3.4-6. SUPPLEMENTAL UT ILITY ENERGY REQUIRED. WITH RESIDENTIAL ENERGY STORAGE ADDED TO WIND GENERATOR SYSTEM

\begin{tabular}{|c|c|c|c|}
\hline \multirow{2}{*}{$\begin{array}{c}\text { STORAGE SIZE } \\
\text { KWh }\end{array}$} & \multicolumn{3}{|c|}{ WIND SITE LOCATION } \\
\cline { 2 - 4 } & GREAT FALLS & BLUE HILL & LUBBOCK \\
\hline 0 & 17,443 & 7,680 & 8,424 \\
12 & 14,886 & 5,314 & 5,665 \\
24 & 13,916 & 4,333 & 4,765 \\
48 & 12,722 & 3,221 & 3,881 \\
72 & 11,972 & 2,587 & 3,374 \\
& & & \\
\hline
\end{tabular}

All values in $\mathrm{kWh}$

Subtraction of purchased utility energy using storage, from the quantity required with no storage yields the savings in kWh due to energy storage: 
TABLE 3.4-7 REDUCTION IN RESIDENTIAL ANNUAL ENERGY CONSUMPTION DUE TO STORAGE

\begin{tabular}{|c|c|c|c|}
\hline \multirow{2}{*}{$\begin{array}{c}\text { STORAGE SIZE } \\
(\mathrm{kWh})\end{array}$} & \multicolumn{3}{|c|}{ WIND SITE LOCATION } \\
\cline { 2 - 4 } & GREAT FALLS & BLUE HILL & LUBBOCK \\
\hline 12 & 2557 & 2366 & 2759 \\
24 & 3527 & 3347 & 3659 \\
48 & 4721 & 4459 & 4543 \\
72 & 5471 & 5093 & 5050 \\
\hline
\end{tabular}

All values in $\mathrm{kWh}$

The above data is presented graphically in Figure 3.4-6, which indicates the narrow range of energy displacement over the various sites.

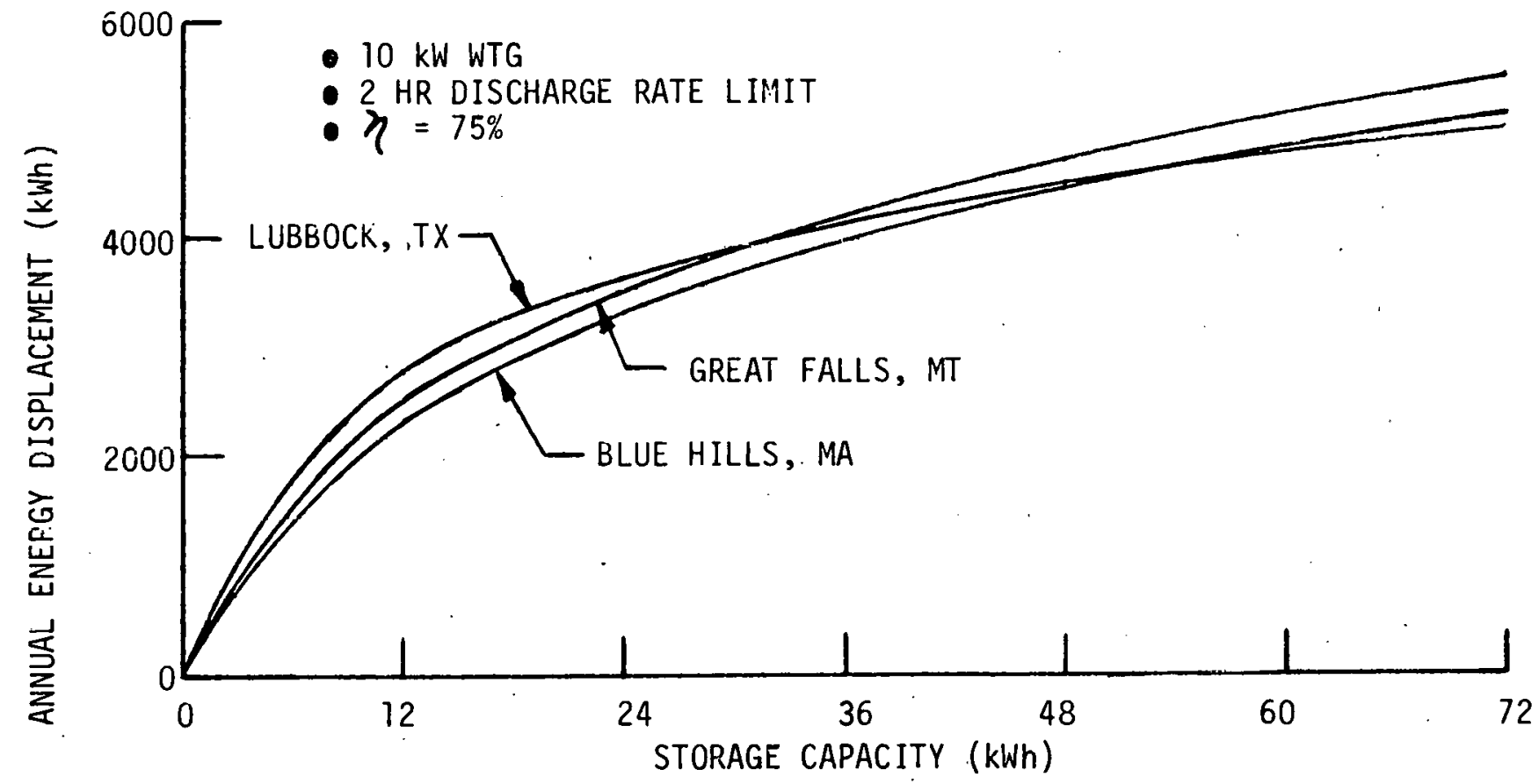

FIGURE 3.4-6. LOCATION EFFECT ON RESIDENTIAL ENERGY DISPLACEMENT USING STORAGE 
A representative mean energy displacement curve was constructed from the individual site data for use in the further, more detailed analysis that follows. This representative mean is shown in Figure 3.4-7.

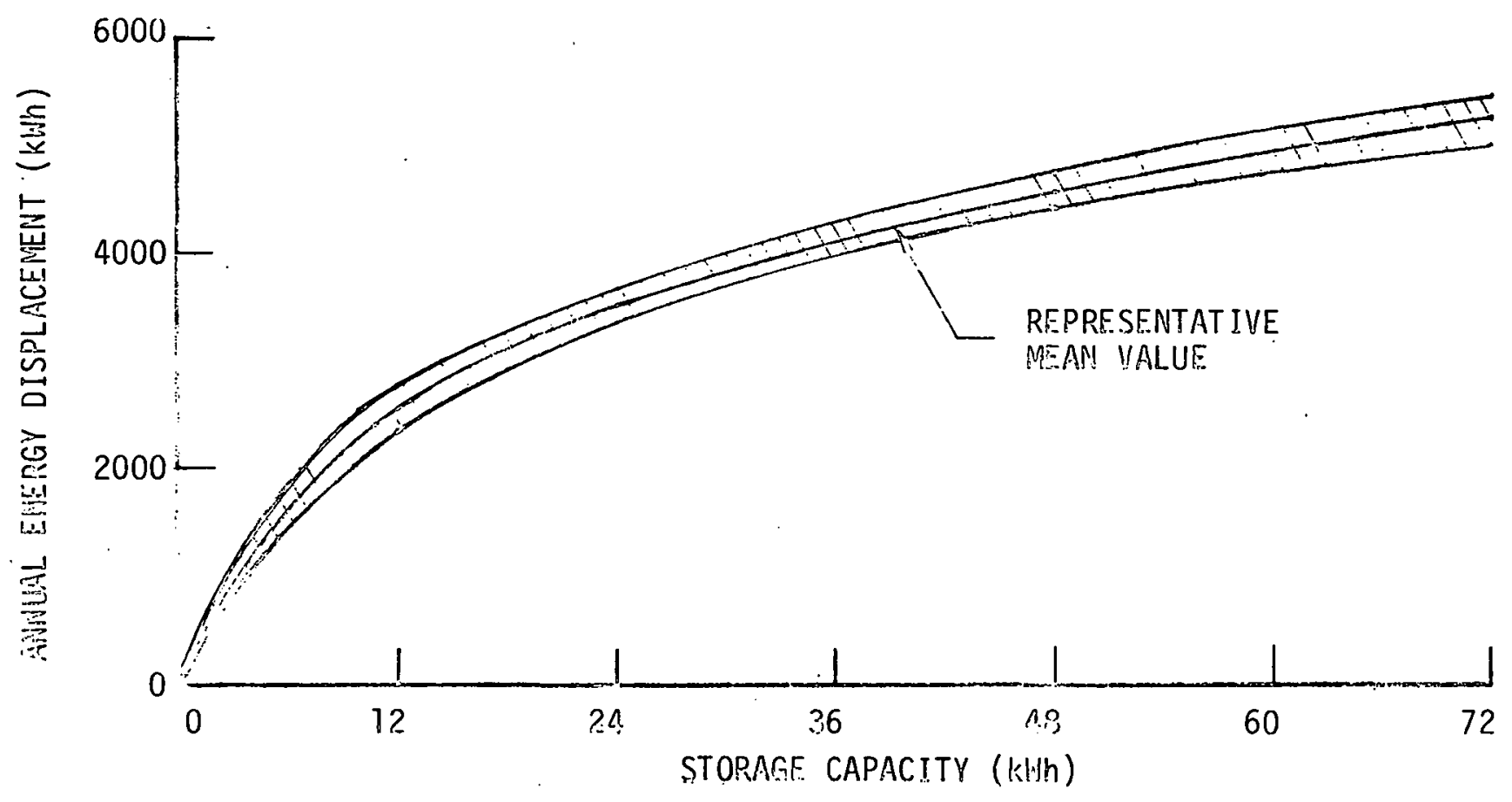

FIGURE 3.4-7. REPRESENTATIVF. MEAN RESIDENTIAL ENERGY DISPLACEMENT DUE TO STORAGE

\subsubsection{COST GOALS AND PARAMETRIC ANALYSIS}

The numerics required to carry out the residential cost goal evaluation are explained and the results presented in this section. The types of storage systems to be compared include: lead-acid batteries, advanced batteries, inertial (flywheel), and pneumatic storage. The selection of these candidates for residential use was discussed in Section 1.2 and in Volume I of this report. 
It should be noted here; however, that the selection of these systems for further analys is is not indicative of a final recommendation for their use, but merely a further step in their assessment. The immediate purpose here is to apply the results of the computer modeling to these specific concepts .

\subsubsection{Determination of Energy Storage Break-Even Costs}

The break-even cost for residential energy storage systems was determined by finding the difference between the capitalized annual displaced energy credit and rapitalized 0\&M cost3. The uverall procedure for determining the break-even cost consisted of the following steps:

1. Selection of the storage system, WTG size, location and storage capacity.

2. Determination of the WTG annual energy performance with and without storage.

3. Determination of the annual displaced energy credit due to addition of storage, using average cost of electricity.

4. Determination of the capitalized displaced energy credit, accounting for the effects of storage efficiency.

5. An estimate of the capitalized 08M costs for subtraction from the step 4 result.

6. Comparison of storage system breakeven cost from step 5 with projected actual or estimated system costs. 
The first two steps above were discussed in the previous section; discussion of the remaining steps follows.

\subsubsection{Cost of Electricity}

The principal economic benefit associated with addition of residential storage to wind conversion systems is a reduction in the cost of purchased electricity. Recent residential electricity price data for the three selected wind sites and the U.S. as a whole is presented in Table 3.4-8. The United States average value of $4 \$ / \mathrm{kWh}$ was used in subsequent analys is and corresponds closely to the average of the prices at the three wind sites. Analysis was also performed at several electricity price escalation rates.

TABLE 3.4-8. REPRESFNTAT IVE RANGE OF RESIDENTIAL ELECTRIC ENERGY COSTS

\begin{tabular}{|l|c|}
\hline \multicolumn{1}{|c|}{ LOCATION } & $\begin{array}{c}\text { CUNSUMH.K COST OF } \\
\text { ELECTRICITV }(t / k \mathrm{kh}) 28\end{array}$ \\
\hline Blue Hi1l, MA & 5.0 \\
Great Falls, MT & 2.5 \\
Lubbock, TX & 3.5 \\
U.S. Average & 4.0 \\
\hline
\end{tabular}

\subsubsection{Displaced Fnergy Credit}

An annual displaced energy credit for energy storage at $75 \%$ storage efficiency, $A_{F}^{0}$, is determined by multiplying the annual energy displacement by the cost 
of electricity. Using the mean energy displacement as presented in Figure 3.4-7 and the 1976 national average residential price of electricity (4థ/kWh) the $A_{E}^{0}$ versus storage capacity curve of Figure $3.4-8$ is readily computed.

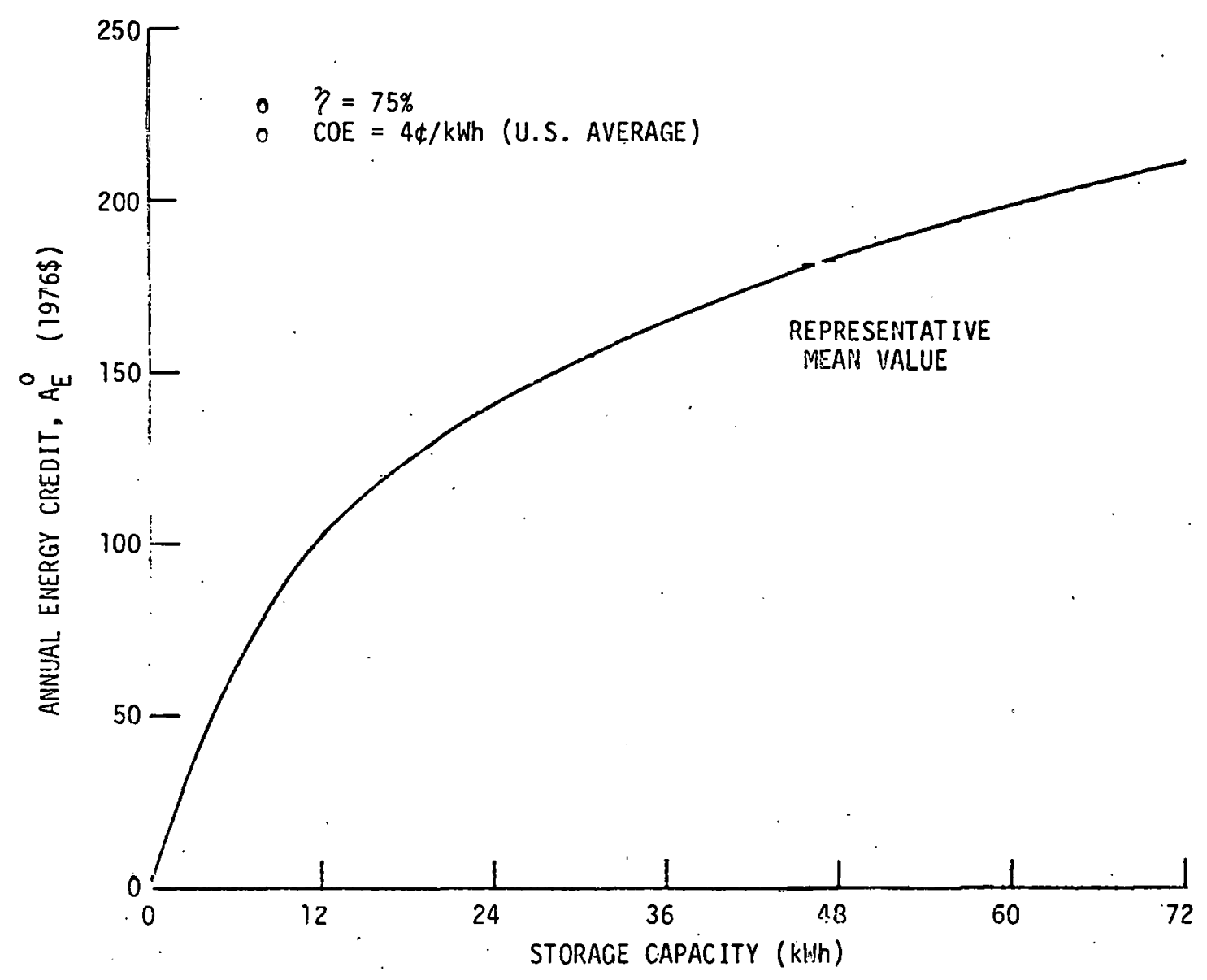

FIGURE 3.4-8. ANNUAL RESIDENTIAL MEAN ENERGY CREDIT VERSUS STORAGE CAPACITY

Electricity price escalation beyond 1976 is accounted for by computing $M_{e}$, the levelizing value of an escalating cost stream: $26, ? 7$ 


$$
M_{e}=\frac{r(1+e)}{r-e} \quad\left[\frac{(1+r)^{n}-(1+e)^{n}}{(1+r)^{n}-1}\right]
$$

where

$$
\begin{aligned}
& r=\text { discount rate } \\
& \mathrm{e}=\text { annual electricity price escalation rate } \\
& \mathrm{n}=\text { storage system life - years }
\end{aligned}
$$

The discount rate, $r$, for the homeowner is assumed to be the after-tax cost of a $9 \%$. loan to an individual in a $20 \%$ incremental tax bracket, which can be shown to be $7.2 \%$. Using the capital recovery factor (CRF) or mortgage rate equation:

$$
\mathrm{CRF}=\frac{r(1+r)^{n}}{(1+r)^{n}-1}
$$

and adding an additional 2.5\% annually for taxes and insurance, annual fixed charges can be expressed as a percent of the initial investment. This percent or fixed charge rate $(F C, R)$ is presented below versus $n$, the stürage systcm life.

TABLE 3.4-9. RESIDENTIAL. FIXED CHARGE RATES

\begin{tabular}{|c|c|}
\hline SYSTEM LIFE $(n)$, YRS & FIXED CHARGE RATE (FCR) \\
\hline 10 & .17 \\
20 & .12 \\
30 & .10 \\
\hline
\end{tabular}


An adjustment was made to the fixed charge rate in the case of battery storage to account for a 20 year system 1 ife, but with battery replacement at 10 years with 30 percent salvage value. An equivalent 20 year fixed charge rate was computed at .15 and used in battery break-even cost computations.

Equating fixed charges to energy savings for a start year $\delta$ years from 1976 gives:

$$
\begin{aligned}
& C_{[}^{0}(1+g)^{\delta} \quad F C R=(1+c)^{\delta} M_{e} A_{E}^{0} \\
& \text { where } C_{E}=\text { capitalized energy credit } \\
& g=\text { general inflation rate }
\end{aligned}
$$

and, solving for $C_{E}^{0}$ :

$$
C_{E}^{0}=\left(\frac{i+e}{1+g}\right)^{\delta} \quad \frac{M_{\dot{e}}}{F C R} \quad A_{E}^{0}
$$

A table of the quantity $\left(\frac{1+e}{1+g}\right)^{\delta} M_{e}$ is presented at the end of this section.

Up to this point, energy displacement and credits have been evaluated for $75 \%$ storage efficiency. For storage systems with efficiencies other than $75 \%$, a correction factor, $C_{\eta}$, was determined, which yields a capitalized energy credit:

$$
C_{E}=C_{\text {क日 }} \times C_{E}^{0}
$$


Figure 3.4-9 presents the results of computer runs evaluating the effect of storage efficiency on energy displacement.

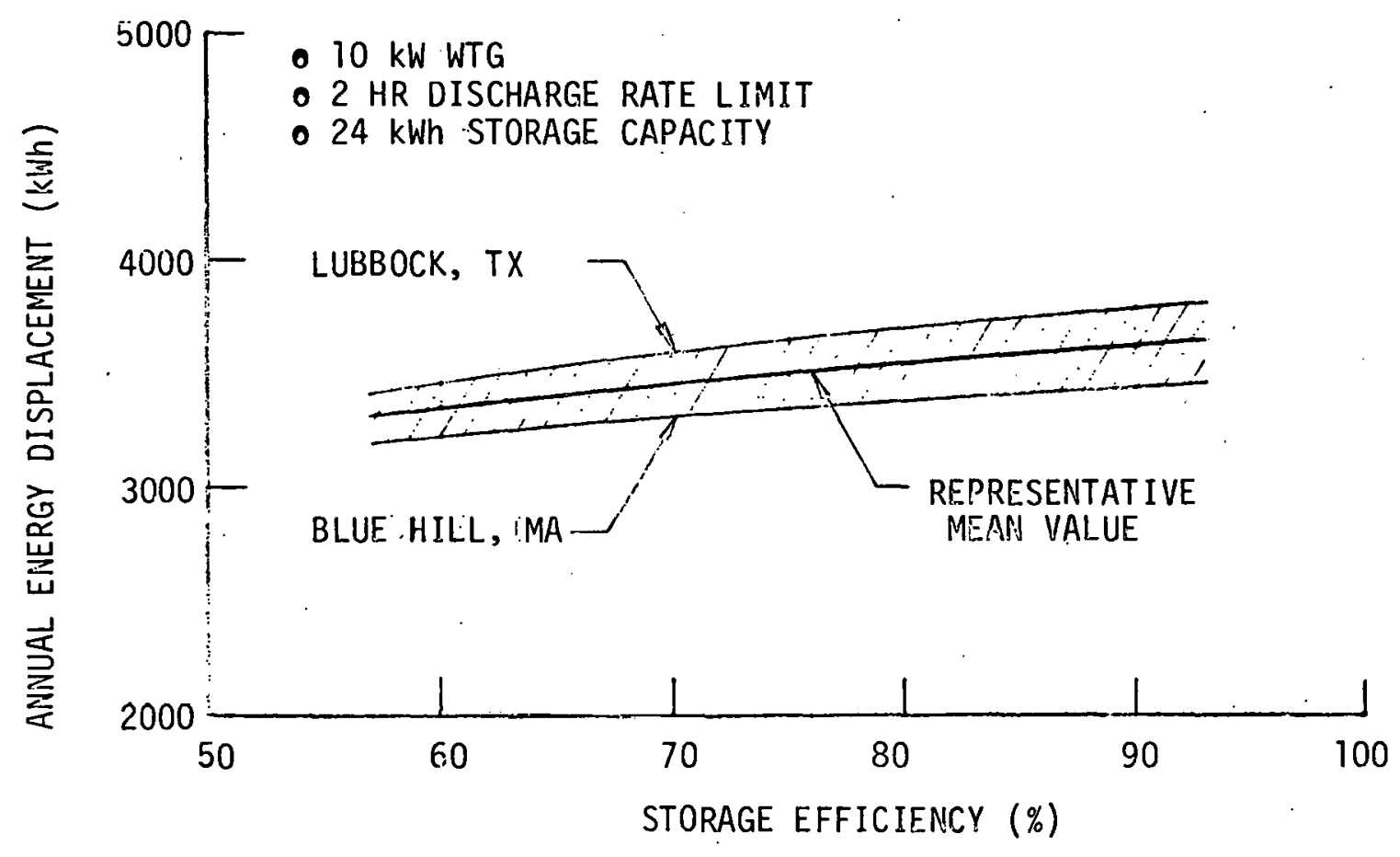

FIGURE 3.4-9. EFFECT OF STORAGE FFFICIENCY ON RE.SIDENTIAL ENERGY DISPLACEMENT

The data of Figure 3.4-9 was used to construct a curve of $C_{n}$, the efficiency correction factor, versus storage efficiency. This is shown in Figure 3.4-10. 


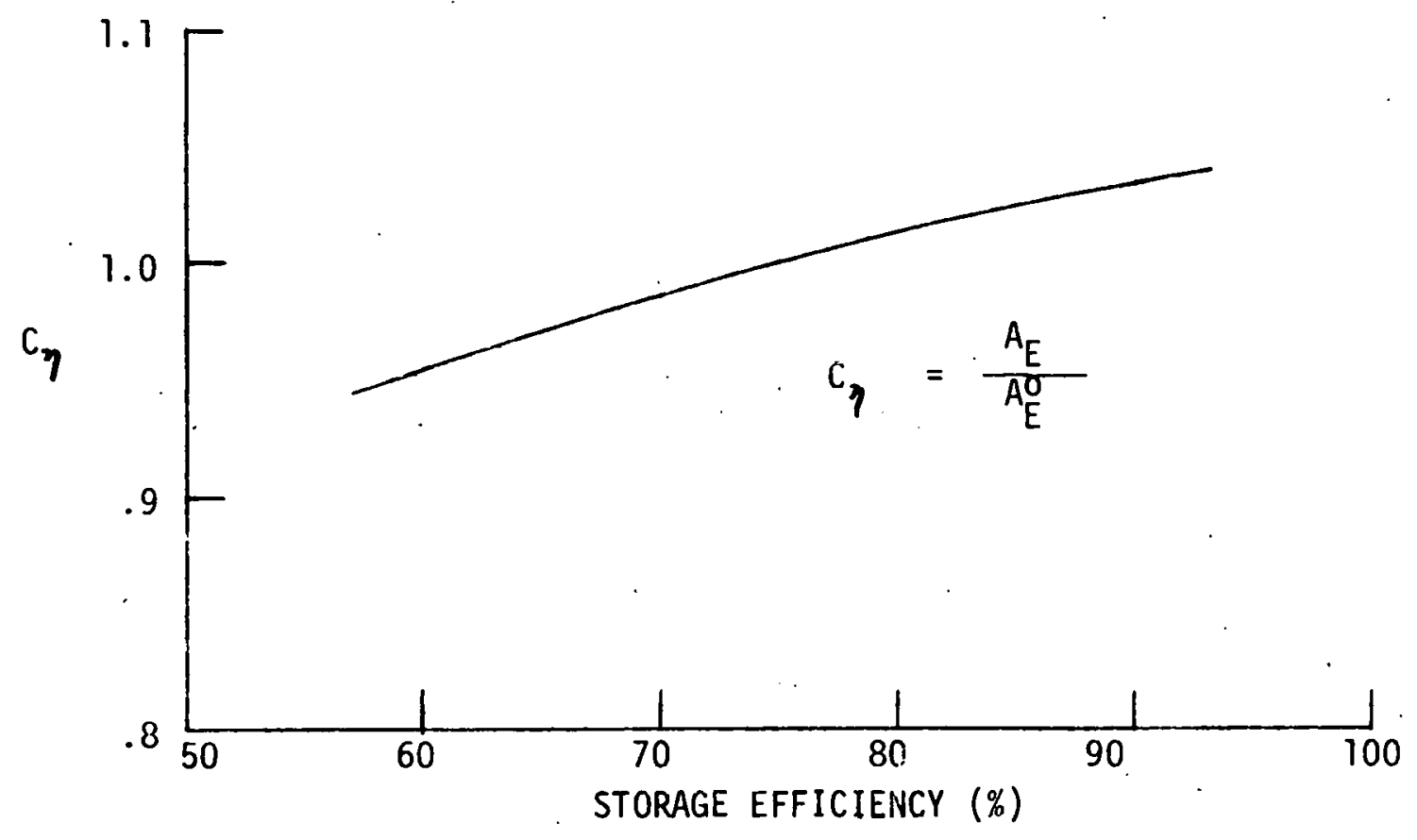

FIGURE 3.4-10. RESIDENTIAL STORAGE EFFICIENCY CORRECTION FACTOR

\section{Energy Credit Multiplier}

Presented below is a table of the energy credit multipliers for use in computing break-even costs at various escalation rates and points in time. Energy Credit $=\left(\frac{1+e}{1+g}\right)^{\delta} M_{e} \times \quad \frac{1976 \text { Savings }}{\text { Fixed Charge Rate }}$ 

TABLE 3.4-10. $\begin{aligned} & \text { ENERGY CREDIT MULTIPLIER } \\ & \text { RESIDENTIAL APPLICATION }\end{aligned}\left(\frac{1+\mathrm{e}}{1+\mathrm{g}}\right)^{\delta} \quad \mathrm{M}_{\mathrm{e}}$,

\begin{tabular}{|c|c|c|c|c|c|c|}
\hline \multirow{2}{*}{ YEAR } & \multicolumn{6}{|c|}{ e $\sim$ ELECTRICITY PRICE ESCALATION RATE } \\
\hline & $5 \%$ & $6 \%$ & $7 \%$ & $8 \%$ & $9 \%$ & $10 \%$ \\
\hline 1976 & 1.5532 & 1.7071 & 1.8802 & 2.0749 & 2.2942 & 2.5413 \\
\hline 1982 & & 1.8071 & 2.1056 & 2.4570 & 2.8711 & 3.3595 \\
\hline 1985 & & 1.8592 & 2.2282 & 2.6736 & 3.2119 & 3.8627 \\
\hline 1988 & & 1.9128 & 2.3579 & 2.9094 & 3.5931 & 4.4412 \\
\hline 1994 & & 2.0247 & 2.6406 & 3.4452 & 4.4967 & 5.8711 \\
\hline 2000 & $\vee$ & 2.1432 & 2.9571 & 4.0796 & 5.6275 & 7.7614 \\
\hline
\end{tabular}

\subsubsection{Operation and Maintenance Costs}

The annual operation and maintenance $\cos t, A_{O M}$, is storage system related and estimated according to the expression:

$$
A_{O M}=a_{O M} \times A S D E
$$

where

$\mathrm{a}_{O M}=$ variable storage O\&M costs in $\$ / \mathrm{kWh}$ of discharge energy - $A S D E=$ annual storage discharge energy

AOM for various types of storage is computed from cost data given in Volume I, Table 5.3-2, and the energy displacement values shown in Figure 3.4-7. 
A minimum annual $0 \& M$ cost of $\$ 15$ was set, corresponding to a minimum type residential service check to be performed by a local service organization. The annual O\&M cost is capitalized in an analogous manner to the energy savings capitalization:

$$
C_{O M}=\frac{M g}{F C R} \quad A_{O M}
$$

where

$$
\begin{aligned}
C_{O M}= & \text { capitalized } 0 \& M \text { costs } \\
M_{g}= & \text { levelizer for a cost stream escalating at the general } \\
& \text { inflation rate (same form as } M_{\rho} \text { previously described) } .
\end{aligned}
$$

\subsubsection{Break-Even Cost}

The break-even cost for the residential storage system is the difference between the capitalized energy credit and the capitalized 0\&M cost:

$$
C_{B E}=C_{E}-C_{O M}
$$

A sample break-even cost computation for lead-acid battery storage is presented below.

\section{Specific Conditions}

- $10 \mathrm{~kW} \mathrm{WTG}$

- 24 kWh capacity - lead-acid battery

- 2 hour discharge rate limit

- $5 \%$ inflation rate, $g$

- $10 \%$ electricity price escalation rate, e

- 20 year systern life, $n$ 
- $7.2 \%$ discount rate, $r$

- $70 \%$ (lead-acid battery) storage efficiency

- Fixed charge rate, $F C R=.15$

- Variable $0 \& M$ cost rate, $a_{\text {OM }}=\$ .0005 / \mathrm{kWh}$

- Annuar energy displacement $=3503 \mathrm{kWh}$ (mean value); ASDE $=3687 \mathrm{kWh}$ (mean value)

- Start year - 2000

- Results in 1976 dollars

The energy credit $A_{E}^{0}$ then becomes:

$$
A_{E}^{0} \quad=.04(3503)=\$ 140.12
$$

From equation (1), $\mathrm{M}_{\mathrm{e}}=2.5413$ and the capitalized energy credit, $\mathrm{C}_{\mathrm{E}}^{0}$ becomes from equation (3):

$$
c_{F}^{0}=\left(\frac{1.10}{1.05}\right)^{24} \quad\left(\frac{2.5413}{.15}\right) \quad(140.12)=\$ 7250
$$

The efficiency correction factor, $C_{\eta}$ for lead-acid batteries $(70 \%$ efficiency) is .986 frem Figure 3.4-10. Therefore, the corrected energy credit becomes from equation (4):

$$
C_{E}=.986(7250)=\$ 7149
$$

The annual $0 \& M$ cost, $A_{O M}$, obtained from equation (5) is:

$$
A_{\text {OM }}=.0005(3687)=\$ 1.84
$$

which is less than $\$ 15.00$. Therefore, $A_{O M}$ is set equal to $\$ 15$.

$$
M_{g}=1.5532
$$


and the capitalized 0\&M cost, $C_{0 M}$, becomes from equation $(6)$ :

$$
C_{O M}=\frac{1.5532}{.15} \quad(15)=\$ 155
$$

The resulting break-even cost from equation ( 7$)$ is then:

$$
C_{B E}=7149-155=\$ 6994
$$

or

$$
C_{B E}=\frac{6994}{24}=\$ 291.4 / \mathrm{kWh} \text { of storage rapacity }
$$

Storage system breakeven costs were computed, using the above methodology, for electricity price escalation equal to general inflation (5\%), for a 1985 start year with $6 \%$ escalation ( $1 \%$ over inflation), and at an extreme for $10 \%$ electricity price escalation with a year 2000 start. Results are tabulated in Table 3.4-11 for the four residential technologies analyzed. 
TABLE $3.4-11$. STORAGE BREAKEVEN COSTS - RESIDENTIAL APPLICATION

\begin{tabular}{|c|c|c|c|}
\hline \multicolumn{4}{|c|}{ ADVANCED BATTERIES } \\
\hline $\mathrm{kWh}$ & $5 \%$ & $6 \%-1985$ & $10 \%-2000$ \\
\hline 12 & 75 & 93 & 429 \\
24 & 54 & 66 & 296 \\
48 & 36 & 44 & 195 \\
72 & 28 & 34 & 149 \\
\hline
\end{tabular}

\begin{tabular}{|c|c|c|}
\hline \multicolumn{3}{|c|}{ LEAD-AC ID BATTERIES } \\
\hline $5 \%$ & $6 \%-1985$ & $10 \%-2000$ \\
\hline 74 & 91 & 423 \\
53 & 65 & 291 \\
36 & 44 & 192 \\
28 & 34 & 147 \\
\hline
\end{tabular}

\begin{tabular}{|c|c|c|c|}
\hline \multicolumn{4}{|c|}{ FLYLHEEL } \\
\hline kWh & $5 \%$ & $6 \%-1985$ & $10 \%-2000$ \\
\hline 12 & 97 & 119 & 547 \\
24 & 67 & 82 & 375 \\
48 & 44 & 54 & 246 \\
72 & 34 & 41 & 188 \\
\hline
\end{tabular}

\begin{tabular}{|r|r|r|}
\hline \multicolumn{3}{|c|}{ PNEUMATIC } \\
\hline $5 \%$ & $6 \%-1985$ & $10 \%-2000$ \\
\hline 91 & 113 & 521 \\
65 & 80 & 359 \\
44 & 54 & 237 \\
34 & 41 & 181 \\
\hline
\end{tabular}

All values in $\$ / k W h$ of storage capacity

Differences in efficiency, O\&M costs and FCR combine to create a separation in the breakeven costs for each concept. By themselves these breakeven costs do not indicate the desirability of a particular concept.

A comparison of breakeven costs versus storage cost projections is presented for batteries in Figure 3.4-11. The nominal case of $6 \%$ electricity price 


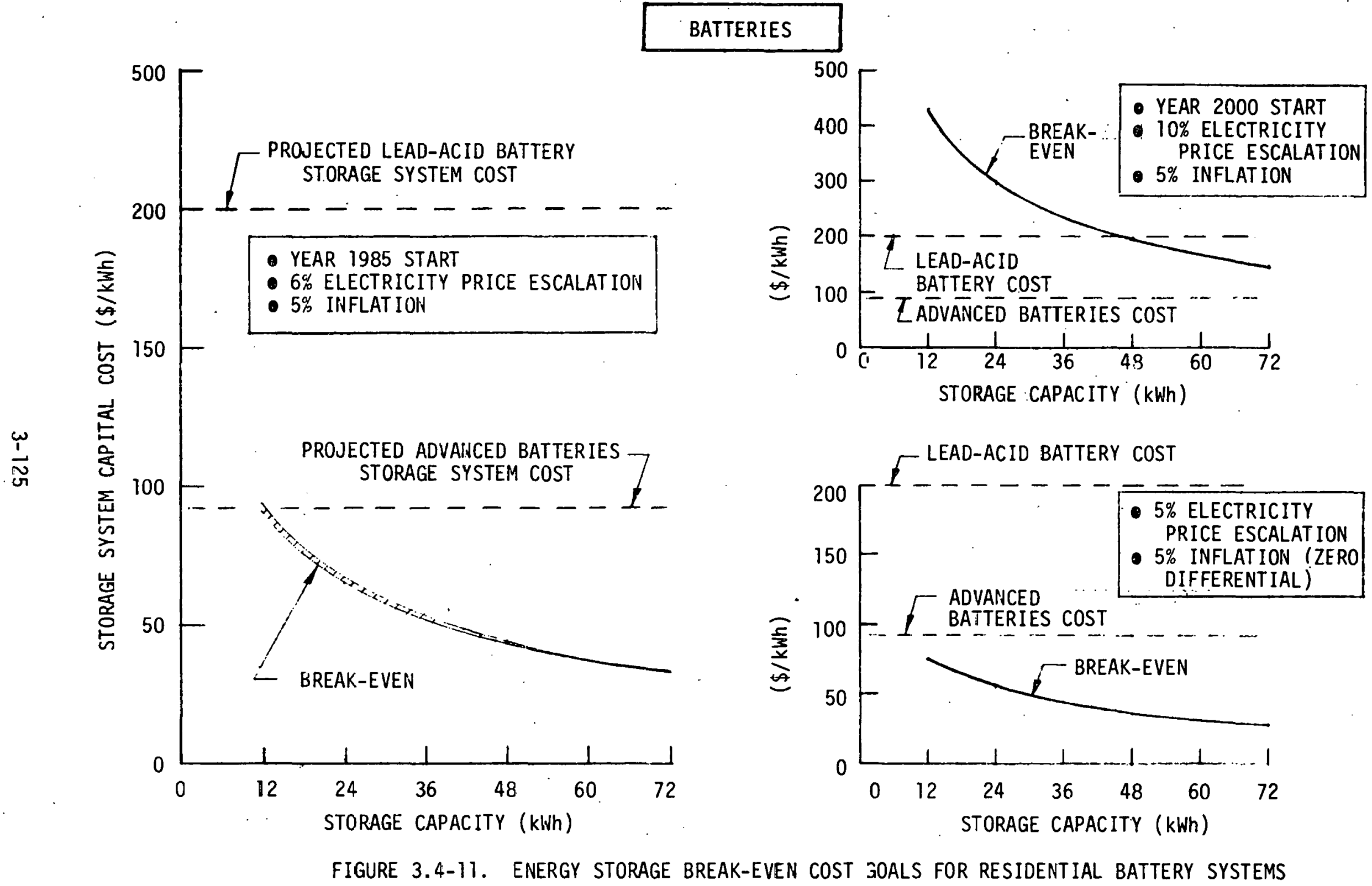


escalation and 1985 start year shows marginal viability for advanced batteries at about $12 \mathrm{kWh}$ capacity and a price of $92 \$ / \mathrm{kWh}$. At year 2000 with $10 \%$ escalation, both types of batteries show breakeven costs greater than system cost estimates, and would therefore offer economic viability under these conditions. Flywheel and pneumatic energy storage breakeven costs are shown: in Figure 3.4-12. Note that neither demonstrate viability until the $10 \%, 2000$ case. System cost estimates shown on the figures are taken from Table 5.3-2 of Volume I of this study report. These were selected as representative for the respective technologies, based on currently available information. With cost data continually changing, the format of the charts was made such that the reader could easily use updated cost estimates as they become available.

There are obviously many start year - escalation rate combinations that will achieve economic viability for a given storage system. Figure 3.4-13 shows battery storage. system breakeven costs versus start year and electricity price escalation rate. Cost estimates for lead-acid and advanced batteries are overlaid as dashed lines. At $8 \%$ escalation, the figure shows advanced batteries becoming economic in 1983, while at $7 \%$ viability is delayed until about 1992. The reader can use any source for system cost estimates and electricity price projections and test viability with this chart. Figure 3.4-14 is a similar chart for flywheel and pneumatic storage. Note that only at very high 9 and $10 \%$ escalation rates is economy achieved. 


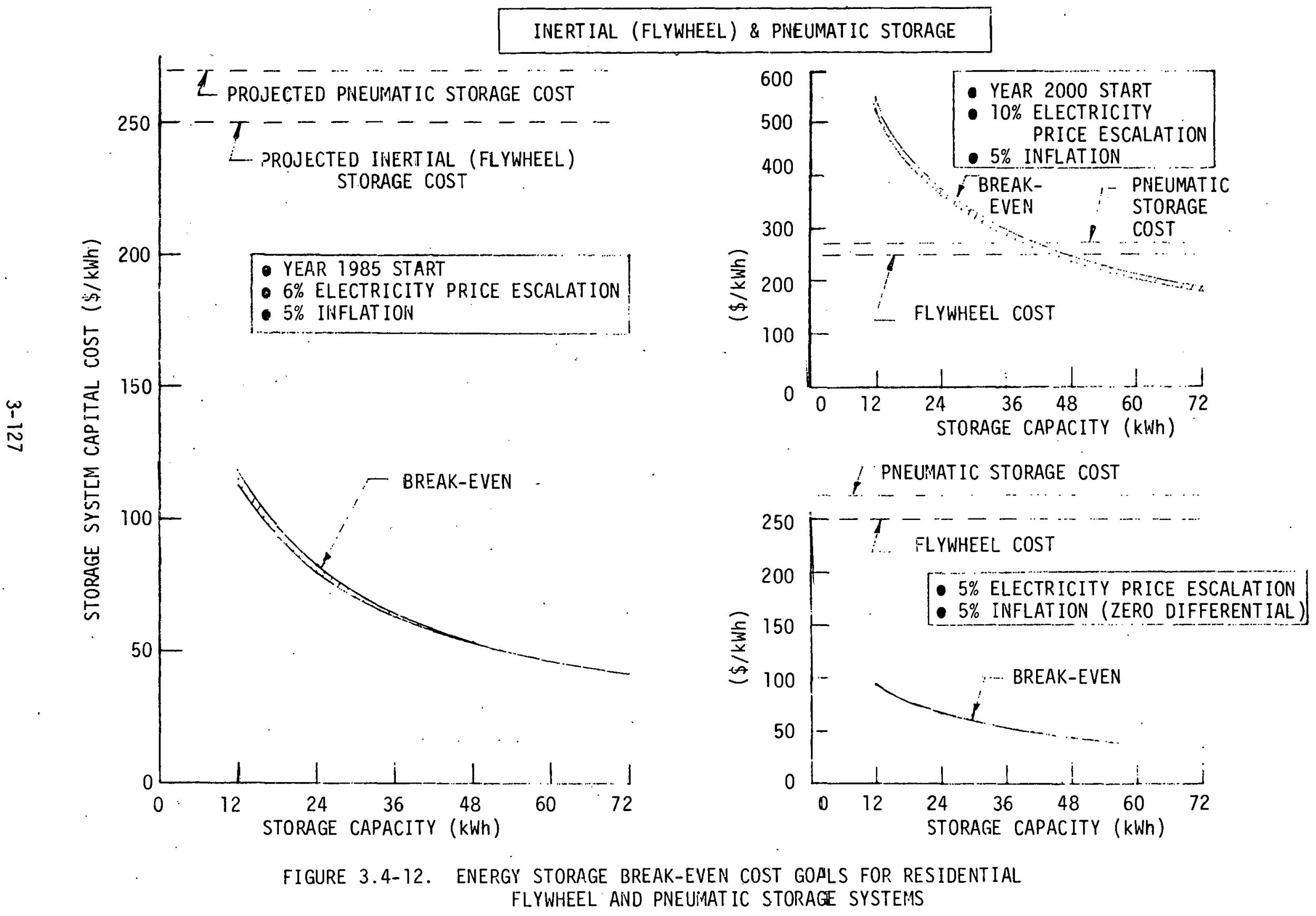




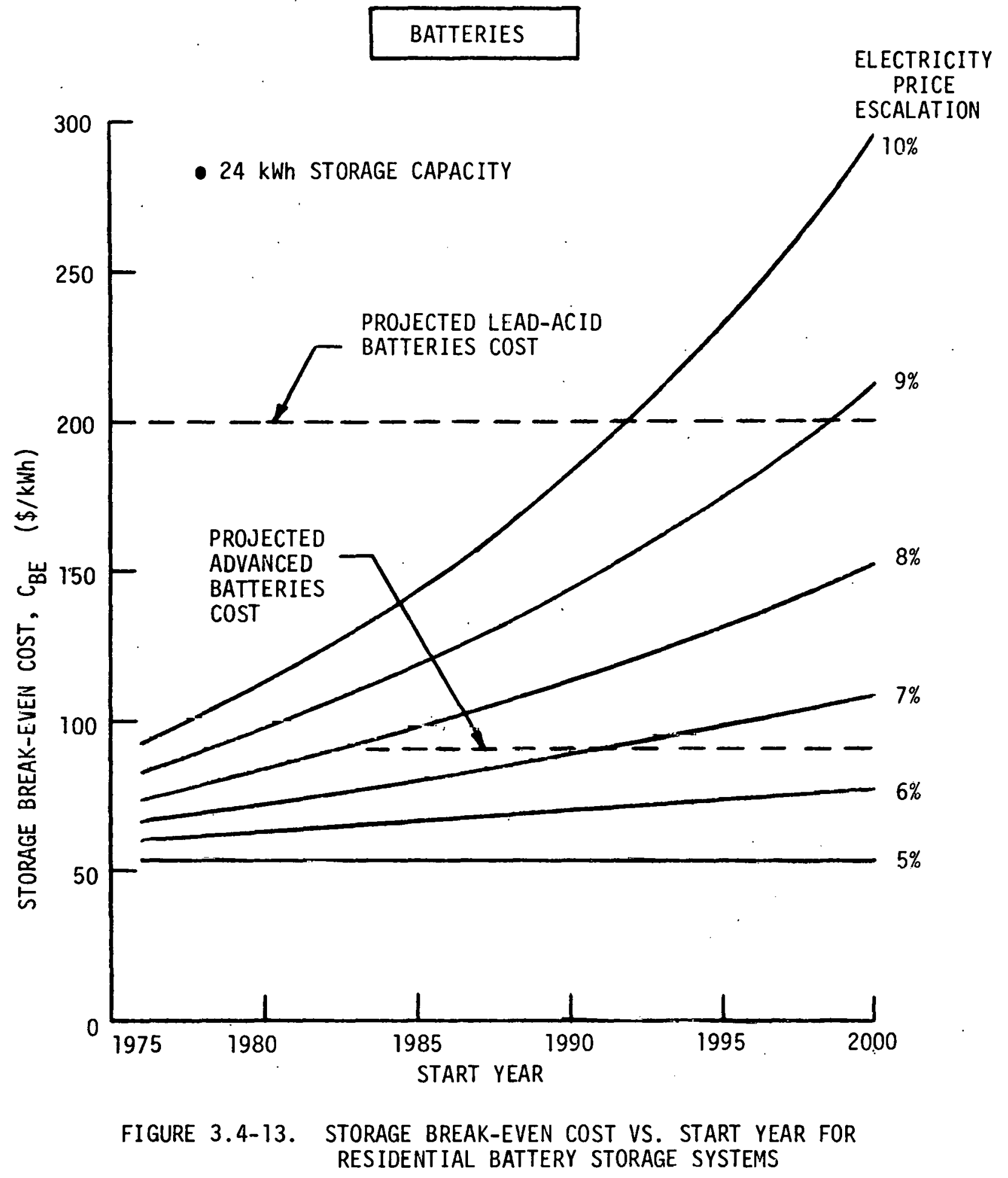


FLYWHEEL \& PNELMATIC STORAGE

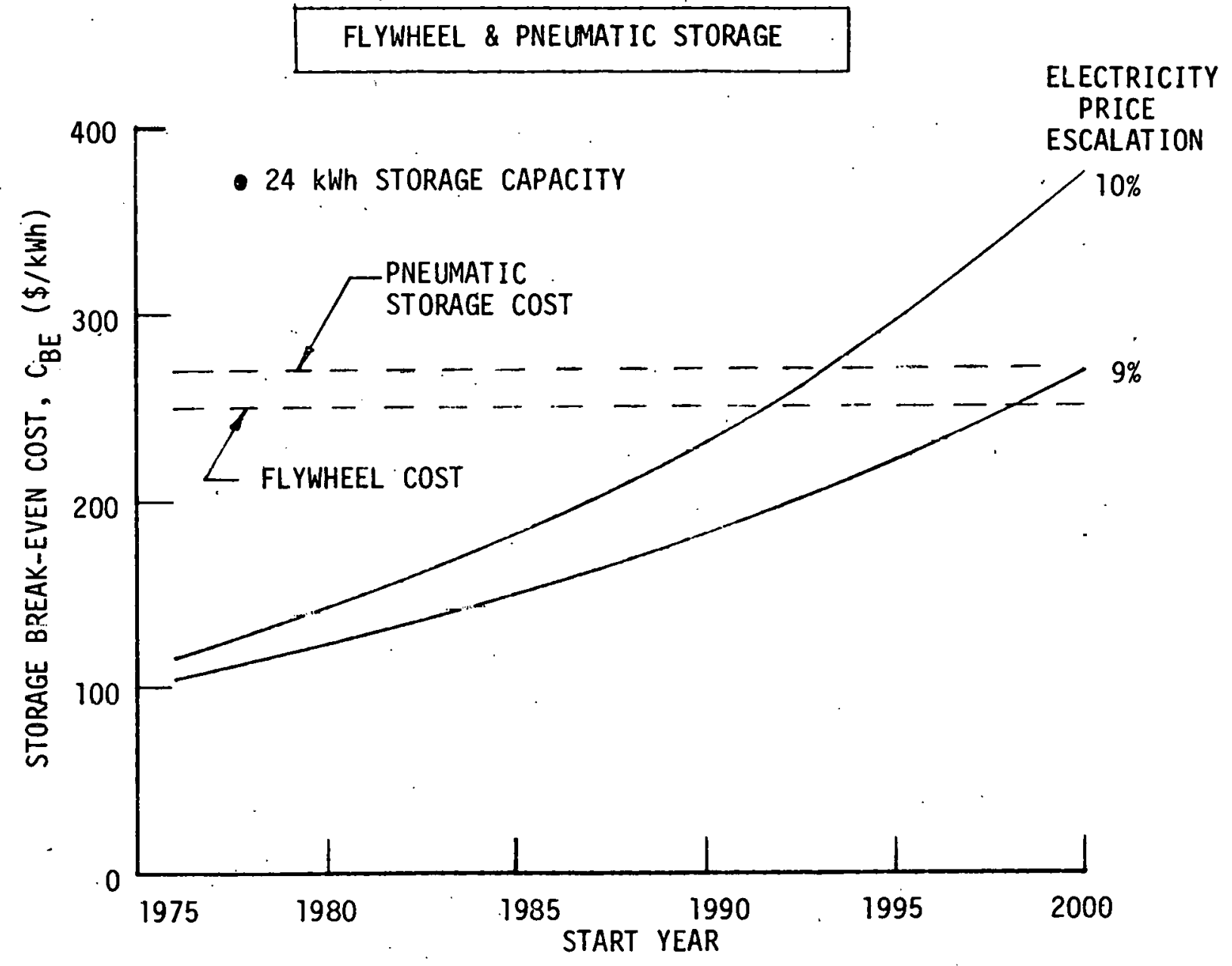

FIGLIRE 3.4-14. STORAGE BREAKEVEN COST VS. START YEAR FOR RESIDENTIAL FL YWHEEL AND PNEUMATIC STORAGE SYSTEMS

\subsubsection{Storage Capacity Optimization}

When viability is achieved, the optimum storage size is determined by the maximum sapitalized salings. Fur example, advanced batteries at year 2000, $10 \%$ escalation give the following data: 
TABLE 3.4-12. VALUES FOR OPTIMUM STORAGE DETERMINATION

\begin{tabular}{|c|c|c|c|c|}
\hline $\begin{array}{l}\text { STORAGE SIZE } \\
(\mathrm{kWh})\end{array}$ & $\mathrm{C}_{\mathrm{BE}}: \frac{\$}{\mathrm{kWh}}$ & $\operatorname{COST} ! \frac{\$}{\mathrm{xWh} !}$ & SAVINGS: $\frac{\$}{\mathrm{kWh}}$ & $\begin{array}{l}\text { TOTAL } \\
\text { CAPITALIZED } \\
\text { SAVINGS } \$:\end{array}$ \\
\hline 12 & 429 & 92 & 337 & 4044 \\
\hline 24 & 296 & & 204 & 4896 \\
\hline 48 & 195. & & 103 & $4944^{\star}$ \\
\hline 72 & 149 & $v$ & 57 & 4104 \\
\hline
\end{tabular}

* OPTIMUM

A general trend shown by this residential storage analysis is that optimum capacities greater than about $24 \mathrm{kWh}$ require extreme economic conditions. 12 to $24 \mathrm{kWh}$ capacity appears to represent the best size range for residential storage. As storage costs drop and electricity price escalation rises, the optimum amount. of storage will increase with time.

\subsubsection{Wind System Enhancement}

Once storage is available at a cost below its breakeven value, the cost difference can be reflected in an increased allowable price for the basic wind turbine generator system. Another perspective is that the total wind plus storage system has a breakeven value. As cost of storage is lowered, WTG cost can rise and still meet total system breakeven. Figure 3.4-15 shows this effect for three increasingly severe economic conditions. At 1985, with $6 \%$ escalation, $24 \mathrm{kWh}$ of $20 \$ / \mathrm{kWh}$ storage increases WTG allowable cost from $\$ 817 . / \mathrm{kW}$ to over $900 \$ / \mathrm{kW}$. The potential for system economic enhancement increases with escalation rate and start year delay. 

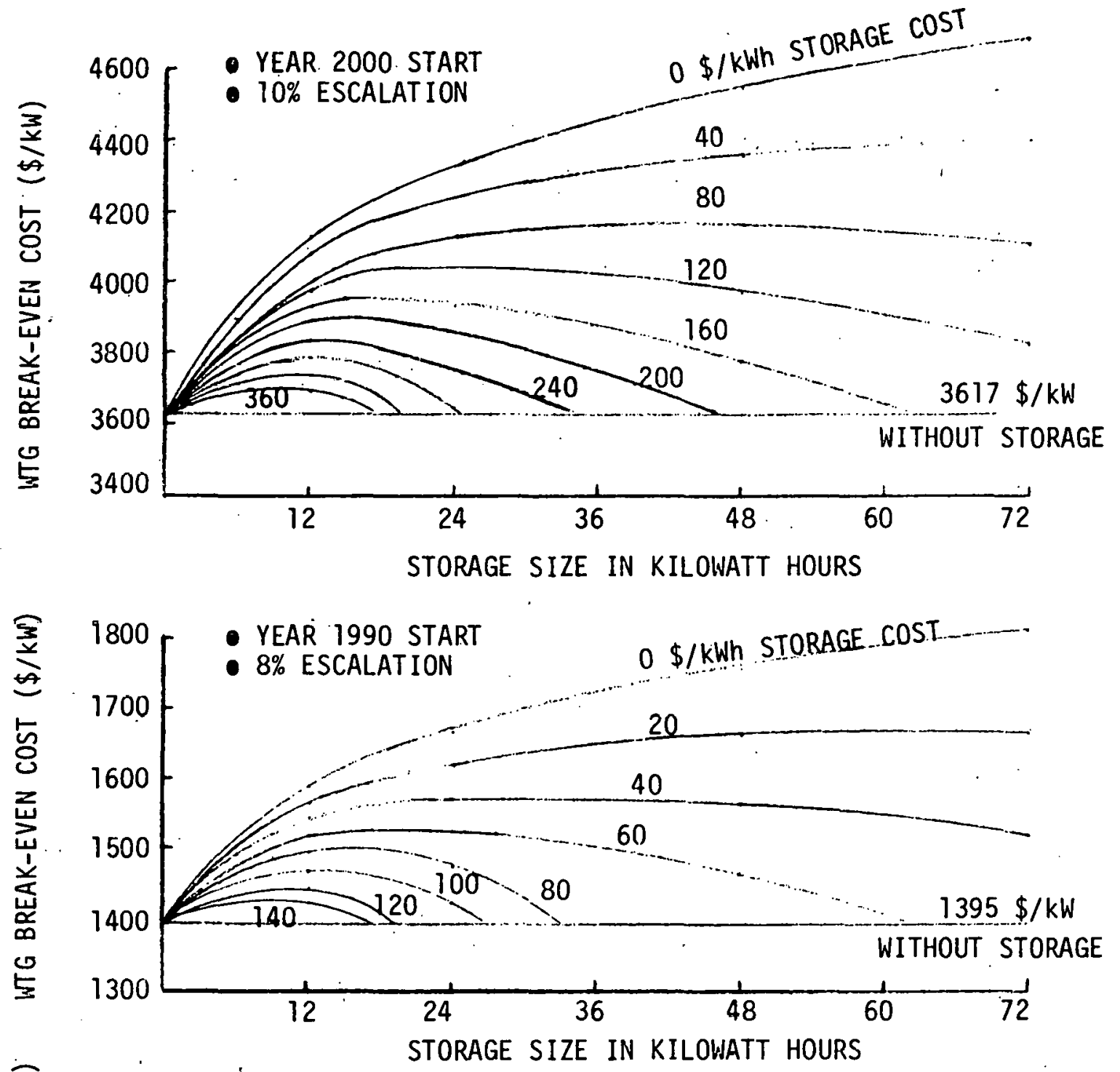

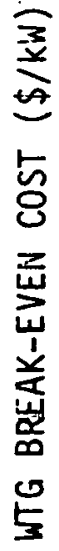

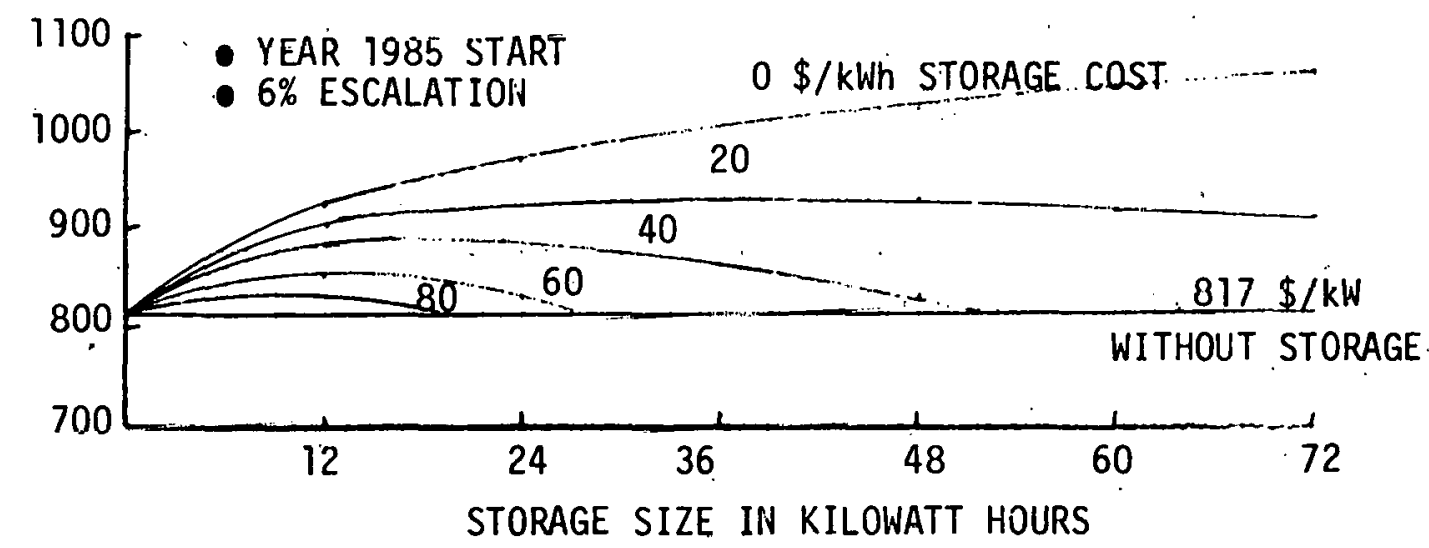

FIGURE 3.4-15. INCREASE IN WIND SYSTEM BREAK-EVEN COSTS DUE TO ENERGY STORAGE 


\subsection{ANALYSIS AND PROJECTION OF INTERMEDIATE WIND SYSTEM COST GOALS}

\subsubsection{ENERGY MANAGEMENT}

The intermediate size applications for wind energy conversion and energy storage cover a very broad range. Individual industrial plants offer one. possibility but require specific analyses which are not necessarily broadly representative. After due consideration of candidate applications defined in a recent study of overall 1 wind energy conversion, ${ }^{12}$ it was decided that consideration of a complex typical of a shopping center or cluster of small businesses might be most useful for purposes of this study. The energy management/energy storage problem can be seen to have two significant aspects:

1. The need to meet some portion of the total load demand with wind or wind plus storage in order to reduce the overall energy cost of electricity.

2. The need to reduce the costs of electricity based on the power demand rate portion of typical rate schedules.

Because of the variability of the wind and precision of dispatch planning for stored energy that would be involved, Item 2 was found to require special analyses which would involve assumptions of uncertain value. More specifically, the ability to limit power demand charges to some predetermined level by use of stored energy requires that storage output be $100 \%$ reliably available on call. Since this criteria could not be met with wind-dedicated storage charging (within reasonable storage size limits), Item 2 was eliminated from further consideration; however, the economics and potential value of peak reductions and load leveling with storage are discussed in Section 3.7. 
In the case of Iten! 1, the availability of wind conversion energy at times of light load demands can be made more attractive by use of storage which accepts excess generation and saves the wind energy until needed. The improvement (reduction in utility energy use) resulting from the use of storage was analyzed for selected conditions of load and wind power output. As in the residertial case, a one way power flow to the load was assumed, with the uitlity providing a net "Make-Up" to fully meet the actual load demands.

\subsubsection{WIND ENERGY AVAILABILITY AND CONVERSION}

The previnus discussion in Sectiun 3.3.2.1 pertaining to wind energy patterns and wind turbine output applies to the Intermediate case alsc. A 500 $\mathrm{kW}$ wind turbine was used as the basic wind conversion system. Its principal characteristics are shown in Table 3.5-1. Power output versus wind velocity

TABLE 3.5-1. $500 \mathrm{~kW}$ WIND GENERATOR SYSTEM CHARACTERISTICS

\begin{tabular}{|l|l|}
\hline & \multicolumn{1}{|c|}{ DESIGiN VALUES } \\
\hline Rated Power & $500 \mathrm{~kW}$ \\
Design Wind Velocity & $5.36 \mathrm{~m} / \mathrm{s}(12 \mathrm{MPH})$ \\
Generatur. Parameters & $\begin{array}{l}\text { Synchronous, } 500 \mathrm{~kW}, 4160 \mathrm{VAC}, \\
60 \mathrm{~Hz}, 3-\mathrm{Phase}, 1800 \mathrm{RPM}\end{array}$ \\
Rotor & $2 \mathrm{Blade}, 29.3 \mathrm{RPM}$ \\
Rotor Diameter & $55.29 \mathrm{~m}(181 \mathrm{ft})$ \\
Rotor Ax1s Height & $42.9 \mathrm{~m}(141 \mathrm{ft})$ \\
Wind Velocities: & $3.55 \mathrm{~m} / \mathrm{s}(7.94 \mathrm{MPH})$ \\
Cut-in & $7.32 \mathrm{~m} / \mathrm{s}(16.37 \mathrm{MPH})$ \\
Cut-out & $15.7 \mathrm{~m} / \mathrm{s}(35.12 \mathrm{MPH})$ \\
Annual Energy Production(Design) & $1.86 \times 10^{6} \mathrm{kWh}$ \\
\hline
\end{tabular}


is presented in Figure 3.5-1. This perfornance curve, in conjunction with Sandia-supplied weather tapes, was used to compute the hour-by-hour WTG power output. Annual totals for the two wind site locations analyzed were found to be:

$$
\begin{array}{ll}
\text { Lubbock, Texas } & 1780 \mathrm{MWh} \\
\text { Blue Hill, Massachusetts } & 1990 \mathrm{MWh}
\end{array}
$$

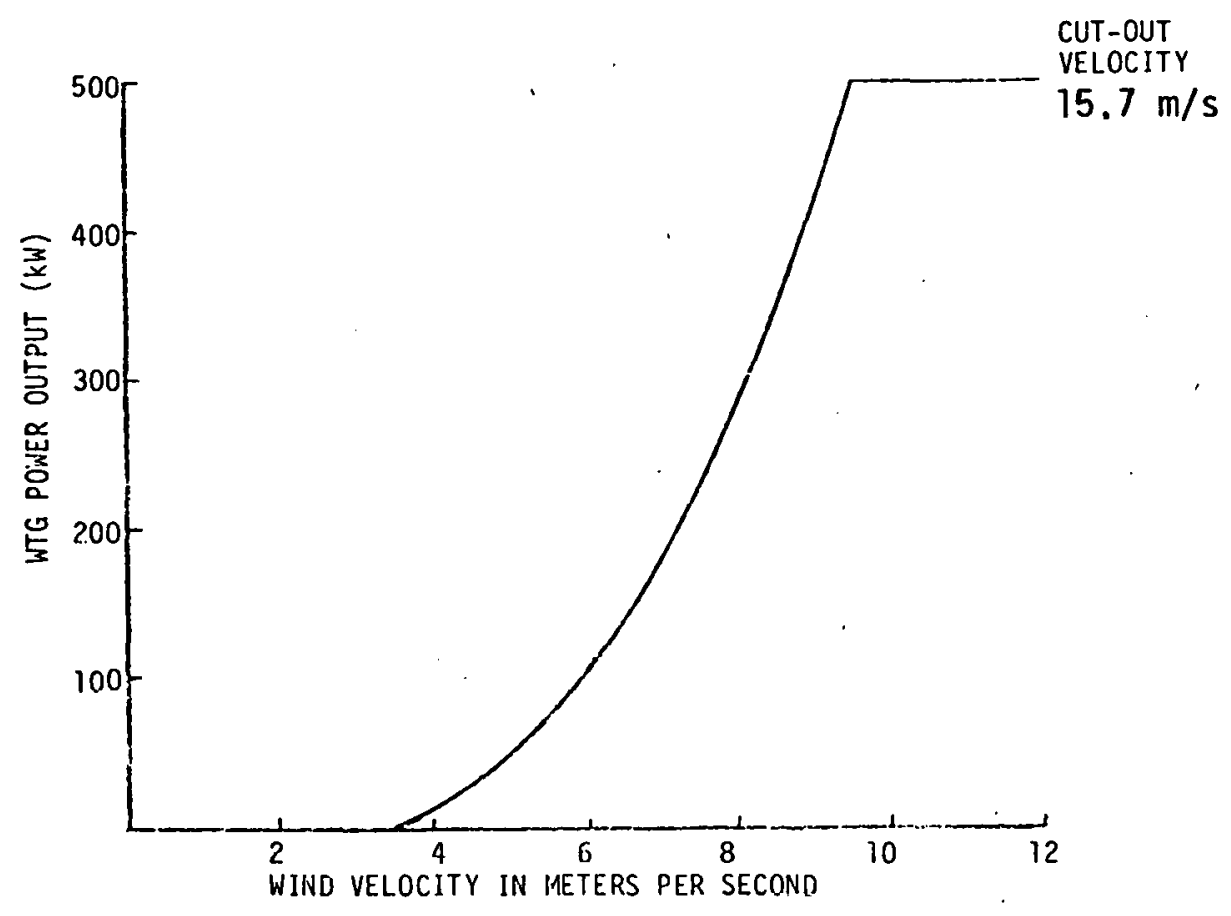

FIGUR.E 3.5-1. $500 \mathrm{~kW}$ WTG POWER OUTPUT VERSUS WIND V'FLOCITY

\subsubsection{LOAD DEMANDS}

A daily load pattern was assumed as shown in Figure 3.5-2. Several levels of $P$, the maximum demand, were investigated in the analysis. This maximum load was assumed to occur from 10 A.M. to 10 P.M. daily and drop to $25 \%$ of 


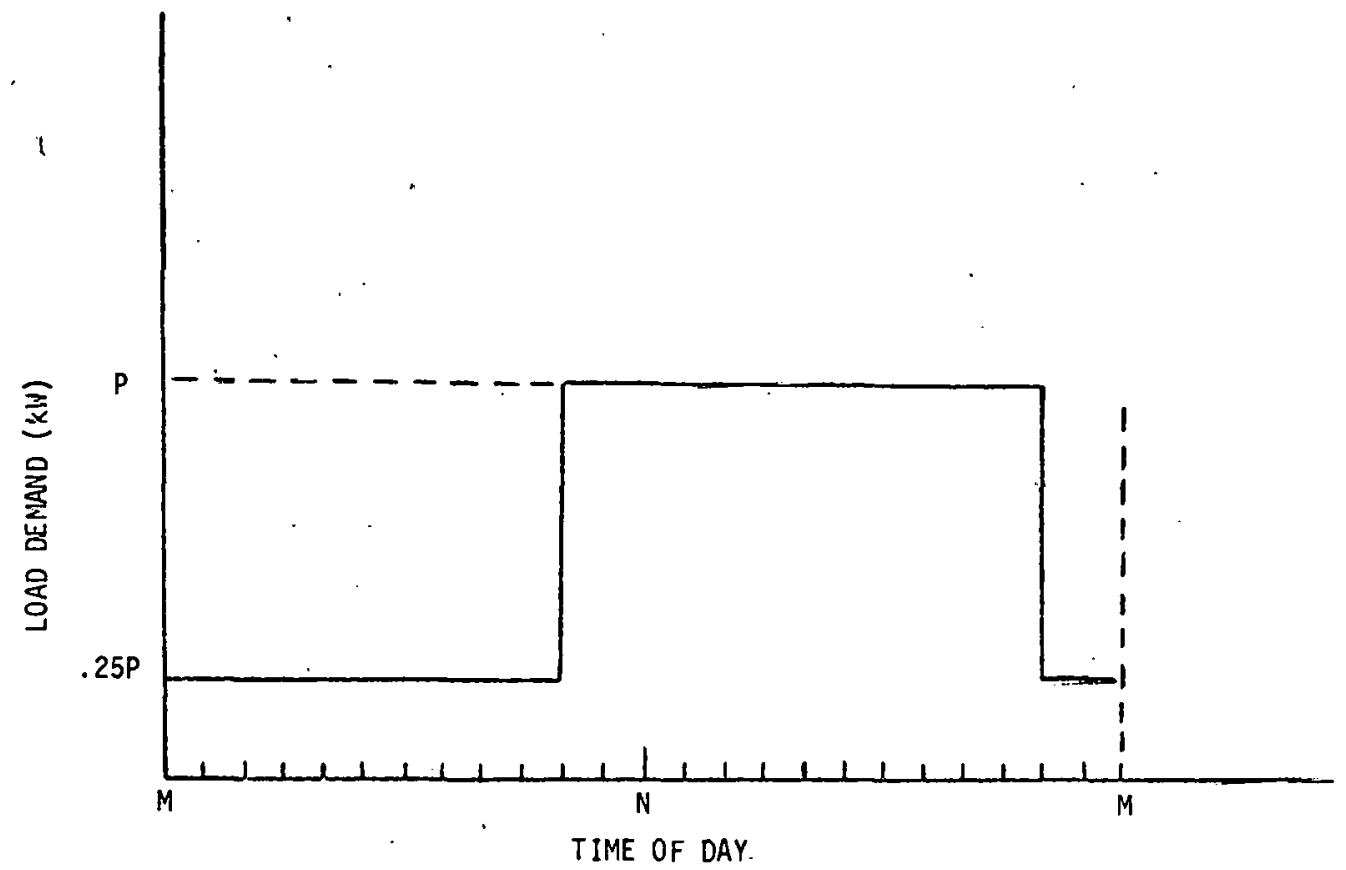

FIGURE 3.5-2. ASSUMED LOAD PROFILE FOR INTERMEDIATE APPLICATION

peak value the remainder of the time, thus reflecting an "idealized" load curve for a shopping center or commercial complex. Table 3.5-2 presents annual energy demand as a function of the maximum power demand.

TABLE 3.5-2. ANNUAL LOADS - INTERMEDIATE APPLICATION

\begin{tabular}{|c|c|}
\hline PEAK LOAD DEMAND, P (kW) & AiNUAL LOAD (MWh) \\
\hline 200 & 1,095 \\
250 & 1,369 \\
300 & 1,643 \\
\hline
\end{tabular}


The range of loads which could be matched to the intermediate size WTG is clearly very large, and this load - WTG relationship is somewhat analogous to "penetration" as defined for the utility case. The sizing reflected by Table 3.5-2 is primarily one of convenience for the purpose of analysis. In many intermediate applications, clusters or multiple 500 kW WTG units would be appropriate. Ten to twenty such WTG units, for example, would be a reasonable number to serve a very large facility having a similar load profile. A very large suburban shopping center, for example, could be expected to require total energy inputs in the order of 5-6 MW, and $20 \times 10^{6}$ MWhiyear. Having already dealt with multiple units in the utility case, it was deemed of greater interest here to investigate the effects of a different type of load pattern and rate structure.

\subsubsection{GENERATION AND LOAD IMATCHING WITHOUT STORAGE}

Baseline no-storage cases were computed for each location and the range of total lnad demands. The hour-by-hour tapes of wind turbine output and electrical demand were matched by computer program to determine what portiun of WTG output could be supplied directly to the load. Excess WTG energy and required utility makeup power were also computed and summed for the full 8760 hours. Results are shown in Table 3.5-3. 
TABLE 3.5-3. INTERMEDIATE LOAD MATCHING WITH A $500 \mathrm{~kW}$ WTG-NO STORAGE

\begin{tabular}{|l|c|c|c|c|}
\hline LOCATION & $\begin{array}{c}\text { PEAK LOAD } \\
(\mathrm{kW})\end{array}$ & $\begin{array}{c}\text { WTG ENERGY } \\
\text { UTILIZED(MWh) }\end{array}$ & $\begin{array}{l}\text { EXCESS WTG } \\
\text { ENERGY (MWh) }\end{array}$ & $\begin{array}{c}\text { UT ILITY } \\
\text { PURCHASED } \\
\text { ENERGY(MWh) }\end{array}$ \\
\hline Lubbock, TX & 200 & 700.6 & 1082.0 & 394.4 \\
& 250 & 839.0 & 943.7 & 529.8 \\
& 300 & 962.4 & 820.2 & 680.7 \\
\hline \multirow{2}{*}{ Blue Hill,MA } & 200 & 758.4 & 1234.2 & 336.6 \\
& 250 & 906.0 & 1086.6 & 462.8 \\
& 300 & 1042.3 & 950.3 & 600.2 \\
\hline
\end{tabular}

\subsubsection{GENERATION AND LOAD MATCHING INCORPORATING STORAGE}

Further analysis consisted of adding incremental storage quantities in order to use wind turbine excess energy to further offset purchased electrical energy. Hour-by-hour modeling was performed for a full year. Systel: operational strategy was similar to that for the residence (Section 3.4.5) with one exception.. In the intermediate case, a one-hour delay in changing from the utility, power back to WTG power was introduced in order to avoid excessive switching and also to provide an operational sequence adaptable to equipment already available or conceptually defined. Kesults of the computer analysis are presented in Table 3.5-4 in terms of utility purchased electricity. Subtraction from the baseline no storage case yields the quantity of purchased electricity saved due to energy storage. Results are shown in Table 3.5-5. 
TABLE 3.5-4. PURCHASED UT ILITY ENERGY WITH INTERMEDIATE WIND SYSTEM ENERGY STORAGE

\begin{tabular}{|c|c|c|r|r|r|r|}
\hline \multirow{2}{*}{$\begin{array}{c}\text { STORAGE } \\
\text { SIZE } \\
(\mathrm{kWh})\end{array}$} & \multicolumn{3}{|c|}{ LUBBOCK, TX } & \multicolumn{3}{c|}{ BLUE HILL, MA } \\
\cline { 2 - 7 } & 200 & 250 & 300 & 200 & 250 & 300 \\
\cline { 2 - 7 } & & & & & \multicolumn{2}{c|}{ LOAD DEMAND (kW) } \\
\hline & 394.4 & 529.8 & 680.1 & 366.6 & 462.8 & 600.2 \\
500 & 277.6 & 414.3 & 564.4 & 247.7 & 371.8 & 512.2 \\
1000 & 229.7 & 365.4 & 523.3 & 201.2 & 324.0 & 463.8 \\
1500 & 197.2 & 325.1 & 480.8 & 164.8 & 282.5 & 420.4 \\
2000 & 171.7 & 298.4 & 447.3 & 136.9 & 250.2 & 387.9 \\
3000 & 141.3 & 256.0 & 403.1 & 95.2 & 202.8 & 335.4 \\
4000 & 121.9 & 235.4 & 378.8 & 69.0 & 167.7 & 294.7 \\
\hline
\end{tabular}

PURCHASED ENERGY IN MWh

TABLE 3.5-5. ANNUAL ENERGY DISPLACEMENT DUE TO ENERGY STORAGE

\begin{tabular}{|c|c|c|c|c|c|c|}
\hline \multirow{2}{*}{$\begin{array}{c}\text { STORAGE } \\
\text { SI 7F } \\
(\mathrm{kWh})\end{array}$} & \multicolumn{3}{|c|}{ LUBBOCK, TX } & \multicolumn{3}{c|}{ BLUE HILL, MA } \\
\cline { 2 - 7 } & \multicolumn{3}{|c|}{ LOAD DEMAND (kW) } & \multicolumn{3}{c|}{ LOAD DEMAND (kW) } \\
\cline { 2 - 7 } & 200 & 250 & 300 & 200 & 250 & 300 \\
\hline & 116.8 & 115.5 & 115.7 & 88.9 & 91.0 & 88.0 \\
500 & 164.7 & 164.4 & 156.8 & 135.4 & 138.8 & 136.4 \\
1000 & 197.2 & 204.7 & 199.3 & 171.8 & 180.3 & 179.8 \\
1500 & 222.7 & 231.4 & 232.8 & 199.7 & 212.6 & 212.3 \\
2000 & 253.1 & 273.8 & 277.0 & 241.4 & 260.0 & 264.8 \\
3000 & 272.5 & 294.4 & 301.3 & 267.6 & 295.1 & 305.5 \\
4000 & & & & & & \\
\end{tabular}

ENERGY DISPLACEMENT VALUES IN MWh 
The stored energy displacement (energy savings due to storage) of Table 3.5-5 are presented graphically in Figure 3.5-3 which shows that peak load demand has little effect except at the larger storage sizes. The plotted data extremes produce a representative mean curve as shown in Figure 3.5-4. This mean was used in the detailed analys is of Section 3.5.6 which follows:
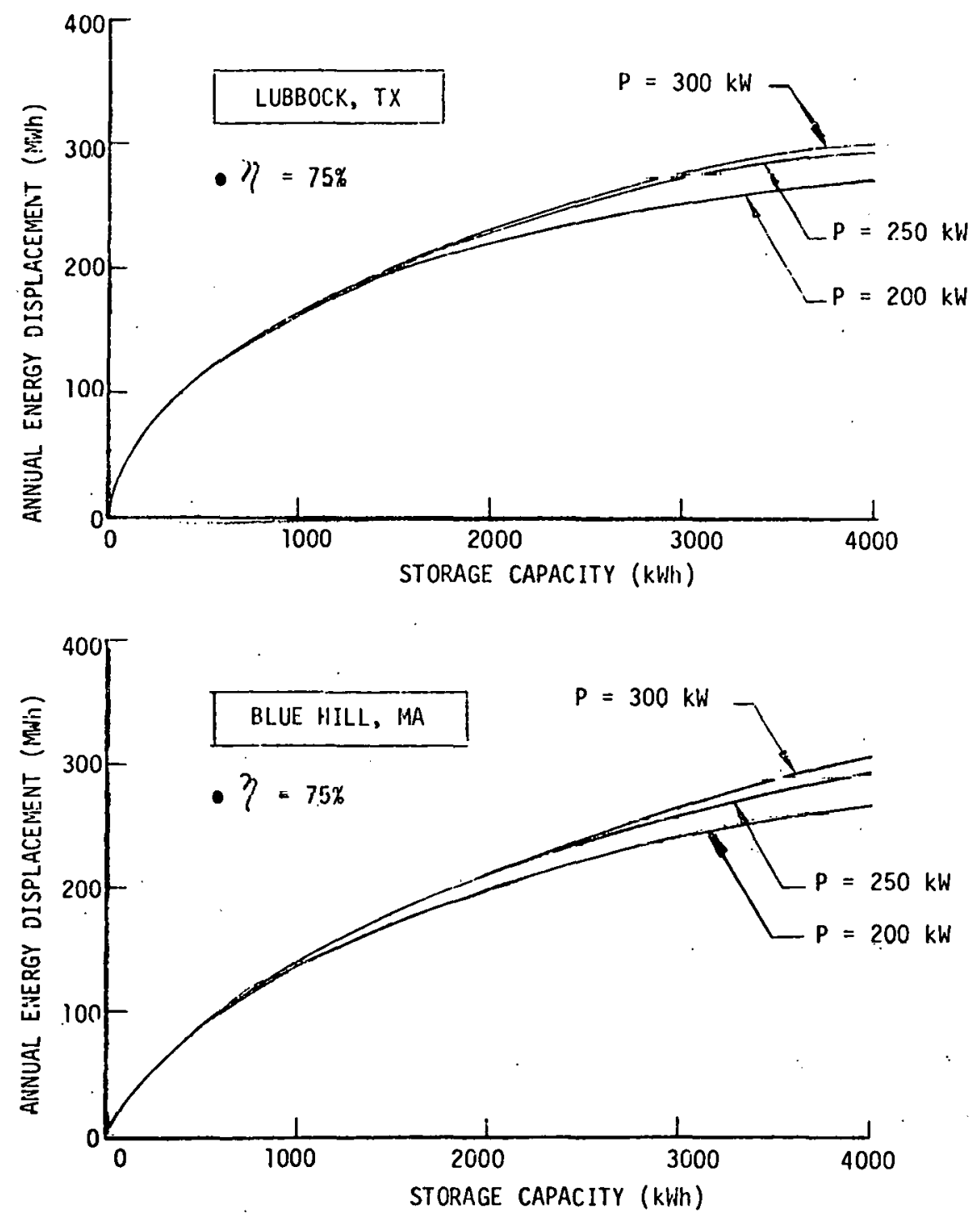

FIGURE 3.5-3. ANNUAL ENERGY DISPLACEMENT - INTERMEDIATE APPLICATION 


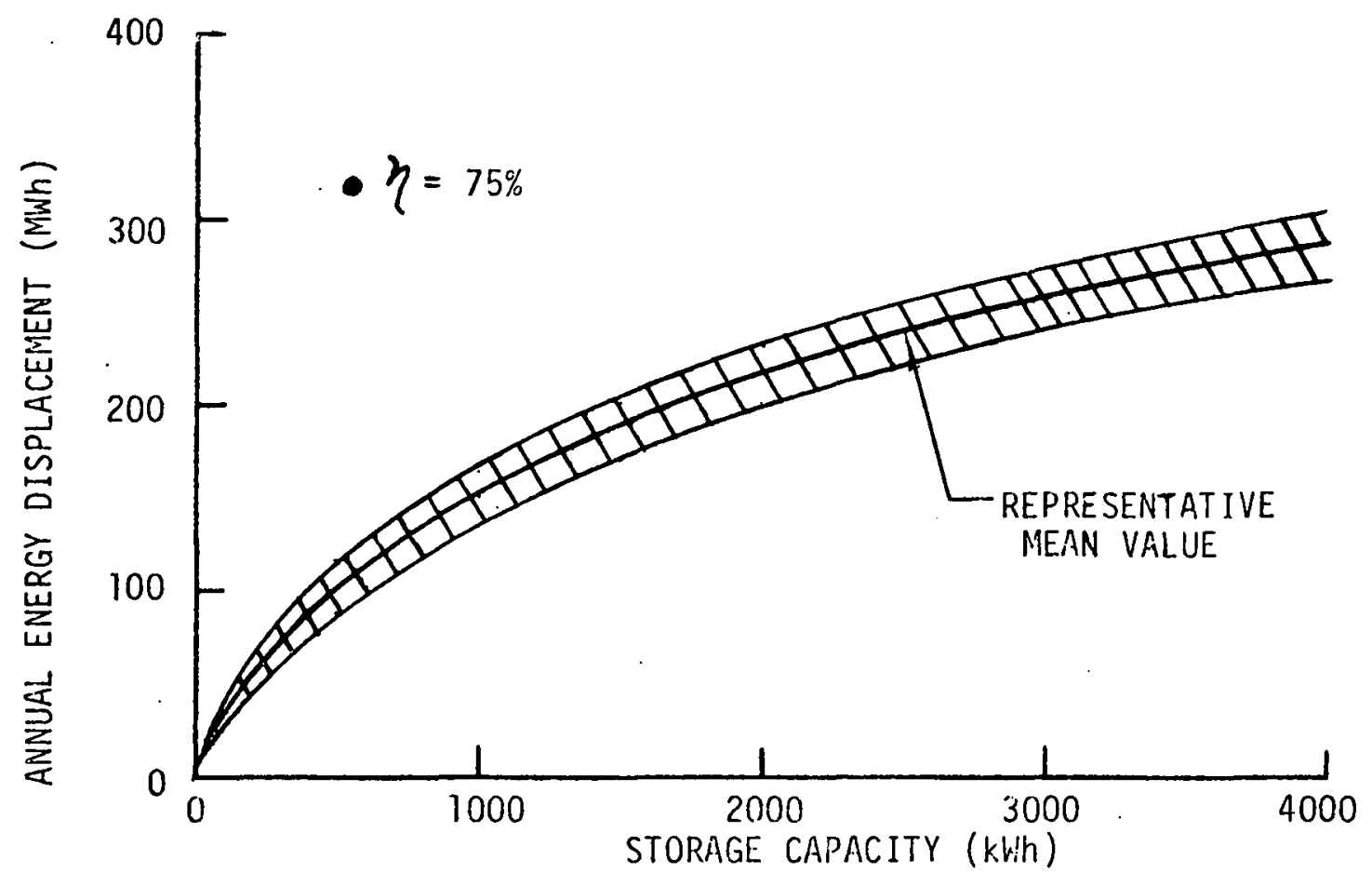

FIGURE 3.5-4. MEAN ENERGY DISPLACEMENT. DUE TO ADDITION OF STORAGE - INTERMEDIATE APPLICATION

\subsubsection{COST GOALS AND PARAMETRIC ANALYSIS}

Candidate energy storage concepts selected for further cost goal determination for use with wind energy systems in intermediate applications include:

1. Pumped Hydro

a. Above ground

b. Underground

2. Underground Compressed Air

3. Batteries
a. Lead-acid
b. Advanced

4. Inertial (Flywhee 1)

5. Hydrogen 
Several of these storage systems are applicable only to very large scale intermediate applications. Included in this category are pumped hydro and underground compressed air storage which, in addition, have highly sitespecific requirements.

The numerics required to carry out the intermediate cost goal evaluation are explained and the results presented in detail in this section.

\subsubsection{Determination of Energy Storage Break-Even Costs}

The break-even cost for intermediate energy storage systems was determined by finding the difference between the capitalized annual displaced energy credit and capitalized 0\&M costs divided by a factor accounting for the cost of money during construction. The procedure for determining the break-even cost consisted of the following steps:

1. Selection of the storage system, WTG size, location and storage capacity.

2. Determination of the WTG annual energy performance with and wi thout storage.

3. Determination of the annual displaced energy credit for the addition of storage, using the cost of electricity for the location of interest.

4. Determination of the capitalized displaced energy credit, accounting for the effects of storage efficiency.

5. An estimate of the capitalized 0\&li costs for subtraction from the Step 4 result. 
6. Application of a construction cost factor (CCF) to account for interest during the construction phase, where applicable.

7. Comparison of the storage system break-even cost with projected actual or estimated system costs.

Steps 1 and 2 were discussed in the previous section; Steps 4 through 6 are included in the following sections.

\subsubsection{Cost of Electricity}

Intermediate size commercial and industrial applications typically have utility rate schedules with both an energy (kilowatt hour) and a power demand $(\mathrm{kW})$ component. Energy storage employed with a wind conversion system can only reduce the energy component and, under typical declining block rate structures, onty the lower valued blocks of energy. The reason for this is that the variability of the wind reduces the probability of âlways having stored energy to limit the $\mathrm{kW}$ demand peak, and thereby assure a lower power demand rate. Also, with respect to the energy demand component, the wind/storage combination acts, in effect, to reduce the need for energy which, if purchased from the utility, would have been billed at the lower end of the rate structure. 1976 cost data of the Federal Power Commission 27 show an average national price of about $4 \$ / k W h$ for industrial electricity in the consumption range of this application. Due to the nonelimination of demand charges and the declining block structures, $2 \$ / k W h$ electricity was assumed for the value of the incremental energy displaced by storage. It is, of course, recognized that strong Congressional action is underway which might eliminate the declining block structure. When this 
occurs, the value of stored energy will be dramatically increased and would generally show dollar results per kWh similar to residential values. Further discussion on the effects of rate structures on storage economics will be found in Section 3.7 .

\subsubsection{Displaced Energy Credit}

The annual displaced energy credit at $75 \%$ storage efficiency, $A_{E}^{0}$, is given by:

$$
A_{E}^{0}=\text { C.O.E. } X \text { ANNUAL ENERGY STORAGE DISPLACEMENT }
$$

where

$$
\text { r.n.E. = Cost of [lectiriclty }
$$

Using the values from the mean energy storage displacement curve of Figure 3.5-4 and the assumed $2 \notin / k W h$ value of energy saved, the $A_{E}^{0}$ versus storage capacity curve of Figure $3.5-5$ results:

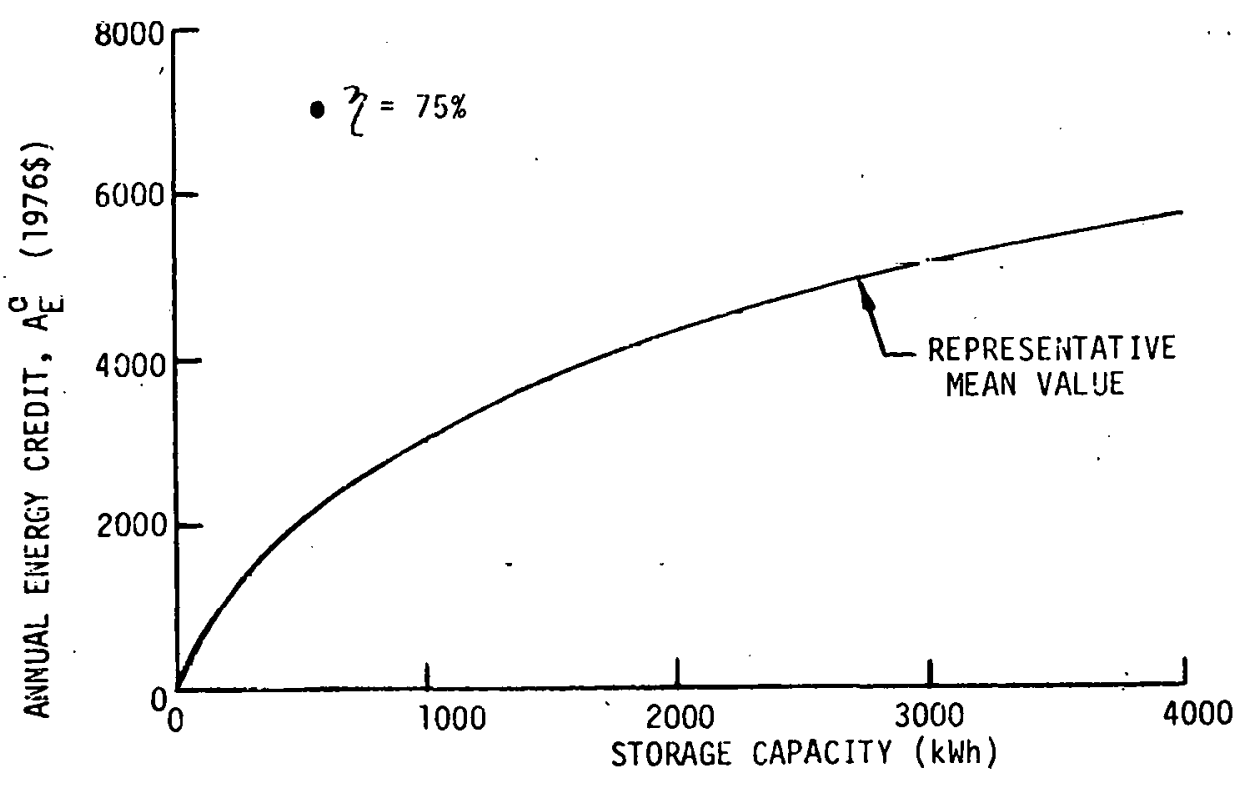

FIGURE. 3.5-5. MEAN ENERGY CREDIT VERSUS STORAGE CAPACITY-INTERMEDIATE APPLICATION 
Determination of the capitalized value, $C_{E}^{0}$, of this energy credit was accomplished in the same general manner as for the residential application (Section 3.4.6.3), thus:

$$
C_{E}^{0}=\left(\frac{1+e}{1+g}\right)^{\delta} \frac{M_{e}}{F C R} \quad A_{E}^{0}
$$

where

$$
\begin{aligned}
\mathrm{C} & =\text { capitalized energy credit, } \$ \\
\mathrm{e} & =\text { electricity price escalation rate } \\
\mathrm{g} & =\text { general inflation rate } \\
\delta & =\text { years from } 1976 \text { to start } \\
M_{\mathrm{e}} & =\text { energy savings multiplier } \\
\mathrm{FCR} & =\text { fixed charge rate }
\end{aligned}
$$

Principal differences from the residential case are in $r$, the discount rate and FCR the fixed charge rate. An after tax cost of capital of 10 percent was used for the discount rate in intermediate applications. The fixed charge rate must be on a before-tax basis in order to account for the tax deductibility of energy. The FCR's for various storage system lifetimes are given below:

TABLE 3.5-6. INTERMEDIATE FIXED CHARGE RATES

\begin{tabular}{|l|l|}
\hline SYSTEM LIFE & FCR \\
\hline 10 YEAR & .27 \\
20 & .23 \\
30 & .22 \\
\hline
\end{tabular}


In the case of battery systems, which were assumed to require 10 year replacenent of the batteries only, with 30 percent salvage value, an equivalent 30 year fixed charge rate of .26 was computed.

The energy savings derived up to this point assumed 75 percent storage efficiericy. For storage systems with efficiencies other than 75 percent, a correction factor, $C_{y}$ was applied with the capitalized energy credit becoming:

$$
C_{E}=C_{\eta} \times C_{E}^{0}
$$

Figure 3.5-6 presents the results of computer runs evaluating the effect of storage efficiency. on annual energy displacement due to storage use. Figure 3.5-6 also gives the related dollar value of the annual energy credit for different storage efficiencies.

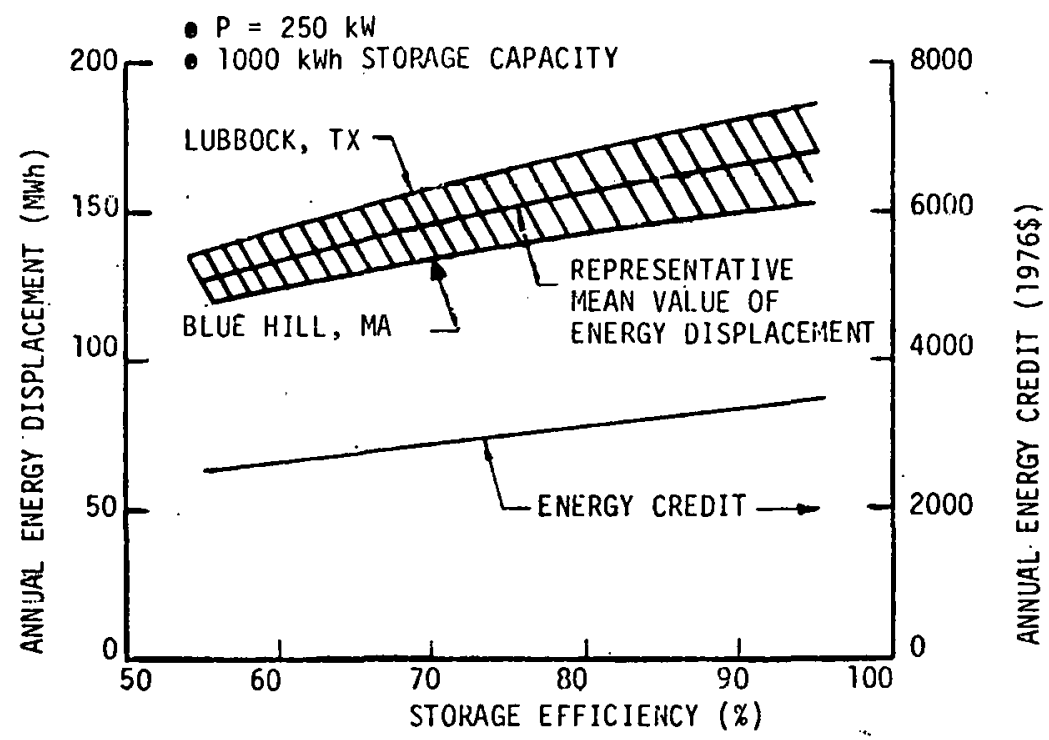

FIGURE 3.5-6. EFFECT OF STCRAGE EFFICIENCY ON ENERGY DISPLACEMENT DUE TO STORAGE - INTERMEDIATE APPLICATION 
The energy credit data shown in the curve of Figure $3.5-6$ was used to calculate the efficiency correction factor, $C_{i}$, for intermediate applications. This result is shown in Figure 3.5-7 below:

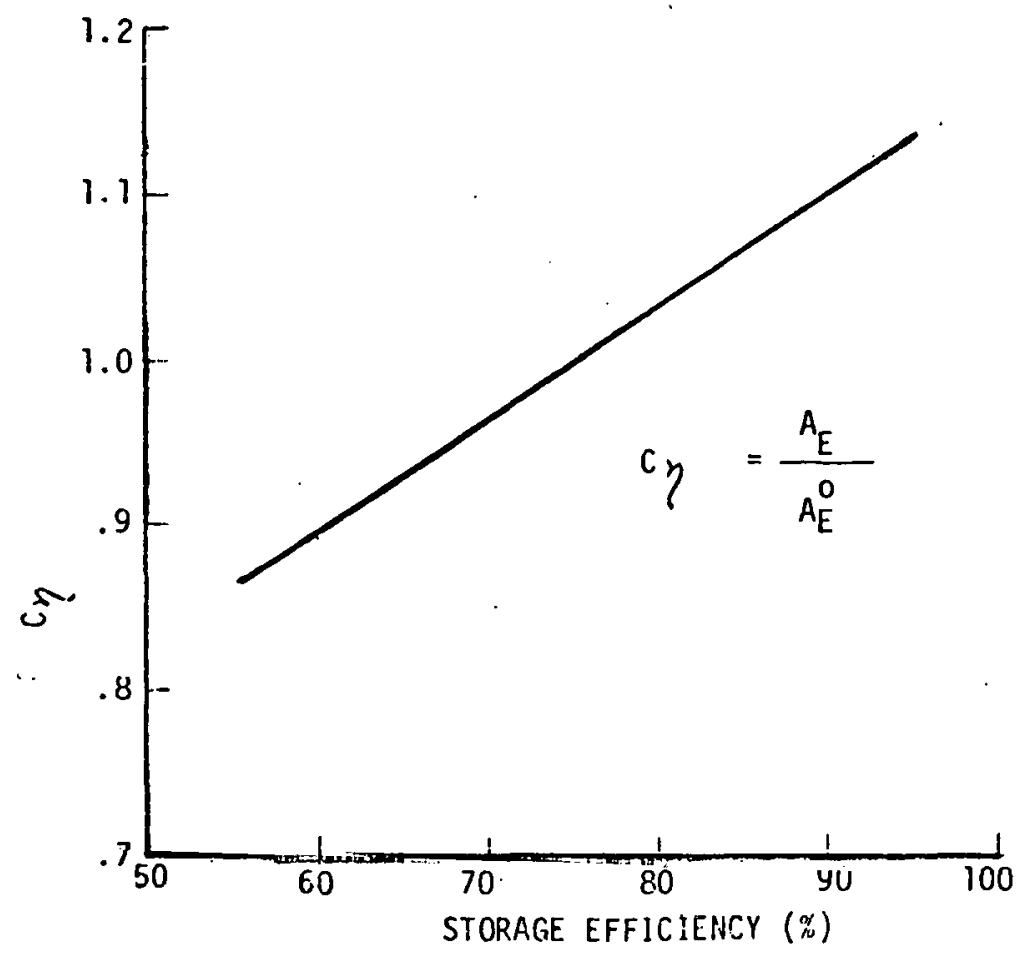

FIGURE 3.5-7. STORAGE EFFICIENCY CORRECTION FACTOR -

INTERMEDIATE APPLICATION

Energy Credit Multiplier

Presented below, for reader convenience, are values of the energy credit multiplier, $\left(\frac{1+e}{1+g}\right)^{\delta} M_{e}$, as used in the energy credit equation at the start of this section. 
TABLE 3.5-7. ENERGY CREDIT MULTIPLIER $\left(\frac{1+e}{(1+g}\right)^{\delta} M_{e}-$ INTERIMEDIATEE APPLICAT ION

\begin{tabular}{|c|c|c|c|c|c|c|}
\hline \multirow{2}{*}{ YEAR } & \multicolumn{6}{|c|}{ ELECTRICITY PRICE ESCALATION RATE (e) } \\
\hline & $5 \%$ & $6 \%$ & $7 \%$ & $8 \%$ & $9 \%$ & $10 \%$ \\
\hline $\begin{array}{l}1976 \\
1982 \\
1985 \\
1988 \\
1994 \\
2000\end{array}$ & $\begin{array}{c}1.6759 \\
\end{array}$ & $\begin{array}{l}1.8858 \\
1.9962 \\
2.0538 \\
2.1130 \\
2.2366 \\
2.3675\end{array}$ & $\begin{array}{l}2.1330 \\
2.3886 \\
2.5277 \\
2.6750 \\
2.9956 \\
3.3547\end{array}$ & $\begin{array}{l}2.4249 \\
2.8715 \\
3.1247 \\
3.4002 \\
4.0264 \\
4.7678\end{array}$ & $\begin{array}{l}2.7710 \\
3.4678 \\
3.8794 \\
4.3399 \\
5.4312 \\
6.7971\end{array}$ & $\begin{array}{l}3.1824 \\
4.2070 \\
4.8371 \\
5.5615 \\
7.3521 \\
9.7192\end{array}$ \\
\hline
\end{tabular}

\subsubsection{Operation and Maintenance Costs}

The annual operation and maintenance cost, $A_{O M}$, is storage system related and was estinated according to the expression:

$$
A_{\text {OM }}=a_{O M} \times \text { ASDE }
$$

where

$$
\begin{aligned}
& { }^{{ }^{O M}}=\text { variable storage } 0 \& M \text { cost in } \$ / \mathrm{kWh} \text { of discharge energy } \\
& \text { ASDE }=\text { annual storage discharge energy. }
\end{aligned}
$$

Table 3.5-8 below lists the computed 0\&M costs at a storage capacity of $1000 \mathrm{kWh}$ for each of the intermediate size candidate storage systems investigated. 
TABLE 3.5-8. ANNUAL ENERGY STORAGE OPERATION AND MAINTENANCE COSTS WIND SYSTEM STORAGE CHARGING

\begin{tabular}{|l|c|}
\hline \multicolumn{1}{|c|}{ STORAGE SYSTEM } & $\mathrm{A}_{\mathrm{OM}}(1976 \$ / \mathrm{kWh})^{\star}$ \\
\hline Underground Pumped Hydro & .168 \\
Above Ground Pumped Hydro & .168 \\
Underground Compressed Air & 1.180 \\
Lead-Acid Batteries & .106 \\
Advanced Batteries & .636 \\
Inertial (Flywhee1) & 1.180 \\
Hydrogen & .601 \\
\hline
\end{tabular}

$\star 1000 \mathrm{kHh}$

The capitalized value, $\mathrm{C}_{O M}$, is then:

$$
C_{O M}=\frac{M_{g}}{F C R} \quad A_{O H}
$$

where $M_{g}$ is the general inflation multiplier discussed in Section 3.4.6.4.

\subsubsection{Break-Even Cost}

The break-even cost goals for an intermediate application reflect the difference between the capitalized values of energy credit and 0\&M cost as adjusted by a storage system related factor to account for interest during construction. 21,28

$$
C_{B E}=\frac{C_{E}-C_{O M}^{\circ}}{C C F}
$$


where $C_{B E}=$ break-even storage

$$
\text { CCF }=\text { construction cost factor }
$$

The construction cost factor was taken in a range from. 1.05 for short leadtime systems, such as batteries, to 1.4 for pumped hydro systems. Table 3.5-9 lists the construction cost factors and fixed charge rates for the stcrage systems considered for intermediate application.

TABLE 3.5-9. CONSTRUCTION COST FACTORS AND FIXED CHARGE RATES INTERMEDIATE APPL.ICATION

\begin{tabular}{|l|c|c|c|}
\hline \multicolumn{1}{|c|}{ STORAGE SYSTEM } & LIFE (YRS) & CCF & FCR \\
\hline 1. Pumped Hydro & 50 & 1.40 & .22 \\
2. Underground & 30 & 1.17 & .22 \\
Compressed Air & 10 & 1.05 & .26 \\
3. Batteries & 20. & 1.05 & .23 \\
4. Inertial. (Flywhee 1) & 20 & 1.05 & .23 \\
5. Hydrogen & & & \\
\hline
\end{tabular}

A sample break-even cost calculation is presented below for lead-acid battery storage. 


\section{Specific Conditions}

- $250 \mathrm{~kW}$ load power demand

- $1000 \mathrm{kWh}$ storage capacity - lead-acid batteries

- 2 hour discharge rate limit

- $5 \%$ inflation rate, $\mathrm{g}$

- $10 \%$ electricity price escalation rate, e

- 30 year system life, $n$

- $10 \%$ discount rate, $r$

- $70 \%$ storage efficiency

- Fixed Charge Rate (FCR) $=.26$

- Variable 0\&M rate (aOM) $=\$ .0005 / \mathrm{kWh}$

- Annual Energy Displacement $=150 \mathrm{MWh}$ (mean value)

- $\mathrm{ASDE}=212 \mathrm{MWh}$ (mean value)

- Start year 2000

- Results in 1976 dollars

From equation ( 1 )

$$
A_{E}^{0}=.02(150,000)=\$ 3,000
$$

From equation (2) and Table 3.5-7

$$
C_{E}^{0}=\frac{9.7192}{.26} \cdot(3,000)=\$ 112,145
$$

The efficlency currection factor for lead-acid batteries (70\% efficiency), obtained from Figure $3.5-7$ is:

$$
C_{\eta}=.97 \text {. }
$$

Therefore, from equation (3)

$$
C_{E}=.97(112,145)=\$ 108,780
$$

The annual 0\&M cost from equation (4) is

$$
A_{O M}=.0005(212,000)=\$ 106
$$


From equation (5) and Table 3.5-7

$$
c_{O M}=\frac{1.6759}{.26}(106)=\$ 683
$$

From Table 3.5-9: CCF (lead-acid batteries) $=1.05$ and the break-even cost is obtained from equation (6) as:

$$
\begin{aligned}
C_{B E}=\frac{108,780-683}{1.05} & =\$ 102,949 \\
& \text { or } \$ 102.9 / \mathrm{kWh} \text { of storage capacity }
\end{aligned}
$$

\subsubsection{Capital Cost Comparisons}

Table 3.5-10 shows the results of the computation of break-even capital costs and comparison with projected system costs for one set of conditions for all of the storage methods considered in this portion of the study, without regard to the assessment of suitability for use with wind energy conversion. This comparison was made in order to provide more insight into the original rankings based on levelized annual cost. The results of these viability computations are discussed further in Section 1.1. Break-even costs were computed at $1000 \mathrm{kWh}$ of storage capacity and a storage system duty cycle of ten hours. The extreme economic conditions of $10 \%$ fuel price escalation rate and a year 2000 start which were also used, provide a maximum opportunity within the overall economic groundrules used in the study, for any particular conceft to demonstrate a potential for viability. 
TABLE 3.5-10. BREAK-EVEN COSTS COMPARED WITH SYSTEM COST EST IMATES FOR YEAR 2000, 10\% FUEL ESCALATION, WIND SYSTEM CHARGING - INTERIEDJATE APPLICATION

\begin{tabular}{|l|c|c|c|c|}
\hline \multicolumn{1}{|c|}{ STORAGE CONCEPT } & $\begin{array}{l}\text { BREAK- } \\
\text { EVEN } \\
\text { CAPITAL } \\
\text { COST }\end{array}$ & $\begin{array}{c}\text { COST } \\
\text { EST IMATE }\end{array}$ & $\triangle$ & $\begin{array}{l}\text { POTENTIAL } \\
\text { VIABILITY }\end{array}$ \\
\hline Underground Pumped Hydro & 98 & 23 & +75 & Yes \\
Above-Ground Pumped Hydro & 98 & 19 & +79 & Yes \\
Underground Compressed Air & 107 & 34 & +73 & Yes \\
Lead-Acid Batteries & 103 & 140 & -37 & No \\
Advanced Batteries & 103 & 67 & +36 & Yes \\
Inertial Storage (Flywhee1) & 119 & 217 & -98 & No \\
Hydrogen & 92 & 45 & +47 & Yes \\
\hline
\end{tabular}

All Costs in $1976 \$ / \mathrm{kWh}$

The results 1 isted in Table 3.5-10 indieatc five storage methnds of potential viability for the intermediate application in a dedicated storage mode of operation: both types of pumped hydro, underground compressed air, advanced batteries, and hydrogen. The first four, plus lead-acid batteries (due to wide-spread interest) were selected for further detailed economic analysis.

Using the methodology outlined previously, storage system break-even costs for these concepts as a function of storage capacity were computed for (1) electricity price escalation equal to general inflation (5\%), (2) a 1985 start year with $6 \%$ escalation ( $1 \%$ over inflation), and (3) the extreme of a year 20010 start with a $10 \%$ electricity price escalation rate. The resulting 
cost goals provide values for a nominal case and upper and lower bounds. A comparison of these break-even costs, with each of the four storage system cost projections overlaid, is presented in Figure 3.5-8. The riominal case of $6 \%$ electricity price escalation and a 1985 start year shows: (1) viability for pumped hyáro at storage capacities of less than $1000 \mathrm{kWh}$ assuming a projected cost of $\$ 19 / \mathrm{kWh}$ and (2) a possibility of marginal viability for underground compressed air at storage capacities of less than $500 \mathrm{kWh}$ at a projected cost of $\$ 34 / \mathrm{kWh}$. Projected costs for both battery systems must be significantly reduced in order to obtain viability in the nominal case. At year 2000 with $10 \%$ escaldllun, advanced batteries indicate viability for storage capacities of less than $2500 \mathrm{kWh}$ at a projected cost of $\$ 67 / \mathrm{kWh}$ and lead-acid batteries indicate marginal viability at storage cafacities of $500 \mathrm{kWh}$ or less assuming a cost of $\$ 140 / \mathrm{kWh}$. The system cost projections represented as dashed lines on the figure are taken from Volume I of this study report. As in the utility and residential applications, these costs for the intermediate case were selected as representative of the respective technologies based on information currently available. The system cost projection used for lead-acid batteries was obtained from data arid consultation supplied by C\&D Batteries, while the cost projection for the remaining technologies were taken at the utility values in the absence of suitable information to permit meaningfur scaling. Due to the fact that much of the cost data is subject to continued change, the format of Figure 3.5-8 was structured to facilitate the application of updated cost information as it becomes available.

For a given stcrage system, there exists a range of start year-escalation rate combinations that will result in economic viability. Pumped hydro and 

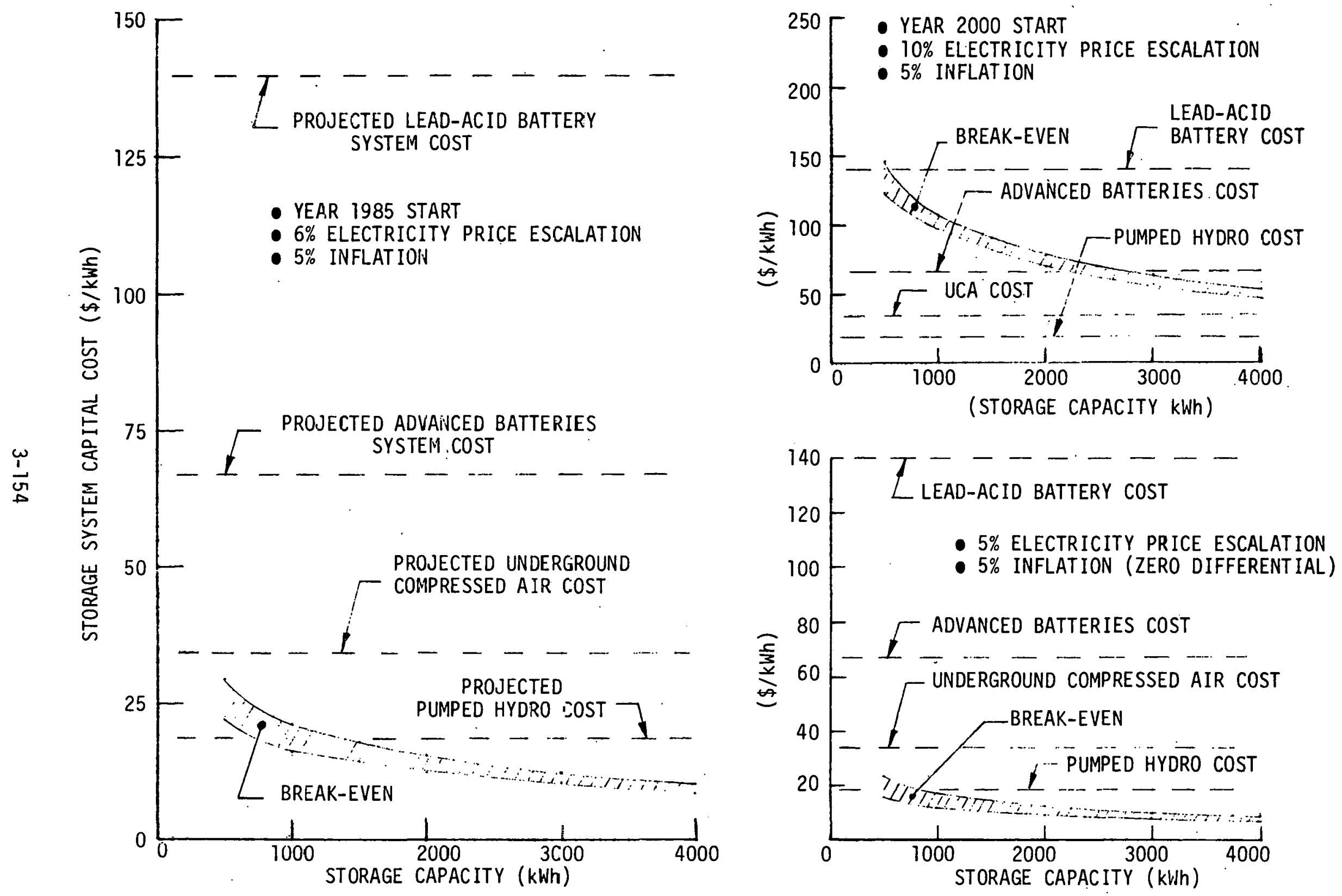

FIGURE 3.5-8. ENERGY STORAGE BREAK-EVEN COST GOALS - INTERMEDIATE APPLICATION 
compressed air storage break-even costs for several escalation rates are presented as a function of start year in Figure 3.5-9 for a nominal storage capacity of $1000 \mathrm{kWh}$. Projected system costs are overlayed as dashed lines. At $6 \%$ escalation, it is seen that pumped hydro (above ground) becomes viable around 1982 for dedicated wind energy storage.

At $7 \%$ escalation, pumped hydro would be economically viable at the present time for dedicated systems, while compressed air will not reach viability until after the year 2000. In contrast, compressed air reaches viability by 1982 at $9 \%$ escalation and becomes economic by 1988 at $8 \%$ escalation. This figure affords the reader an opportunity to test viability of these storage systems using any source for projected costs. Figure 3.5-10 is a similar chart for battery storage. Note that only at very high (9 and 10\%) escalation rates is economy achieved for advanced batteries. 


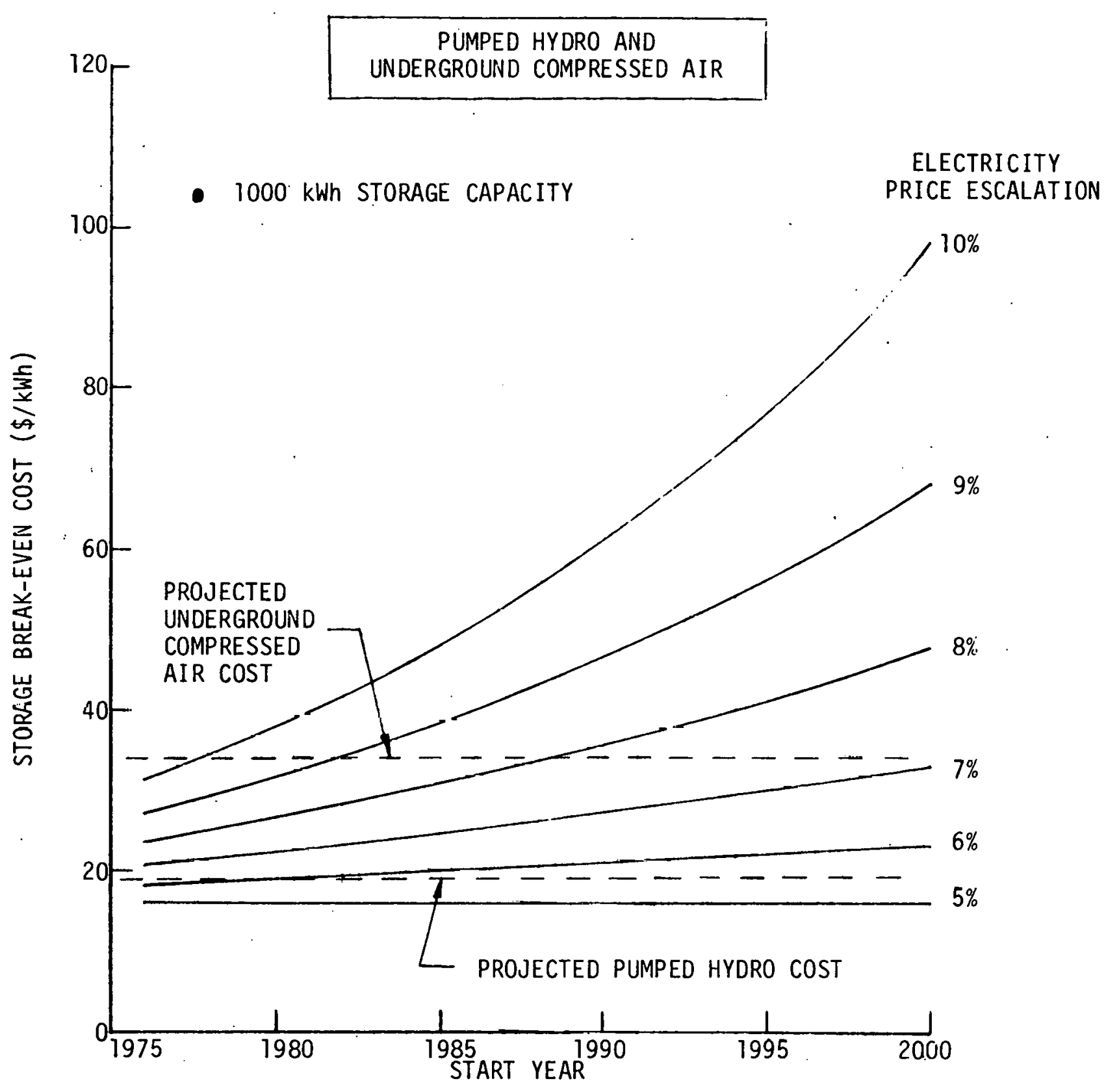

FIGURE 3.5-9. STORAGE BREAK-EVEN COST VS. START YEAR FOR PUMPED HYDRO AND UNDERGROUND COMPRESSED AIRINTERMEDIATE APPLICATIONS 


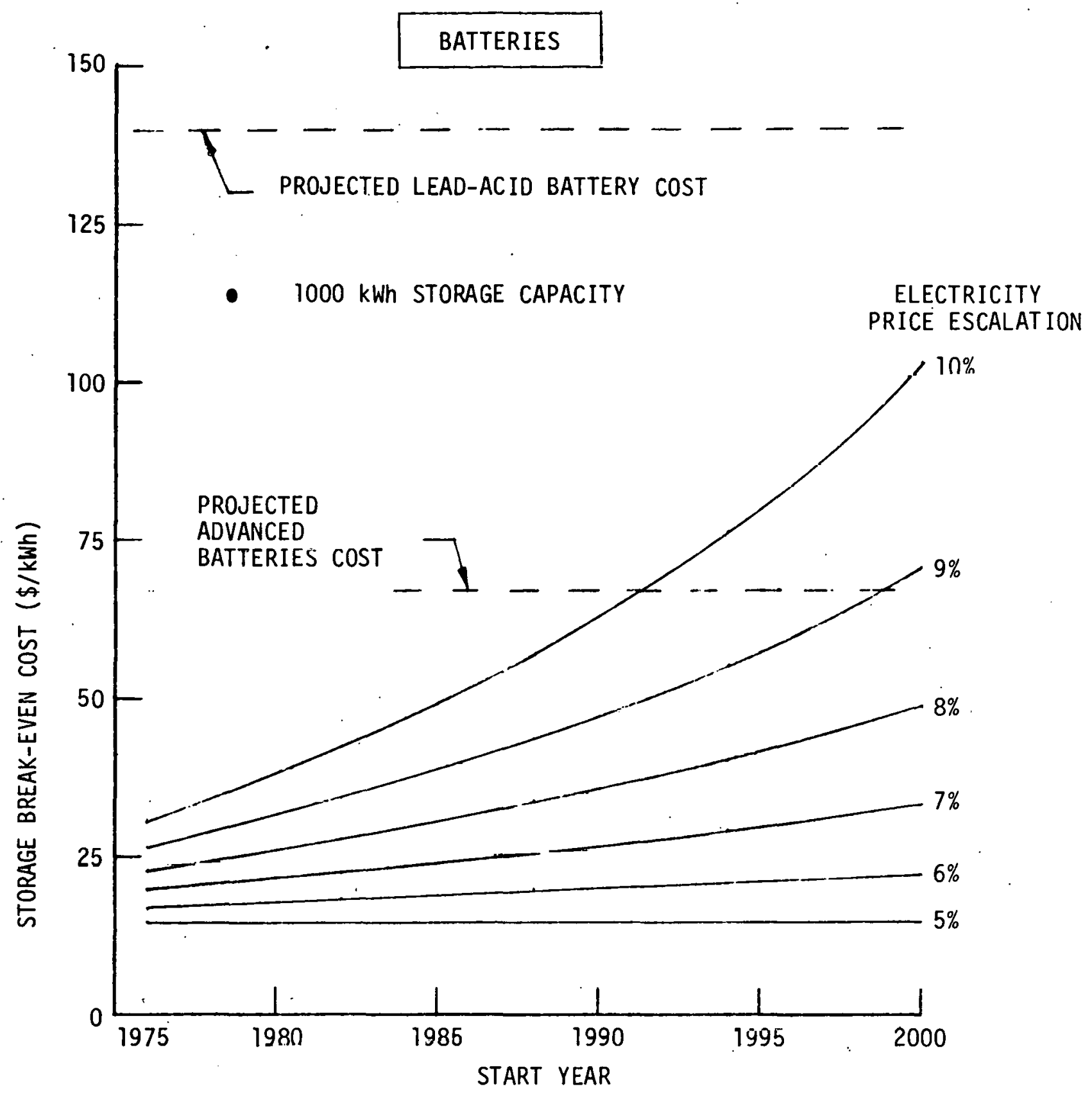

FIGURE 3.5-10. STORAGE BREAK-EVEN COST VS. START YEAR FOR BATTERY STORAGE SYSTEMS - INTERMEDIATE APPLICATIONS 


\subsubsection{Storage Capacity Optimization}

The optimum storage capacity for the intermediate case was determined in a manner analogous to the residential application, by maximizing the capitalized savings when viability is achieved. As an example, Table

3.5-11 presents cost data as a function of storage size for advanced batteries at year 2000 and $10 \%$ escalation.

TABLE 3.5-11. OPTIMUM STORAGE SIZE FOR ADVANCED BATTERIES INTERMEDIATE APPLICATION

(year $2000,10 \%$ escalation)

\begin{tabular}{|c|c|c|c|c|}
\hline $\begin{array}{c}\text { STORAGE } \\
\text { SIZE } \\
\text { (kWh) }\end{array}$ & $\begin{array}{l}C_{B E} \\
(\$ / k W h)\end{array}$ & $\begin{array}{l}\text { COST } \\
(\$ / k W h)\end{array}$ & $\begin{array}{l}\text { SAVINGS } \\
(\$ / \mathrm{kWh})\end{array}$ & $\begin{array}{c}\text { TOTAL } \\
\text { CAPITALIZED } \\
\text { SAVINGS } \\
(\$)\end{array}$ \\
\hline $\begin{array}{r}250 \\
500 \\
1000 \\
1500 \\
2000\end{array}$ & $\begin{array}{l}175 \\
140 \\
103 \\
86 \\
71\end{array}$ & $1^{67}$ & $\begin{array}{r}108 \\
73 \\
36 \\
19 \\
7\end{array}$ & $\begin{array}{l}27,000 \\
36,500 * \\
36,000 \\
28,500 \\
14,000\end{array}$ \\
\hline
\end{tabular}

As seen from the table, the optimum economic situation for advanced batteries occurs at the relatively small capacity of $500 \mathrm{kWh}$, even when computed at the extreme economic conditions of this example. Obviously, as storage costs drop and electricity price escalation rates increase, the optimum storage size will increase with time. 


\subsection{EFFECTS OF MULTIPLE-SOURCE CHARGING AND WIND FORECASTING}

The use of energy storage to improve the value and usability of windgenerated energy has been treated in depth in previous sections on the basis of a direct tie of the storage device to the wind source for storage charging. As shown, this results in a certain value being realized from the addition of storage capacity to the wind system. It is possible, however, to define alternative concepts in which the storage system is in reality shared by and made available to all of the generating units in the utility system. This method was defined for study ptirposes as "multiple source charging". It offers a means of compensating for the low energy capture un days of low wind when wind-dedicated storage could not be fully charged. This concept is evaluated further in the remainder of this section, along with the implications of having varying degrees of prior knowledge of wind energy availability through forecasting.

\subsubsection{UTILITY SYSTEM ENERGY ALLOCATION}

Two key factors concerning wind energy use in a utility grid need to be kept in mind:

1. Presence of energy storage is not a pre-requisite for the use of wind energy in a utility system.

2. Wind energy at any point in time has a value which corresponds with the incremental cost of the energy which it displaces.

As a result of the above, wind energy may be considered as merely another source of generation in the overall utility grid. Storage capacity which the wind could not charge due to low wind output is brought into operation by the rest of the grid providing off-peak charging energy. Figure 3.6-1 111ustrates the process. 

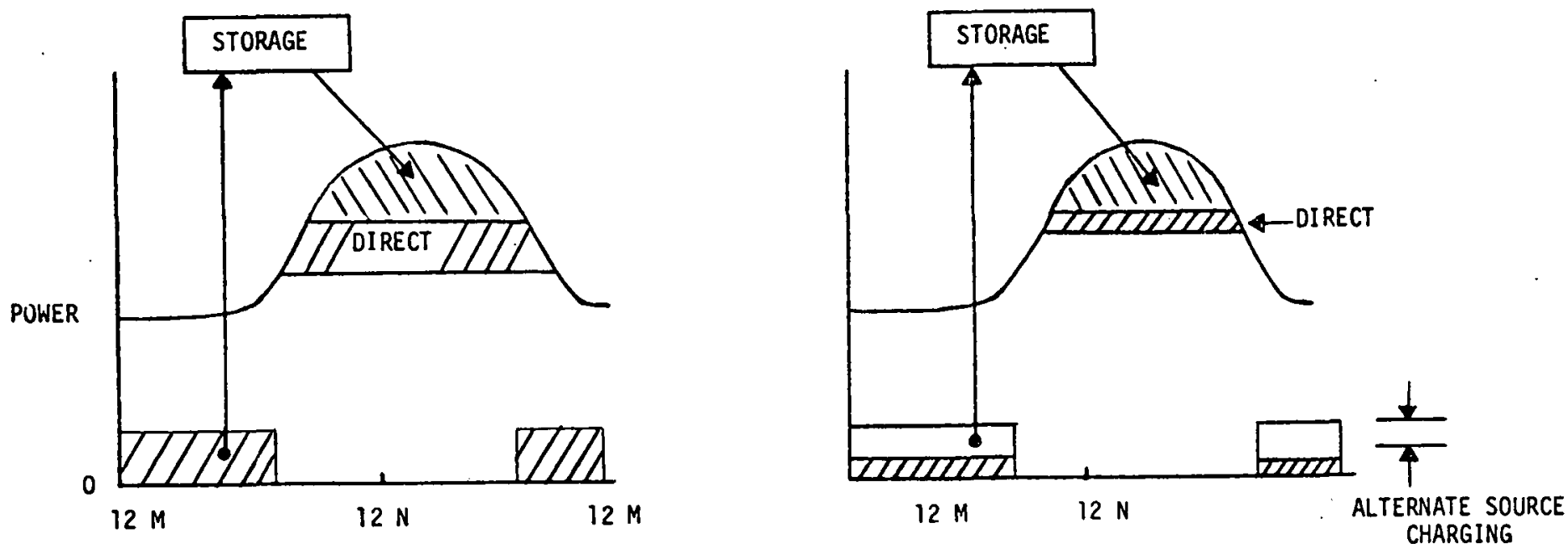

FIGURE 3.6-1. THE ROLE OF UTILITY MAKE-UP IN MULTIPLE SOURCE CHARGING

The left hand side of the diagram shows the normal situation in which a wind-plus storage system provides both a direct load contribution and a stored energy contribution. In the right hand portion of the diagram, a depleted storage system is depicted along with lesser direct and stored energy contributions. With alternate or multiple source charging, the difference would be nade up by the total grid capacity. The lfmit case occurs when storage cannot be charged at all by the wind system due to low output. In this case, multiple source and utility only off-peak charging become equivalent. Any wind energy present under these conditions may be used immediately as available and becomes part of the total utility generation capability, even though the timing of its availability may be unsuited to off-peak charging. Since the entire utility may potentially contribute to the storage charging requirement, the benefits of more predictable charging cycles will be realized and better storage capacity utilization (more energy cycles) will occur. 


\subsubsection{MODEL FOR MULTIPLE SOURCE CHARGING}

The operating strategy for this situation is based on the following groundrules:

1. Storage discharge will only occur to displace load of quality C or higher.

2. Storage will be charged with the energy difference between the system load and the strata $D$ (lowest value) generation capacity.

3. The storage system $S O C$ is managed on a daily basis to provide a near optimum displaçement. nf the highcst qualily energy. To this end, the program logic determines daily, that value of system load which is required to drive the SOC to its pre-determined minimum value for each day.

The system "B" load tape was processed by the computer model on än hourbj-hour basis for 8760 hours and the results tabulated. Table 3.6-1 shows a typical data page from this computer run.

\subsubsection{COST GOALS AND PARAMETRIC TRADE-OHFS}

The results of model data runs are shown in Figure 3:6-2 for a wide range of storage capacities. A comparison of the above energy savings for wind system dedicated storage is shown in Figure 3.6-3. The improved results from systern wide charging over dedicated charging are evident, with an improvement in the order of $3: 1$. 
TABLE 3.6-1. SAMPLE COMPUTER OUTPUT FOR UT ILITY/MULTIPLE SOURCE STORAGE CHARGING

\section{MWh STORAGE CAPACITY}

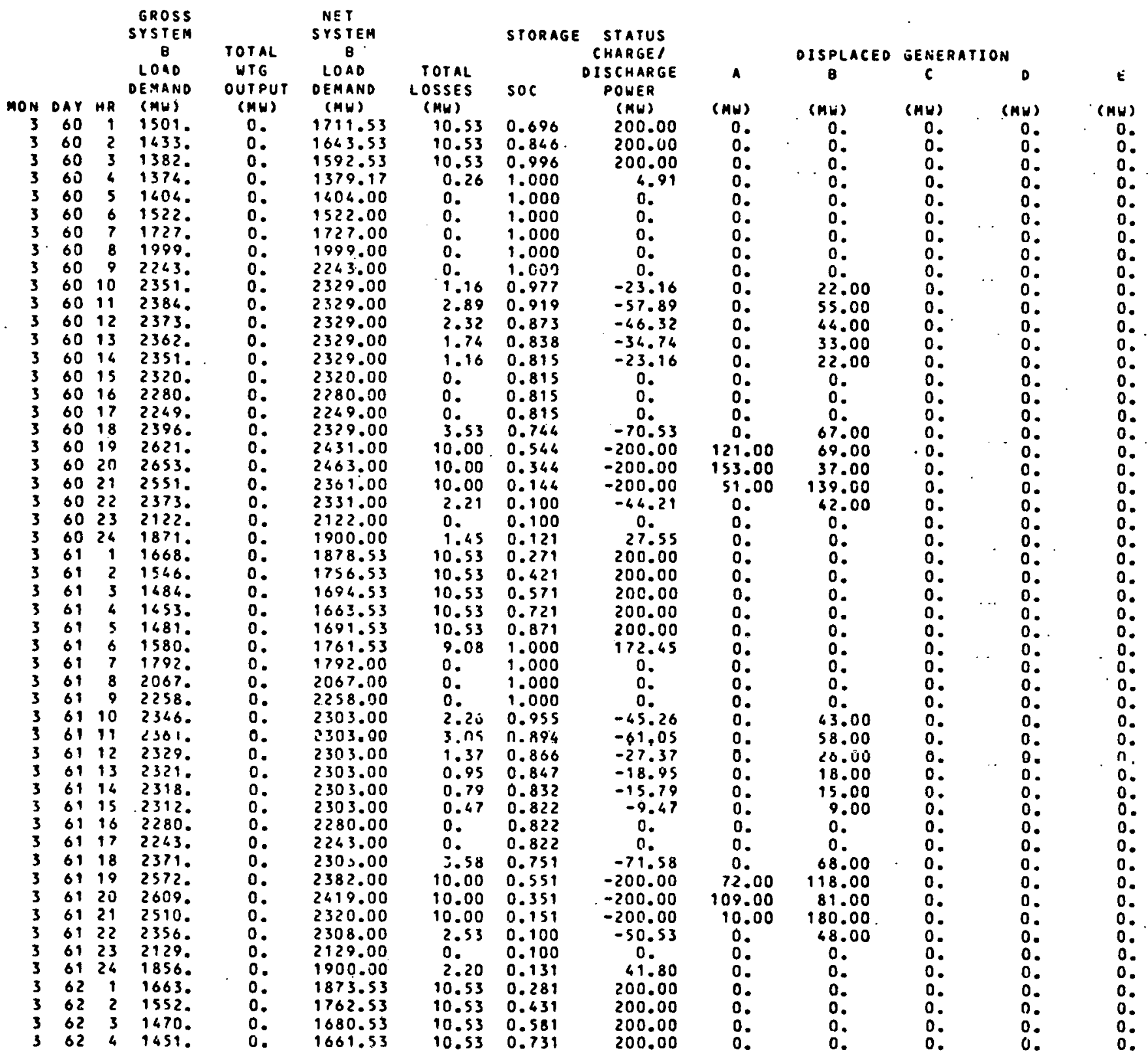




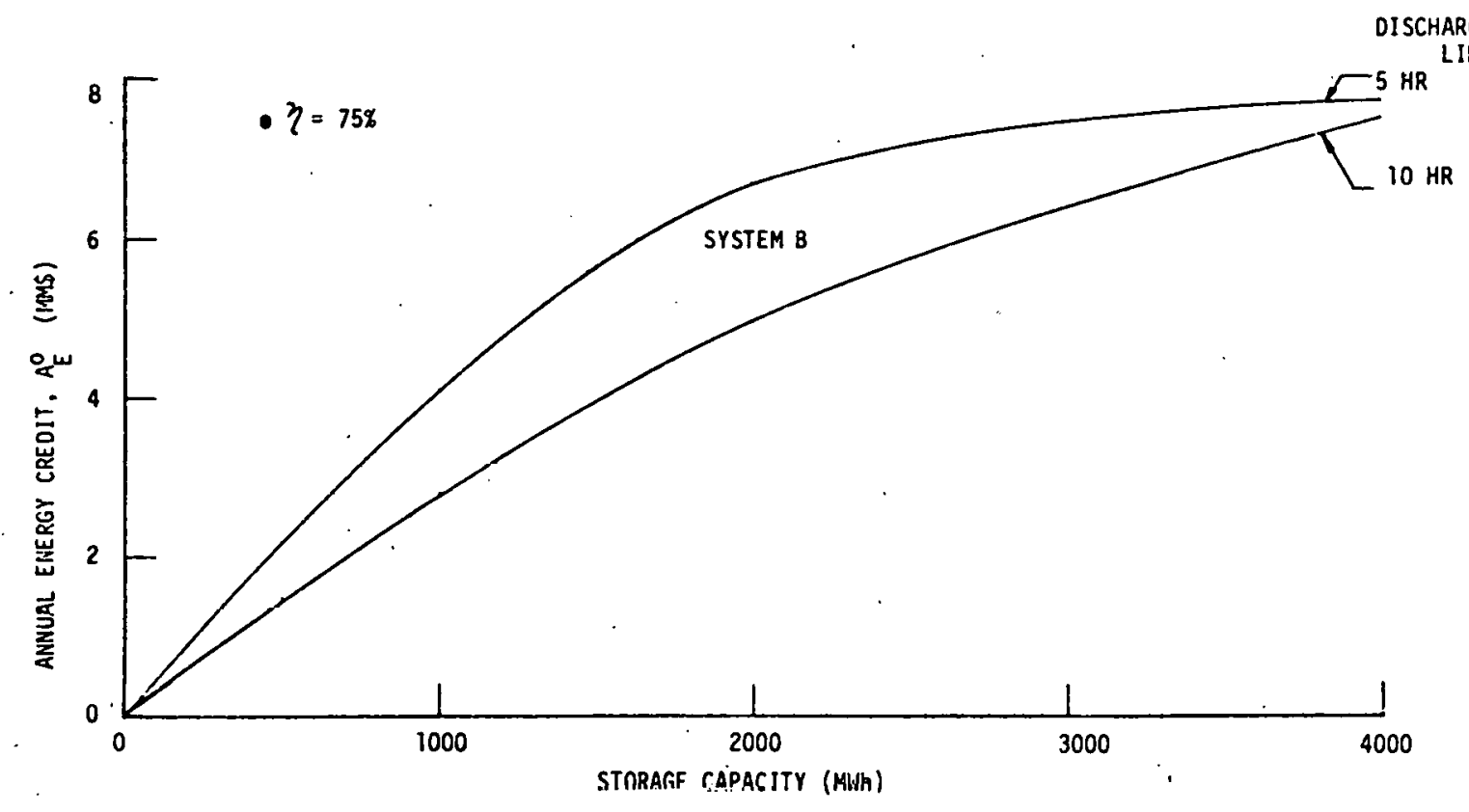

FIGURE 3.6-2. ANNUAL ENERGY SAVINGS - UTILITY ONLY CHARGING

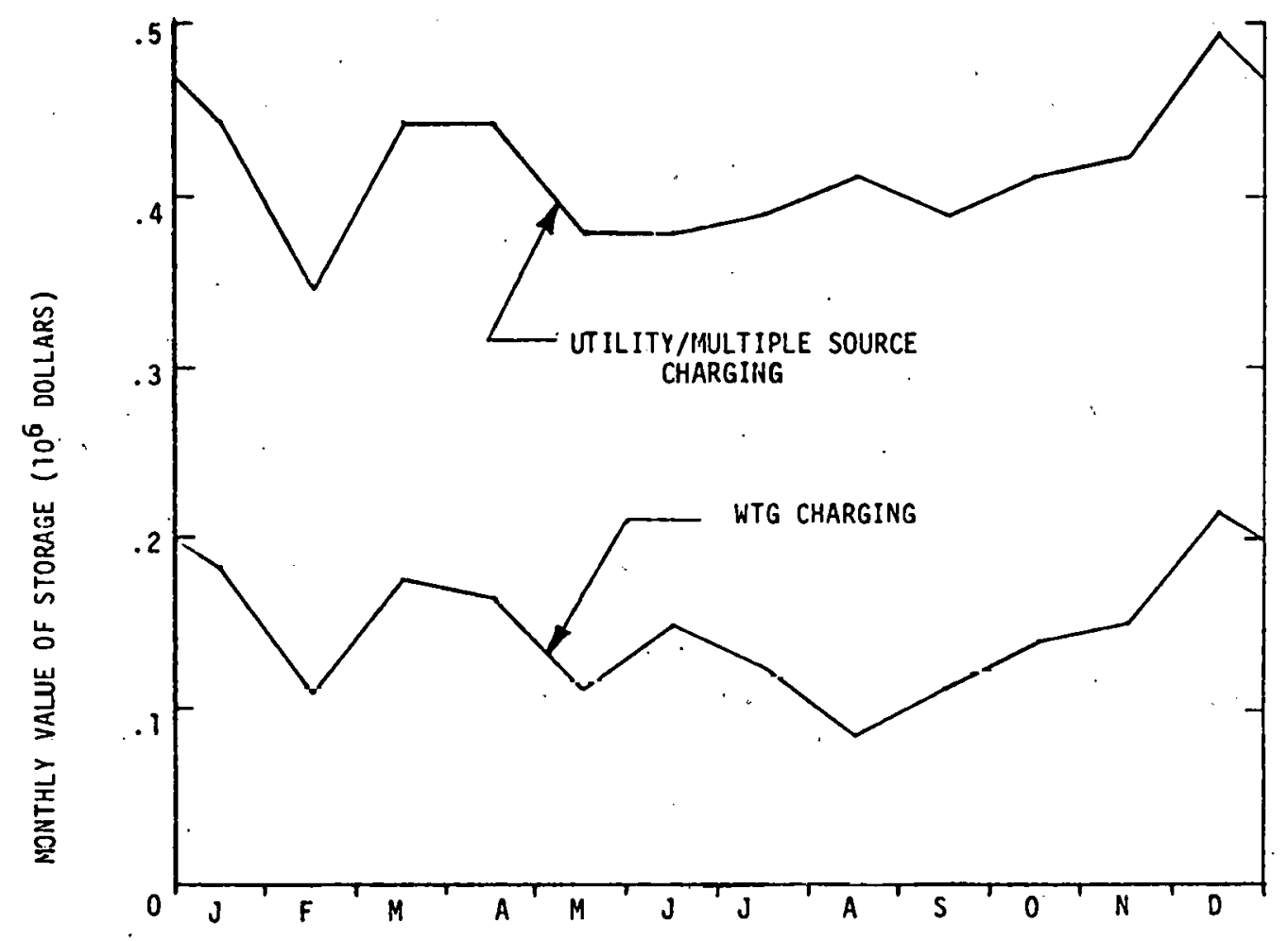

FIGURE 3.6-3. COMPARISON OF STORAGE ENERGY CREDIT WITH WTG CHARGING VS.' BASELOAD CHARGING (2000 MWh STORAGE CAPACITY) 
Storage system break-even costs were computed in the same manner as described previously with one exception. Capacity credit was taken at a full $\$ 140 / \mathrm{kW}$, which accounts for the full availability of stored energy on demand. This credit was established on the basis of the improved availability of stcred energy under the conditions described. The capacity credit assumes displacement of peaking units only (Gas Turbines). Figures 3.6-4 and 3.6-5 present the results of break-even cost computations at 5 hour and 10 hour discharge rates respectively, along with present storage system cost estimates. The improved storage economics are readily apparent. At the nominal case of $6 \%$ fuel price escalation rate and a 1985 start, all storage systems except lead-acid batteries showed some degree of viability. By or prior to year 2000 the latter also shows viability. The more competitive position of batteries at 5 hours vs. 10 hours is also evident. Figures 3.6-6 and 3.6-7 present break-even cost vs. start year and fuel price escalation rate for lead-acid batteries. This portrayal more clearly displays the time frame of potential viability for lead-acid batteries. It may be notec that at $9 \%$ escalation, viability for a 5 hour battery occurs by 1984 while a 10 hour battery would take ten years longer to show viability under the same economic conditions. These charts may be used to test approximate viability for any start year, fuel price escalation rate and storage system cost. The reader is cautioned, however, against thinking of these results as having pinpoint accuracy sincc numerous assumptions are required in the analysis. Further, it is conceivable that system costs shown will vary and will also very possibly continue to drop with technology advances. Hence, these values should be considered as indicative of ranges $\geq+10 \%$. 

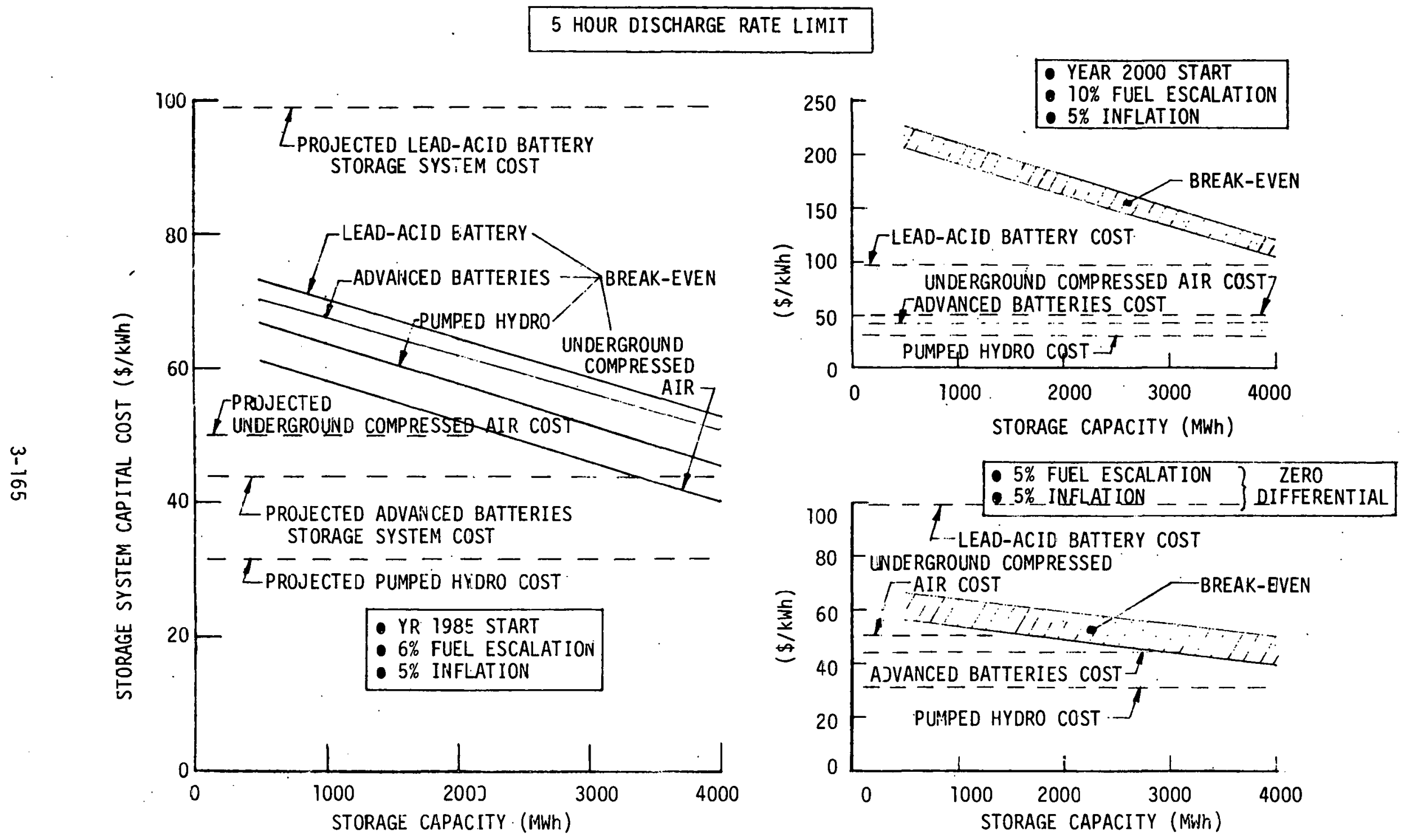

FIGURE 3.6-4. RANGE OF BREAK-EVEN COSTS AND PROJECTED STORAGE SYSTEM COSTS FOR SELECTED ECONOMIC CONDITIONS - UTILITY ONLY CHARGING (MULTIPLE SOURCE) 

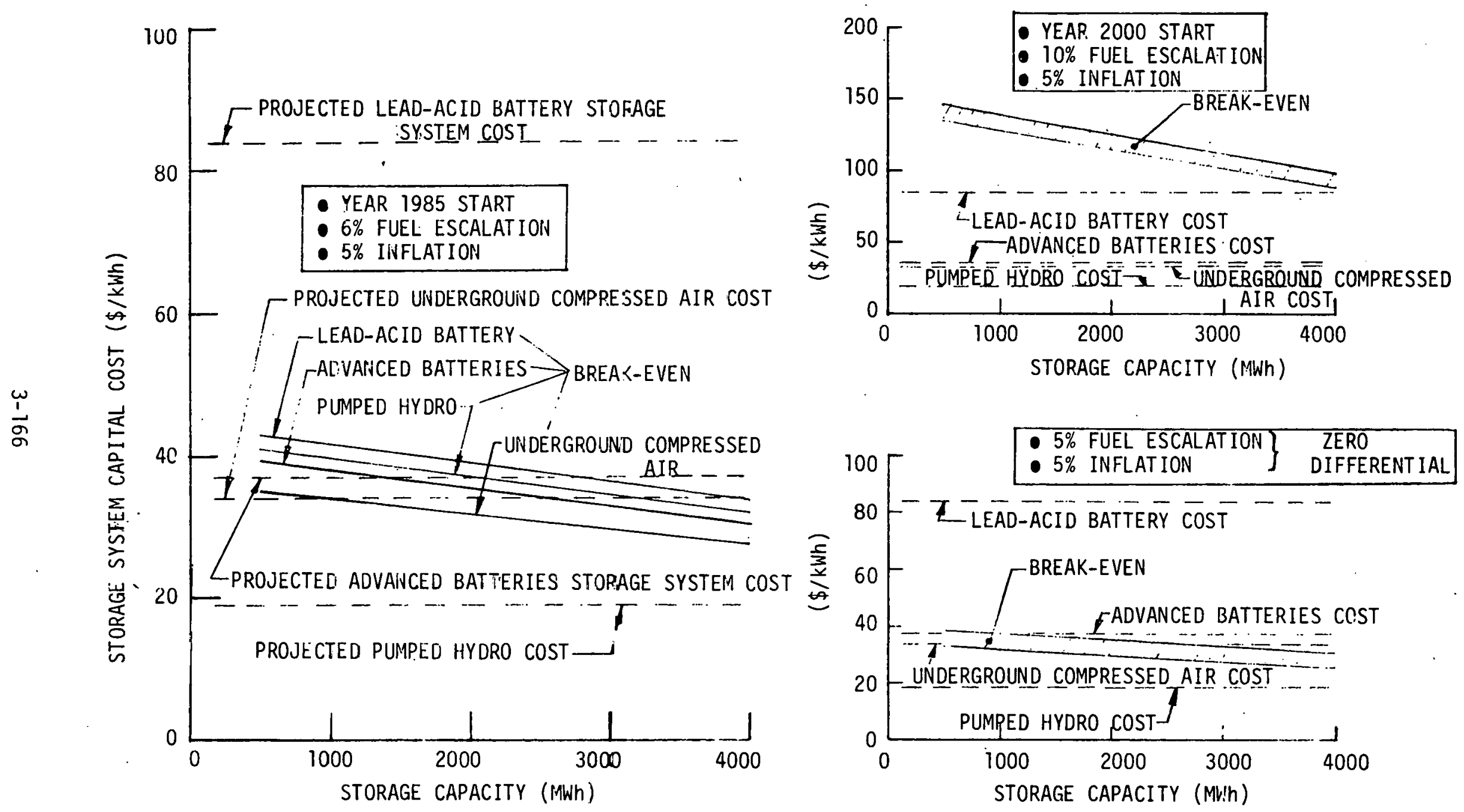

FIGURE 3.6-5. RANGE OF BREAK-EVEN COSTS AND PROJECTED STORAGE SYSTEM COSTS FOR SEL.ECTED ECONOMIC CONDITIONS - UTILITY ONLY C.HARGIIG (MULTIPLE SOUR 
LEAD-ACID BATTERIES

( 5 HOUR DISCHARGE RATE)

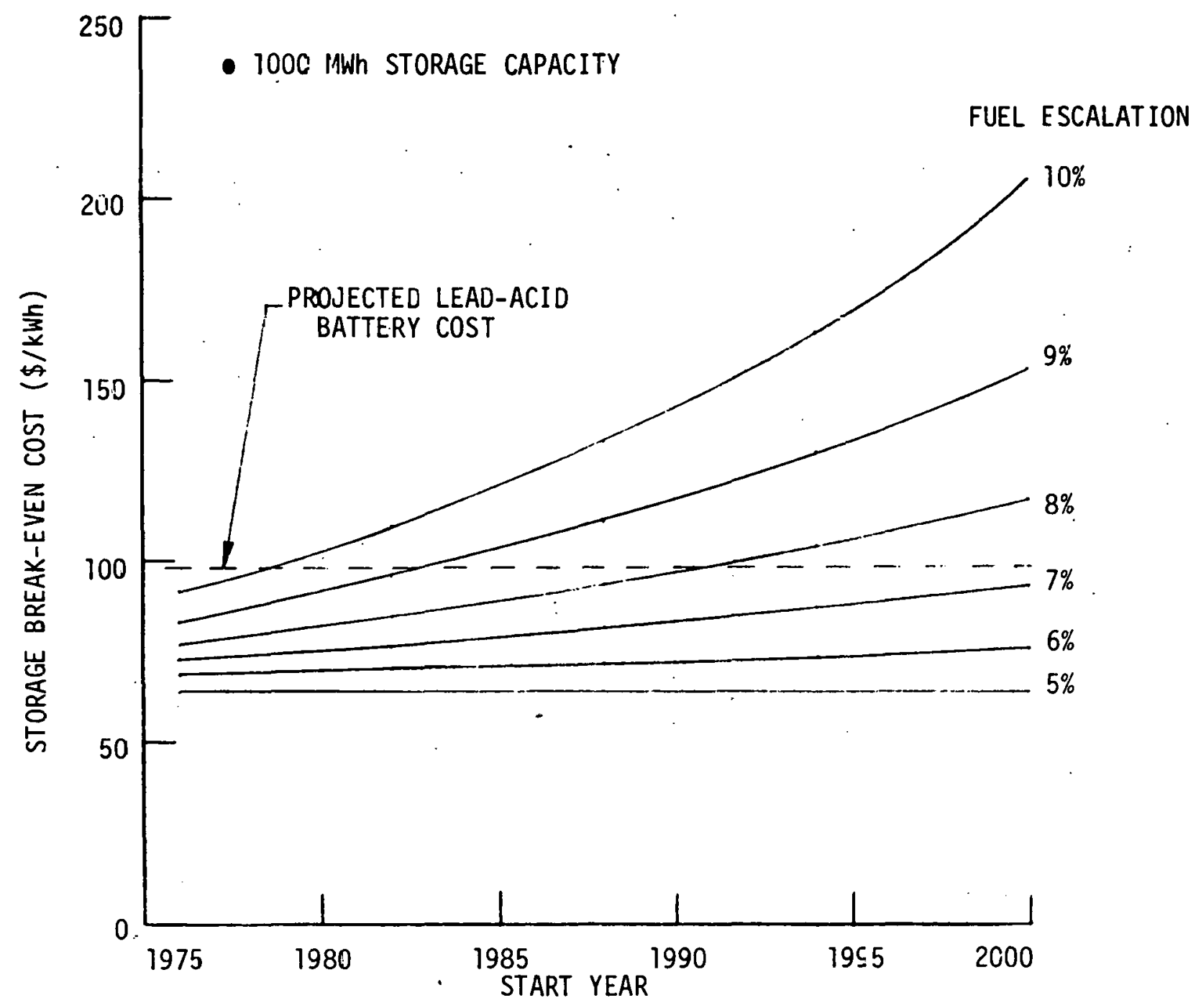

FIGURE 3.6-6. IMPACT OF START YEAR AND FUEL PRICE ESCALATION (COST OF GENERATION) ON STORAGE BREAK-EVEN COST GOALS - UTILITY ONLY CHARGING (MULTIPLE SOURCE) 


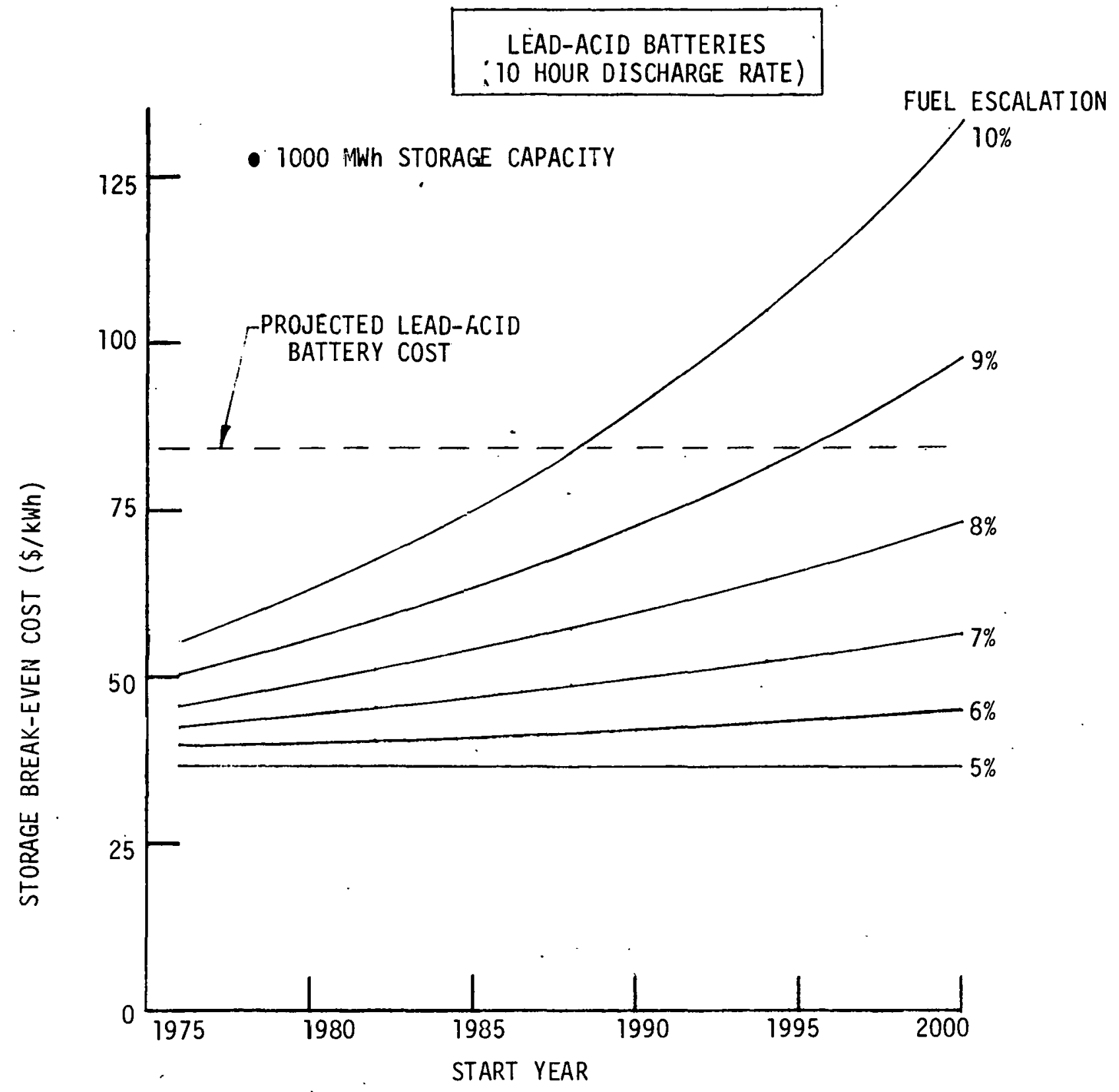

FIGURE 3.6-7. IMPACT OF START YEAR AND FUEL PRICE ESCALATION (COST OF GENERATION) ON STORAGE BREAK-EVEN COST GOALS - UTILITY ONLY CHARGING (MULTIPLE SOURCE) 


\subsubsection{EFFECTS OF WIND FORECASTING}

Forecasting must necessarily involve not only prediction of wind conditions and the resultant WTG output, but other factors which affect a utility system's load demand. The objective of this area of investigation was to consider the impact on resultant energy values with the presence of such knowledge.

\subsubsection{Storage Dispatch with 100\% Forecasting Accuracy}

This condition would reqliire perfect knowledge of the wind availability and load demand for some period of time prior to commitment of storage discharge to lieet the load. The further in advance, obviously the more perfect the planned dispatch results. Because the previous utility-only charging case accomplished short term (up to 24 hours) management of the state of change values in the model, this case was taken as the standard for comparison with more random logic alternatives.

\subsubsection{Storage Dispatch without Forecasting}

Whereas it appears reasonable to assume some degree of weather forecasting ability based on current weather prediction technology, and probably an even higher degree of utility load forecasting, based on historical as well as real time data, the question then becomes: What should the operating strategy be if the forecast fails? "Failure" was herein defined as either non-availability of a forecast, or a near real-time set of events contrary to the forecast. Use of some operational dispatch strategy different from the normal or planned strategy with good forecasting present appeared to be indicated. Accordingly, several alternative strategies were explored. 
Selection of Alternative Operational Strategies

The selection of a good operational strategy for storage utilization is a difficult task in itself and appears to merit further investigation beyond the scope of this study. Factors affecting the strategy choice include such $i$ teris as knowledge of system load characteristics, equipment in service, short term load trends, storage capacity (if any) and status, seasonal factors and for wind systems, normal output levels and penetration. It was deemed unlikely that an operator could cope with all of these in real time; therefore, one or more standby operational modes for storage dispatch would be necessary if the normal mode was disrupted by lack of usual forecast data.

The task of selecting alternative strategies was simplified for study purposes by examining the gain in values as a unit of energy is moved from one load strata to another (Refer to Figure 3.3-20 for one illustration of the strata concept.). Table 3.6-2 as presented previousiy in Section 3.3.1.2 is helpful here also, as it gives the dollar savings provided by charging 1 kilowatt hour of storage capacity at one level and discharging to a higher valued level for a utility system "B" type load and costs of generation as in Figure 3.3-20. 
TABLE 3.6-2. SAVINGS PER CHARGE/DISCHARGE CYCLE IN $\$ 1 / \mathrm{kWh}$

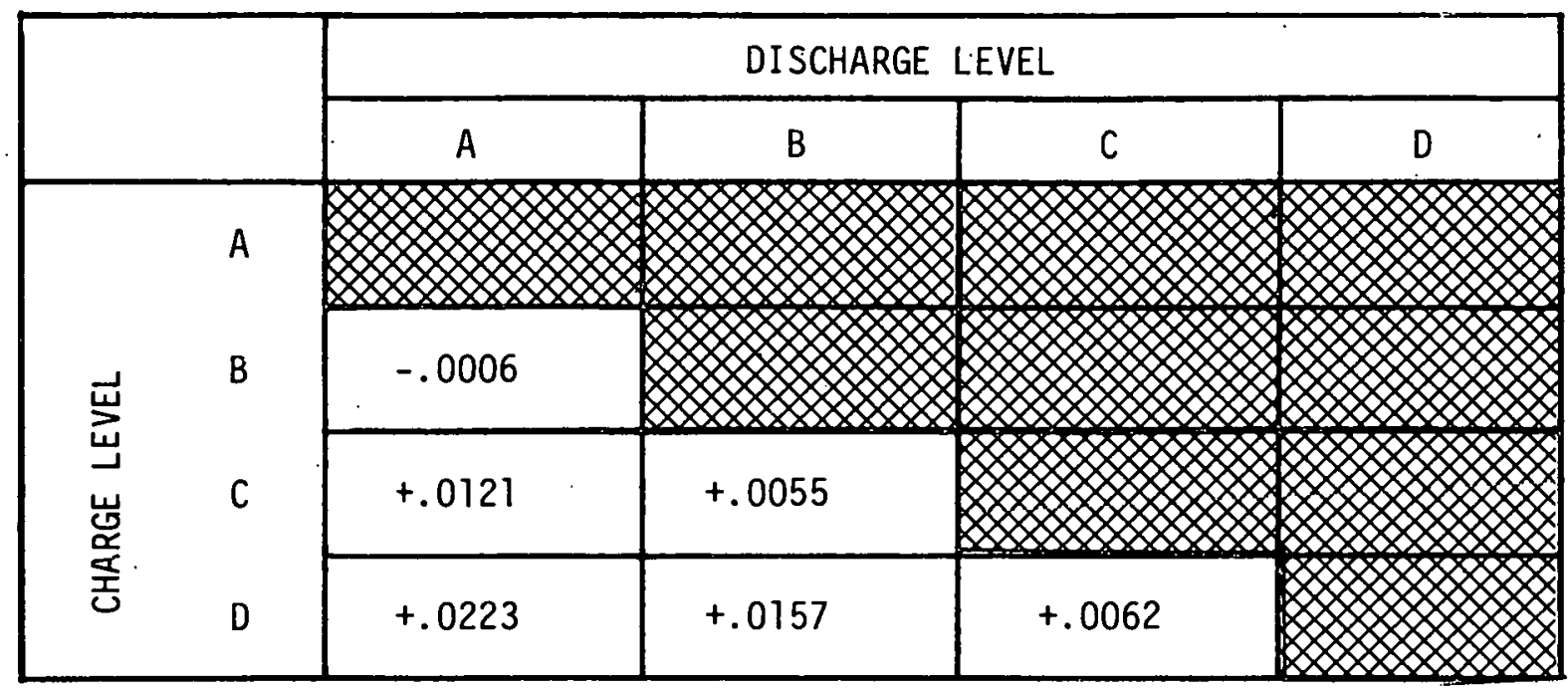

Two basic storage strategies of advantage can be identified by examining the above table:

1. Charge from Card D levels - discharge to A and B levels only.

( $C$ level discharge not permitted due to the possibility of charging at that level.

2. Charge from D level only - discharge to A, B and C levels.

Trial computational runs indicated that operational strategy 2 (above) was best for the utility load characteristics selected for study. This result appeared to be a function of the base load (level D) charging capacity available. (In this case quite large over a wide range of storage capacity). As storage size was increased to the point where level $D$ was inadequate for charging, it was also observed that a large portion of the potential level $A$ and $B$ displacement had already taken place; therefore, little additional benefit was gained by level $C$ charging. 
Once the basic strategy was established, several variations of discharge priorities were tried for a representative week of system operation.

Table 3.6-3 shows a representative computation table for these analyses:

TABLE 3.6-3 STORAGE DISPATCH OPTION ANALYSIS

Option 3-Day 6 (Typical)*

\begin{tabular}{|c|c|c|c|c|c|c|c|c|c|c|}
\hline & \multicolumn{4}{|c|}{$\begin{array}{l}\text { UT ILITY LOAD } \\
\text { DEMANDS BY STRATA } \\
\text { (MW) }\end{array}$} & \multirow[b]{2}{*}{$\begin{array}{l}\text { STORED } \\
\text { ENERGY } \\
\text { (MWh) }\end{array}$} & \multirow[b]{2}{*}{$\mathrm{SOC}$} & \multicolumn{4}{|c|}{$\begin{array}{l}\text { STORAGE ENERGY } \\
\text { DELIVERED TO } \\
\text { LOAD (MWh) }\end{array}$} \\
\hline HOUR & $A$ & B & C & $\begin{array}{c}D \\
\text { (EXCESS) }\end{array}$ & & & A & B & C & $D$ \\
\hline $\begin{array}{r}1 \\
2 \\
3 \\
4 \\
5 \\
6 \\
7 \\
8 \\
9 \\
10 \\
11 \\
12 \\
13 \\
14 \\
15 \\
16 \\
17 \\
18 \\
19 \\
20 \\
21 \\
22 \\
23 \\
24\end{array}$ & $\begin{array}{r}7 \\
26 \\
41 \\
17\end{array}$ & $\begin{array}{r}55 \\
125 \\
150 \\
150 \\
150 \\
150 \\
125 \\
98 \\
123 \\
150 \\
150 \\
150 \\
7\end{array}$ & $\begin{array}{r}246 \\
300 \\
300 \\
300 \\
300 \\
300 \\
300 \\
300 \\
300 \\
300 \\
300 \\
300 \\
300 \\
300 \\
71\end{array}$ & $\begin{array}{r}349 \\
489 \\
541 \\
559 \\
552 \\
506 \\
371 \\
39\end{array}$ & $\begin{array}{l}200 \\
200 \\
200 \\
200 \\
200 \\
200 \\
- \\
- \\
- \\
- \\
- \\
-7.37 \\
-27.37 \\
-43.16 \\
-175.79 \\
-131.58 \\
-103.16 \\
-129.47 \\
-200.0 \\
-82.11 \\
- \\
- \\
- \\
-\end{array}$ & $\begin{array}{l}.250 \\
.400 \\
.550 \\
.700 \\
.850 \\
1.000 \\
1.000 \\
1.000 \\
1.000 \\
1.000 \\
1.000 \\
.993 \\
.965 \\
.922 \\
.746 \\
.615 \\
.512 \\
.382 \\
.182 \\
.1000 \\
1 \\
\downarrow\end{array}$ & $\begin{array}{r}7 \\
26 \\
41 \\
17\end{array}$ & $\begin{array}{r}150 \\
125 \\
98 \\
123 \\
106\end{array}$ & & \\
\hline & & & & & & & 253 & 602 & & \\
\hline
\end{tabular}

* 1000 MWh Storage Capacity 
The value of the stored energy discharge was found to be $\$ 14,558$ for the example shown, whereas if the match had been perfect, the value would have been $\$ 15,066$.

The discharge options examined are shown in Table 3.6-4, along with total results for the representative week.

TABLE 3.6-4. ALTERNATIVE DISCHARGE OPTIONS AND RESULTS OF 7 DAY USE

\begin{tabular}{|c|c|c|}
\hline STORAGE DISS.HARGE STRATLGY & $\begin{array}{l}7 \text { DAY SNVINGS } \\
\text { (\$ } \$ \text { STUE TO TO }\end{array}$ & $\begin{array}{l}\% \text { MAX. } \\
\text { SAVINGS }\end{array}$ \\
\hline $\begin{array}{l}\text { 1. Discharge to cost of generation strata } \\
A \text { or } B \text { only, whenever they occur; } \\
\text { Weekend discharge to } A, B \text {, or } C \\
\text { without priority }\end{array}$ & 75,767 & 87.7 \\
\hline $\begin{array}{l}\text { 2. No discharge until hour } 11 \text {. Once } \\
\text { strata } A \text { demand appears, discharge } \\
\text { only to } A \text { until it disappears, then } \\
\text { discharge to level B. Weekend dis- } \\
\text { charge as in } 1 \text { (above). }\end{array}$ & 79,521 & 92.0 \\
\hline $\begin{array}{l}\text { 3. Discharge to strata } A \text { only until hour } \\
15 \text {, then to strata } A \text { and } B \text {. Weekend } \\
\text { discharge to } A, B \text { or } C \text { as they occur. }\end{array}$ & 79,786 & 92.4 \\
\hline $\begin{array}{l}\text { 4. Same as } 3 \text {, but dicharge to load } \\
\text { strata } C \text { permitted from hour } 22 \mathrm{cn} \text {. }\end{array}$ & 80,961 & 93.7 \\
\hline $\begin{array}{l}\text { 5. Discharge to exactly meet load } \\
\text { demands in nrder of highest priority, } \\
\text { ( } i . e . \text {., "A" first). (This option } \\
\text { requires } 100 \% \text { kncwledge of net load } \\
\text { demands). }\end{array}$ & 86,390 & 100.0 \\
\hline
\end{tabular}


The first four strategies above are based on knowledge of load characteristics which a utility system dispatcher could be expected to have. In addition, it is highly probable that other knowledge such as the previous day's load demands or the rate of increase of load demand could be employed to further improve the utilization and in turn, the resultant value of storage.

\subsubsection{Interpretation of Results}

As the data in Table 3.6-3 shows, the achievable energy savings values for the week closely approach the maximum value with 100\% daily knowledge of the load. If the basic storage charge logic (\#2) identified from Table 3.6-1 is coupled with any one of the dispatch options analyzed above, the range of results falls within about $12 \%$ of those obtained with approximately $100 \%$ forecasting of the wind/load combination. This indicates, in essence, that any good operational strategy coupled with undedicated or multisource storage charging can give effective results without forecasting. Since some degree of wind/load forecasting can be expected, the gap between actual and maximum possible savings will be still narrower. A "50\% forecasting" accuracy as considered in the original task becomes somewhat of a moot point under these conditions. Furthermore, there are a multitude of strategy possibilities for achieving results falling between $0-100 \%$ forecasting.

The presence of wind energy generation in the utility system is compatible wi th the results shown since charging of the energy storage system is still done with excess base load energy. whether or not the excess is the result of wind-supplied energy. When wind energy is present, it has the 
effect ${ }^{-}$of lowering the demand on other generating units and stored energy would be dispatched accordingly. Unpredictable short term changes such as a late afternoon wind gust could cause a slight loss in stored energy value for the day if the wind system were displacing a high percentage of strata $A$ and $B$ energy, thereby causing the storage system not to be fully discharged that day. In the normal situation, wind conditions would likely be anticipated adequately on an hour-by-hour basis to allow efficient and complete dispatch of stored energy.

One final note of caution may be appropriate. Altliough less than perfect torecasting might appear to lie between the extremes identified here, in actuality, adherence to operational modes based on an incorrect forecast could produce worse results than having no forecast at all. An example would be the discharge of storage to a low value level of the load strata in anticipation of a predicted high WTG output during a peak load time. When the wind energy fails to materialize under these conditions, expensive peaking equipment must be used. With no forecast at all, use of a specific operational strategy, similar to those discussed previously, would very likely have assured an adequate stored energy reserve to meet the peak demand. 


\subsection{VALUE OF TRANSIENT SMOOTHING}

\subsubsection{OBJECTIVE OF INVESTIGATION}

The principal purpose of study investigations in this area was to determine the value attributable to smoothing of transient wind conversion system output via energy storage. "Value" was considered in terms of technical necessity as well as economic impact.

\subsubsection{DESCRIPTION OF THE SMOOTHING PROBLEM}

The variability of wind energy conversion system output is well known and encompasses rather large swings in instantaneous power output. The need and/or benefit of smoothing this output has at least two aspects of particular interest:

1. The technical need to limit output power variations in order not to disrupt the magnitude and/or synchronism of the power flow to an assigned load or a jointly fed power grid.

2. The potential for economic improvement in value of the wind system output if smoothing were accomplished by energy storage.

In addressing these issues, it is necessary to distinguish between outputs devoted to single loads and those contributing to a larger network. The characteristics of each of these situations are discussed in the following section. 


\subsubsection{EFFECT OF GENERATION AND LOAD RELATIOHSHIPS}

\subsubsection{Single Loads with a Single Generating Source}

For the case of single loads served by single wind turbine generators, the requirement for energy storage is largely dependent on the requirements of the specific type or types of load to be served. Some loads for specific applications of wind power are "interruptible" by their nature. Two possible examples are the pumping of water for reservoir storage or irrigation purposes, and resistive heating loads. In the water pumping example, the constancy of flow rate may be of lesser significance than the total quantity of water pumped over a specified time span. Consequently, the principal requirement resulting from wind output fluctuations would be selection of pump motors and contactor devices rated for this type of duty. Other inquiries made during the study (Section 2), have indicated that selection of equipment with such ratings is feasible.

In the resistance heating example, no power input regulation would be required as long as specified voltage limits were not exceeded. Power variability could affect thermostatic duty cycles, and the need for back-up, but the integrated heating output of the WECS over a given period of time would be identical for the same total energy input.

Unfortunately, however, most of the electrical equipment encountered in diversified loads is designed to produce acceptable results when operating within narrow limits of power, voltage and frequency (the latter in the case of ac loads). This fact necessitates that some form of power conditioner 
be used in conjunction with the generating source in order to match it to the load.

One straightforward method for matching the source to the load is to simply overdesign the source and then by use of series or shunt regulating techniques, discard a certain percentage of the source power so that the delivered power exactly matches the load demand. When the source power falls below the demand, the supply is simply interrupted until the generator (source) can once again provide an adequate output level. This method has been used on numerous occasions for simple, photovoltaic-powered satellites where interruptions in operation can be tolerated while the satellite is shadowed in passing behind the earth. Systems of this type are generally energy-wasteful due to oversizing of the power source, and as indicated, operation of load devices is severely limited.

A second method for matching a single source and load would be to introduce energy storage. Ine regulation characteristics of the storage device may he adequate in some cases for the needs of the loads being served, so that, in addition to absorbing excess power from the source, the power is also available to the load at compatible voltage levels. With this approach, the load is still served during temporary periods of no generation. The character of the load again determines whether storage is required. The amount of storage capacity is determinable based on specification of the time which loads must be carried should source power be interrupted.

The general functioning of load dedicated systems may be considered further, based on the overall relationships shown in Figure 3.7-1. 

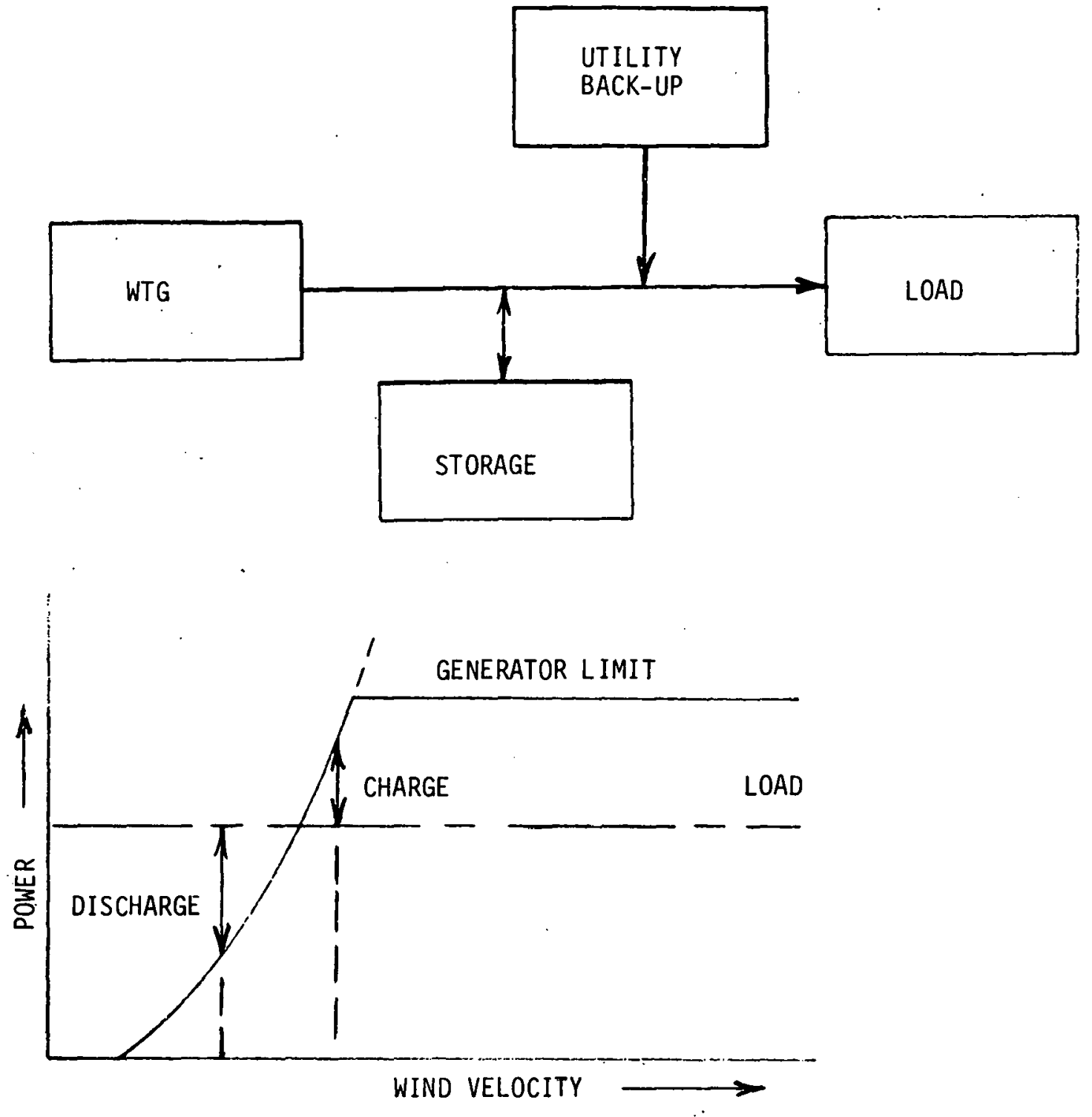

FIGURE $3.7-1$ LOAD DEDICATED SYSTEMS

Load demands can be met only up to the output rating of the wind turbine (assuming normal overload protection). Further, if a dc WTG system happened to be in use rather than ac, an inverter would be required (not shown), which would also limit the system output according to it.s rating. Any luad requirements, including starting transients, which exceed WTG system capabilities would be met by the utility back-up. If no back-up were present, the WTG system would have to be of a larger rating or arrangements made to drop excessive loads. Thus, although the storage system might be adequate in 
itself, other restrictions in the system, such as the presence of an inverter or the arrangement of switching devices may limit the transient smoothing capability of the storage system.

Considering transients associated with generation rather than load demands; the lower portion of Figure 3.7-1 indicates the situation for a wind turbine system. The generator element of the rotor/generator system is rated at some specified wind velocity. At high velocity, steps must be taken to assure that the turbine power output does not increase, since otherwise the generator rating will be exceeded. Note that energy storage placed downstream of the generator would be ineffective in absorbing the higher rotor output because of the generator limitations. Alternative strategies for handling excessive wind velocity include modifying the aerodynamic performance by adjusting rotor blade pitch and by allowing the rotor speed to increase with a commensurate increase in the rotor kinetic energy. The latter approach is only applicable to dc or non-synchronous ac generation.

Within the range of WTG capabilities, sudden increases or decreases in output must be considered. As WTG size is increased, the rotational inertia of the WTG smoothes some of these variations with increased effectivity. In studies performed on a $100 \mathrm{~kW}$ WTG system in Germany ${ }^{\star}$, it was found that typical variations of $\pm 30 \%$ in instantaneous power output occurred. If the measurement time intervals were increased to 6 minutes, the average range of power excursions were found to be only $\pm 6 \%$. A five-to-one reduction in power level fluctuation was thereby found possible using storage capacity sufficient to carry the load

Hutter, U., "Eine Windturbine mit 34m Rotor-Durchmesser," DFL-Mitteilungen, No. $8,1968$. 
for only 6 minutes.

Figure $3.7-2$ shows a U.S. Weather Bureau wind velocity trace for Boston, MA which reveals representative wind velocity variations which would produce comparable power output fluctuations. Based on the above information it would appear that without considering specific individual load or load device ratings, only a very short-time energy storage capacity need be considered for reducing WTG output power variations to a reasonable level. Beyond a nominal range of 5-15 minutes, the choice of storage size, therefore, becomes more a function of conservative design or the desire to store energy solely for the value it might have at a later time.

The cost of 10 minutes of storage capacity at $100 \mathrm{~kW}$ output rating and $\$ 70 \mathrm{~kW}$ $+\$ 40 / \mathrm{kWh}$ would, therefore, be $\$ 7,667$. The value of this storage in terms

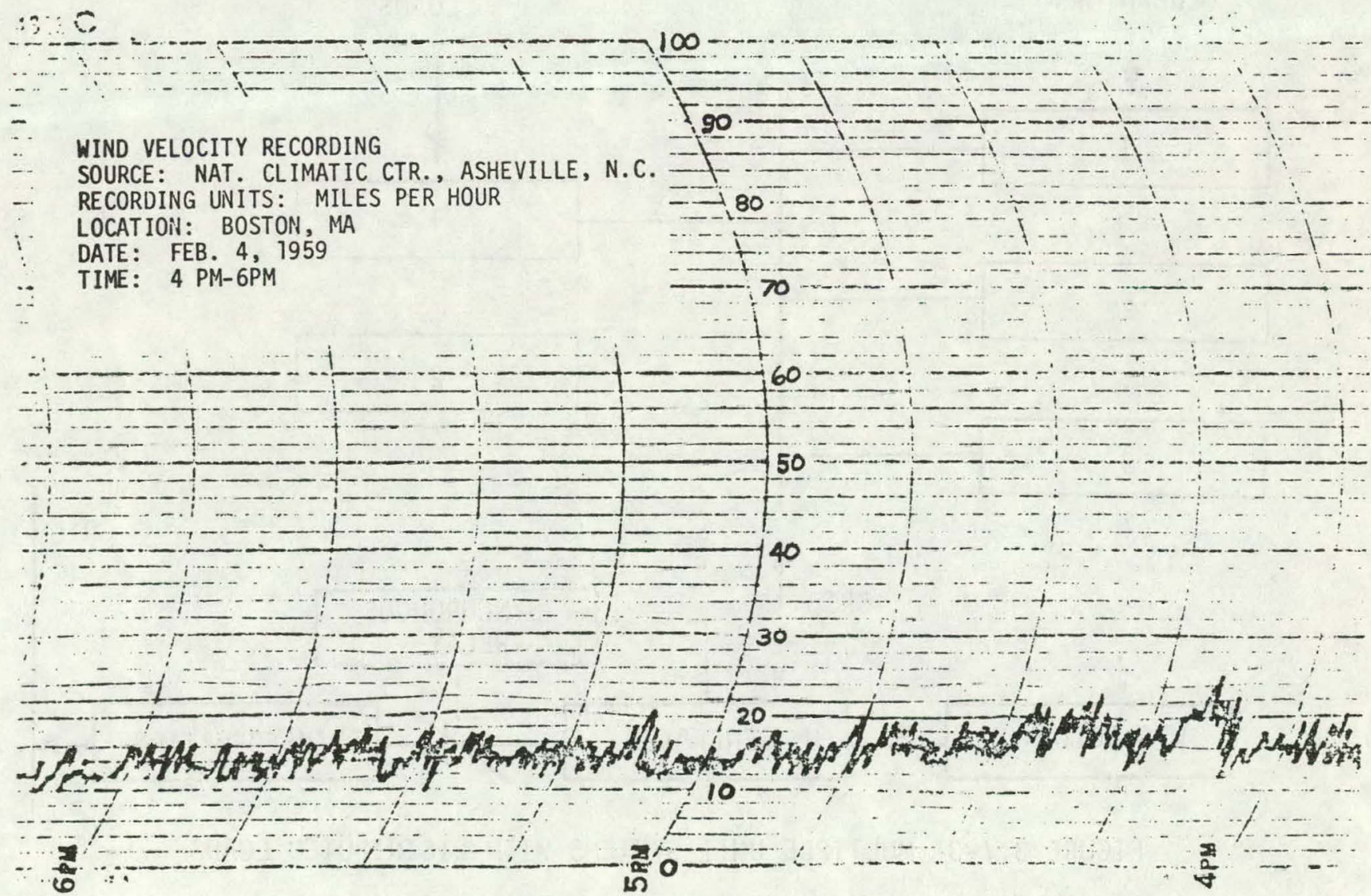

FIGURE 3.7-2 REPRESENTATIVE WIND VELOCITY TRACE 
of increased annual energy displacement would vary widely but could not be expected to justify the expense. Consequently, the value must be judged on the basis of whether the expected load requirements could be met wi thout storage (via utility back-up or other means). If not, then the cost of this relatively small amount of storage capacity becomes an intrinsic and inseparable part of the wind conversion system cost, and must be designed into the system. The question of storage then becomes a specific design issue and should be resolved for individual applications, rather than generalized.

\subsubsection{Multiple Loads with Multiple Generation Units}

For distributed generation and load systems, the situation may be depicted as in Figure 3.7-3.

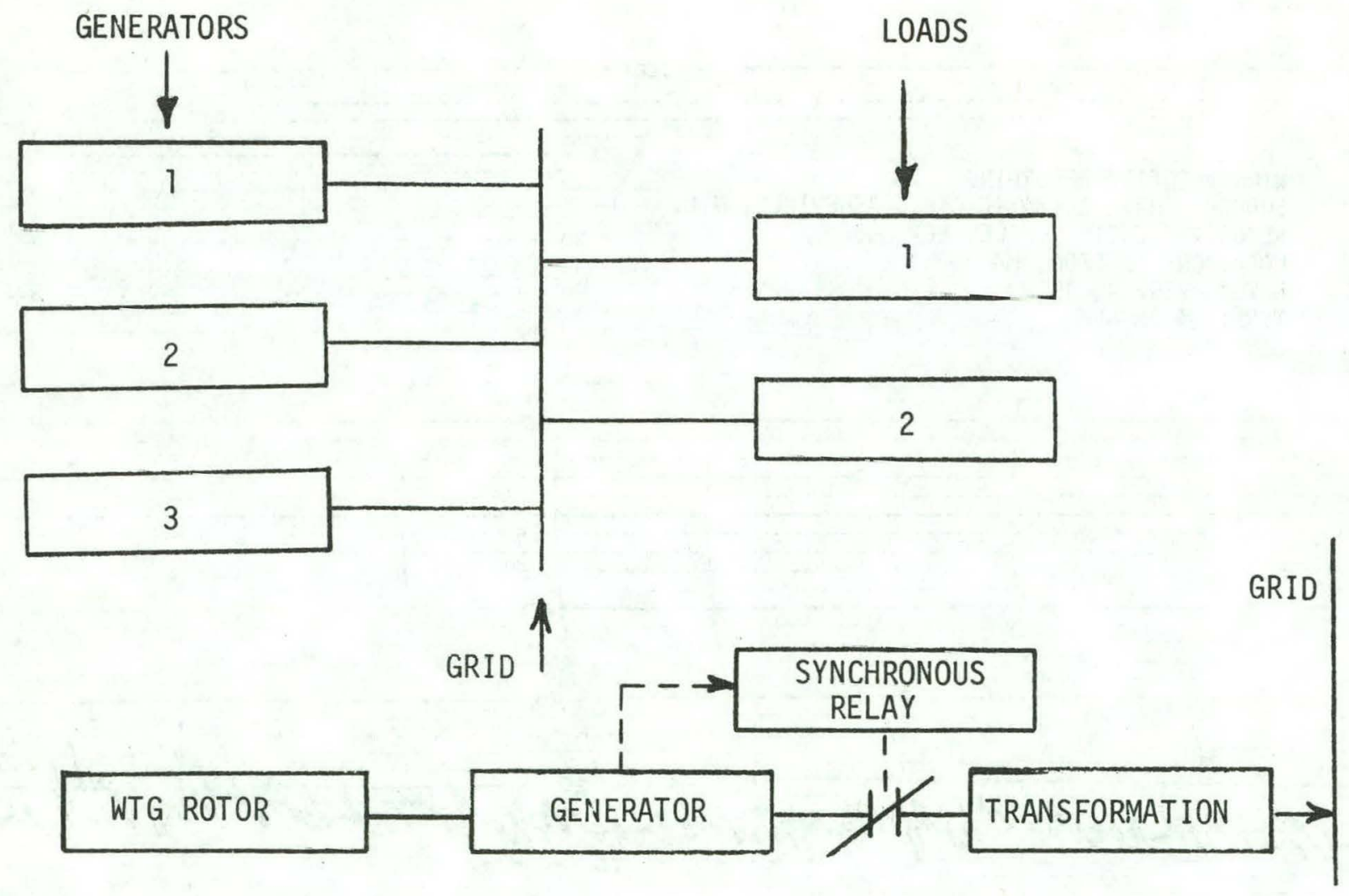

FIGURE 3.7-3 MULTIPLE UNIT SYSTEMS WITH DISTRIBUTED LOADS 
The effect of fluctuations in the output power of any one WTG unit is levelized at the grid since the transient wind conditions at all locations in a dispersed array are not likely to be the same at any particular time. The fluctuations in total output may, therefore, be considered self-smoothing to a certain extent. Spinning reserve or general system storage would be used to modify the resultant total power supplied by the utility system to its loads. Investigations of. gust effects in such a system were conducted in a recent system study*, and it was concluded that the presence of downstream energy storage was not technically adequate as a means of transient smoothing.

Variable, but synchronized ac output is inserted directly into the grid. The variable wind power is handled by the elastic coupling of the generator and utility grid up to the rated limit of power transfer. If this limit is exceeded because of a wind gust, the power flow is interrupted by the synchronizing relay thereby preventing possible damage to the generator. Other controls at the WTG are then enabled which will prevent overspeed by modifying the rotor aerodynamic characteristics through pitch control. Synchronism must subsequently be re-acquired. As noted earlier for the dedicated load case, any use of energy storage for transient smoothing purposes would be limited by the basic generator rating.

Since the grid system can function without storage being required solely because of use of WTG's, value from storage can only be attributed to benefits from delayed energy use. This benefit has been previously analyzed (Section 3.1). It should be noted that if energy storage is used in this type of distributed

\footnotetext{
* "System Dynamics of Multi-Unit Wind Energy Conversion System Application", General Electric Co.; ERDA Contract E(49-18)-2332, 1977.
} 
system, the storage capacity selected will in all probability be larger than that which would have been selected to provide smoothing in any case. Thus both benefits will be realized, although no economic benefit is deemed attributable to the smoothing.

In case of dc WTG output, a converter is used and variable speed wind turbine operation is possible since the WTG rotor is non-synchronous with the utility grid power frequency. In this case, the WTG rotor can kinetically store the energy of wind gusts.

Figure 3.7-4 shows the relationships and the energy transfer behavior. The latter is explained as follows:

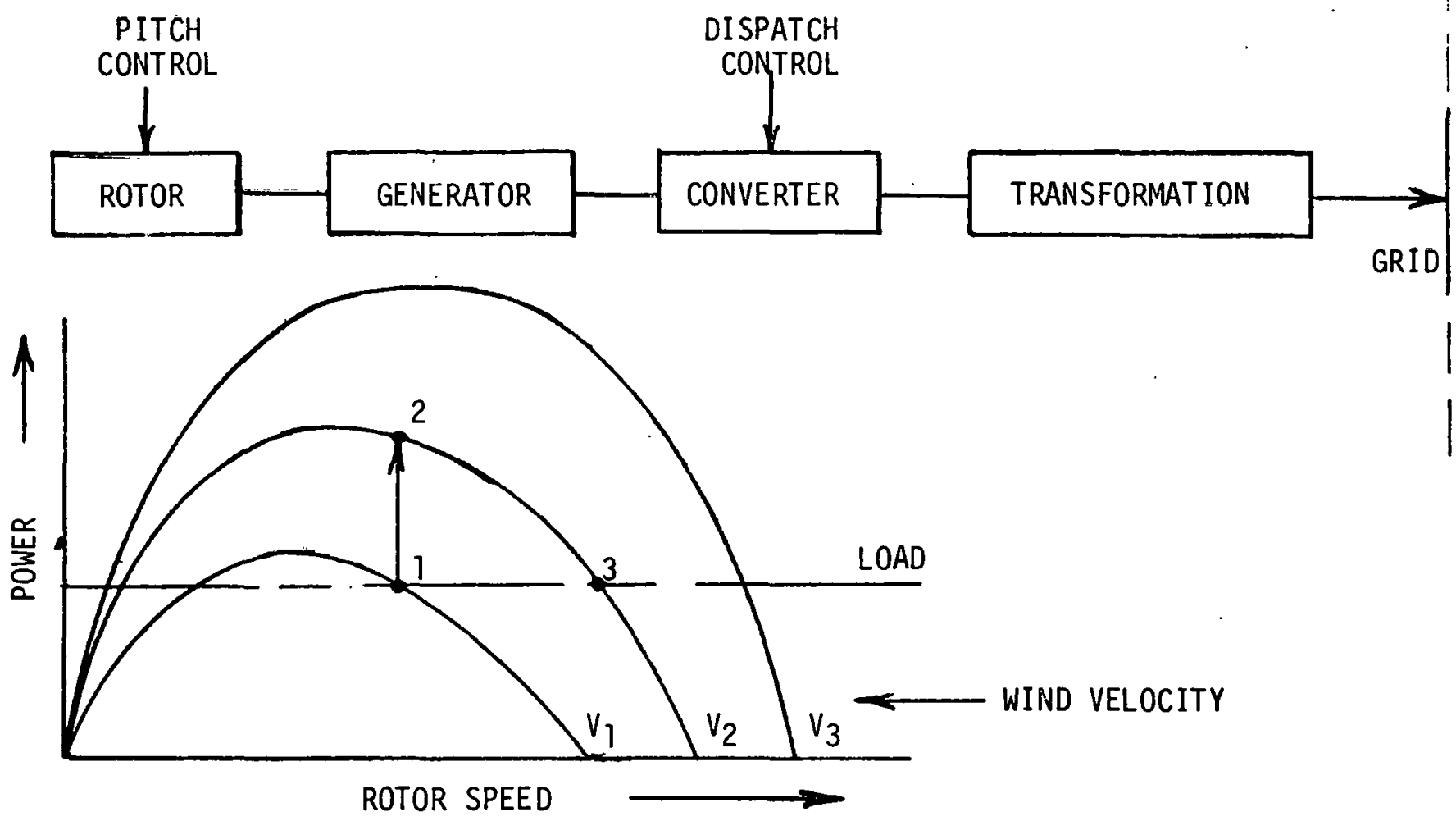

FIGURE 3.7-4 WIND CONVERSION SYSTEM USING DC GENERATION 
Each curve shows the dependence of shaft power on rotor speed for a given value of wind velocity. Though the curves are only representational, their basic shapes are consistent with expected behavior. For a specific wind velocity, no power is generated at zero rotor speed nor at the maximum freewheeling speed. The maximum power is generated at some intermediate rotor speed between these extremes. Point (1) represents a nominal operating condition at the load and rotor speed shown for a wind velocity of $V_{1}$. The load is established by the dispatch controls of the DC/AC converter. Assume there is a sudden change in wind velocity to $v_{2}$. The rotor inertia does not permit a sudden change in rotor speed and therefore the nperating point shifts to point (2). Assuming no change in the load, the power difference between points (2) and (1) must then be applied to increasing the rotor kinetic energy. As the rotor speed increases, the power difference narrows until finally equilibrium is reached at point (3). With a negative gust, a reverse action takes place with kinetic energy used to sustain the load.

It is clear that many alternative strategies could be used to operate the $D C$ wind generator. Changes in load, blade pitch, and generator excitation represent several possibilities. Regardless of the metnod, the previous example indicates the degree of operational flexibility provided by inherent inertial energy storage of the WTG.

Through several examples, the above discussion provides a perspective on the transient smoothing capability of storage used with wind enerqy conversion systems. The economic benefit provided by the transient smoothing capability of energy storage is marginal at best. The examples indicate that for certain 
cases the consequence of not using energy storage is fully acceptable in terms of the resulting transient behavior. In other cases, storage may be a necessary adjunct for assuring technical performance. However, in these latter cases it was not possible to identify a clear economic benefit, per se, associated with short-term transient smoothing. On the other hand, the long-term benefits of energy storage are beyond question as established previously in an earlier section.

\subsubsection{SPECIAL CASE - POTENTIAL VALUE OF SMOOTHING FOR INTERMEDIATE APPLICATIONS}

Output smoothing from energy storage can substantially enhance the value of energy from a wind energy system under many existing and proposed utility rate schedules. The basic objective of the storage smoothing in this case is to alter the purchased electricity versus time of day profile to one which is less expensive for the utility to supply and for which the utility is therefore able to offer preferential rates.

Figure 3.7-5 presents the Philadelphia Electric Company industrial rate schedule applicable to the Valley Forge General Electric facility. This schedule puts a strong premium on load leveling as does the Georgia Power Company schedule, also shown. For example, a Philadelphia customer with a maximum demand of $1000 \mathrm{~kW}$, using $360,000 \mathrm{kWh}$ in a month would pay a monthly bill of $\$ 8961$ for an average energy price of $\$ .025$ per $k W h$. For a perfectly level load of $500 \mathrm{~kW}$, for 720 hours, the same $360,000 \mathrm{kWh}$ would cost only $\$ 6616$, dropping the average energy price to $\$ .018$ per $\mathrm{kWh}$. 
Availability

Untransformed electric service from the primary supply lines of the Company's distribution system where the Custorner installs, owns, and maintains, any transforming, switching and other receiving equipment required. However standard primary service is not available in areas where the distribution voltage has been changed to $13 \mathrm{kV}$ unless the Customer was served with standard primary service prior to the conversion of the area to $13 \mathrm{kV}$.

Current Characteristics.

Standard primary service.

Monthly Rate Table

Capacity Charge Prices: Per KW of billing demarid:

$\$ 4.07$ per $\mathrm{kW}$ for the first $50 \mathrm{~kW}$

$\$ 2.17$." " " excess over $50 \mathrm{~kW}$

Energy Charge Prices:

$2.40 \$$ per kWh for the first 150 hrs use of b1lling demand but not less than $5,000 \mathrm{kWh}$.

$1.60 \$$ per kWh for the next $150 \mathrm{hrs}$ use of billing demand

$1.164 "$ " " additional use.

State Tax Adjustment $\mathrm{Cl}$ ause and Fuel Adjustment Clause apply to this rate.

- Phlldulelphia tlectric Company

MONTHLY RATE - ENERGY CHARGE INCLUDING DEMAND CHARGE:

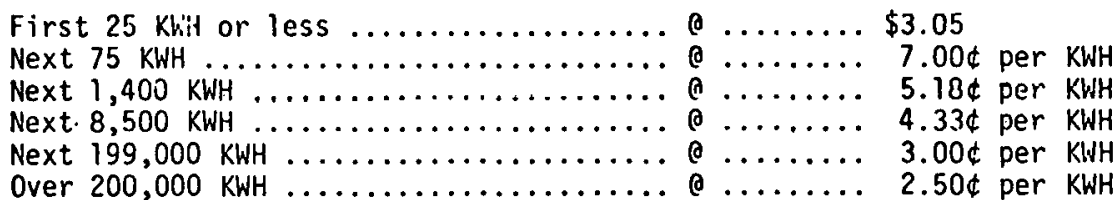

All consumption in excess of

$200 \mathrm{KWH}$ per $\mathrm{KW}$ of Demand,

which is also in excess of

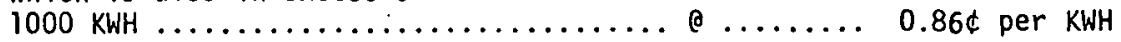

All consumption in excess of

$400 \mathrm{KWH}$ per KW of Demand,

which is also in excess of

$2000 \mathrm{KWH}$

e

$0.62 \ddagger$ per KWH

Minimum Monthly Bill:

A. $\$ 3.05$ per meter plus $\$ 3.05$ per $\mathrm{KW}$ of Demand in excess of $5 \cdot \mathrm{KW}$.

B. Athletic Field Lighting: $\$ 12.00$ per meter for lighted athletic fields, provided service is limited to the field lighting equipment itself and such incidental load as may be required to operate coincidentally with field lighting equiprnent.

FUEL ADJUSTMENT:

The amount calculated at the above rate is subject to increase or decrease under the provisions of tra Company's Fuel Adjustment Rider, Schedule "PA-1".

- Ceorgia Puwer Company

FIGURE 3.7-5 TYPICAL INDUSTRIAL ELECTRIC RATE SCHEDULES 
Addition of a wind energy conversion system (WECS) to an application with a previously level load will reduce the total electric bill but, if peaks are not reduced also, the energy supplied will be worth only the lowest price increment - $\$ .0116 / \mathrm{kWh}$ in the Philadelphia Electric rate schedule. This is easily shown by assuming a $500 \mathrm{~kW}$ WECS with capacity factor of .35 is added to the level load plant and computing the old and new electric bills:

$$
\begin{aligned}
& \text { Monthly WECS output }=.35(24)(30)(500)=126,000 \mathrm{kWh} \\
& \text { New electric demand }=360,000-126,000=234,000 \\
& \text { Maximum demand }=500 \mathrm{~kW} \text { (with and wi thout WECS) } \\
& \text { Pricing Blocks }=150 \times 500=75,000 \mathrm{kWh}
\end{aligned}
$$

\begin{tabular}{rlr|}
\hline \multicolumn{3}{c|}{ OLD BILL } \\
4.07 & $\times 50$ & $\$ 203.50$ \\
+2.17 & $\times 450$ & 976.50 \\
+75.000 & $\times .024$ & 1800.00 \\
$+75,000 \times .016$ & 1200.00 \\
$+210,000 \times .0116$ & 2436.00 \\
& TOTAL & $\$ 6616.00$ \\
\hline
\end{tabular}

\begin{tabular}{rrr|}
\hline \multicolumn{3}{|c|}{ NEW BILL } \\
$4.07(50)$ & $\$ 203.50$ \\
$+2.17 \times 450$ & 976.50 \\
$+75,000 \times .024$ & 1800.00 \\
$+75,000 \times .016$ & 1200.00 \\
$+84,000 \times .0116$ & 974.40 \\
TOTAL & $\$ 5154.40$ \\
\hline
\end{tabular}

The savings of $\$ 1461.60$ divided by WECS contribution of 126,000 kWh yield $\$ .0116 / \mathrm{kWh}$ for the WECS energy value which is also evident from comparison of the two bills.

Now suppose energy storage is added such that the WECS output is smoothed to 
a constant $150 \mathrm{~kW}$. Energy delivery is reduced to $108,000 \mathrm{kWh}(150 \times 30 \times 24)$ due to storage inefficiency, but maximum utility demand has been reduced to $350 \mathrm{~kW}$. This makes the billing blocks $52,500 \mathrm{kWh}$ and the bill is reduced to:

$\begin{array}{rr}4.07(50) & \$ 203.50 \\ +2.17(300) & 651.00 \\ +52,500(.024) & 1260.00 \\ +52,500(.016) & 840.00 \\ +147,000(.0116) & 1705.20 \\ \text { TOTAL BILI. WTTH } & \\ \text { STORAGE } & \$ 4659.70\end{array}$

Thus storage has provided a savings of $\$ 494.70$ per month over the savings from the WECS alone. Capitalization of this savings will yield the storage break-even cost. Assuming a fixed charge rate (FCR) of .22, system life of 30 years and fuel price escalation of $5 \%$, or zero differential to the baseline inflation rate, the break-even cost is:

$$
\begin{aligned}
& \operatorname{Cost}_{B E}=\frac{M_{f} \times \text { annual savings }}{F C R} \\
& \text { where } M_{f}=\text { fuel price multiplier }(1.6759 \text { for } 5 \%, 30 \text { years }) \\
& \text { Cost }_{B E}=\frac{1.6759(12)(494.70)}{.22}=\$ 45,222
\end{aligned}
$$

Storage requirements to completely level the output of a $500 \mathrm{~kW}$ WECS may prove quite large for certain regions. A combination of energy storage and load management techniques may offer the most economic solution. Philadelphia Electric is one of many utilities encouraging load management for high energy 
consuming industrial or commercial users. 'To this end they offer consulting services and low night rates in addition to the load leveling incentive inherent in their basic structure.

Storage also has load leveling value for intermediate applications without WECS present. Assume a commercial operation with an electric demand of $1000 \mathrm{~kW}$ from $8 \mathrm{AM}$ to 4 PM and $200 \mathrm{~kW}$ for the remaining 16 hours per day. Total demand is $336,000 \mathrm{kWh}$ per month and the PE rate schedule will yield a monthly electric bill of $\$ 8,682.60$. Now suppose storage were added to produce a level load. At .75 efficiency, $3840 \mathrm{kWh}$ of storage would produce a level demand of $520 \mathrm{~kW}$ from the utility. Charging energy would be 16 hours $x 320 \mathrm{~kW}$ or $5120 \mathrm{kWh}$, which is reduced to 3,840 available due to the .75 efficiency. Discharging for 8 hours gives $480 \mathrm{~kW}$ which, added to the $520 \mathrm{~kW}$ utility supply gives the $1000 \mathrm{~kW}$ daytime requirement. Computation of an electric bill for a $520 \mathrm{~kW}$ constant demand yields $\$ 6876.84$ per month for a savings of $\$ 1805.76$. Capitalizing as before:

$$
\begin{aligned}
\operatorname{Cos}_{B E} & =\frac{1.6759(12)(1805.76)}{.22} \\
& =\$ 165,069.45
\end{aligned}
$$

on a kWh basis:

$$
\left(\frac{\$}{\mathrm{kWh}}\right)_{\mathrm{BE}}=\frac{165,069.45}{3840}=\$ 42.99 \frac{\$}{\mathrm{kWh}}
$$

This is a conservative value and will be greater for higher fuel escalation rates and delayed start year. For example, at $70 \%$ fuel escalation rate and 1990 start, the above break-even value increases to $\$ 71.26 / \mathrm{kWh}$. 
The value of storage employed in this manner is highly susceptible to utility rate structure changes. One rate structure change that is now underway and will likely continue, is time-of-day or peak load pricirig. This would alter the storage operational strategy and very likely change the economic storage size. Peak load pricing might also extend the benefits of load leveling to the residential sector, which now has little incentive in present rate structures. 
REFERENCES AND BIBLIOGRAPHY 
VOLUME III

\section{CITED REFERENCES}

1. "Design Study of Wind Turbines, $50 \mathrm{~kW}$ to $3000 \mathrm{~kW}$ for Electric Utility Applications, Analysis and Design", General Electric Company, NASA, Final Report CR 134935, 1975.

2. Hightower, S.J. and Watts, A.W., "A Proposed Conceptual Plan for Integration of Wind Turbine Generators with a Hydroelectric System", Bureau of Reclamation-USDI, Paper-Missouri Basin Systems Group, Sioux Falls, S.D., March 1977.

3. Bush, J.B. et al, "Economic and Technical Feasibility Study of Compressed Air Storage", General Electric Company, Final Report, ERDA 76-76, March 1976.

4. "Lead-Acid Batteries for Utility Application", Workshop II, EPRI Special Report, March 1977.

5. "Proceedings of the Symposium and Workshop on Advanced Battery Research and Design", Chicago Section - The Electrochemical

Society and Argonne National Laboratory, ANL-76-8, March 1976.

6. "Engineering Study of a 20MW Lead-Acid Battery Energy Storage Demonstration Plant", Bechtel Corp. Final Report, ERDA Contract $E(04-3)-1205$, 0ct. 1976 .

7. Berkowitz, D.G. and Brown, J.T., "Advanced Technology Lead-Acid Storage (Atlas) Batteries on Electric Utilities", Westinghouse Electric Corp.

8. Birk, J.R., "The Lead-Acid Battery for Electric Utilities", Electric Power Research Institute, Dec. 1976.

9. "Summary of Workshop on Battery Considerations for the Best Facility", Jan. 1975.

10. "Battery considerations for the Best Facility Study", The BEST Facility Study Project Team, Jan. 1977.

11. "The Best Factlity Workshop II", EPRI, Apr. 1977.

12. "Wind Energy Misston Analysis", General Electric Company, Final Report, ERDA Contract EY-76-C-02-2578, Feb. 1977.

13. "Economic and Technical Feasibility Study for Energy Storage Flywheels", Rockwell International, ERDA Document 76-65, Dec. 1975. 
14. "Energy Storage Systems Study (Hydrogen)," General Electric Co., Direct Energy Conversion Programs Report, September 1976.

15. Kirpich, A., et. al., "Conceptual Design and Systems Analysis of Photovoltaic Systems", General Electric Co., Final Report, ERDA Contract EY-76-C-04-3686, March 1977.

16. Shepard, N.F., et. a1., "Definition Study for Photovoltaic Residential Prototype System", General Electric Co., Space Division, NASA-LeRC, Contract NAS-19769, September 1976.

17. "Development of Sodium Sulfur Batteries for Utility Application", General Electric Co., Annual Report, EPRI Project 128-3, December 1976.

18. Bush, K., Private Communication, AiResearch Mfg. Co., of Arizona, Garrett Corp., February 1977.

19. Van Sant, J.H., Private Communication, The Hydro-Quebic Institute of Research, Varennes, Quebec, Canada, February 1977.

20. Sandia Tape 1962/63 Weather Tape (19 Stations).

21. "An Assessment of Energy Storage Systems Suitable for Use by Electric Utilities", Public Service Electric and Gas Company of N.J., Final Report - EPRI Research Project 225, Report EM 264, July 1976.

22. Re€:d, J., "Wind Power Climatology", ERDA Contract No. AT (29-1)-789, SAND 74-0348, Albuquerque, NM, 1975.

23. Privale Communication - H. Stoll, GE/EUSED, March 1977.

24. Berkowitz, D.G., and Brown, J.T., "Advanced Technology Lead-Acid Storage (ATLAS) Batteries on Electric Utilities", Proc. Energy Storage Symposium, Electrochemical Society, 1976.

25. Cooper, V.R., Pepper, J.W., "Rationale for the EPRI Thermal-Mechanical Energy Storage Program", EPRI, Proc. American Power Conference, Vol. 38, 1976.

26. Grant, E.L. Principles of Engineering Economy, The Ronald Press Co., iNY, 1950.

27. Doane, J.W., O'Toole, R.P., and Chamberlin, R.G., Jet Propulsion Laboratories, Bos, P.B., Electric Power Research Institute, Maycock, P.D., Division of Solar Energy, "The Cost of Energy from Utility-Owned Solar Electric Systems, A Required Revenue Methodology for ERDA/EPRI Evaluations, ERDA, ERDA/JPL-1012-76/3, June 1976.

28. "Typical Electric Bills 1976 (Residential, Commercial, Industrial)", Federal Power Commission', Report No. FPC R88, January 1976. 
29. Comtois, W.H., "Power Plant Construction Schedules, Escalations and Interest Dliring Construction", Westinghouse Electric Corp., American Power Conference, April 1976.

30. "All Electric Homes in the United States", Federal Power Commission, FPC R-87, 1976. 
VOLUME II I

SUPPLEMENTAL BIBLIOGRAPHY

Asbury, J.G., et. al., "Solar Energy and Electric Utilities, Can They Be Interfaced?", Argonne National Laboratory, ANL/ES-52.

Braun, C., Cherniavsky, E.A., and Salzano, F.J., "The Economic Incentive for Introducing Electric Storage Devices into the National Energy System", Brookhaven National Laboratory, 1975.

"Digest of Current Research in the Electric Utility Industry", Electric Power Research Institute, Report RD-2, May 1976.

"Energy Storage", NASA Literature Search, 33159, August 1976.

"Energy Storage (I): Using Electricity More Efficiently", Science, Vol. 184, May 1974.

"Investigation of Storage System Designs and Techniques for Optimizing Energy Conversion in Integrated Utility Systems", Battelle Columbus Laboratories, Final Report, NASA Contract NAS 9-14628, March 1976.

Johnson, C.C., Smith, R.T., and Swanson, R.K., "Electric Utility Aspects of Windpower", Southwest Research Institute.

Jorgensen, G.E., and Lotker, M., Northeast Utilities Service Co,, and Meier, R.C., and Brierley, D., Kaman Aerospace Corp., "Design, Economic and System Considerations of Large Wind-Driven fenerators".

Kalhammer, F.R., and Zygiellbaum, P.S., "Potential for Large-Scale Energy Storage in Electric Utility Systens", Winter Meeting, ASME, November 1974.

Kirschiaum, H.S., and Somers, E.V., Westinghouse Electric Corp., and Sulzberger, V.T., Public Service Electric and Gas Co., of Newark, NJ, "Evaluation of Offshore Site for Wind Energy Generation".

Landgrebe, A.R., and Klunder, K.W., "Energy Storage Technology", ERDA, Proc. Energy Storage Symposium, Electrochemical Society, March 1976.

Lotker, M., "Northeast Utilities Participation in the Kaman/NASA Wind Power Program", Northeast Utilities Service Co.

Marsh, W.D., "Energy Storage in Electric Utility Generating Systems"; General Electric Co., Report 143, June 1976.

iNo11, E.M., Wind/Solar Energy For Radiocommunications, and Low-Power Electronic/E Tectric Application, 1975. 
Ramakumar, R., and Hughes, W.L. "Electrical Technology Overview and Research at Oklahoma State University as Applied to Wind Energy Systems", Oklahoma State University.

Ramakumar, R., "Development and Adaptation of Field Modulated Generator Systems for Wind Energy Applications, Oklahoma State University.

Schneider, T.R., and Snow, R.V., "Assessment of Storage Systems: The Device Utility Interface", Public Service Electric and Gas Co., IEEE Winter Power Meeting, 1976.

Sulzberger, V.T., and Zemkoski, J., "The Potential for Application of Energy Storage Capacity on Electric Utility Systerns in the United States", PT I \& II, Public Service Electric and Gas Co., 1976.

Zlotnick, M., "Energy Storage for Wind Energy Conservation Systems", Div. of Conservation Research and Technology, ERDA, 1975. 


\section{APPENDICES}

Appendix A - Glossary and Definitions

Appendix B - Data Tables

B1 - Wind Energy Conversion System Storage Charging, Lubbock, TX Wind Data Si te

B2 - Wind Energy Conversion System Storage Charging, Blue Hill, MA Wind Data Site

B3 - Wind Energy Conversion System Storage Charging, Great Falls, MT Wind Data Site

B4 - Utility/Multiple Source Storage Charging

B5 - Efficiency Effocts 


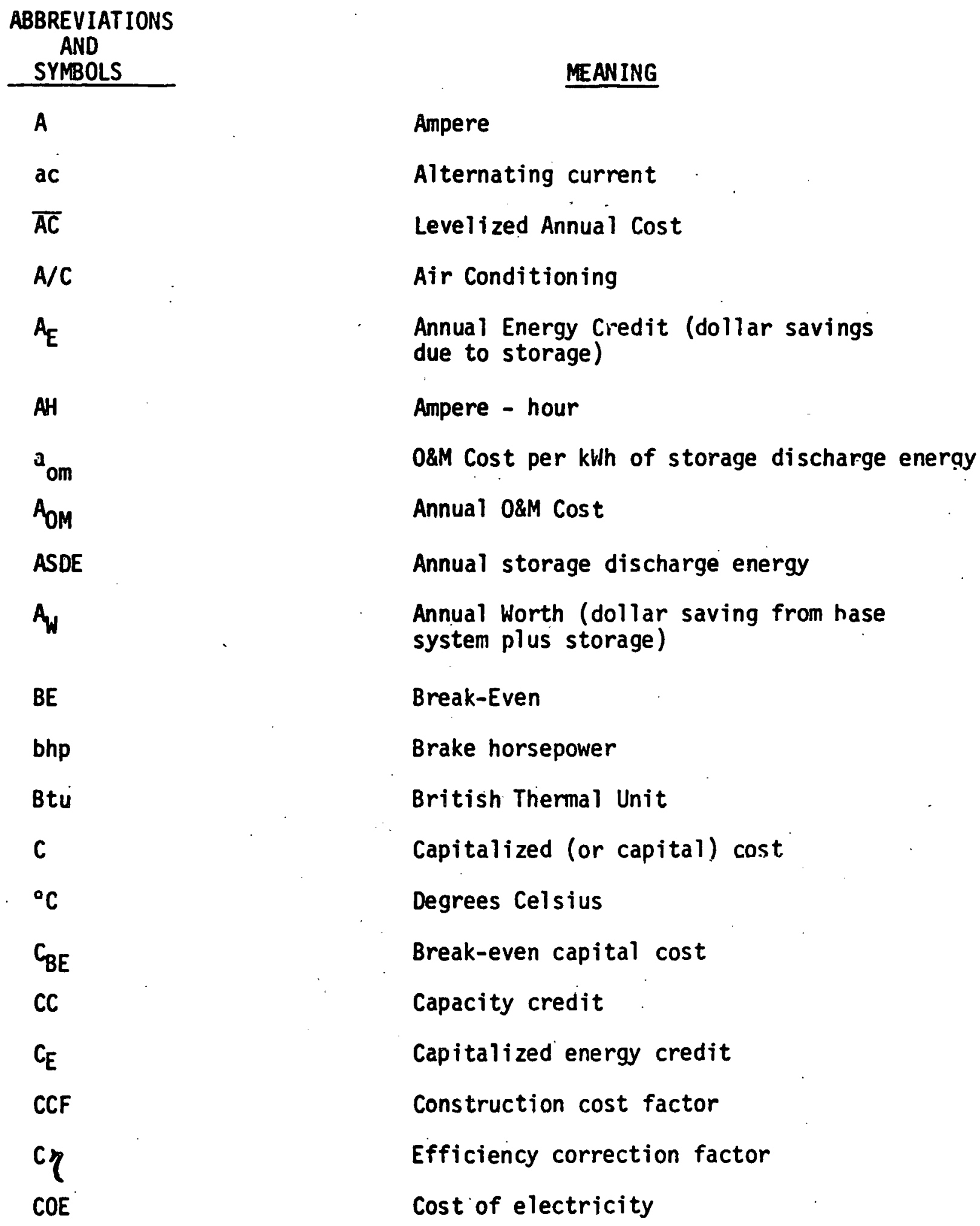

MEANING

Ampere

Alternating current

Levelized Annual Cost

Air Conditioning

Annual Energy Credit (dollar savings due to storage)

Ampere - hour

08M Cost per kWh of storage discharge energy

Annual O\&M Cost

Annual storage discharge energy

Annual Worth (dollar saving from hase system plus storage)

Break-Even

Brake horsepower

British Thermal Unit

Capitalized (or capital) cost

Degrees Celsius

Break-even capital cost

Capacity credit

Capitalized energy credit

Construction cost factor

Efficiency correction factor

Cost of electricity 
ABBREVIATIONS

AND

SYMBOLS

MEAN ING

$C_{\text {OM }}$

CRF

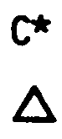

dc

e

EDP V

$E_{D U}$

E DU

$f$

${ }^{\circ} \mathrm{F}$

FER

gal.

9

gp

h

H

$\mathrm{H}_{2}$

hp

WV

$\mathrm{Hz}$

kV

$\mathrm{kW}$

kWh
Capitalized value of 0\&M Costs

Capital recovery factor

Effective carrying capacity, MW

Delta, difference

Direct current

Electricity price escalation rate

Energy supplied to load from storage/PV

Energy supplied to load from undedicated storage

Energy supplied to load from storage/WECS

Fuel price escalation rate

Degrees Fahrenheit

Fixed charge rate

Gálion

General inflation rate

Gallons per minute

Hour (or $\mathrm{Hr}$ )

Head, hydrostatic

Hydrogen (system)

Horsepower

High voltage

Hertz (frequency)

Kilovolt

Kilowatt

Kilavatt-hour

A-2 


\section{ABBREVIATIONS}

AND

SYMBOLS

M.

m

MPH

$\mathrm{m} / \mathrm{s}$

MN

MVA

MWe

Mh

n

$\eta$

0

P

PF

Psi

Psig

$\rho$

R

$r$

$R / C \quad G / T$

RPM

SCF

sec

SG

$S / C \quad G / T$

SOC
MEANING

Multiplier for an escalating cost stream

Meter

Miles per hour

Meter per second

Megawatt

Megavolt ampere

Megawatt-electric

Megawatt hour

Life (system) years

Efficiency

Phase (electric power)

Power

Power factor

Pressure, pounds per square inch

Pressure, pounds per square inch-gauge

Air density, value of

Risk factor

Discount rate

Regenerative Cycle - gas turbine

Revolutions per minute

Standard cubic foot

Second (time)

Specific gravity

Simple cycle - gas turbine

State of charge 


\begin{tabular}{ll}
$\begin{array}{c}\text { ABBREVIATIONS } \\
\text { AND } \\
\text { SYMBOLS }\end{array}$ & \multicolumn{1}{c}{$\begin{array}{c}\text { MEANING } \\
\text { STAG }\end{array}$} \\
$t$ & $\begin{array}{l}\text { Combined cycle steam and gas turbine system } \\
\text { (GE Trademark) } \\
\text { time (or temperature) }\end{array}$ \\
$T$ & $\begin{array}{l}\text { Torque (lb. ft.) } \\
v\end{array}$ \\
$V$ & Velocity, linear \\
$W$ & Volt \\
{[]$^{0}$} & Watt \\
& Any value taken at $75 \%$ efficiency \\
(superscript zero)
\end{tabular}


AEP

ASME

BEST

BOP

BTTL

CVT

DECP

EUSED

IEEE

LOLP

MPS

O\&M

PPS

PSH

PV

PVCS

SA

T\&D

WECS

WTG
Advanced Energy Programs, General Electric Company

American Society of Mechanical Engineers

Battery Energy Storage Test (facility)

Balance of Plant

Building Transient Thermal Load

(a computer program)

Continuously variable transmission

Direct Energy Conversion Programs; General Electric Company

Electric Utility Systems Engineering Department, General Electric Company

Institute of Electrical and Electronic Engineers

Loss of Load Probability

Monthly Production Simulation

(a computer program)

Operation and Maintenance

Pure pumped storage

Pumped storage - hydro

Photovoltaic

Photovoltaic conversion system

Solar Array

Transmission and Distribution

Wind energy conversion system

Wind Turbine Generator 
Annual Energy Displacement

Array (PV)

Base load

Breakeven Cost

Bus

Capacity Credit

Capital Costs

Capitalized Value

Capacity Factor

Cell

Concentration Ratio

Converter

Cost Goal

Cut-in Velocity

Cut-out Velocity
- Quantity of energy replaced by PVCS, WEC and/or Energy Storage discharge

- Photovoltaic cells complete with mounting fixtures.

- The generally constant portion of utility generated power output.

- The cost at which two alternative methods are equivalent from the owner's viewpoint.

- A major electrical interconnection or tie.

- A credit earned for ability to replace a conventional generating unit.

- The investment associated with initial purchase of major equipment or facilities.

- An equivalent presen $t$ value (dollars) representing cost (or worth) of an annual sum of money for a given period of time.

- The ratio of actual (realized) energy. output to maximum output at rated power for some period of time (usually a year).

- The smallest electro-chemical unit in a battery energy system.

- The factor by which basic insolation is multiplied or "concentrated" by a given type of $\mathrm{PV} /$ solar array.

- A class of devices for performing $D C / A C$ power conversion or "inversion".

- Break-even cost, or a minimum objective to economically justify an alternative method.

- The wind velocity at which a WTG commences power generation.

- The wind velocity at which a WTG terminates power generation. 


\section{Dedicated Storage}

Discharge/Charge Rate

Diversified Load

Duty Cycle

Effective Carrying Capacity

Escalation Rate

Forced Outage Rate

Heat Rate

Insolation

Intermediate Application

Levelized Annual Cost
- An energy storage system charged solely from WECS/PVCS or any single energy source.

- The time rate for transferring energy to or from storage at rated power.

- A mix of different types of power consuming devices, in resideritial use, various appliances, motors, etc. as opposed to space heating or water heating loads.

- The duration and periodicity of operation of a device.

- The power capacity that can be reliably furnished from storage.

- The annual percent by which fuel (or other commodity) iincredses in price. May be different from general inflation.

- The annual amount of unscheduled out-of-service time for power generation units.

- The amount of thermal input to a power generating unit necessary to produce 1 kWh of output

$(3413 \mathrm{Btu} / \mathrm{kWh} \div$ heat rate $=$ unit efficiency).

- Solar radiation received at some specific point, e.g., a soiar cell. Has both direct and diffuse components.

- A broad class of commercial or industrial energy consumers below the utility scale and above the residential scale. (study definition).

- An annual sum which, if expended each year over a specified time for equipment or services, would be equivalent to the summation of all actual costs, during the same period, for fixed and variable charges, including burdens. 
Load Duration

$\operatorname{Mix}$

Multiple Source

Off-Peak

Peaking Units

Penetration

Shunt Regulator

Start Year

Storage System Cost

System-wide Storage

Zero Differential Escalation
- The time during which the load (utility power demand) exceeds a given magnitude. Usually summed for time periods of particular interest.

- The specific combination within a utility system of various generating units using different types of fuels (i.e., coal, nuclear, oil, etc.).

- Refers to power supplied from systemwide generation and/or a mix of power sources.

- Refers to utility load demand or power generation occurring at other than peak load hours of the day.

- Utility generating units assigned solely to respond to the periods of highest load demand.

- The percent of total power generation capacity contributed by PVCS/WECS based on peak power output rating.

- A device or devices with the function of dissipating excess power from a PVCS or other source in order to maintain desired power levels.

- The first year of system operation and benefit return.

- A current estimated cost of a storage system or a projected future cost.

- An energy storage system accessible to and chargeable by any generating source in the system having available and/or excess capacity.

- A condition where the general inflation rate and the escalation of a specific commodity (such as fuel) are identical. 
Conversion Factors

Unit/Quantity.

Solar cell area, $\mathrm{m}^{2}$

Langley

$\mathrm{m} / \mathrm{s}$
Mu? tiplying Factor

.114

3.68

2.237
Converted/Equivalent

Unit/Quantity

PV output, kw (c) $60^{\circ} \mathrm{C}$ and $1 \mathrm{~kW} / \mathrm{m}^{2}$ normal insolation)

$B t u / f t^{2}$

MPH 
TABLE B-1. WIND ENERGY. CONVERSION SYSTEM STORAGE CHARGING UT IL ITY APPL ICATION

(LUBBOCK, TX, WIND DATA, $\eta=75 \%$ )

\begin{tabular}{|c|c|c|c|c|c|c|c|c|c|}
\hline \multirow{2}{*}{$\begin{array}{l}\text { STORAGE } \\
\text { CAPACITY } \\
\text { (MWh) }\end{array}$} & \multirow{2}{*}{ (MW) } & \multicolumn{4}{|c|}{ ANNUAL ENERGY DISPLACEMENT (MWh) } & \multirow{2}{*}{$\begin{array}{l}E_{\mathrm{DW}}^{0} \\
\text { (MISh) }\end{array}$} & \multirow{2}{*}{$\begin{array}{l}\text { ASDE } \\
\text { ("illih) }\end{array}$} & \multirow{2}{*}{$\begin{array}{l}A_{W}^{0} \\
\text { (MMS) }\end{array}$} & \multirow{2}{*}{$\begin{array}{l}A_{E}^{0} \\
\text { (MM\$) }\end{array}$} \\
\hline & & \begin{tabular}{|ll} 
COST & $A$ \\
BEGIME & $A$ \\
\end{tabular} & B & c & D & & & & \\
\hline & \multirow[b]{2}{*}{0} & \multirow[b]{2}{*}{49.804} & \multirow[b]{2}{*}{182,552} & \multicolumn{2}{|c|}{$10 \%$ PENETRATION } & \multirow{3}{*}{ - } & \multirow{3}{*}{ - } & \multirow{3}{*}{11.219} & \multirow{3}{*}{-} \\
\hline 0 & & & & \multirow[t]{2}{*}{329.716} & \multirow[t]{2}{*}{445,639} & & & & \\
\hline & HARGE & $\angle$ IMIT $=5 \mathrm{HR}$ & & & & & & & \\
\hline $\begin{array}{l}250 \\
500\end{array}$ & $\begin{array}{r}50 \\
100\end{array}$ & $\begin{array}{l}58,786 \\
65,302\end{array}$ & $\begin{array}{l}192,166 \\
202,056\end{array}$ & $\begin{array}{l}334,500 \\
339,629\end{array}$ & $\begin{array}{l}411,097 \\
379,283\end{array}$ & \multirow[t]{2}{*}{$\begin{array}{l}23,380 \\
44,915\end{array}$} & \multirow[t]{2}{*}{$\begin{array}{l}25,113 \\
48,243\end{array}$} & \multirow[t]{2}{*}{$\begin{array}{l}11.585 \\
11.904\end{array}$} & \multirow[t]{2}{*}{$\begin{array}{l}.366 \\
.685\end{array}$} \\
\hline & \multicolumn{2}{|c|}{ DISCHARGE RATE LIMIT $=10 \mathrm{HR}$. } & \multirow{3}{*}{$\begin{array}{l}192,117 \\
200,874 \\
216,111 \\
238,211 \\
261,146\end{array}$} & \multirow{3}{*}{$\begin{array}{l}335,905 \\
342,208 \\
355,226 \\
381,268 \\
430,302\end{array}$} & \multirow{3}{*}{$\begin{array}{l}412,203 \\
381,824 \\
328,645 \\
245,805 \\
133,273\end{array}$} & & & & \\
\hline $\begin{array}{r}250 \\
500 \\
100 c \\
2000 \\
4000\end{array}$ & $\begin{array}{r}25 \\
50 \\
100 \\
200 \\
400\end{array}$ & $\begin{array}{l}56,682 \\
62,185 \\
69,925 \\
77,856 \\
82,057\end{array}$ & & & & \multirow[t]{2}{*}{$\begin{array}{r}22,632 \\
43,195 \\
79,190 \\
135,263 \\
211,433\end{array}$} & \multirow[t]{2}{*}{$\begin{array}{r}24,310 \\
46,396 \\
85,059 \\
145,288 \\
227,103\end{array}$} & \multirow[t]{2}{*}{$\begin{array}{l}11.547 \\
11.833 \\
12.303 \\
12.952 \\
13.663\end{array}$} & \multirow[t]{2}{*}{$\begin{array}{l}.328 \\
.614 \\
1.084 \\
1.733 \\
2.444\end{array}$} \\
\hline & \multicolumn{2}{|c|}{ DISCHARGE RATE LIMIT = $15 \mathrm{HR}$. } & & & & & & & \\
\hline \multirow[t]{2}{*}{$\begin{array}{r}375 \\
750 \\
1500 \\
3000 \\
6060\end{array}$} & \multirow[t]{2}{*}{$\begin{array}{r}25 \\
50 \\
100 \\
200 \\
4 c 0\end{array}$} & $\begin{array}{l}57,454 \\
63,241 \\
71,326 \\
79,160 \\
82,507\end{array}$ & \multirow[t]{2}{*}{$\begin{array}{l}194,767 \\
205,532 \\
223,033 \\
247,400 \\
265,767\end{array}$} & $\begin{array}{l}339,825 \\
349,452 \\
367,955 \\
403,951 \\
463,512\end{array}$ & $\begin{array}{r}401,355 \\
362,681 \\
297,543 \\
196,791 \\
76,717\end{array}$ & \multirow[t]{2}{*}{$\begin{array}{r}29,974 \\
56,153 \\
100,242 \\
168,439 \\
249,714\end{array}$} & $\begin{array}{r}32,196 \\
60,314 \\
107,672 \\
180,923 \\
268,222\end{array}$ & $\begin{array}{l}11.625 \\
11.967 \\
12.509 \\
13.246 \\
13.928\end{array}$ & $\begin{array}{l}.406 \\
.748 \\
1.290 \\
2.027 \\
2.709\end{array}$ \\
\hline & & & & $20 \% \mathrm{PE}$ & TRATION & & & & \\
\hline 0 & 0 & $6.1,412$ & 236,044 & 586,956 & $1,131,010$ & - & - & 18.764 & - \\
\hline & HAPGE & LIMIT $=5 \mathrm{HR}$ & & & & & & & \\
\hline $\begin{array}{l}2000 \\
4000\end{array}$ & $\begin{array}{l}400 \\
800\end{array}$ & $\begin{array}{l}91,390 \\
97,901\end{array}$ & $\begin{array}{l}298,769 \\
323,471\end{array}$ & $\begin{array}{l}661,703 \\
734,460\end{array}$ & $\begin{array}{l}883,624 \\
730,019\end{array}$ & $\begin{array}{l}167,450 \\
271,420\end{array}$ & $\begin{array}{l}179,859 \\
299,537\end{array}$ & $\begin{array}{l}20.776 \\
21.695\end{array}$ & $\begin{array}{l}2.012 \\
2.931\end{array}$ \\
\hline & HARGE & $L I M I T=10 \mathrm{H}$ & & & & & & & \\
\hline $\begin{array}{r}500 \\
1000 \\
2000 \\
4000\end{array}$ & $\begin{array}{r}50 \\
100 \\
200 \\
400\end{array}$ & $\begin{array}{l}72,376 \\
80,352 \\
89,512 \\
96,771\end{array}$ & $\begin{array}{l}253,221 \\
268,356 \\
292,375 \\
318.617\end{array}$ & $\begin{array}{l}602,921 \\
620,491 \\
659,456 \\
730,102\end{array}$ & $\begin{array}{r}1,065,848 \\
1,005,747 \\
899,164 \\
745,300\end{array}$ & $\begin{array}{r}44,106 \\
84,787 \\
156,931 \\
261,078\end{array}$ & $\begin{array}{r}47,375 \\
91,071 \\
168,562 \\
280,427\end{array}$ & $\begin{array}{l}19.349 \\
19.848 \\
20.626 \\
21.573\end{array}$ & $\begin{array}{l}.585 \\
1.084 \\
1.862 \\
2.808\end{array}$ \\
\hline & & & & 30\% PE & IRATION & & & & \\
\hline & HARGE & LIMIT $=10 \mathrm{H}$ & & & & & & & \\
\hline $\begin{array}{r}0 \\
1000\end{array}$ & $\begin{array}{r}0 \\
100\end{array}$ & $\begin{array}{l}67,297 \\
85,909\end{array}$ & $\begin{array}{l}260.045 \\
291,342\end{array}$ & $\begin{array}{l}721,466 \\
756,361\end{array}$ & $\begin{array}{l}1,974,324 \\
1,849,036\end{array}$ & 84,804 & 91.090 & $\begin{array}{l}24.728 \\
25.737\end{array}$ & 1.069 \\
\hline
\end{tabular}


TABLE B-2. WIND ENERGY CONVERSION SYSTEM STORAGE CHARGING UT IL ITY APPL ICATION

(BLUE HILL, MA, WIND DATA, ? =75\%)

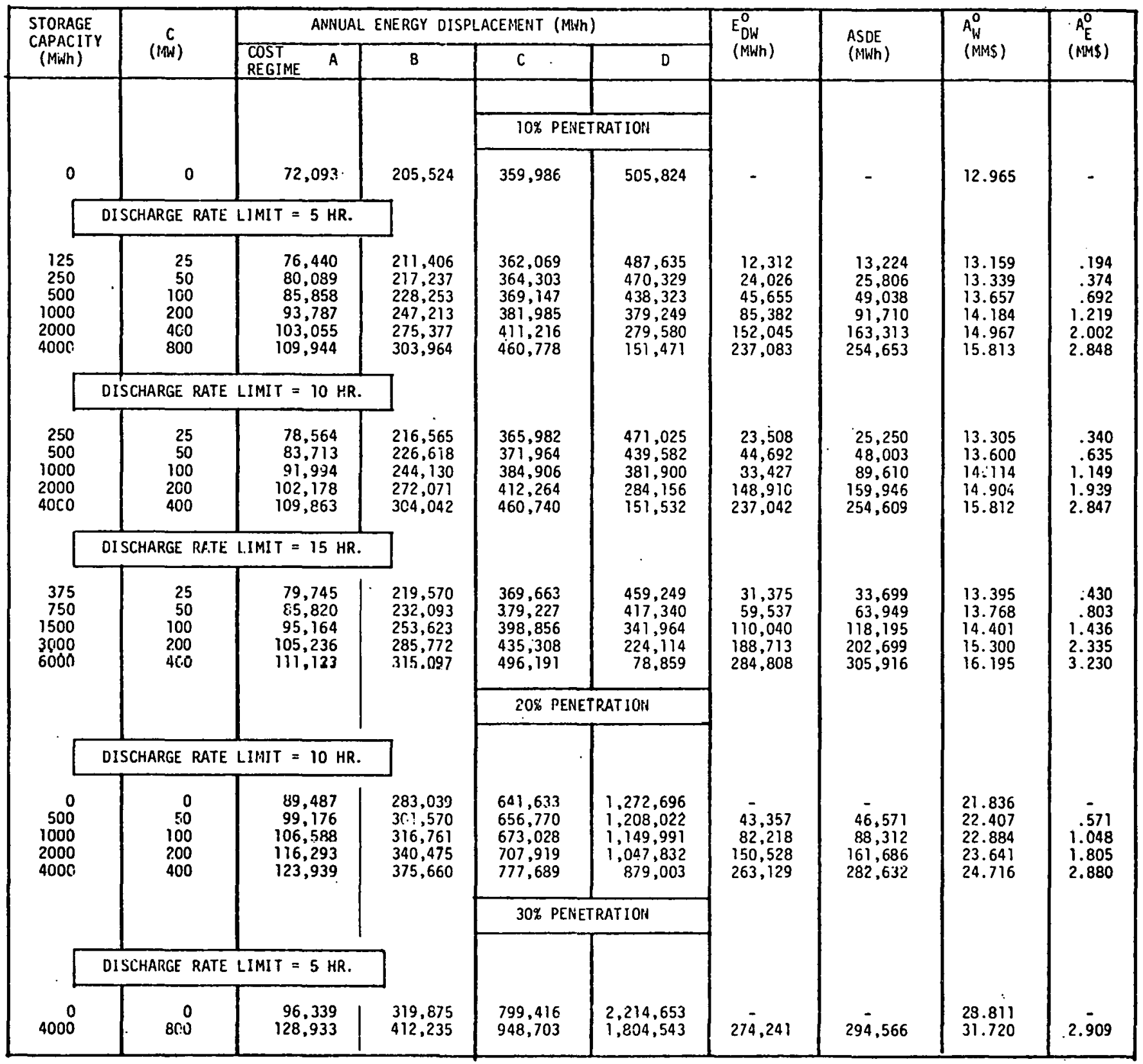


TABLE B-3. WIND ENERGY CONVERSION SYSTEM STORAGE CHARGING UT ILITY APPLICATION

(GREAT FALLS, MT, WIND DATA,

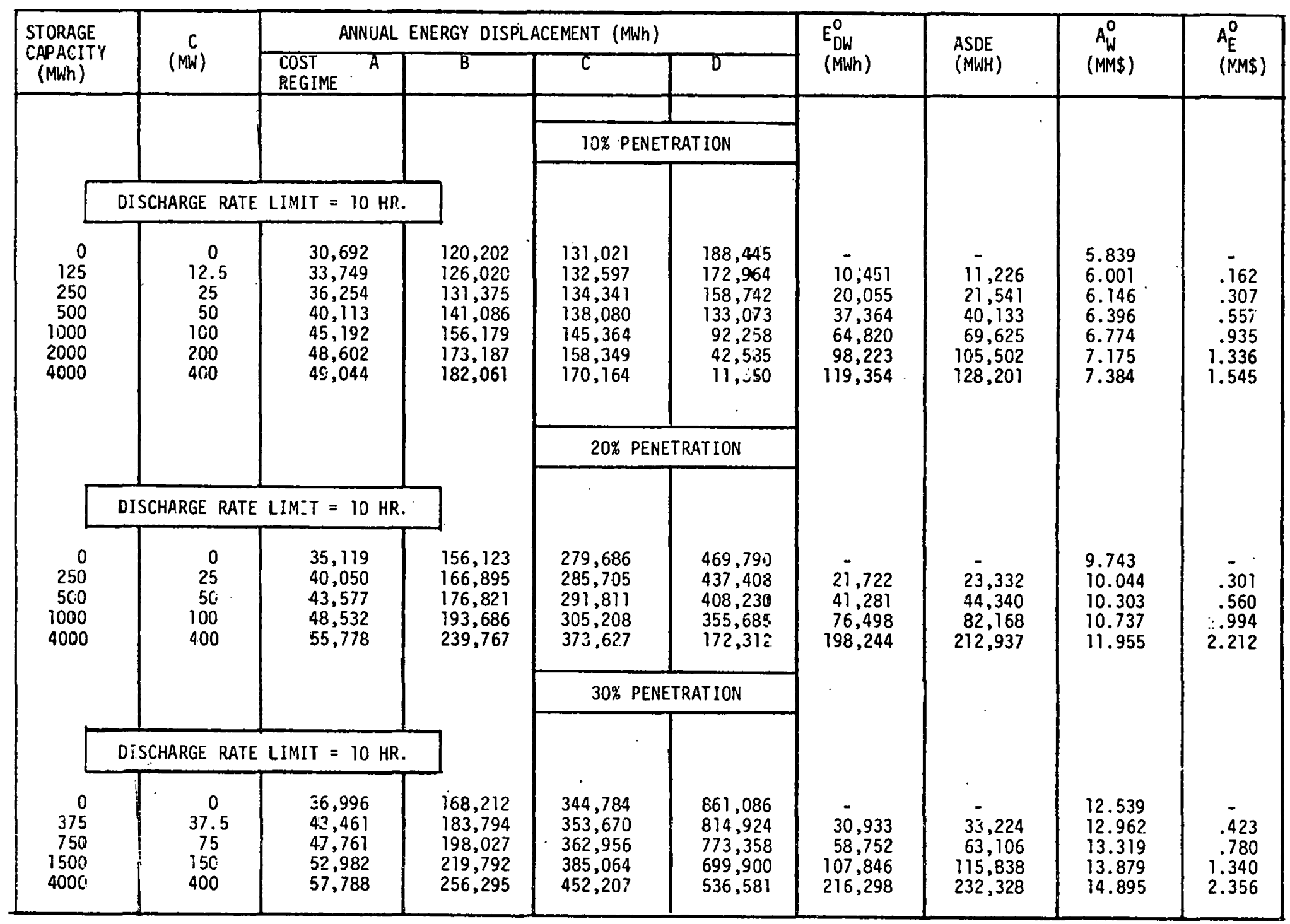


TABLE B-4. UTILITY/MULTIPLE SOURCE STORAGE CHARGING

EFFICIENCY - 75\%

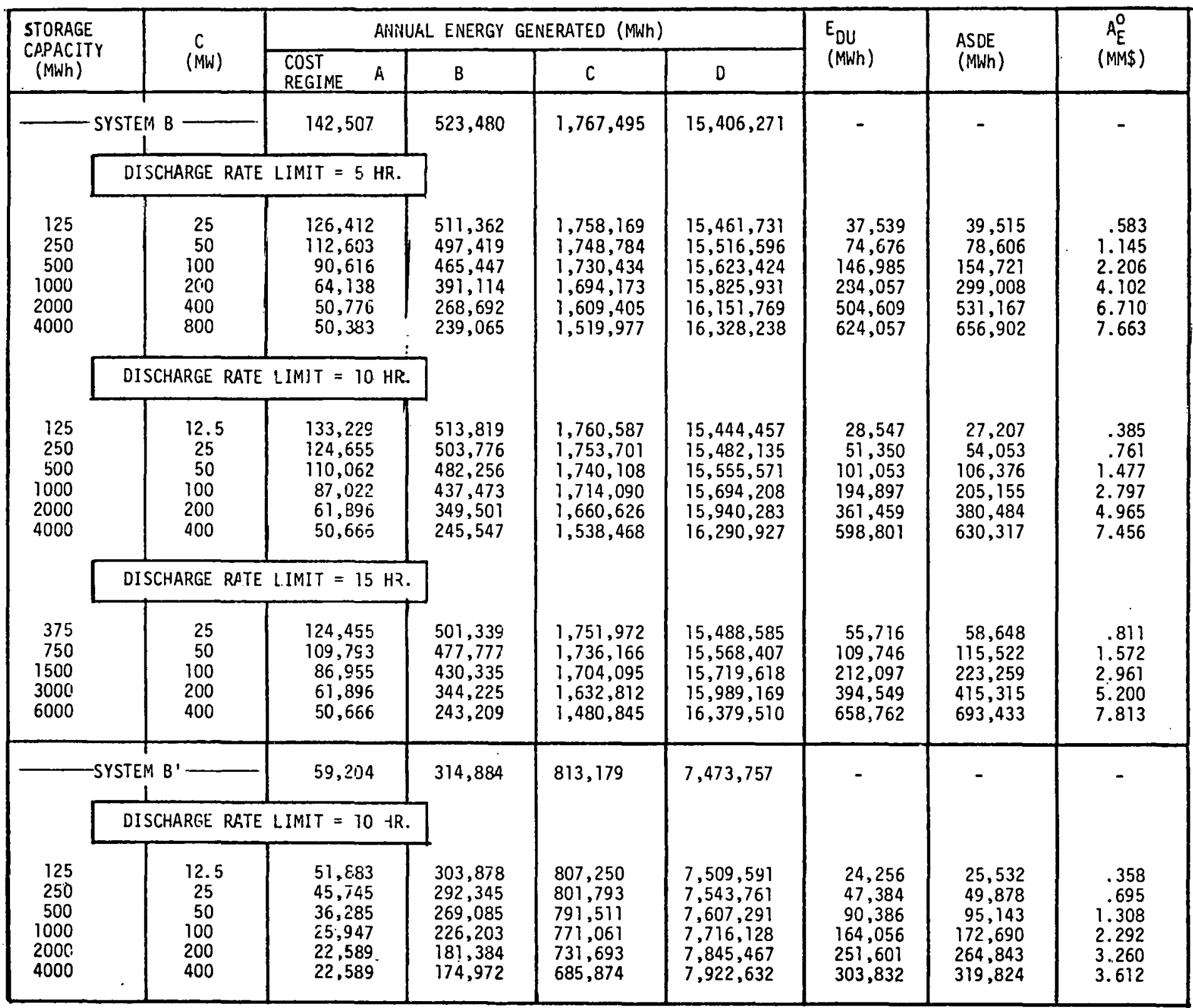


TABLE B-5. EFFICIENCY EFFECTS (1000 MWh STORAGE CAPACITY, 10 HOUR DISCHARGE RATE LIMIT)

\begin{tabular}{|c|c|c|c|c|c|c|c|c|}
\hline \multirow{2}{*}{$\begin{array}{l}\text { TYP. } \\
\text { STORAGE } \\
\text { CHF.RGING }\end{array}$} & \multirow{2}{*}{ SITE } & \multirow{2}{*}{$\eta_{(\%)}$} & \multicolumn{4}{|c|}{ ANNUAL ENERGY DISPLACEMENT (MW!h) } & \multirow{2}{*}{$\begin{array}{c}E_{D W}^{0} \\
(M W h)\end{array}$} & \multirow{2}{*}{$\underset{(M M \$)}{A_{E}^{O}}$} \\
\hline & & & $\begin{array}{ll}\text { COST } & A \\
\text { REGIME } & \end{array}$ & $B$ & $\bar{C}$ & D & & \\
\hline & & & \multicolumn{3}{|c|}{$10 \%$ PENETRAT ION } & & & \\
\hline WTG & LUBBOCK,TX & $\begin{array}{l}60 \\
75 \\
90\end{array}$ & $\begin{array}{l}68,489 \\
69,925 \\
70,789\end{array}$ & $\begin{array}{l}213,472 \\
216,111 \\
217,949\end{array}$ & $\begin{array}{l}353,389 \\
355,226 \\
356,043\end{array}$ & $\begin{array}{l}310,315 \\
328,645 \\
343,811\end{array}$ & $\begin{array}{l}73,278 \\
79,190 \\
82,709\end{array}$ & $\begin{array}{l}.885 \\
1.084 \\
1.224\end{array}$ \\
\hline WTG & BLUE HILL, MA & $\begin{array}{l}60 \\
75 \\
9:\end{array}$ & $\begin{array}{l}91,502 \\
91,994 \\
92,248\end{array}$ & $\begin{array}{l}242,175 \\
244,130 \\
245,225\end{array}$ & $\begin{array}{l}382,614 \\
3 \varepsilon: 4,906 \\
3 \varepsilon 6,048\end{array}$ & $\begin{array}{l}359,670 \\
381,900 \\
399,488\end{array}$ & $\begin{array}{l}78,629 \\
83,427 \\
85,918\end{array}$ & $\begin{array}{l}.969 \\
1.149 \\
1.270\end{array}$ \\
\hline $\begin{array}{l}\text { BASELCAD } \\
\text { SYSTEM B }\end{array}$ & & $\begin{array}{l}60 \\
75 \\
90\end{array}$ & $\begin{array}{l}90,903 \\
87,022 \\
84,026\end{array}$ & $\begin{array}{l}454,724 \\
437,473 \\
420,479\end{array}$ & $\begin{array}{l}1,723,285 \\
1,714,090 \\
1,708,171 .\end{array}$ & $\begin{array}{l}15,715,728 \\
15,694,208 \\
15,678,116\end{array}$ & $\begin{array}{l}167,570 \\
194,897 \\
220,806\end{array}$ & $\begin{array}{l}2.749 \\
2.797 \\
3.387\end{array}$ \\
\hline
\end{tabular}

